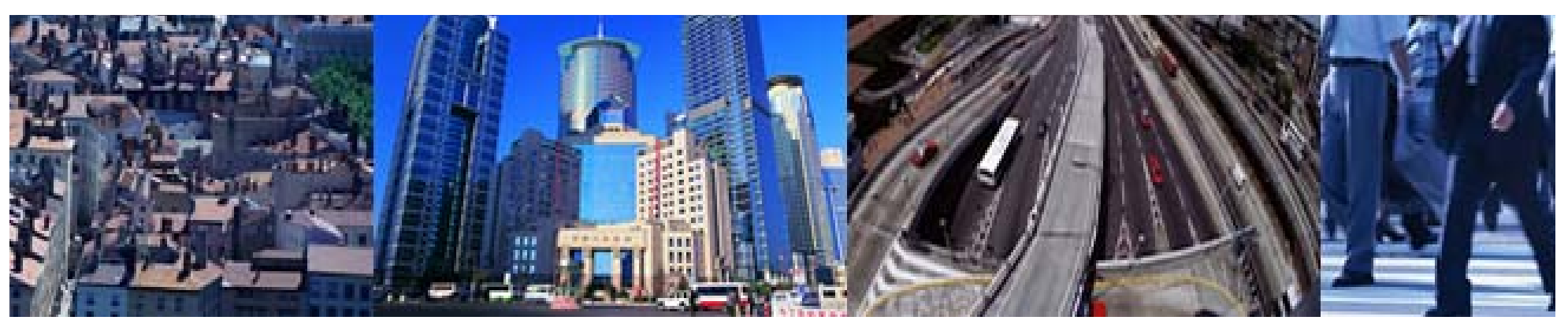

\title{
Urban Trends and Policies in OECD Countries
}

Please cite this paper as:

Kamal-Chaoui, L. and Sanchez-Reaza, J. (eds.) (2012), "Urban Trends and Policies in OECD Countries", OECD Regional Development Working Papers 2012/01, OECD Publishing.

http://dx.doi.org/10.1787/5k9fhn1ctjr8-en

\section{OECD Regional Development Working Papers 2012/01}

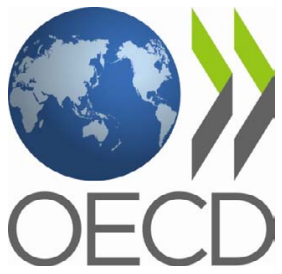

Lamia Kamal-Chaoui and Javier SanchezReaza

JEL Classification: O1, O3, Q2, Q3, Q4, Q5, R1, R2, R3, R4, R5 


\section{OECD REGIONAL DEVELOPMENT WORKING PAPERS}

This series is designed to make available to a wider readership selected studies on regional development issues prepared for use within the OECD. Authorship is usually collective, but principal authors are named.

The papers are generally available only in their original language, English or French, with a summary in the other if available.

The opinions expressed in these papers are the sole responsibility of the author(s) and do not necessarily reflect those of the OECD or the governments of its member countries.

Comment on the series is welcome, and should be sent to gov.contact@oecd.org or the Public Governance and Territorial Development Directorate, 2, rue André Pascal, 75775 PARIS CEDEX 16, France.

OECD Regional Development Working Papers are published on www.oecd.org/gov/regional/workingpapers

Applications for permission to reproduce or translate all or part of this material should be made to: OECD

Publishing, rights@oecd.org or by fax +33 145249930.

(C) OECD 2012 


\section{ACKNOWLEGDEMENTS}

This working paper is one in a series of OECD Working Papers on Regional Development of the OECD Public Governance and Territorial Development Directorate, conducted under the responsibility of Joaquim Oliveira Martins, Head of the OECD Regional Development Policy Division (www.oecd.org/regionaldevelopment).

The report has been produced and coordinated by Ms. Lamia Kamal-Chaoui, Head of Urban Unit, OECD's Regional Development Policy Division, and Javier Sanchez-Reaza, Economist. The work first was conducted under the responsibility of Mario Pezzini, former Deputy Director, Public Governance and Territorial Development Directorate, and then taken over by Joaquim Oliveira Martins, Head of the Regional Development Policy Division. Contributions were provided by Tadashi Matsumuto, Olaf Merk, Daniel Sanchez-Serra, Mario Piacentini, Alexis Robert, Dorothee AllainDupré, Michael G. Donovan, Xiao Wang and Kasuko Ishigaki. The findings draw upon various OECD Territorial Reviews of National, Regional and Urban areas, as well as OECD synthesis reports on regional policies, in particular Regions Matter (2009) and Competitive Cities in the Global Economy (2006). The report has also benefitted from background contributions from Professor Paul Cheshire (London School of Economics), Colin Crouch (University of Warwick Business School) and Adam Ostry (Chair, OECD Working Party on Territorial Development Policy Issues in Urban Areas, and Director, Infrastructure Canada).

Further enquiries about OECD urban development programme should be addressed to Lamia Kamal-Chaoui (lamia.kamal-chaoui@oecd.org) 



\section{TABLE OF CONTENTS}

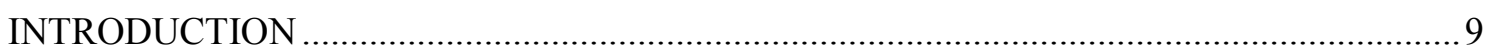

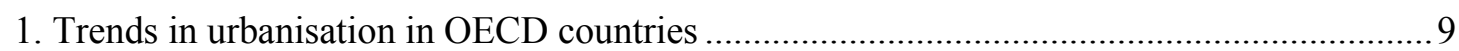

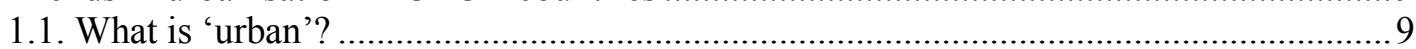

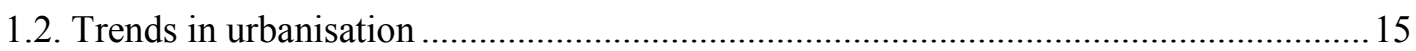

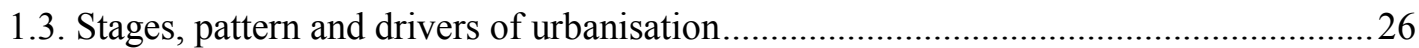

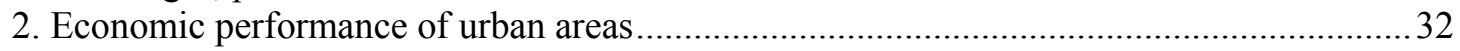

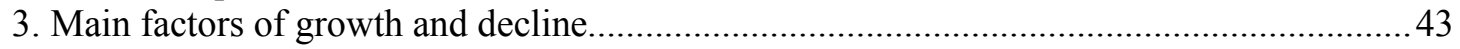

3.1. What are the main drivers of economic growth in urban areas? ..................................43

3.2. Social disparities, exclusion and poverty: the urban paradox......................................48

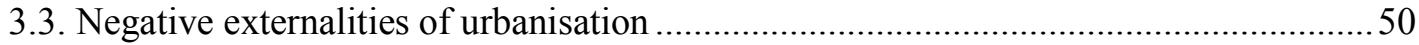

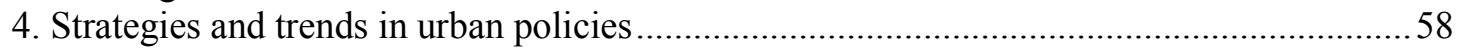

4.1. Urbanisation, market forces and strategic planning …............................................5

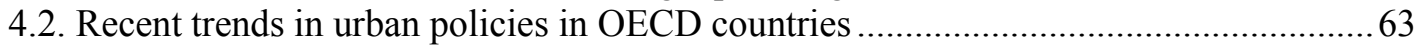

4.3. Urban areas and the new paradigm for regional development in OECD countries.......71

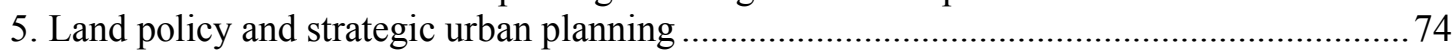

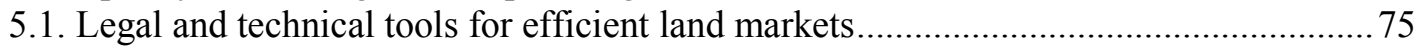

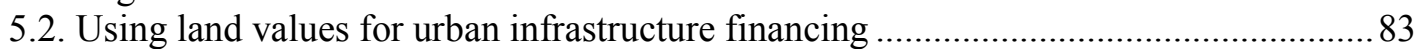

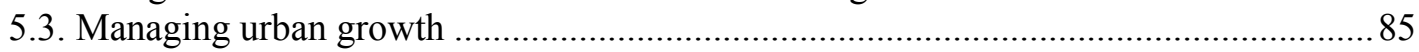

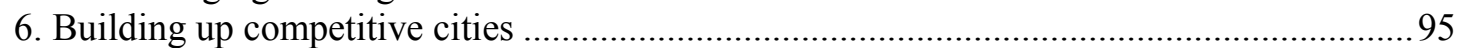

6.1. Fostering competitiveness and innovation in urban regions......................................95

6.2. Fostering city competitiveness whilst ensuring that others do not fall into neglect.... 111

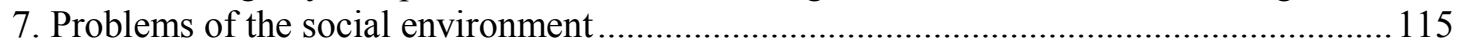

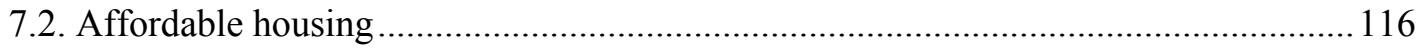

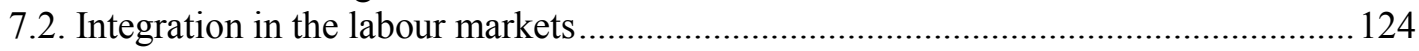

7.3. Integrated urban development for distressed neighbourhoods .................................. 127

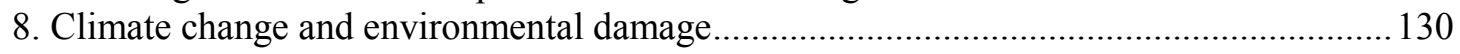

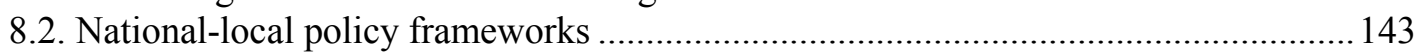

8.3. Incorporating climate change into existing national, regional and urban

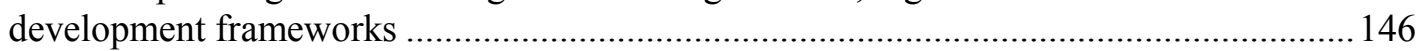

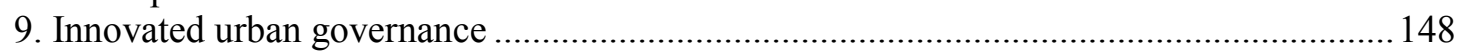

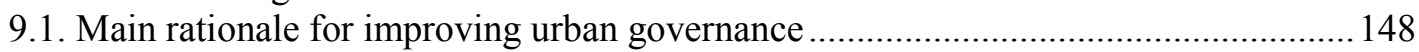

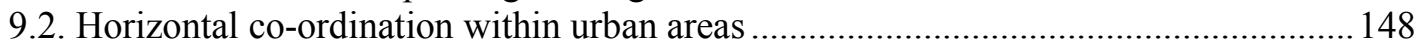

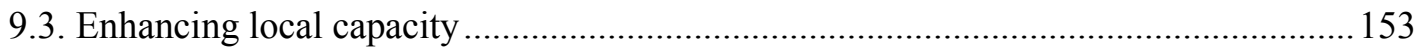

9.4. Beyond the public sphere: involving the private sector in the supply

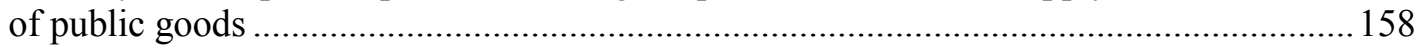

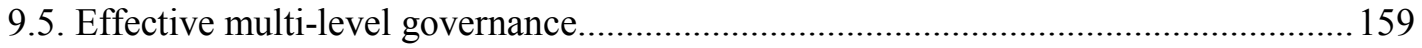

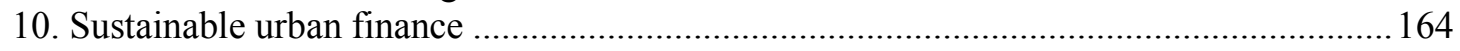

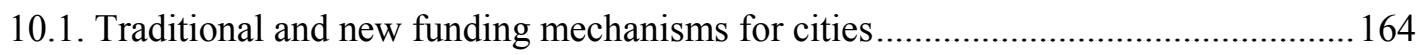

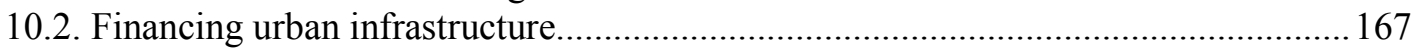

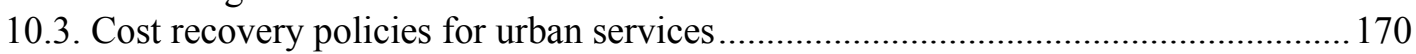

10.4. Experiences of OECD countries with local debt and borrowing.............................170

10.5. Experiences with public-private partnerships in OECD countries ............................ 171

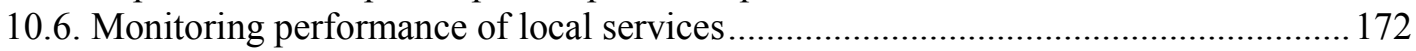




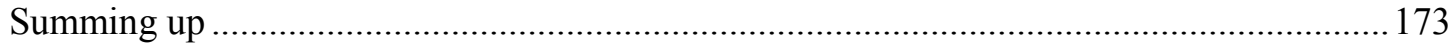

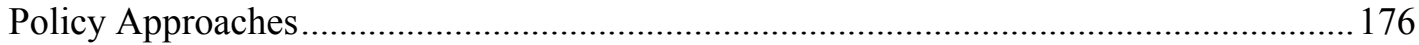

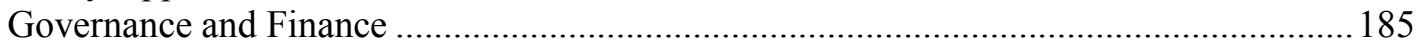

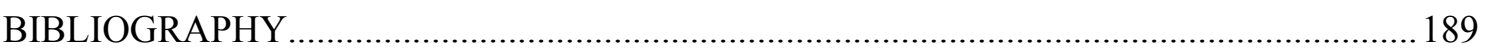

\section{Tables}

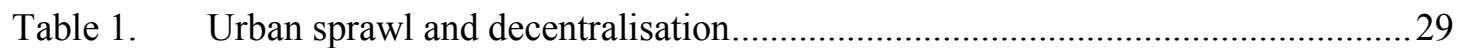

Table 2. National urban policies in a sample of OECD countries .......................................65

Table 3. Old and new paradigms of regional policy ......................................................... 72

Table 4. Problem recognitions and expected policy effects of urban growth management75

Table 5. Collection and disclosure of land transaction price information .........................79

Table 6. Public Policies for managing urban growth and protecting open space ...............85

Table 7. Examples of industry cluster policies in metropolitan regions ........................... 102

Table 8. House price-to-income ratios and floor area per person owner-occupied ...........117

Table 9. House rent-to-income ratios and floor area per person rented housing ..............117

Table 10. Housing affordability in Canada.................................................................... 117

Table 11. Key variables influencing housing affordability...........................................118

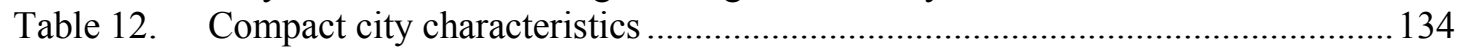

Table 13. Main purposes of a selection of metropolitan co-operative arrangements .........151

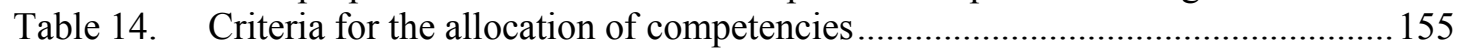

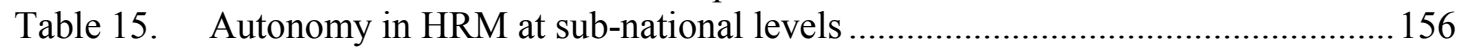

Table 16. Autonomy in recruitment or in setting the average wage bill...........................156

Table 17. Examples of national policies to support local capacity in OECD countries .... 157

\section{Figures}

Figure 1. Urban and Rural Population in the World and the OECD (1950-2030).............. 15

Figure 2. Urbanisation in OECD and non-OECD countries ........................................... 16

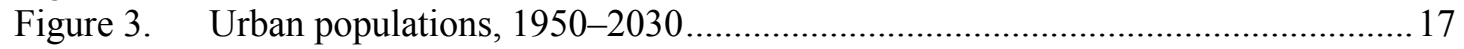

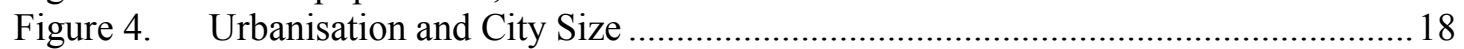

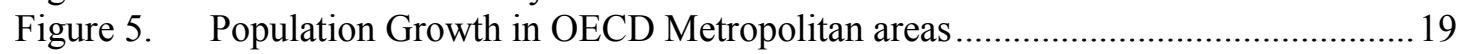

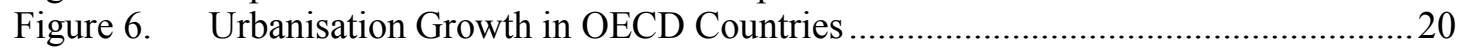

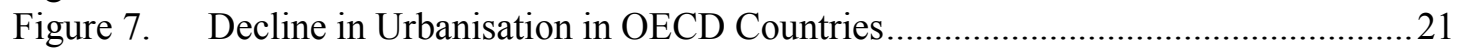

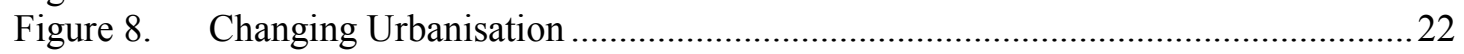

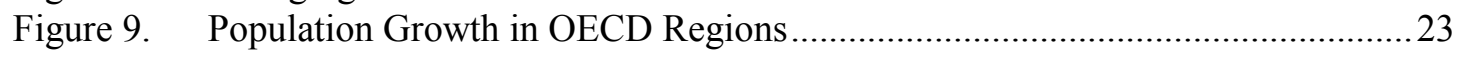

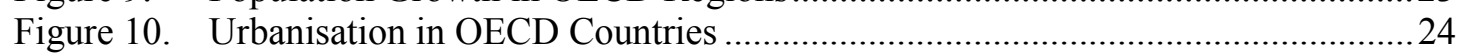

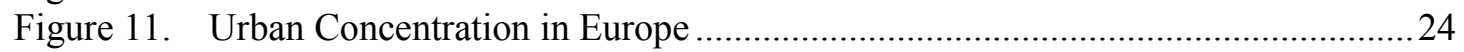

Figure 12. Urban Concentration in Asian OECD Countries ...............................................25

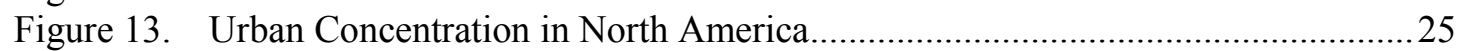

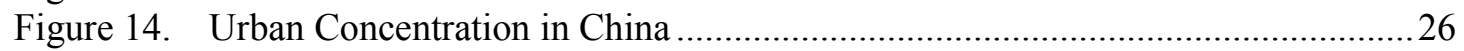

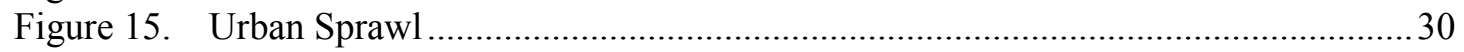

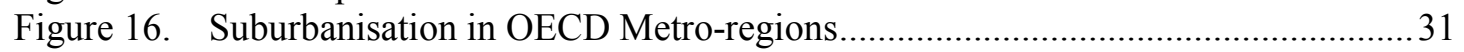

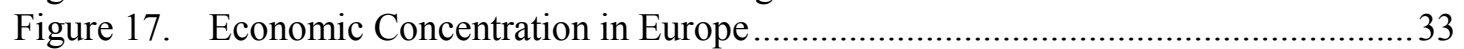

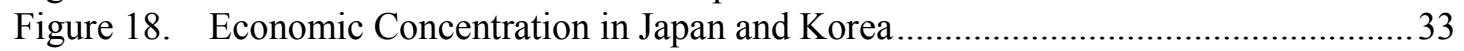

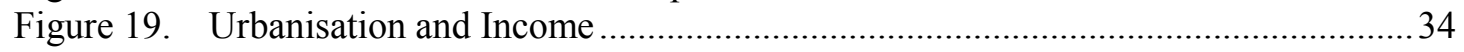

Figure 20. Growing economic importance of China's 53 metropolitan regions .....................35

Figure 21. Change in metropolitan region's share of China's GDP, 1998-2004 ...................37 
Figure 22. Economic Performance in OECD Urban Areas..................................................39

Figure 23. Economic Performance and City Size ……..................................................... 40

Figure 24. City Size and Economic Performance …….....................................................4

Figure 25. Factors determining per capita GDP Differentials..............................................4

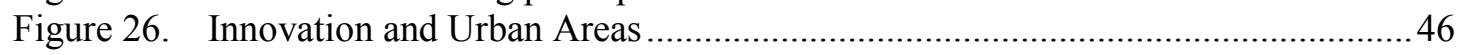

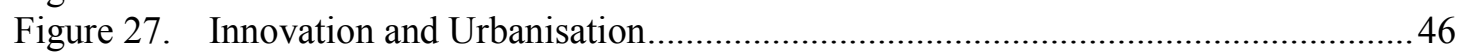

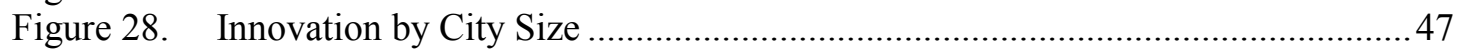

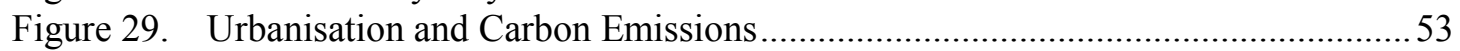

Figure 30. Urban Density and Carbon Emissions in Transport ...........................................5

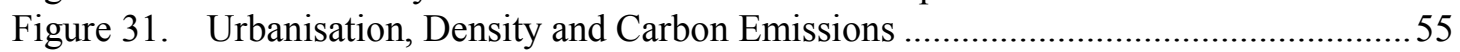

Figure 32. Concentration of Carbon Emissions in the USA …........................................56

Figure 33. Economic Growth with Local Policies ...............................................................5 57

Figure 34. Changes in Attractiveness and Local Pollution Emissions across

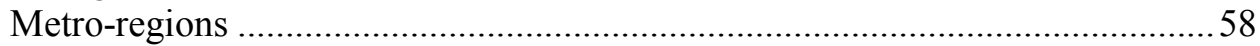

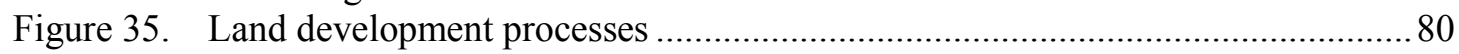

Figure 36. Geographic information systems: overlay analysis of urban poverty

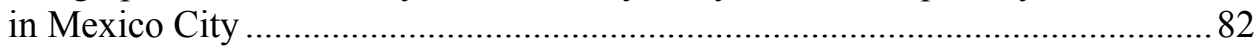

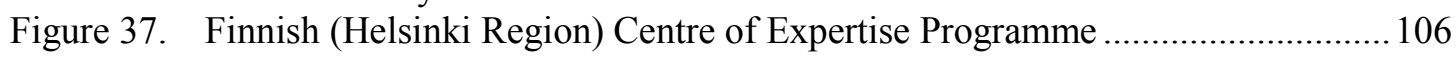

Figure 38. Changes of the number of house buildings and the prices..................................119

Figure 39. Share of sub-central government in general government spending by .....................

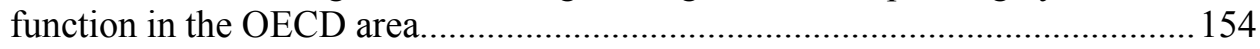

Figure 40. Fee income as share of total city revenue (2005) ............................................ 166

Figure 41. Revenue sources of transit agencies in selected OECD metropolitan areas (2008)

\section{Boxes}

Box 1. OECD metropolitan regions: data and definition................................................. 14

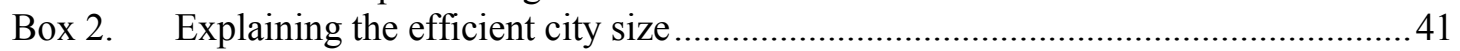

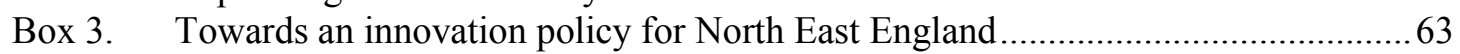

Box 4. Examples of OECD countries that tried to monitoring the growth

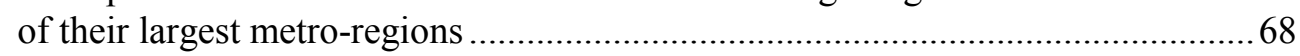

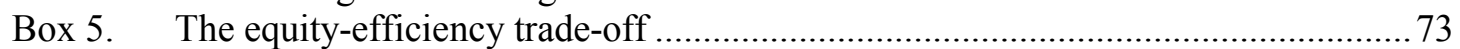

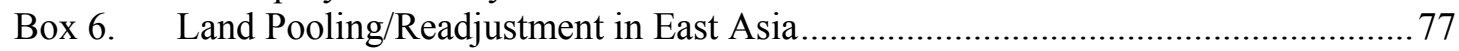

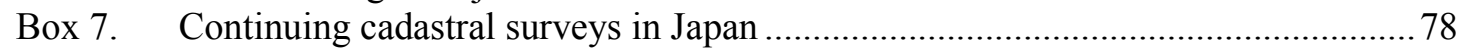

Box 8. Schemes to link land conversion profit to local finance in the Netherlands ............84 84

Box 9. Land Conversion in France, Germany and the Netherlands ...................................8 88

Box 10. Urban Growth Boundaries in OECD countries....................................................91

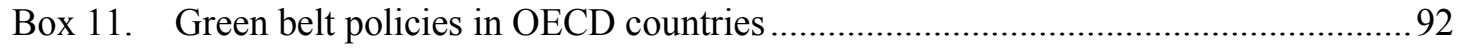

Box 12. Examples of Brownfield policies in OECD countries..............................................94

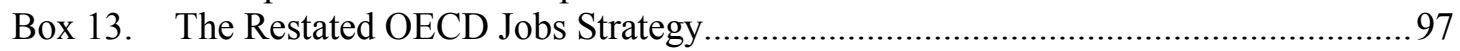

Box 14. Generalising access to education in Chile..............................................................99

Box 15. Examples of different metropolitan cluster approaches and focuses .......................101

Box 16. A well-functioning Triple Helix model: the example of the Helsinki

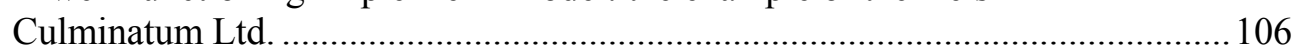

Box 17. Regional innovation policy in Japan, Norway and Italy ....................................... 107

Box 18. Developing urban hubs by promoting innovation in Finland............................... 109

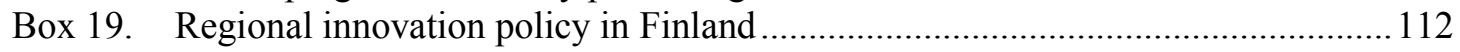

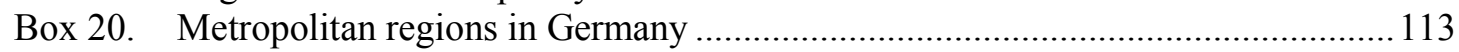

Box 21. Effect of regulations on housing costs in the United States .................................119

Box 22. Regulatory reform based on the Liveable Communities Act of Minnesota........... 122 
Box 23. Supply of affordable housing by the non-profit sector.

Box 24. Policies for integrating immigrants into the labour market in Stockholm ....

Box 25. Fighting urban poverty and distressed neighbourhoods in Mexico, France, and Rotterdam

Box 26. Regional Policy and Climate Change: examples from a selection of OECD countries

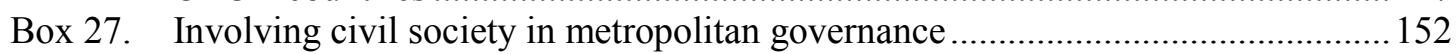

Box 28. Forms of public-private partnerships .............................................................. 158

Box 29. Contractual arrangement in urban areas in France, Sweden

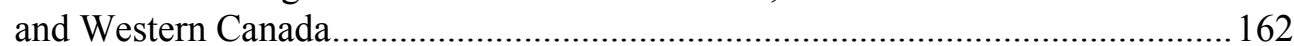

Box 30. Contractual tools used at the metropolitan level in France and Switzerland ......... 163 


\section{URBAN TRENDS AND POLICIES IN OECD COUNTRIES}

\section{Introduction}

This paper presents an overview of trends in urban policies in OECD countries with the objective to identify successes and failure. The policy concept used in this paper is the OECD's new paradigm of regional development policy. Globalisation confronts regions, whether urban or rural, with new opportunities and threats. The new paradigm's objective is to reduce persistent inefficiency (under utilisation of resources resulting in income below potential) and persistent social exclusion (primarily, an excessive number of people below a given standard in terms of income and other features of wellbeing) in specific places. According to the new paradigm, regional policy aims at helping each region, whether wealthy or not, to maximise its own comparative advantages in a positive sum game that contributes to national objectives.

For urban areas, this means that concentration of resources in a place is enabled by forces set in motion by agglomeration economies but that does not necessarily translate into economic performance. Agglomeration economies are conditional on the existence of a pooled labour market, backward and forward linkages among firms, and knowledge spillovers. The key appears to be how assets are used, how different stakeholders interact and how synergies are exploited. The market may not always achieve this alone. There are also negative externalities associated with urbanisation, including congestion and environmental costs, as well as emergence of pockets of poverty and exclusion as the creation of jobs is not always commensurate to economic growth in urban areas. For these two main reasons, there is a rationale for urban public policies with a role of higher level of governments.

This paper will start with an attempt to define urban areas and overview of urbanisation trends in OECD countries. Sections 2 and 3 respectively discuss the economic performance of urban regions as well as the main factors of growth and decline. In Section 4, the rationale for developing public policies for urban development is discussed in light of the limits raised from planning development in a market context. The section attempts to provide as well an overview of recent trends in national urban policies in OECD countries. A selection of specific urban policy tools are then being discussed from Sections 5 to 8, including land use and spatial planning, as well as competitiveness, social and environmental policies for urban areas. Sections 9 and 10 address some of the issues of urban and multi-level governance for policy implementation as well as urban finance. The paper conclude with some key trends and policy messages that emerge from the previous sections and that can provide valuable information for policy-makers in their preparation of a national urban strategy.

\section{Trends in urbanisation in OECD countries}

\subsection{What is 'urban'?}

For the first time in history, the majority of people live now in urban areas. The proportion of the world's population which is urban has been growing rapidly and a larger fraction of the total 
population lives within cities now that at any previous period in history (United Nations, 2007, Principles and Recommendations for Population and Housing Census). Over the past two or three decades this urbanisation trend has been fastest in developing countries and, as a broad generalisation, the faster the rate of economic growth, the more rapid has been the trend towards urbanisation of population.

However, defining what is urban has been a difficult task and there is no commonly agreed definition. Each country defines the term urban in its own way and they can refer to cities, towns, villages, conurbations or localities. There are a number of approaches in which criteria are based to determine what an urban area is. An economic approach would be based on administrative units and would define urban areas using a threshold for labour force (economically active population rates) in agriculture (United Nations, 1974). A geographic approach would consider that density is the main indicator of urbanity. In general, this kind of analysis takes population or houses in a territory (not necessary an administrative unit) as a unit of analysis.

Unless definitions of 'urban' are comparable, international comparisons of levels or rates of urbanisation can be difficult. For instance, using data from the 1991 Census of Population and the only then valid administrative definition of London - the City of London - London's population was 4.5 million, but if London was defined as the statistical unit used as a 'region' by Eurostat - Greater London - then its population was 6.89 million. ${ }^{1}$ In the same vein, the population of the administrative city of Paris -City of Paris de Paris - at the same date was 2.152 million. Was Paris the bigger or smaller city? If both were defined in terms of functional criteria - their 'economic spheres of influence', then London's population in 1991 was 12.5 million compared to Paris with 11.4 million.

There are three different criteria whereby cities can be defined:

Administrative 'competence' - is the place classified as a city for administrative purposes

Physical indicators - the density of buildings, of people or of other indicators such as the proportion of any unit of area covered by hard surfaces (such as concrete or asphalt) ${ }^{2}$ or the intensity of night light emissions.

Functional definitions relating to the behaviour of households and firms to reveal the boundaries of what is 'urban' territory (see below for instance the OECD Metropolitan Database).

Each of these methods of urban definition has strengths and weaknesses.

The most obvious advantage of using administrative definitions of 'city' is that it is easy - both in terms of gathering statistics and politically. The fact that policy and funding for data gathering is ultimately dependent on governments should not be ignored. A further implication of this is that if the interest is in urban policy, the administrative units are frequently those for which policy is implemented. The most obvious disadvantage of using administrative and political boundaries is that they are often arbitrary and reflect often ancient patterns of life. The basis on which they are defined and the frequency with which they are redefined varies widely, not only between, but also within countries. Most of the urban residents of the OECD live in administrative cities which are physically

1. This problem is illustrated in Cheshire and Gornostaeva (2001)

2. See for example Burchfield et al's (2006) measure of urban coverage in the continental USA. 
attached to older central cities and act as residential suburbs - suburban neighbourhoods of much larger metro regions. ${ }^{3}$

Cities identified on physical criteria are almost as easy to gather data for in resource terms as administrative cities are but they, too, suffer, some disadvantages. There are problems when it comes to international comparisons because of differing patterns between countries in settlement patterns sometimes reflecting institutional differences and sometimes historical or topographical ones. Moreover the trade-off between simplicity for gathering data and accuracy for capturing urban reality may err too far on the side of simplicity.

Using administrative areas also brings about difficulties as in some cases land-use restrictions can force the functional area to leap over those obstacles. The UK and the Netherlands have strong and -in the UK's case especially- highly restrictive land-use planning systems designed to constrain urban land take and particularly protect designated areas from urban development. The result is large 'green' un-built areas - in the UK's case as Greenbelts surrounding its major cities; in the case of the Netherlands as a 'Greenheart' separating its four major cities of the Randstad. In England, the area of its Greenbelts is 1.5 times the total area occupied by all urban development (Barker, 2006). The result is not only that developed areas tend to be higher density but, more importantly, that functionally cities leap across protected green areas. This is in contrast to a country such as Belgium or Switzerland where land use planning is unrestrictive so urbanisation tends to spread out as people seek lower densities and more personal living space.

The problem of using administrative units when making comparisons among countries is also significant. In France there is a commonly applied physical definition of cities, the agglomération. This uses as its primary criterion the physical distance between buildings. In France where planning is only somewhat restrictive and allows urban development to occur at the physical limit of urban areas (i.e. does not strongly preserve 'green belts') as well as having relatively low overall population densities, applying the concept of the agglomération produces well defined patterns of physically distinct cities. If it is applied to Belgium, however, the whole country from Antwerp to Liége turns out to be one city. Equally, the agglomération definition does not produce comparably complete definitions of cities when applied to the UK or to the Netherlands. There, as noted above, land-use planning policies deliberately prevent incremental and continuous expansion of cities. So as they grow they are forced to leap across green areas.

This implies that for the most valid international comparisons it is useful to use functional definitions of cities. For example, in the comparison between the size of London and Paris, defining the outer limits of both according to where workers travel to jobs in their employment cores makes a much larger difference to the estimated size of London than it does to Paris. The physically defined agglomération of Paris in 1990 had a population of 9 million compared to the population of 11.4 million in its functional urban area. The functionally defined urban area was some $25 \%$ larger than if defined morphologically. In London the comparable figures, applying the identical criteria,

3. For instance, just the core of Barcelona in Spain is divided into 28 municipalities while the municipality of Zaragoza not only includes the whole physical and functional metro area but large areas of near desert, too. As a political unit the City of London still has more autonomy than any other local or regional authority in England but its boundaries are determined by the location of its mediaeval pattern of settlement and do not extend far beyond its Roman walls. The City de Paris reflects an $18^{\text {th }}$ Century pattern of settlement and most US central cities have not incorporated any of their suburban developments for a century. Most of the residents of the US live in administrative cities which are physically attached to older central cities and act as residential suburbs - suburban neighbourhoods of much larger metro regions 
were 6.66 million and 12.52 respectively. Therefore, the functionally defined London was nearly $90 \%$ larger than if defined morphologically.

Defining cities functionally has the additional attraction that it allows the identification of 'urban cores' and 'urban hinterlands'. The former defined usually in terms of job concentrations, although sometimes in terms of enhanced population density and the latter tending to be more heavily residential and with net outward commuting to the core. In turn this makes it possible not just to track 'urban growth' but also to look at its spatial pattern and whether there is decentralisation (suburbanisation) of population or centralisation.

Another advantage of functional definitions is that it is with respect to those that economic actors locate. Firms, when choosing locations, will look for access to infrastructure and labour. People largely locate with respect to job accessibility. None of these decisions will be much affected by administrative boundaries or the location of un-built land protected from urban development (though the value of access to that may be capitalised into house prices). Firms, for example, claim to have superior access to London's Heathrow airport if located in Reading - $40 \mathrm{~km}$ to the west of London than if they are located in London itself. Only a functional definition of London would capture Reading.

The OECD has defined a functional region as a territorial unit resulting from the organisation of social and economic relations and thus a functional sub-division of territories (OECD, 2002d). The most typical concept used is that of labour markets, i.e. the delineation of functional regions in most member countries is based on the principle of commuting conditions. However, official recognition of functional regions as a framework for territorial measures and policy implementation varies fairly significantly from one OECD member country to another. Moreover, it should be noted that employment markets are only one possible basis for delineating functional units. It is also possible to consider the most appropriate definition based on firms' interactions such as the movement of goods, services and information. However, data for such indicators is seldom available.

A main limit of applying functional definitions to identify 'urban' is their complexity and data requirements. Academic studies have defined functional urban regions on the basis of concentrations of employment and commuting hinterlands and used the resulting data to analyse rates of urbanisation, decentralisation/recentralisation, urban economic growth or the influence of national borders or climate on patterns of spatial growth. ${ }^{4}$ Many OECD countries have developed their own definition of urban/metropolitan functional areas (OECD, 2006f). In the US, for instance, Metropolitan Statistical Areas are defined by:

- Establishing a 'nucleus' or core, defined in turn in terms of population (density) amalgamating counties until a threshold is met.

- Identifying adjacent communities that have a high degree of integration with each nucleus. Using data for the smallest units (counties, townships) available determining which adjacent communities end up being part of the MSA is based on commuting - in $200025 \%$ of employed residents (up from $15 \%$ in 1990).

- The process of MSA definition finalises with the amalgamation of counties until a threshold is met.

4. See for example Hall and Hay (1980) or Cheshire and Hay (1989). 
All existing definitions of urban have significant disadvantages from either the conceptual or the practical point of view. Nevertheless, functional definitions are all but essential if the process of urbanisation and its relationship to economic development is to be clearly understood.

To date, international comparison remains limited by the lack of harmonised statistical datasets. For instance, the United Nations recognises the lack of comparable definitions to distinguish urban and rural areas even for the same region (i.e. 52 sets of countries). Yet, the $\mathrm{UN}$ also recognises that in order to have some comparability the appropriate unit of analysis is the locality but suggests that countries define urban and rural areas not only based on population size. According to the UN, some countries have also used other criteria such as density or economic structure (UN, 2007).

The OECD has developed different tools to answer the increasing demand for statistical information at the regional level and allow international comparison of trends and challenges of the different types of regions. These tools have made it possible to develop and OECD Regional Database and an OECD Metropolitan Database.

The OECD Regional Database provides a unique set of comparable statistics and indicators on about 2000 regions in 34 countries. It currently encompasses yearly time-series for around 40 indicators of demography, economic accounts, labour market, social and innovation themes in the 34 OECD member countries. Regions in OECD member countries have been classified according to two territorial levels (TL) to facilitate international comparability. The higher level (Territorial level 2) consists of macro-regions, while the lower level (Territorial level 3) is composed of micro-regions. In addition, OECD small regions (Territorial level 3) are classified according to their geography into predominantly rural, intermediate or predominantly urban. ${ }^{5}$ The methodology is based on the following criteria: population density, degree of rurality and size of the urban centres located within a region. Predominantly urban (PU) refers to regions in which the share of population living in rural local units is below 15\%; predominantly rural regions (PR) refers to regions in which the share of population living in rural local units is higher than $50 \%$. In order to classify regions as PU or PR it is necessary to define local units within each region to their degree of rurality. A local unit is therefore rural if its density is lower than 150 inhabitants per square kilometre.

Whilst the OECD Regional Database allow comparing trends between different types of regions (predominantly urban intermediate and predominantly rural), it does not reflect the reality of functional regions of large metropolitan areas. Metropolitan areas are typically defined as concentrations of population and economic activities that constitute functional economic areas covering a large number of authorities (OECD, 2006f). A specific OECD Metropolitan Database has been developed separately based on criteria of commuting flows and labour market (Box 1). Based on a specific methodology of selection, the metropolitan database includes 78 metro-regions with 1.5 and more inhabitants. This Metropolitan Database has allowed the OECD to make some inferences about the position of one particular metro-region with respect to the others or to the average, as well as to explore key issues concerning metro-regions such as the relationship between urban growth in terms of population) and income (in terms of per capita GDP), ageing and dependency, the importance of capital cities, productivity and the contribution of metro-regions to their national economies. ${ }^{6}$

5. See http://www.oecd.org/dataoecd/35/62/42392595.pdf

6. The OECD Metropolitan Database has been used to assess socio-economic performances of metropolitan areas in the series of OECD Territorial Reviews (see www.oecd.org/gov/cities) 


\section{Box 1. OECD metropolitan regions: data and definition}

The OECD has used a methodology to gather and analyse metropolitan data (see OECD, 2006f). The Metropolitan database is based on four criteria. The first criterion is based on population size and a threshold of 1.5 million people is set to consider the region as metropolitan. Second, the density of population should exceed a critical value set at 150 people per $\mathrm{km}^{2}$. These types of regions are considered as predominantly urban; therefore, it is not only important to be a region with a large population, but it is also necessary that they concentrate in a particular place thereby accounting for higher density rates. Third, it is also fundamental that these regions with large and dense populations constituting urban areas represent a contained labour market. In order to define labour markets, commuting flows are used to calculate net migration rates. Predominantly urban areas at Territorial Level 3 have been selected and a process of adding and eliminating neighbouring regions based on net commuting rates has been carried out. Hence, metro-regions among predominantly urban areas (large and densely populated) are those for which the net commuting rate does not exceed $10 \%$ of the resident population. The fourth criterion has been set to include a small number of important cities in their national context. Therefore, the database also includes cities with less than 1.5 million people, but that account for more than $20 \%$ of their national population; in this event this means just one city, Auckland (Luxembourg and Reykjavik have been left out as they are extreme cases that represent outliers in many of our rankings).

There are a number of cities that have been included in the sample of 78 metro-regions that were over or under-estimated. For instance, London has been defined as a metro-region considerably smaller than the actual commuting zone around the city. Since data at the appropriate level (TL4) are not available for the surrounding regions of Greater London, the alternative would have been to largely over-estimate the metro-region using entire counties such as Essex, Kent or Oxfordshire among others to account for a part of these regions that may be argued to constitute part of London's labour market based on commuting patterns. In contrast, Busan has been slightly overestimated by taking into account the entire regions of Ulsan and Gyeonsangnam-do, large parts of which are effectively conurbated. Similarly, it could be argued that Milan and Zurich have also been overestimated. However, commuting flows and their net rates for Busan and Milan support our definition. Zurich along with the Turkish cities (Ankara, Istanbul and Izmir) were not defined using net commuting rates as flows are not available for them; instead the definition relies on previous studies. Finally, Canadian, Mexican and US cities are already defined by their national authorities and data have been calculated using the corresponding statistical information accordingly. Although the database is supported by a solid methodology and makes extensive use of previous studies and definitions, there are caveats to bear in mind, particularly in the cases of Busan and London.

Source: OECD (2006f), OECD Territorial Reviews of Competitive Cities in the Global Economy, OECD Publishing, Paris.

Summing up, as there is no agreed-upon definition, the OECD uses three types of units of analysis when assessing the socio-economic performances of urban areas.

i) (Urban areas. These refer to urban areas as they are defined by the national authorities of each country. In particular, this is used when referring to UN data. As this unit of analysis refers to single county or municipality-level areas they have the advantage that national statistical institutes frequently make data available at that level. However, often these urban areas are too small or too large to account for a city.

ii) Predominantly urban areas (PU). These are defined by the OECD Regional Typology and used throughout this paper. They are regions where the population living in high-density areas (150 inhabitants per square kilometre) represents at least half of the population in that region. Although PU areas are also based on administrative areas, they are larger than a single municipality. The OECD has been able to produce comparisons across regions and countries using PU areas, but they remain too large for medium-sized cities in some case and too small for metropolitan areas.

iii) Metropolitan areas (functional areas). These refer to commuting areas as defined by the OECD Metropolitan Database, which takes into account population density, net commuting 
rates and type of region. These are typically large cities comprised by a number of administrative and adjacent areas where economic relations are intense.

\subsection{Trends in urbanisation}

World urbanisation trends are currently catching up with the transformations that already took place in OECD countries. According the UN estimations, the world population living in urban areas have just exceeded rural figures (Figure 1). This is a process that the OECD has already experienced at the end of the first half of the $20^{\text {th }}$ century. By 1950 , urban population was already greater than rural. That same milestone occurred in global urban population in 2006. In a way, the challenges that are brought about by a predominantly urban population have already been faced by OECD countries for more than half a century. If global urbanisation in the first half of the 20th century took place predominantly in European cities, population size has made Asia the continent with the most urban population in the world. Africa is also experiencing important transformations as some of the fastestgrowing cities can be found there. The UN forecasts a decline in rural population after 2020 while in the OECD shrinking rural population has been a feature throughout the second half of the $20^{\text {th }}$ century. For both, the world and OECD countries, the UN expects urban population to steadily grow even if at a slower pace in the latter. By $2050,70 \%$ of world population -and $86 \%$ for OECD countries-will live in urban areas.

Figure 1. Urban and rural population in the world and the OECD (1950-2030)

Absolute population numbers

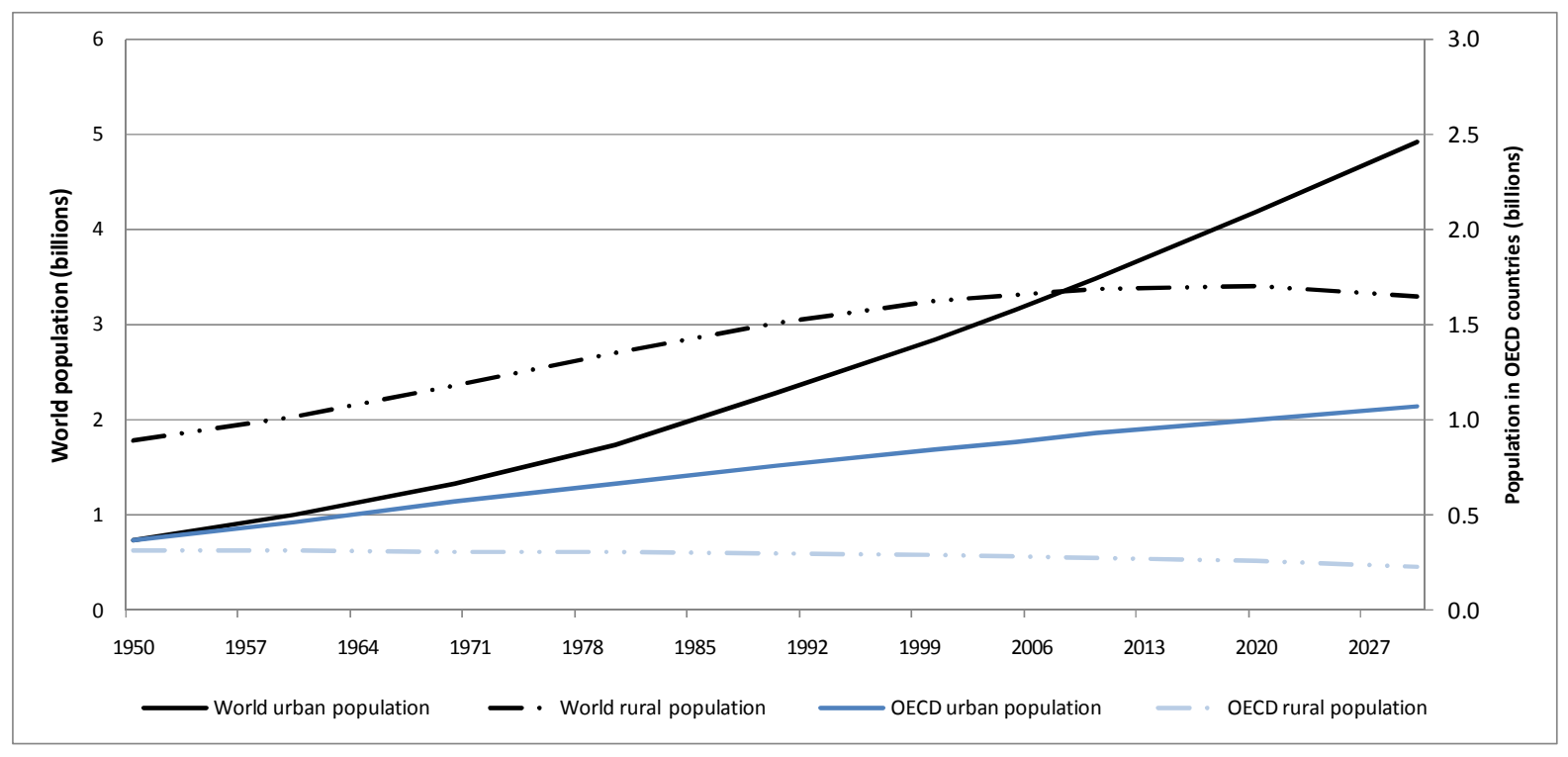

Source: Author's calculations based on data from the UN Population Database, www.un.org/esa/population/.

Urbanisation is higher in OECD countries, but emerging economies have been urbanising at a faster pace. OECD countries such as Australia, Korea, France and Japan are among the most urbanised and some emerging economies such as Chile and Russia have also similar levels of urbanisation (Figure 2). Other large emerging economies such as India and China have urbanised but remain far from OECD levels. However, countries like China have been urbanising faster than any OECD country -except for Korea - in the last 55 years. The share of urban population in China has been growing at $2.1 \%$ annually only second to Korea growing at $2.4 \%$ and it is three times faster than Chile and France and twice as fast as India. 
Figure 2. Urbanisation in OECD and non-OECD countries

Urban population shares (1950-2005)

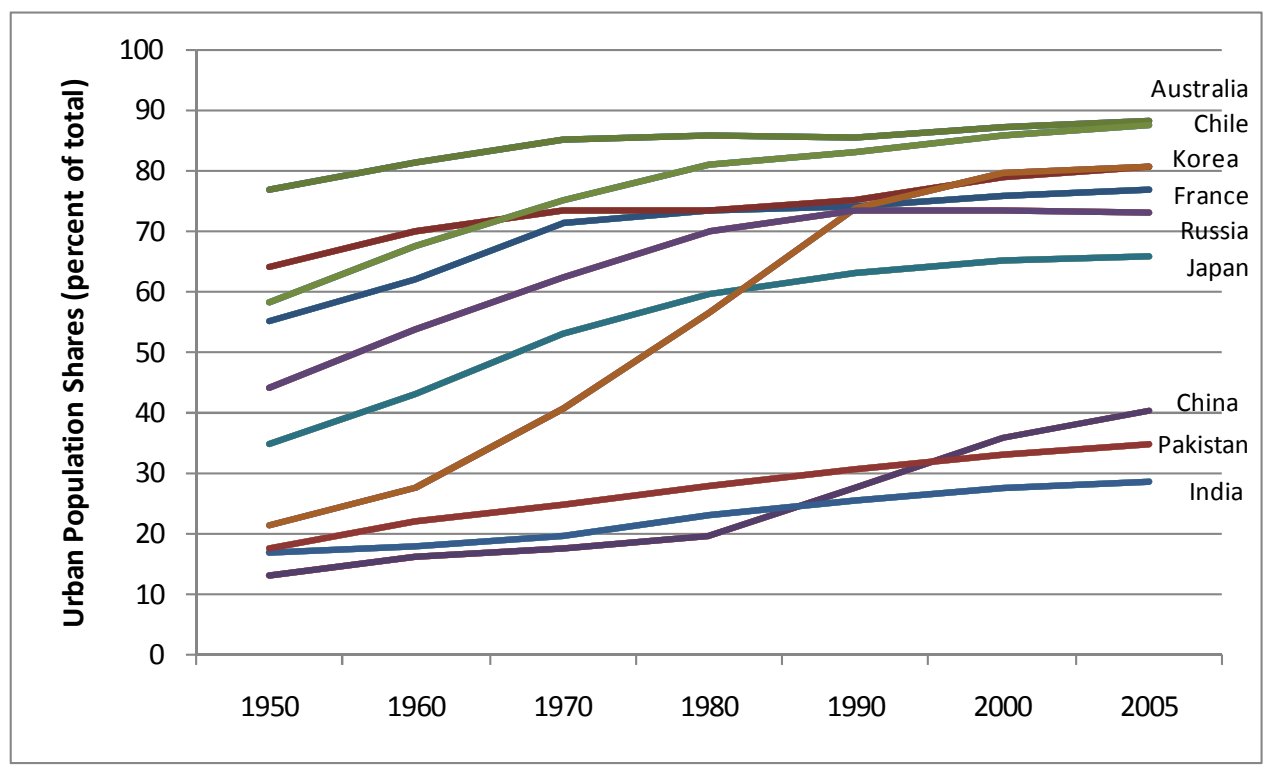

Source: UN Population Database, www.un.org/esa/population/.

China has became the world's largest urban nation with today over 600 million urban citizens. Dating back to the mid-1970s, although then a predominantly rural society and with an urbanisation rate just below $20 \%$, in absolute numbers China became the world's largest urban nation in human history. Since then, total urban population has almost tripled, up from around 200 million in 1980 to 606 million in 2008. Meanwhile, based on the statistical definition, China's urbanisation rate has reached $45.7 \%$ in 2008, up from around $20 \%$ in 1980. Nowadays, China has 660 statutory cities approved according to the administrative designation (NBS, 2008). Within the country, the levels of urbanisation vary among regions. In general, the eastern region has a higher urbanisation rate than the western and the central regions, and urbanisation rate in the northern region is higher than that in the South. For instance, average urbanisation rate of ten major statutory cities in the eastern region reached 54.1\% in 2006, increased by $28.6 \%$ from 1978 level. Those of western region increased from $13.7 \%$ in 1978 to $35.7 \%$ in 2006 , with a growth of $20.9 \%$ during the same period (Kamal-Chaoui et al., 2009).

Various projections indicate that China's urbanisation will continue, at even more rapid rates in parts of the country, well into this century. China's urbanisation level in 2005 was even lower than the average level of low-income countries, far from being the most urbanised developing countries. The Eleventh Five Year Plan (2006-2010) calls for China's urbanisation level to reach 47\% by the end of 2010. The country's pace of urbanisation may well accelerate during the next ten years. The Ministry of Construction released official projections in 2004 suggesting that the country would be $60 \%$ urbanised by 2020 . Notionally, China will cross the $50 \%$ threshold and be a predominantly urban nation by 2013 at the latest (Figure 3). To put China's urbanisation in global perspective, by 2015 China's urban population will be between 680 and 700 million, at least 2.5 times larger than the projected urban population in the United States, and 1.6 times larger than UN projections for India. From 2005-15 China will need to absorb an additional urban population of around 160 million people - the equivalent of almost half the entire urban population of India in 2005. 
Figure 3. Urban populations, 1950-2030

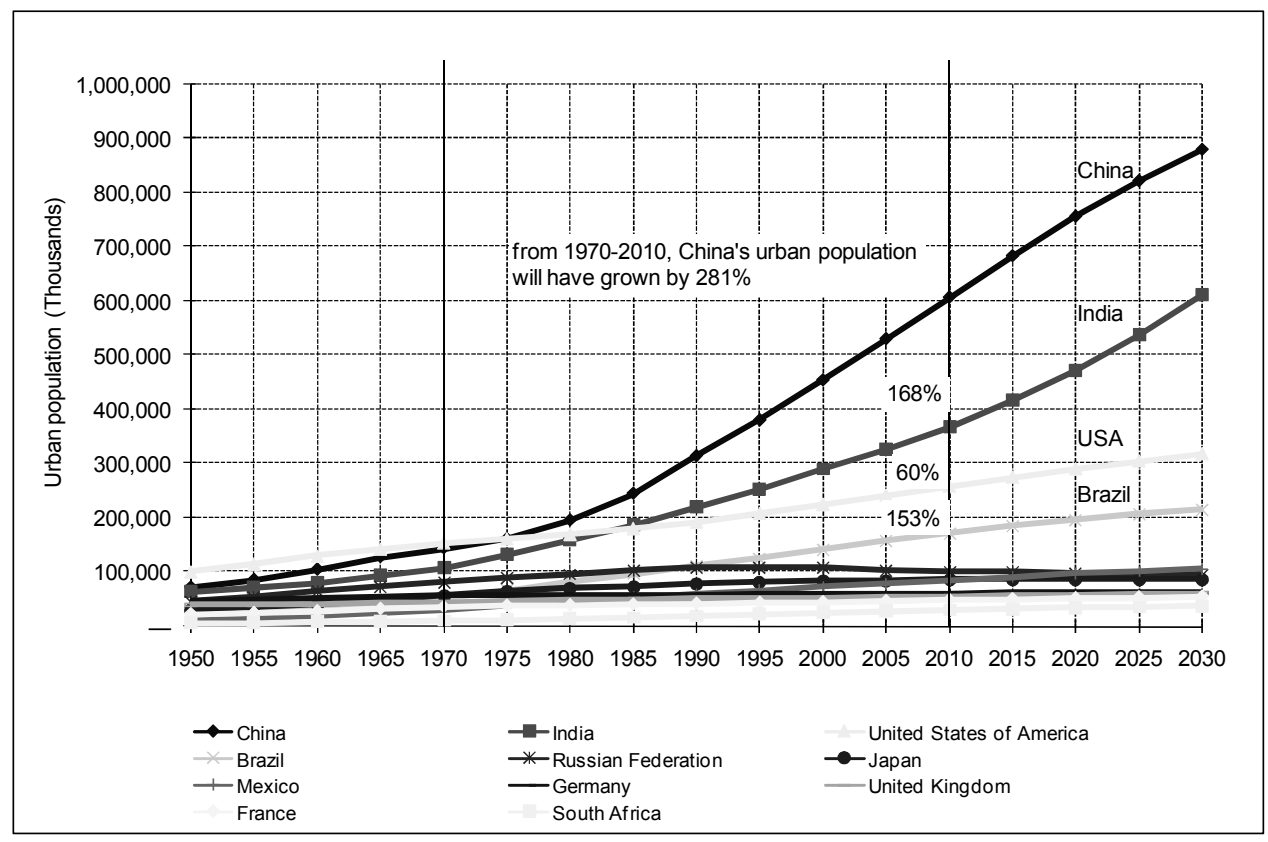

Source: BRICS and selected OECD countries, from United Nations (2007) State of World Population 2007: Unleashing the Potential of Urban Growth, New York: United Nations Publishing.

In OECD countries, large cities are increasingly the places for people in the OECD to live and will likely only increase their influence. Over $70 \%$ of people in the OECD that live in predominantly urban (PU) areas do so in PUs of more than 1.5 million people (Figure 4). Not only that, but these types of cities have registered the highest population growth rates $(0.8 \%$ annually on average $)$ in the OECD. In fact, population in urban areas locate increasingly according to city size. Thus, smaller cities (between 100000 and 500000 people) host in total less population than any other type of cities and they also grow slower ( $0.4 \%$ annually on average). Medium-sized cities grow faster than smaller but slower than larger and they also are host to a lower population than those over 1 million people. Large cities but smaller than 1.5 million people approach but do not reach population growth rates in the latter and they are home to less than $15 \%$ of all urban population in the OECD. The remaining $15 \%$ of urban population live in small and medium-sized PUs. 
Figure 4. Urbanisation and city size

Urban population and growth (1995-2005) according to population size of PUs

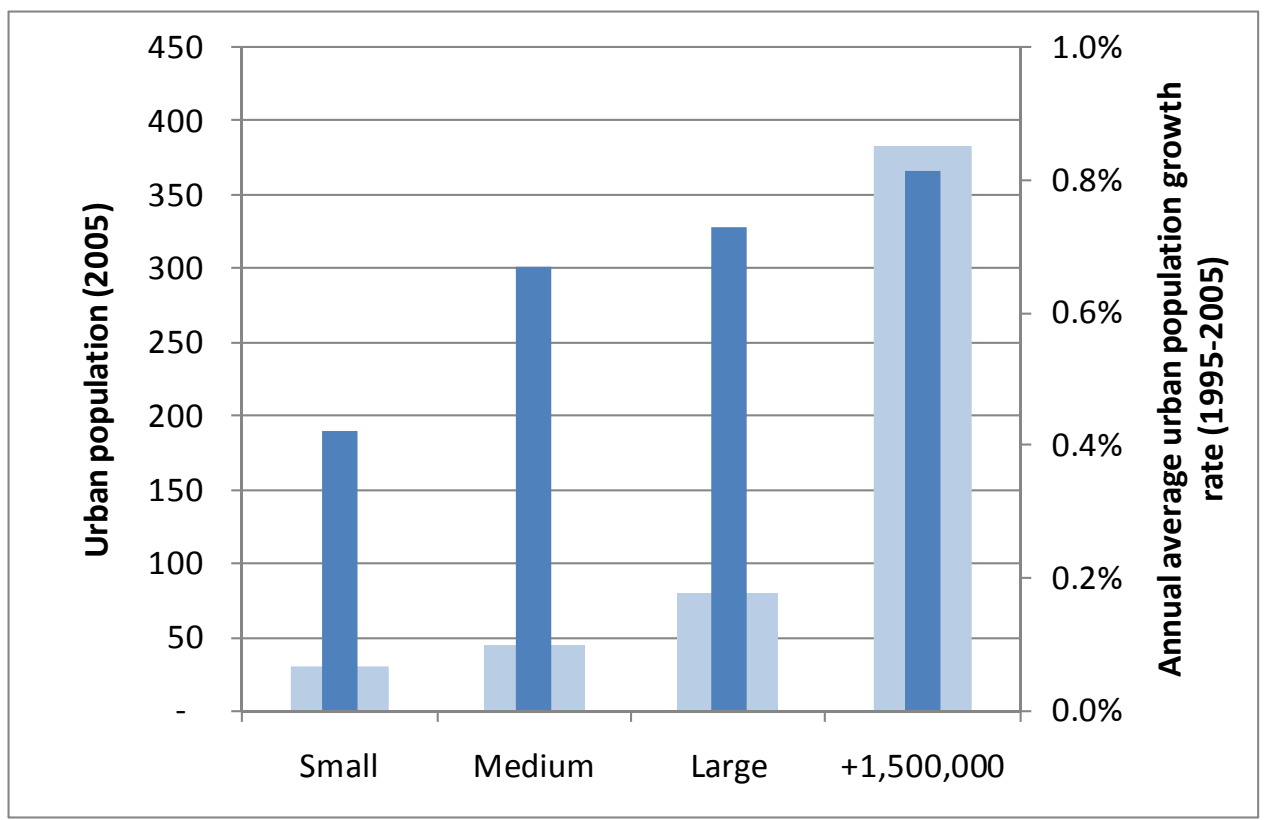

1. This analysis was carried out using only predominantly urban (PU) areas.

2. Small cities are PUs with population between 100000 and 500000 people. Medium-sized cities are PUs with population between 500,000 and 1 million people. Large cities are PUs with population between 1 and 1.5 million people.

Source: Author's calculations based on OECD Regional Database.

Trends among metropolitan regions in the OECD show similar results. In some cases, a single metropolitan region accounts for nearly half of the national population. Seoul, Randstad and Copenhagen represent between 44 and $48 \%$ of their respective national populations. With a few exceptions, namely Berlin, Manchester, Cleveland, Birmingham, Budapest and Pittsburgh, metropolitan areas in the OECD have experienced an increase in population between 1995 and 2005 (Figure 5). On average, OECD metropolitan areas have been growing at an annual pace of almost 1\% since 1995, but cities such as Phoenix, Atlanta and Toronto have observed growth rates several times the average and in many others such as Ankara, Miami, Guadalajara and Washington, metropolitan population expansion has grown at least twice as fast as the average. Madrid, Seoul, Sydney and Mexico City also have experience above-average population increases. 
Figure 5. Population growth in OECD metropolitan areas

Average annual growth rates 1995-2005

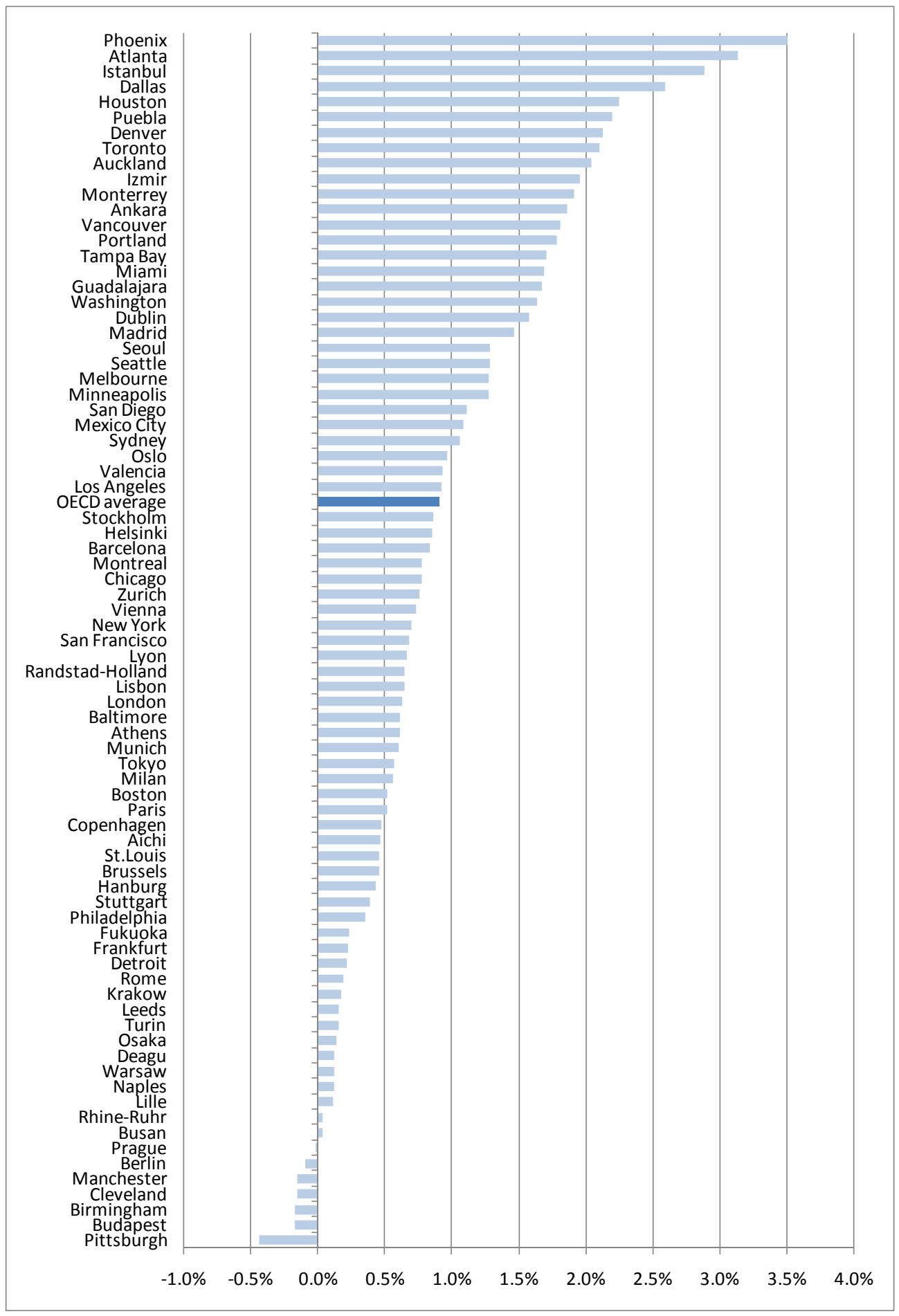

Note: The period of growth in the case of Auckland is 1996-2005.

Source: Author's calculations based on data from the OECD Metropolitan Database. 
Over 20 to 30 years period, OECD countries show different paths of urbanisation and no single trend can be identified. Taking into account the OECD predominantly urban areas, the majority of OECD countries show an increase in their urban population share over a period of 10 to 25 years depending on the availability of data (Figure 6). Gains were particularly notorious in Japan, Mexico, New Zealand and Turkey. Although a number of countries saw their urban population shares shrink (e.g. France, United States, Poland, and United Kingdom) such declines were for the most part marginal except for Hungary and the UK where the shares fell between 2 and 3\% (Figure 7). Finally, a group of countries experienced a decline in urban shares by the end of the 1980s and a recovery throughout the 1990s among which Norway, Spain and Switzerland (Figure 8). The exact opposite trend -an increase and then a decline in urban shares - was found in Korea.

Figure 6. Urbanisation growth in OECD countries

Countries with positive growth of urban population shares
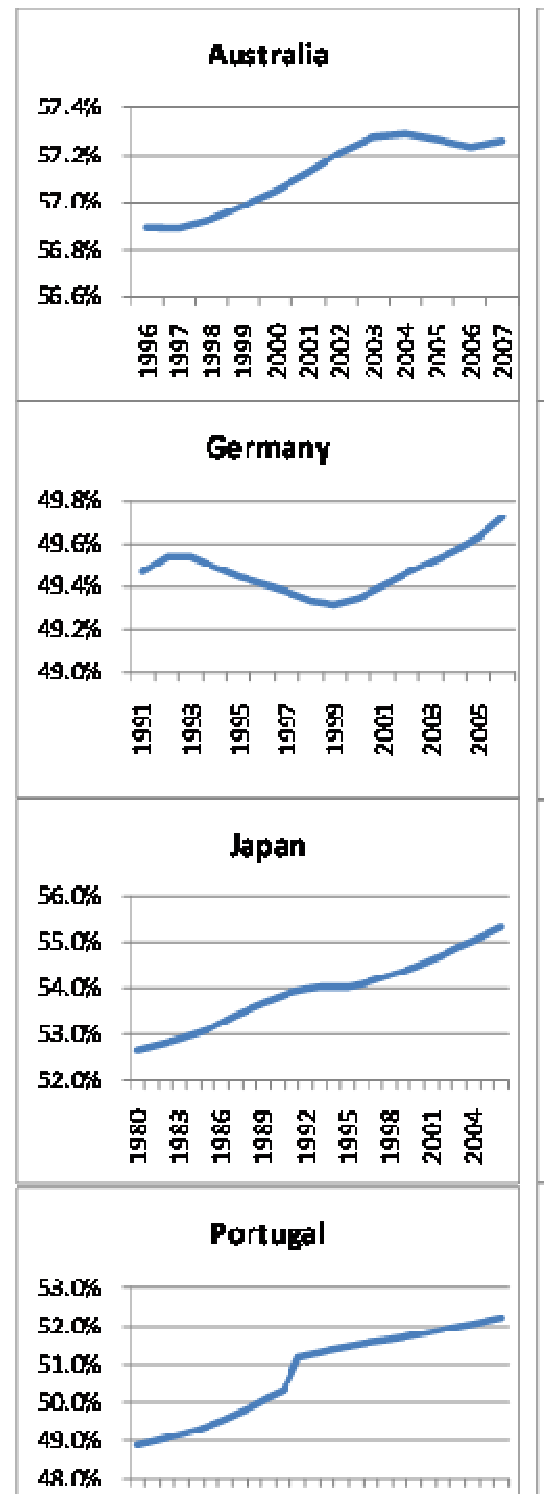

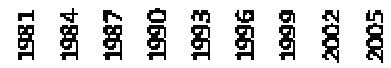

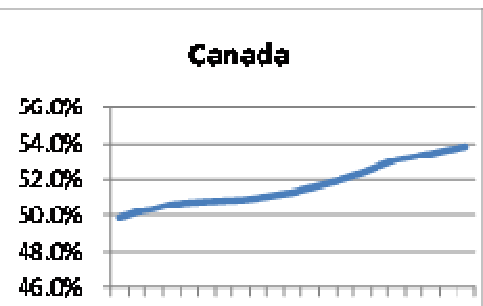

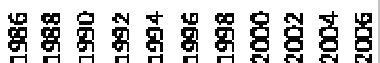

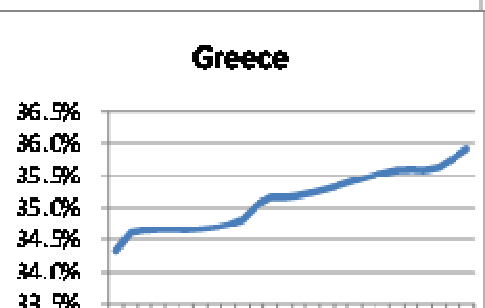

$33.5 \%$

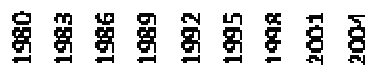
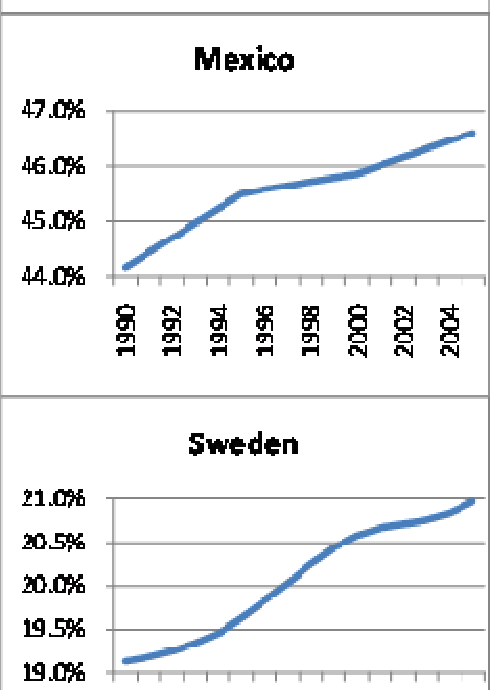

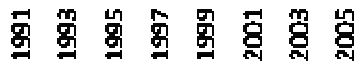

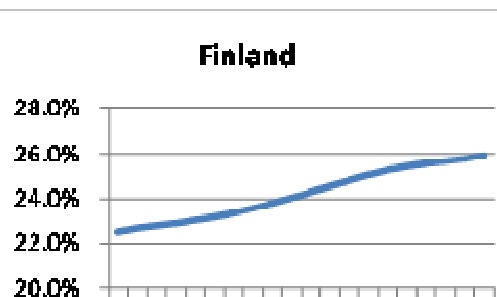

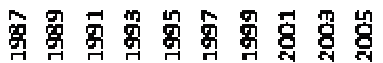
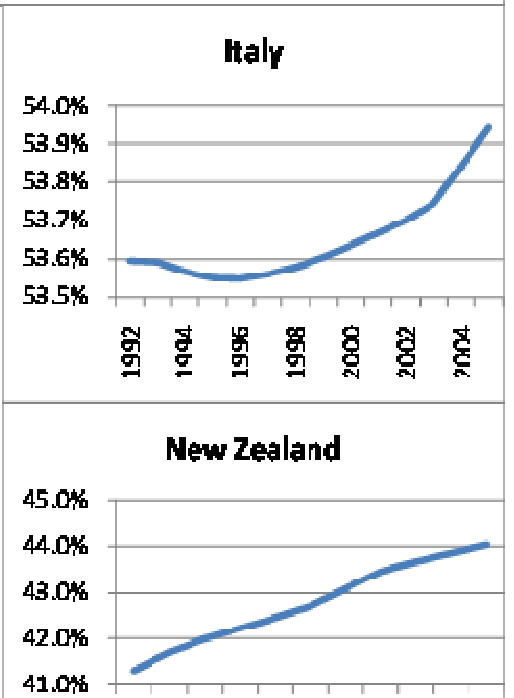

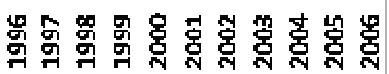

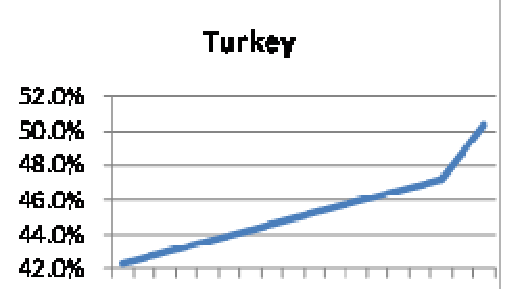

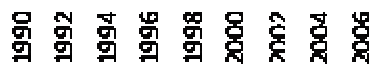

Source: OECD regional database. 
Figure 7. Decline in urbanisation in OECD countries

Countries with negative growth in urban population shares

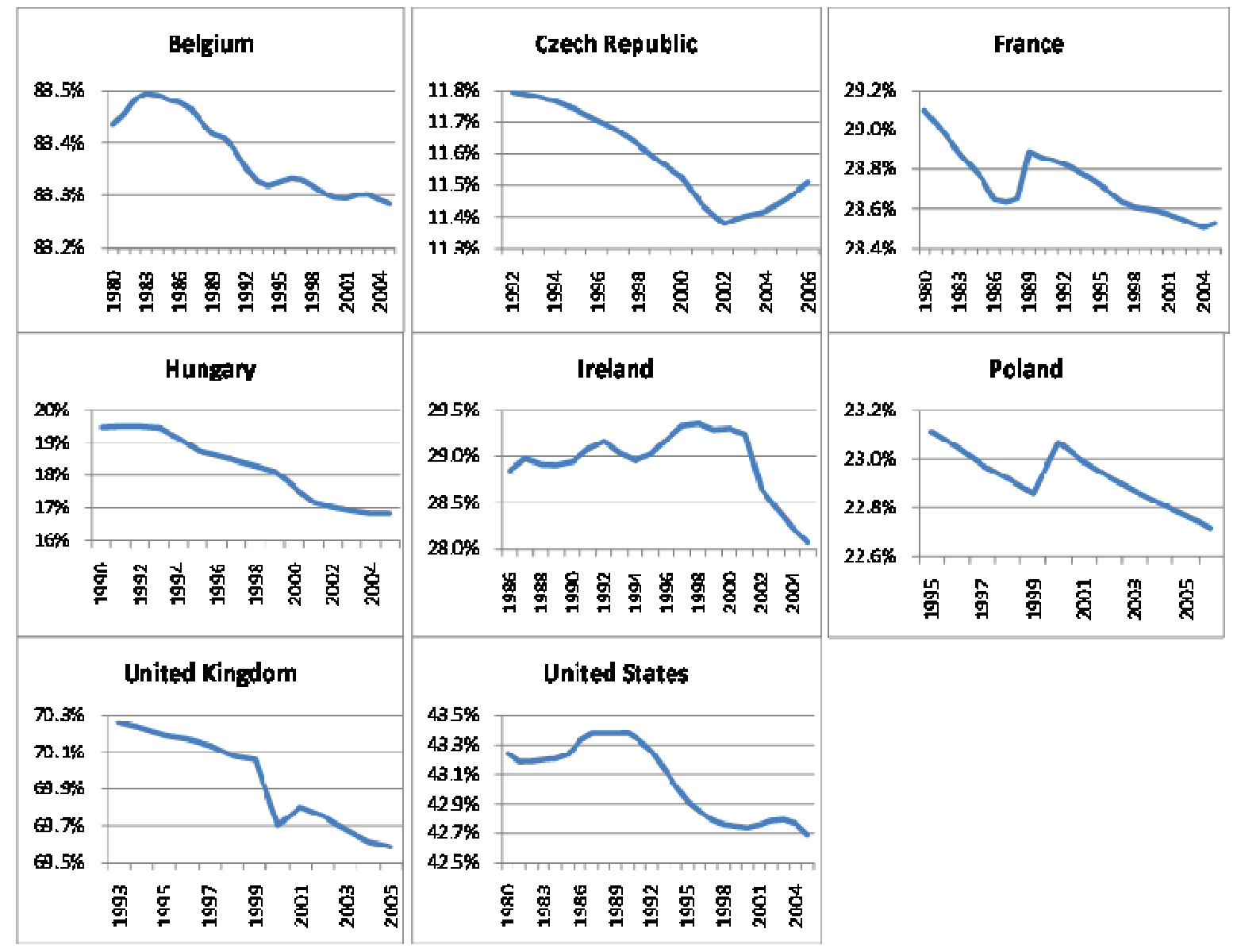

Source: OECD regional database. 
Figure 8. Changing urbanisation

Countries with changing trends in urban population shares
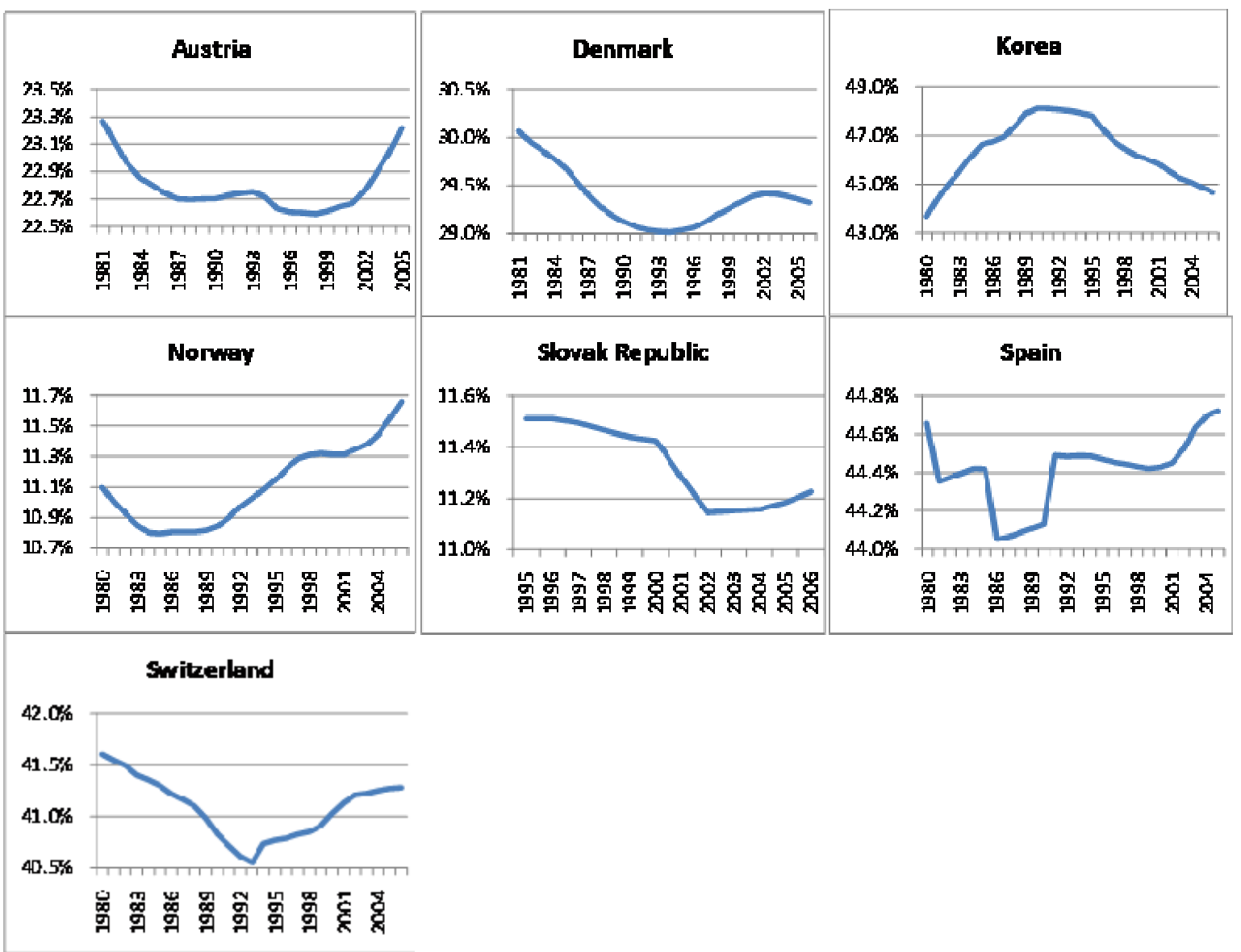

Source: OECD regional database.

More recent trends in population growth - i.e. over 1995-2005 - shows that urbanisation is on the increase almost in OECD countries. Taking into account predominantly urban areas (PU) in the OECD as defined by the OECD regional typology, today more than $53 \%$ of the total population is living in urban areas; this number rises to almost $83 \%$ if we include intermediate regions (IN), less densely populated areas characterised by systems of medium-sized cities. Over 1995-2005, population growth in OECD countries has been more dynamic in urban (PU) areas and intermediate (IN) areas than in rural areas. Only two countries (Belgium and Ireland) show stronger demographic expansion in rural areas (Figure 9). What is more, with a few exceptions in Eastern European countries, all OECD member countries have positive urbanisation growth rates between 1995 and 2005. If PU areas are taken into account, all countries with urbanisation shares higher to the OECD average are becoming increasingly urbanised (Figure 10, see quadrant 1 located above right). As a result, the OECD population is becoming increasingly concentrated in a few places (Figures 11, 12 and 13). For instance, in terms of density (population over land area), Europe is evidently concentrated around the area that stretches from England into South-West Germany. Similarly, Japan shows peaks of concentration around Tokyo and Osaka and Seoul in Korea. In North America, a set of peaks stretch from Chicago and into New York - but also other urban areas - as well as other concentrations in Los Angeles, Mexico City and Monterrey. China's urbanisation seems to stretch all through the coast although it is also taken place in some western inland regions (Figure 14). 
Figure 9. Population growth in OECD regions

Annual population growth rates by types of region (1995-2005) according to PU, IN, PR

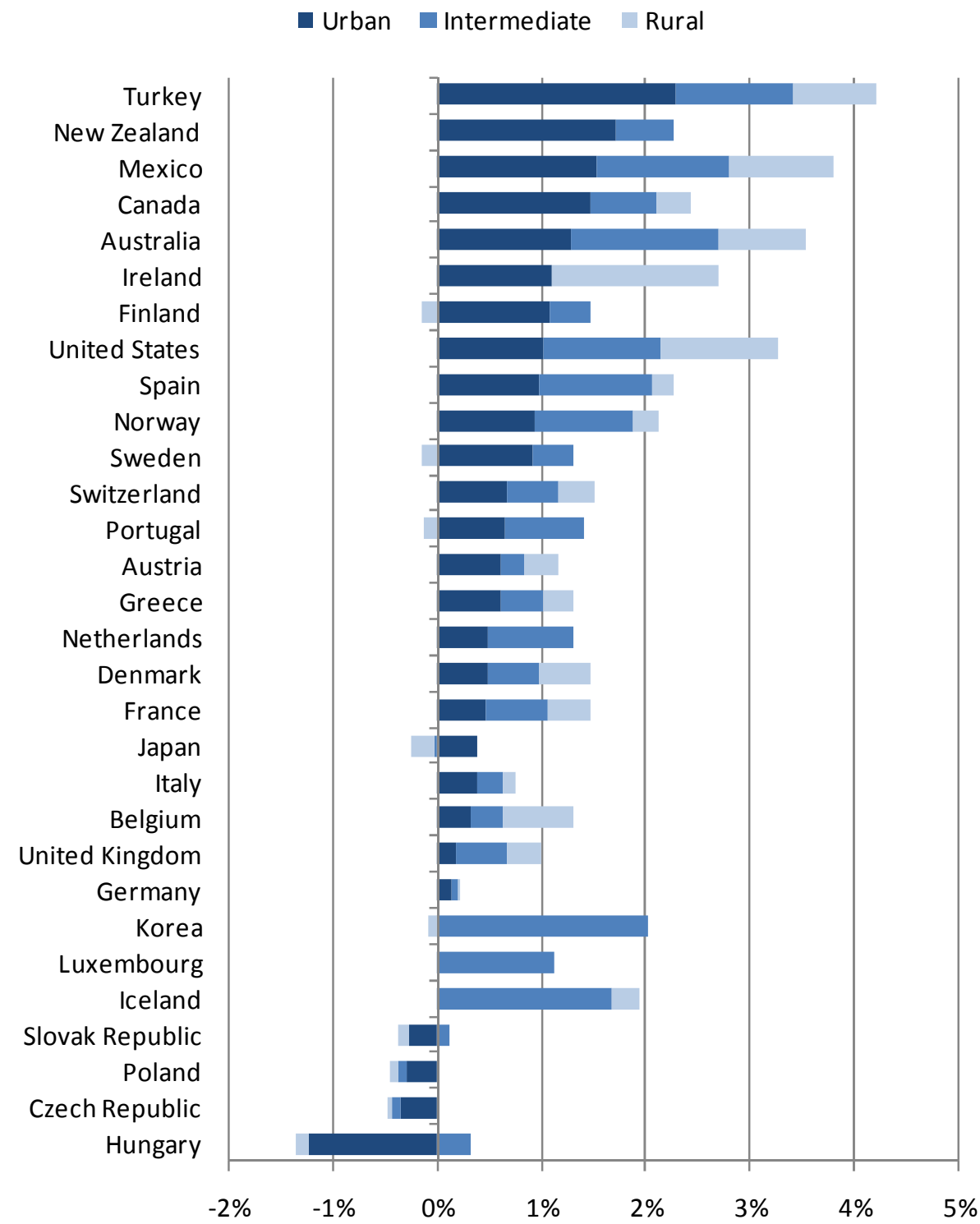

Notes: In some cases like Korea, intermediate regions growth can be accounted by for growth in cities of a smaller size in wider areas that are considered to be intermediate. For instance Gyeonggi-do is an intermediate region that surrounds almost entirely the Seoul area; given that there has been considerable business growth outside the administrative area of Seoul after the deconcentration policy, it is possible that part of that growth has gone to Seoul's suburbs located in Gyeonggi-do.

Source: Author's calculations based on data from the OECD Regional Database. 
Figure 10. Urbanisation in OECD countries

Urbanisation levels and growth according to PU areas (1995-2005)

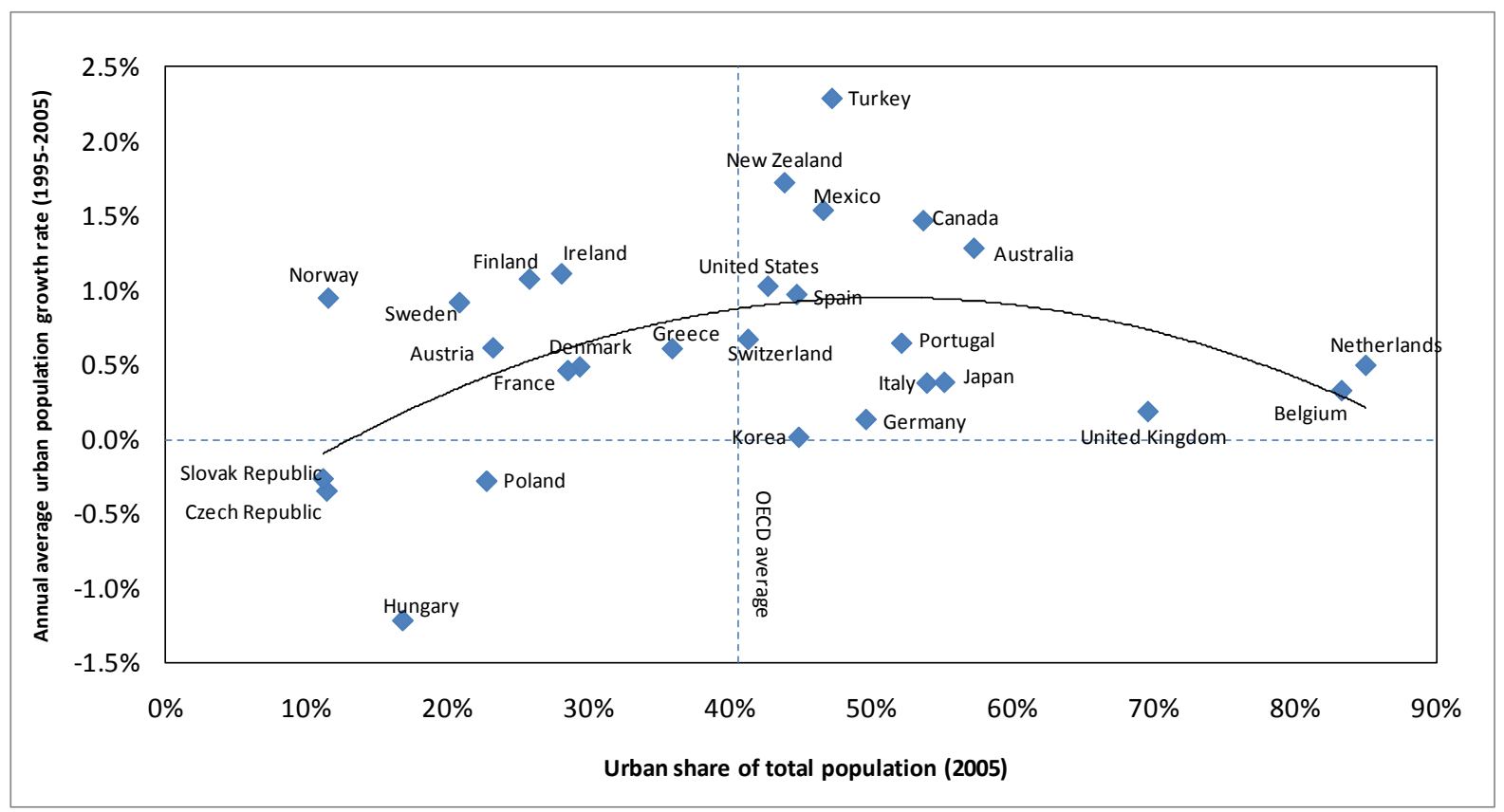

Notes: Urban share of total population by country refers to population in urban regions as a proportion of total population. Iceland and Luxemburg were not included in the sample as the OECD Regional Database identifies no predominantly urban (PU) regions in those countries.

Source: Author's calculations based on data from the OECD Regional Database.

\section{Figure 11. Urban Concentration in Europe}

Population density at TL3 level (inhabitants per square km) in European countries in 2005

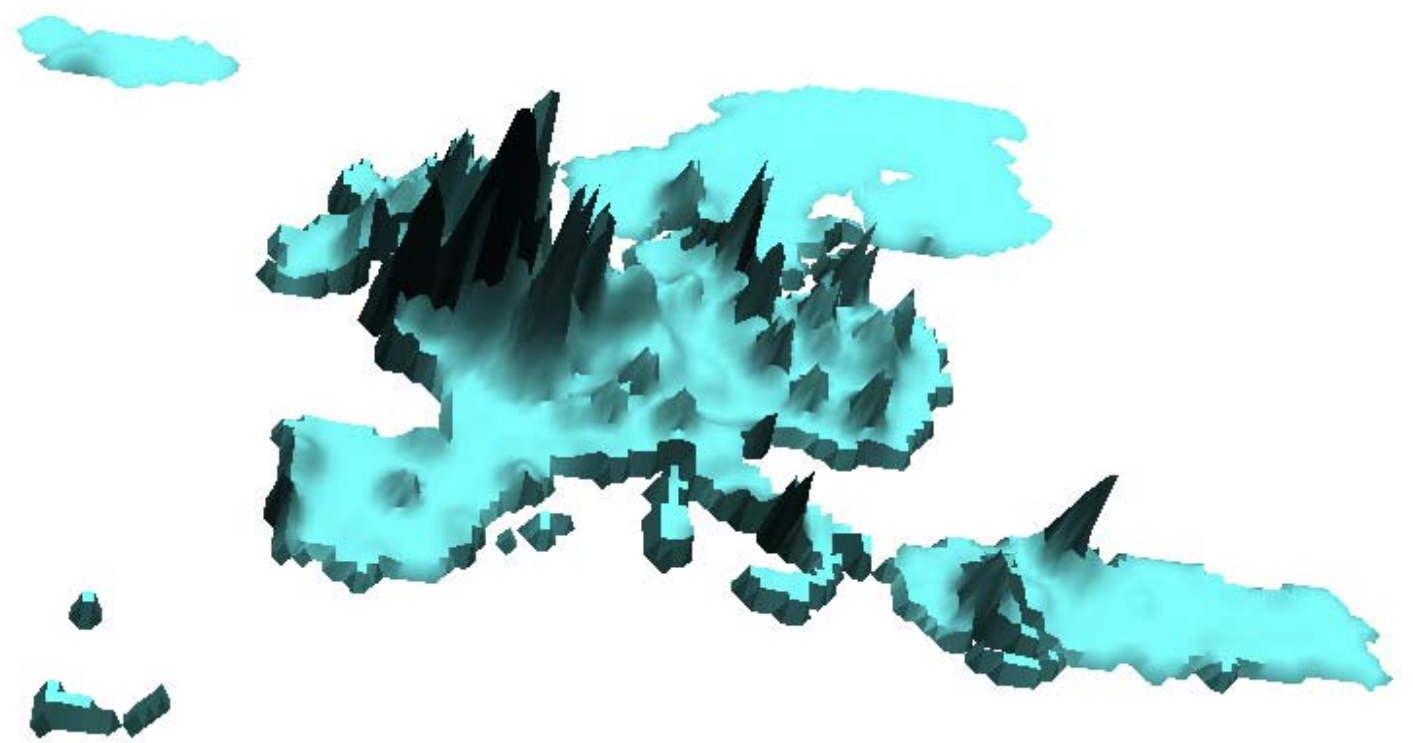

Note: OECD regions are classified at two levels: Territorial Level 2 (TL2) and Territorial Level 3 (TL3).

Source: Author's calculations based on data from the OECD Regional Database. 
Figure 12. Urban concentration in Asian OECD countries

Population density at TL3 level (inhabitants per square km) in Japan and Korea in 2005

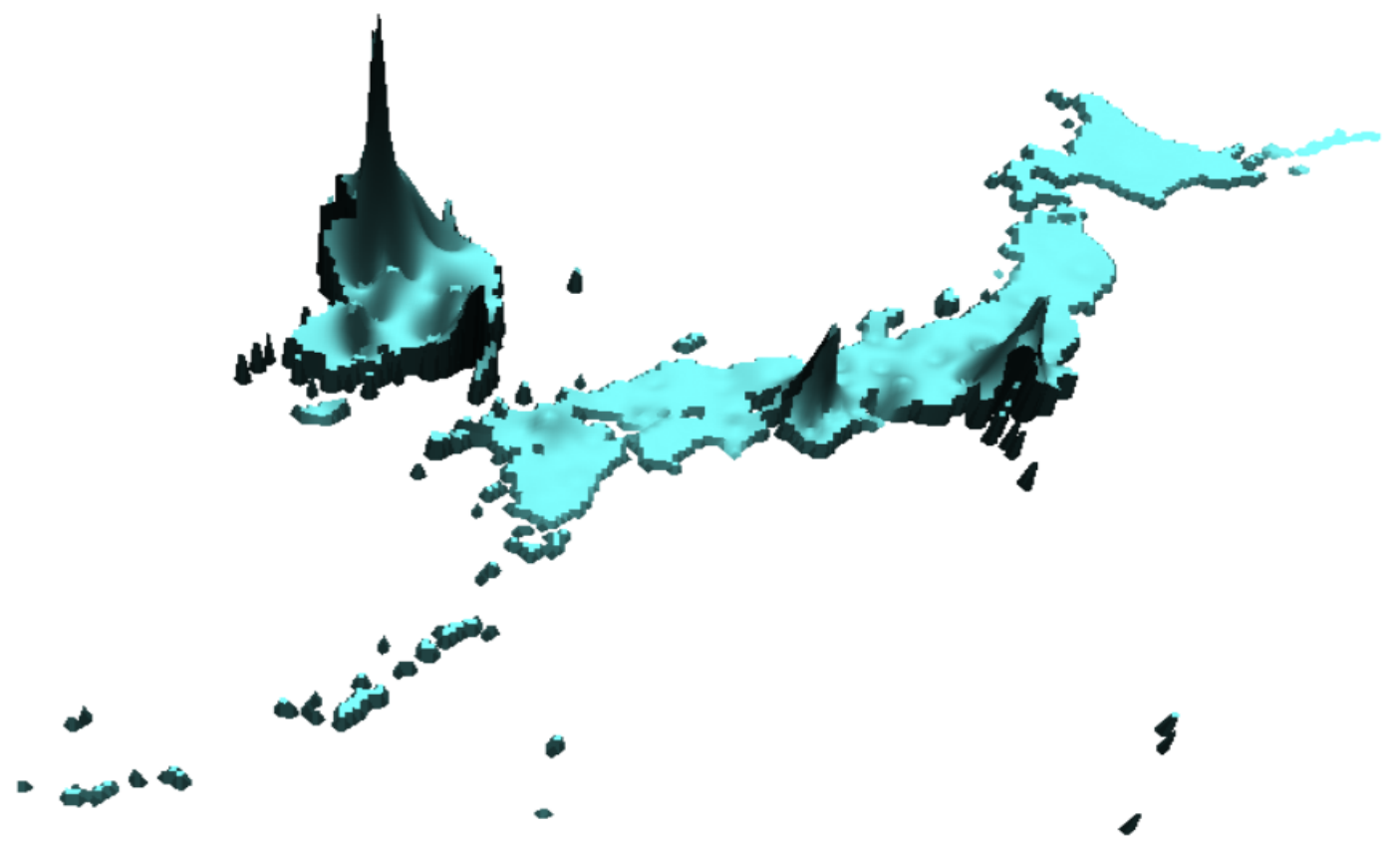

Note: OECD regions are classified at two levels: Territorial Level 2 (TL2) and Territorial Level 3 (TL3).

Source: Author's calculations based on data from the OECD Regional Database.

Figure 13. Urban concentration in North America

Population density at TL3 level (inhabitants per square km) in 2005

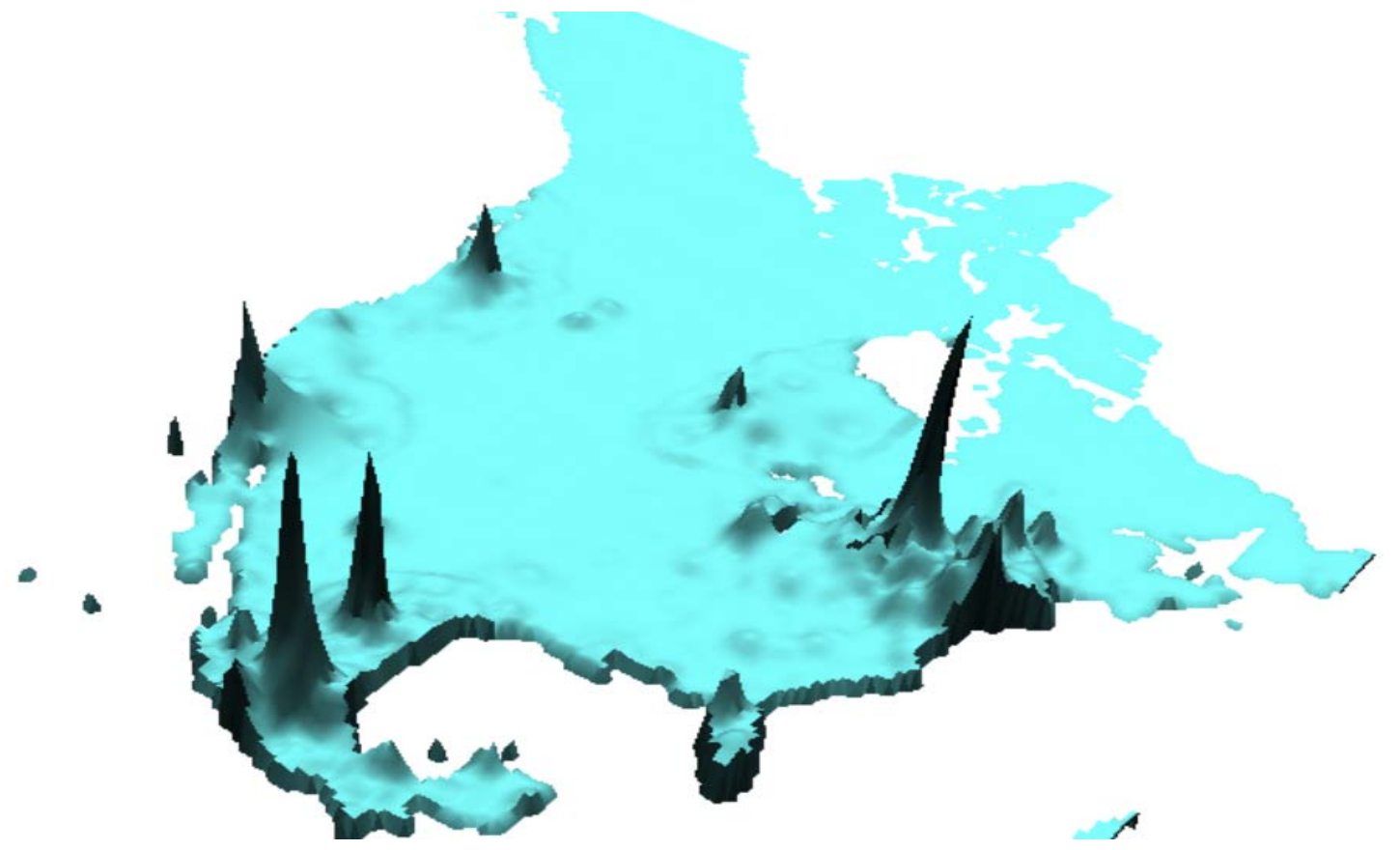

Note: OECD regions are classified at two levels: Territorial Level 2 (TL2) and Territorial Level 3 (TL3).

Source: Author's calculations based on OECD Regional Database. 


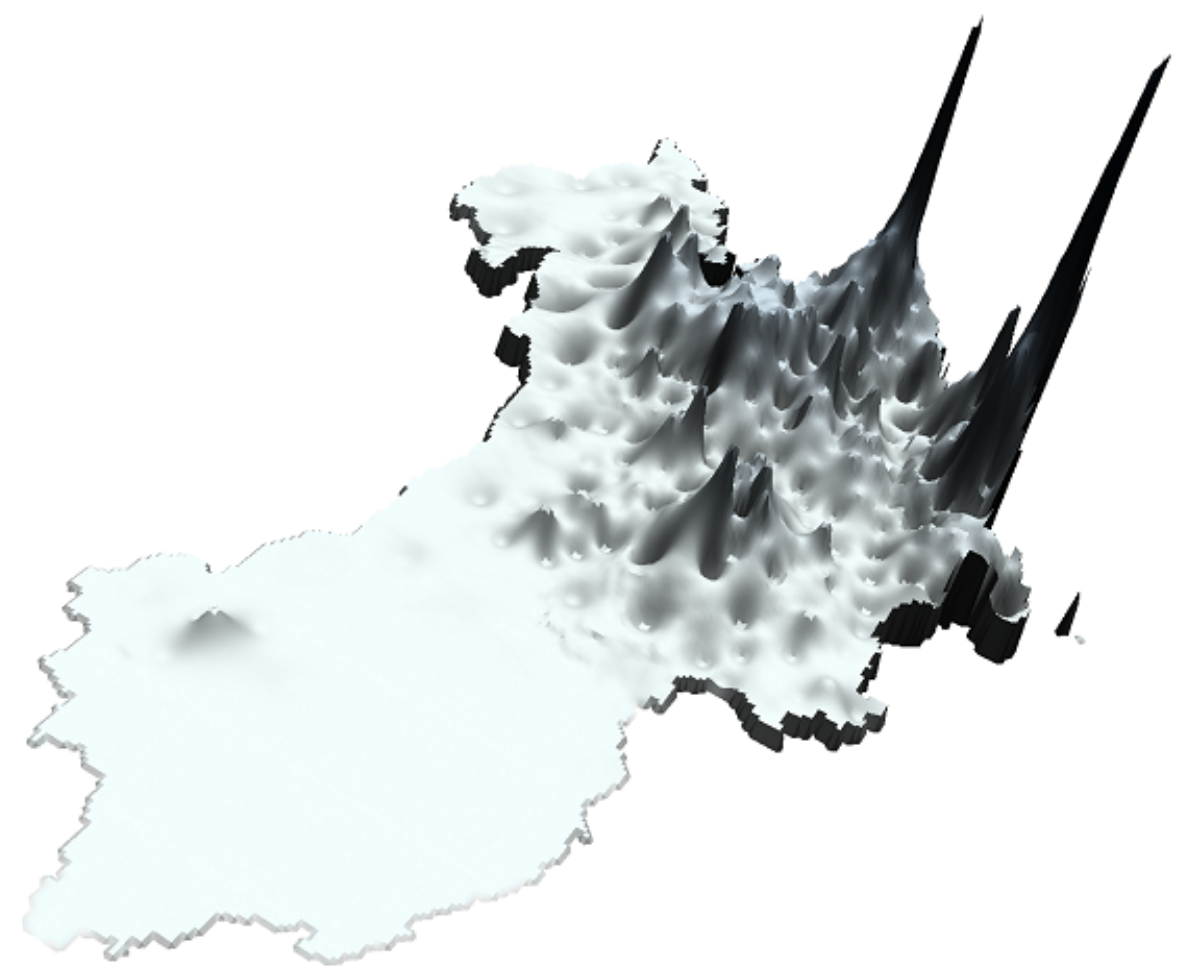

Source: data from National Bureau of Statistics (Census 2000) classified following the OECD regional typology

\subsection{Stages, pattern and drivers of urbanisation}

The process of urbanisation can be related to a process of development. Urbanisation, measured by growth of urban population shares or by urban population growth rates can arguably track economic development. In East Asia, at the start of the period, the most industrialised country - Japan - had the highest urban share but already Korea had a faster rate of growth of urban population. China and India were still largely rural. OECD countries had much larger urban shares of population but slower rates of growth. Several stages of urbanisation and development can be outlined as in Cheshire (1995):

i) Early stages of economic development - rapid growth of urban share and centralisation of population in urban cores

ii) Intermediate stage - slower urban share growth as rural population and peasant agriculture declines and spread of growth to intermediate sized cities and to suburban hinterlands

iii) Mature economic development - slower growth of urban share and even loss of urban populations from some cities and from cores

iv) Post-industrial stages - more or less stable but high share of urban population with renewed growth in largest metropolitan cities and in selected cores but continued growth of many medium sized cities. Decline of older industrial cities and regions. 
China as a whole seems to be following this pattern but still in the first phases of urbanisation. Given the extraordinary rate of economic growth in China, the growth of urban population may be slightly slower than anticipated. The urban share in China in 2005 is significantly below that of the more rural countries of Western Europe in 1950 and lower than was observed in Russia or Chile at the same date. However, one should remain cautious in generalising about China's urbanisation path as a whole as there are many distinct regions, most of which are developing in different ways and different speeds. Yangtze Delta is much more urbanised and economically advanced than the Sichuan Plain, for example (but the latter holds 110 million people, 30 million more than the YD).

For a number of OECD countries, urbanisation growth and rural to urban migration in OECD countries has slowed down since the 1980s, and a process of economic transformation towards tertiarisation of activities occurred in many cities. From a historical perspective, in the 1950s in the USA and the 1960s in Northern Europe, rural-urban migration tended to decline and the predominant pattern in urbanisation became decentralisation and to certain extent decline of some of the older industrial cities. ${ }^{7}$ With globalisation and the large scale movement of industrial production to the newly industrialised countries (NICs) not only was there strong urban growth in the NICs but also manufacturing ceased to be the economic base of large cities in most OECD countries. Economic transformation meant that increasingly employment was concentrated in services sectors - many of which produced an output itself traded (legal, financial and business services, cultural and media industries, medical services, higher education and research, among other) which used less space and were more reliant on access to a large and specialised labour pool. These kinds of activities therefore tended to be locationally more concentrated in large metro-region cores and the attraction of these as living locations was reinforced by falling household size, increasing human capital and particularly increasing female human capital and labour force participation. This meant that for an increasing majority of highly skilled couples large cities became optimal locations (Costa and Kahn, 2000).

In combination these factors (tertiarisation, globalisation, concentration of human capital and increased female participation levels) led to a more fragmented pattern of urbanisation. Some cities, particularly those heavily dependent on ageing industrial structures which had lost comparative advantage continued to decline. Some others, especially the largest metro-regions with the most highly skilled labour forces and strong traded service sectors were 'resurging' (Cheshire, 1995; 2007). Their population, income and employment again grew in absolute terms (for example, London) or in relative terms (for example, New York) and in some cases they experienced renewed population centralisation with their urban cores experiencing population growth. As often, however, this type of high skilled and service-sector dependent growth was visible in medium-sized cities, historically less influenced by the process of the industrial revolution (for example Oxford, Toulouse or Boston). In Western Europe medium-sized cities without a strong industrial base (such as Oxford, in the UK or Ulm, in Germany) were growing and prospering during the 1990s and early 2000s while old smaller and medium-sized cities produced by the industrial revolution (such as Sunderland or Whitehaven in the UK or Valenciennes or Lens in France) continued to decline. Part of the growth of such places was that they developed into 'high-income' dormitory areas of very large and prosperous cities.

Since 1950, Europe's urban population rather than declining has in fact been growing through urban sprawl. If all large functional areas in Western Europe are compared to trends in population in urban cores (administrative units) from 1951 through to 1981 there is a steady movement from centralisation and urban growth towards decentralisation and urban decline. Various 'stages' of development for urban areas can be identified ranging from centralisation (growth in the core) in

7. These two trends could be easily confused if administrative or simpler physical definitions of cities were used. For example, using an administrative or even a simple built-up area definition of London suggested its urban population was in decline. This was never true using functional definitions although there was a slowing of growth and a strong and extensive decentralisation. 
Stage 1 to decentralisation (urban population decline) in Stage 8 with more relative levels in between (see notes to Table 1 for further details). By 1981, three-quarters of Northern European cities were experiencing population decline. During this period, urban population was declining both at the core and in the wider functional areas as a whole with the hinterlands still gaining population (Stage 6 in Table 1). A similar process albeit with slightly milder proportions was also present in France and Northern Italy. This steady progression towards urban decline appeared first in northern Europe but followed by those in France and Northern Italy and then by those of Southern Europe.

However, in the last 30 years urban cores regained population due to intensive use of technology in rural areas and tertiarisation in urban areas. First, the reservoir of potential rural-urban migrants as a result of technical change in agriculture was reduced. Rural to urban migration slowed down as agricultural population declined and its processes made more intensive use of technology. In Northern Europe - even during the 1950s - agricultural employment was low: in Britain, for example, East Anglia, the most agricultural region, had less than $10 \%$ of its labour force in agriculture in 1951 while in Galicia in North West Spain some $50 \%$ of the civil labour force was still in agriculture even in 1975. Second, falling shares of industrial employment in Northern Europe's urban areas were already at such level that by about 1980, less urban population was lost through unemployment and outmigration. Third, the growth of service employment with greater economic advantages of agglomeration and lower penalties from land costs and congestion favouring urban core growth again from some time in the 1970s in northern Europe. Fourth, there was growing attractiveness for living and working in some higher amenity urban cores. Finally, falling family sizes and rising female participation rates reduced the impact of higher housing costs in urban areas or made it affordable through double incomes. 
Table 1. Urban sprawl and decentralisation

Functional areas over 330,000: frequency distribution

\begin{tabular}{|c|c|c|c|c|c|c|c|c|c|c|}
\hline & \multicolumn{8}{|c|}{ Stages of development of urban region1 } & \multicolumn{2}{|c|}{ Urban cores } \\
\hline & 1 & 2 & 3 & 4 & 5 & 6 & 7 & 8 & gaining & losing \\
\hline & \multicolumn{4}{|c|}{ Centralisation } & \multicolumn{4}{|c|}{ Decentralisation } & $2+3+4+5$ & $1+6+7+8$ \\
\hline \multicolumn{11}{|l|}{$1951-1961$} \\
\hline N. Europe2 & 1 & 10 & 8 & 37 & 32 & 11 & 0 & 1 & 87 & 13 \\
\hline France + N. Italy & 0 & 12 & 48 & 35 & 5 & 0 & 0 & 0 & 100 & 0 \\
\hline S. Europe3 & 0 & 72 & 7 & 22 & 0 & 0 & 0 & 0 & 100 & 0 \\
\hline \multicolumn{11}{|l|}{$1961-1971$} \\
\hline N. Europe2 & 1 & 1 & 3 & 14 & 47 & 26 & 5 & 1 & 65 & 35 \\
\hline France + N. Italy & 0 & 1 & 18 & 63 & $\overline{17}$ & 0 & 0 & 0 & 100 & 0 \\
\hline S. Europe3 & 0 & 67 & 13 & $\overline{13}$ & 2 & 0 & 0 & 4 & 96 & 4 \\
\hline \multicolumn{11}{|l|}{$1971-75$} \\
\hline N. Europe2 & 7 & 0 & 2 & 10 & 26 & 42 & 12 & 1 & 38 & 62 \\
\hline France $+\mathrm{N}$. Italy & 0 & 1 & 5 & 35 & 28 & 27 & 3 & 0 & 70 & 30 \\
\hline S. Europe3 & 0 & 4 & 11 & 46 & 33 & 7 & 0 & 0 & 93 & 7 \\
\hline \multicolumn{11}{|l|}{$1975-81$} \\
\hline N. Europe2 & 15 & 0 & 1 & 3 & 17 & 33 & 27 & 4 & 22 & 78 \\
\hline France $+\mathrm{N}$. Italy & 3 & 1 & 1 & 7 & 30 & $\overline{42}$ & 12 & 3 & 40 & 60 \\
\hline S. Europe3 & 0 & 2 & 15 & 48 & 17 & $\overline{15}$ & 0 & 2 & 83 & 17 \\
\hline \multicolumn{11}{|l|}{$1981-91$} \\
\hline N. Europe & 6 & 0 & 3 & 15 & 30 & 28 & 10 & 10 & 47 & 53 \\
\hline France + N. Italy & 0 & 2 & 0 & 8 & $\overline{38}$ & 32 & 12 & 8 & 48 & 52 \\
\hline S. Europe & 2 & 9 & 14 & 14 & 19 & 33 & 5 & 5 & 56 & 44 \\
\hline
\end{tabular}

Cells indicated in bold and underlined contains the median.

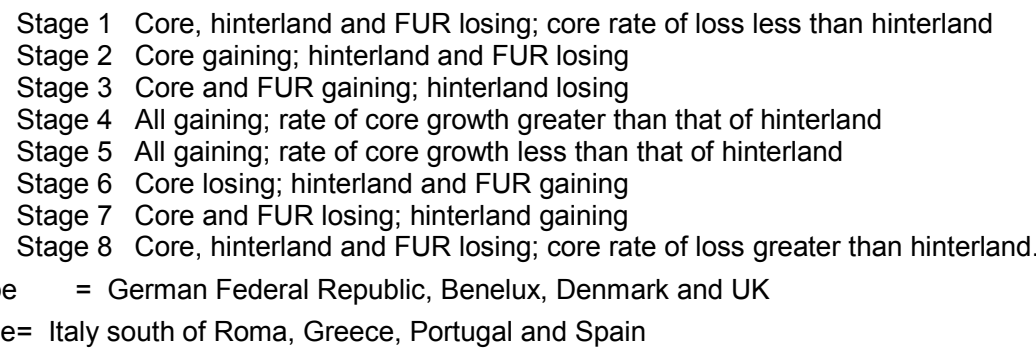

However, the pattern is much more varied with cities in all parts of Western Europe exhibiting both decline and gains in population. From the 1970s researchers had started to note the onset of what was first called 'counter-urbanisation' (Berry, 1976). This was initially hailed as a return to rural living. Later, research showed that this was really a case of 'cities coming to the countryside' (Amcoff, 2006; Leven, 1979); that is, of urban sprawl. But this itself seems part of a wider process of change. In the 1970s Alvin Toffler wrote for example of the coming age of the 'telecottager': people freed by the coming new technology from the need to commute physically but able to participate in 'urban' occupations via the not yet in place internet and perhaps hotdesk in cities from time to time as need demanded (Toffler, 1974). During the era of industrialisation economies of scale interacting with the traditional transport technologies (rail and traditional dock work) had given industrial production an insurmountable competitive locational advantage close to railways, goods yards and docks, in dense industrial cities with labour tied to those locations by high commuting costs. The advent of highways and lorries, coupled with roll-on roll-off ferries and containerisation, freed goods handling activities from such traditional high density urban locations. Industry and wholesale distribution then had a competitive locational advantage where congestion and space costs were low and rapidly became quite dispersed. In the early phases of this adaptation of new transport technologies - from 1960 or so - more labour-intensive industry relocated to the newly industrialising countries while more capital-intensive and technically advanced industry re-located to the more distant and greener areas of higher wage countries (Keeble, et al, 1983). 
Thanks to more efficient transportation system that allowed for further concentration of human capital commuting from rural and intermediate regions and into urban cores, urbanisation in OECD countries has implied a greater use of land and consequently sprawl. Urban land area in the OECD has doubled in the second half of last century (Figure 15). More recently i.e. over 1995-2005, in the majority of OECD metro-regions, the suburban belt grew faster than the core (Figure 16). In Sweden since about 1960, urban change was related to a major expansion of the geographic reach of 'urban' rather than the resurgence of rural living. If the boundaries of urban areas were sustained as they were at the end of each decade urban population growth has exceeded rural population growth in every decade. Indeed, in both the 1960s and 1970s population loss from rural areas had been very substantial. By 1990 s urban population growth was $4.4 \%$ while rural population declined by $1.6 \%$. Urban sprawl was made possible by a more efficient transportation system.

Figure 15. Urban sprawl

Trends in urban land expansion in the world and the OECD

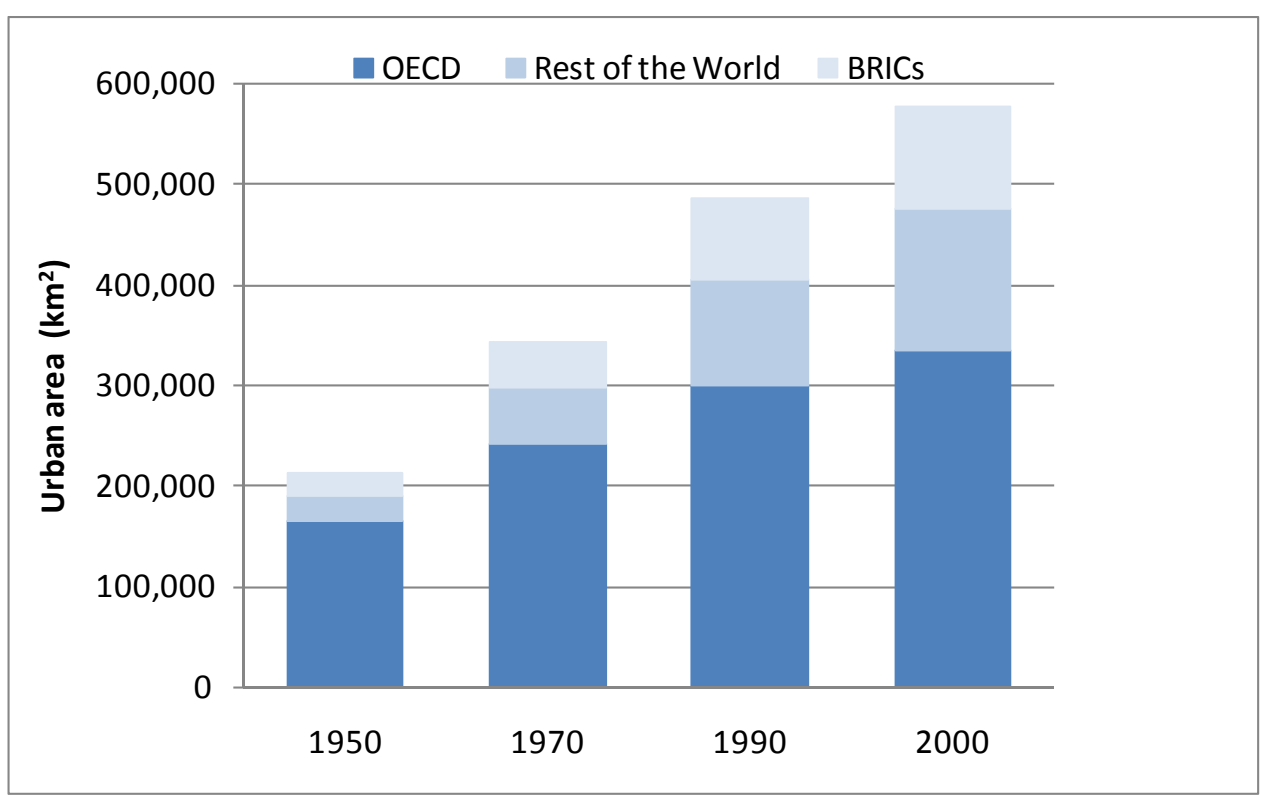

Note: BRIC countries refers to Brazil, Russia, India and China.

Source: OECD (2008a) Environmental Outlook 2030, OECD Publishing, Paris. 
Figure 16. Suburbanisation in OECD metro-regions

Population growth in metro-regions' core and belt compared (1995-2005)

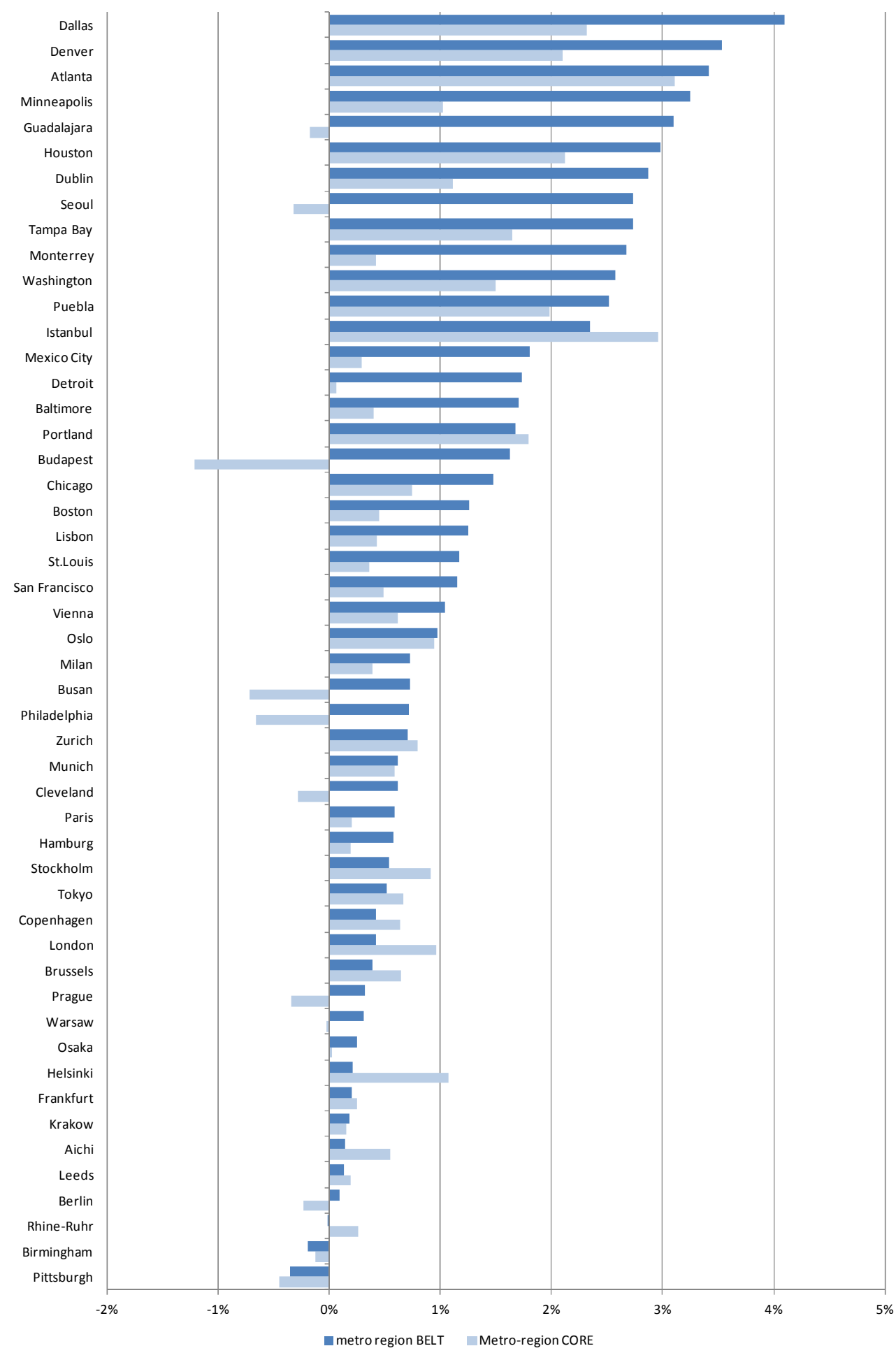

Notes: For US metro-regions, Core-based counties were used to identify Metropolitan Statistical Areas' core.

Source: Author's calculations based on data from the OECD Metropolitan Database. 
Suburbanisation and urban sprawl is becoming now more intense in BRICS countries and in the rest of world. China's sprawling urbanisation has occupied large hectares of land. In a country where arable land per capita is a mere 0.093 hectare and is only 40 percent of the world average level, land use and related food security are of high importance. The Ministry of Land and Resource (MLR) reports that total urban construction land has raised from $13000 \mathrm{~km}^{2}$ in 1990 to $34000 \mathrm{~km}^{2}$ in 2004 , pushing up the urban land elasticity (urban construction land increase/urban population increase) to be 2.28 , twice the acceptable level of 1.12. The average urban construction land per registered person has reached $130 \mathrm{~m}^{2}$, far beyond the average figure of $82.4 \mathrm{~m}^{2}$ in developed countries and $83.3 \mathrm{~m}^{2}$ in developing countries (MLR, 2005) ${ }^{8}$. Urban land expansion speed has reached $11 \mathrm{~km}$ per year, as suggested by the national land survey of 93 statutory cities with above 500000 populations. Moreover, land consumption problem is particular serious in large cities. During 2001-05, urban land use has recorded a higher than national average increase of $44 \%$ in the 30 largest cities. Amongst nine have registered over $60 \%$ increase (Niu et al, 2008).

While lowered transport costs and greatly reduced communications costs have allowed the outsourcing of routine activities such as call centres or accounts, agglomeration economies have reinforced the critical economic role of cities, and in particular of large cities. Rural regions, in proximity to major cities have prospered in OECD countries. Functionally, however, they are now essentially urban and act as significant dormitory areas for the largest cities although still visually 'rural'. Earlier retirement and greater leisure time may allow small numbers of people to move entirely away from cities for some or all of the time (some high paid city workers have their main homes in distant countryside but maintain a second home in the central city - others choose smaller houses in the Central city but a second home in attractive surroundings) the absolute numbers involved are small. This is confined to high income retirees and a small part of the most highly skilled workforce. By far the more common is the annexation of more and more rural areas close to the boundaries of existing urban areas and their conversion into 'peri-urban' - functionally urban - living areas. In absolute terms small numbers of highly skilled and specialised workers, artists, composers, specialised designers or IT workers, can work from homes in distant locations but almost all will have spent a significant part of their formative working lives in large cities. Only when they become established and build up professional networks is it possible to move to more remote rural areas.

\section{Economic performance of urban areas}

Trends in urbanisation and population concentration in OECD countries have been closely linked with concentration of economic activities, production and productivity (OECD, 2009i). In approximately half of OECD countries, more than $40 \%$ of the national GDP is produced in less than $10 \%$ of all regions, which account for a small share of the country's total surface and a high share of the country's population. In Europe, economic activity concentrates around the same places than population -an area that seems to stretch from London to western Germany (Figure 17). In Japan and Korea, economic density is clear in Osaka, Seoul and Tokyo (Figure 18). Such agglomeration effects are fuelled by higher wages that can be paid due to higher productivity levels that in turn attract more workers so that centripetal forces are set in motion. Urban areas tend to offer a pooled labour market that increases the possibility of skills-matching between workers and firms. Firms also agglomerate seeking to reduce risks of contract defaulting, as they have access to a wider set of skills and can establish linkages with suppliers and buyers. Finally, cities are also often places where knowledge spillovers take place, benefiting not only the city but also the wider regional area.

8. Source: Research centre of Ministry of Land and Resource, http://www.crcmlr.org.cn/results_zw.asp?newsId=L712141500152045 
Figure 17. Economic concentration in Europe

Economic density at TL3 level (GDP per square $\mathrm{km}$ ) in 2005

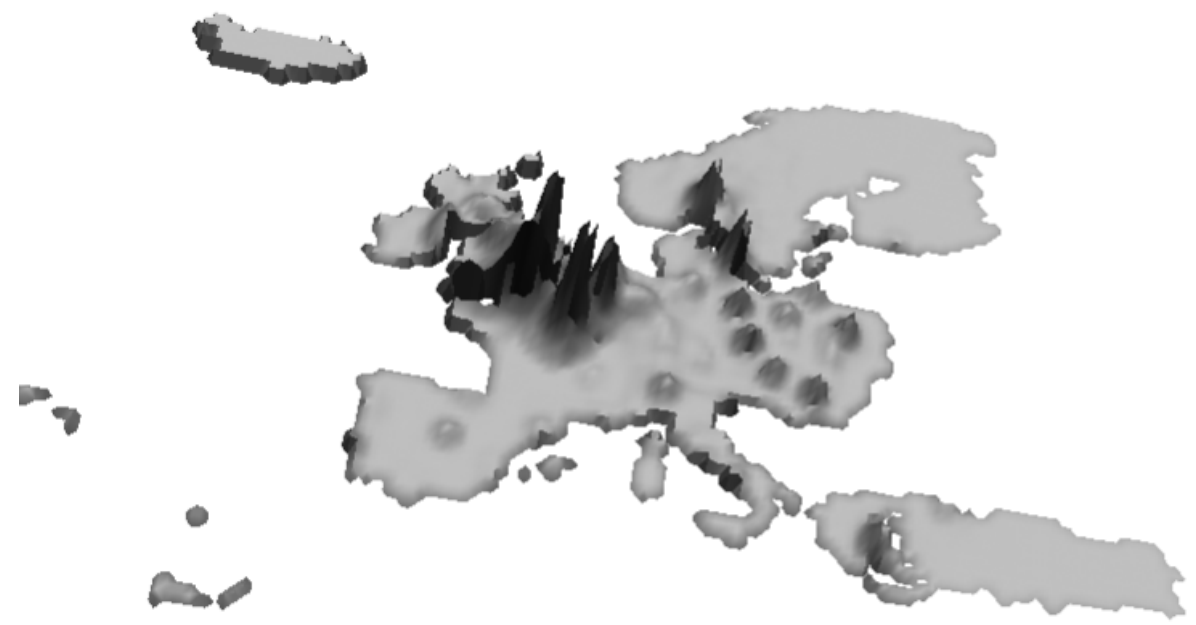

Note: OECD regions are classified at two levels: Territorial Level 2 (TL2) and Territorial Level 3 (TL3).

Source: Author's calculations based on data from the OECD Regional Database.

Figure 18. Economic concentration in Japan and Korea

Economic density at TL3 level (GDP per squared km.) in 2005

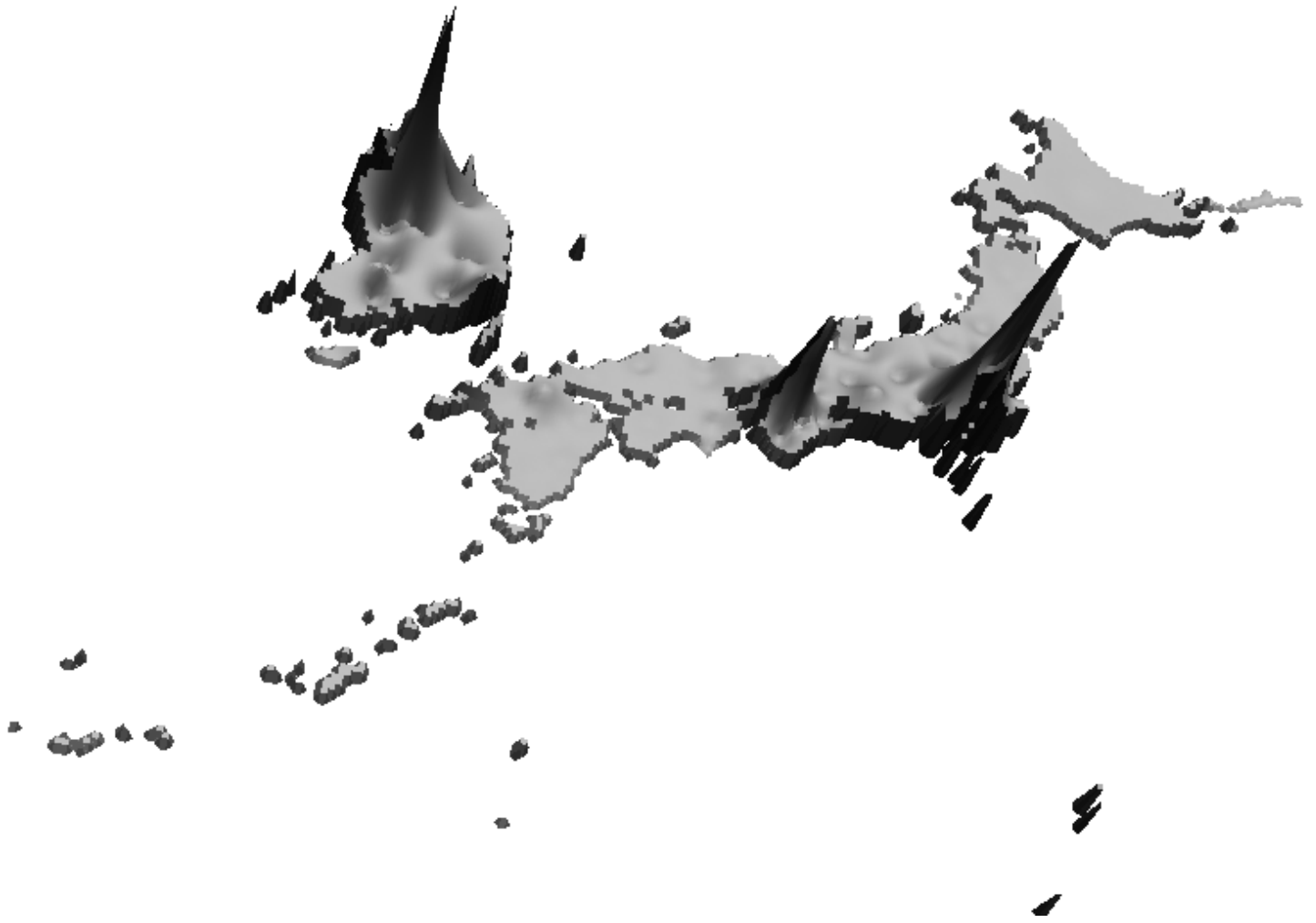

Note: OECD regions are classified at two levels: Territorial Level 2 (TL2) and Territorial Level 3 (TL3). Source: Author's calculations based on data from the OECD Regional Database. 
Urbanisation is generally associated with higher income and productivity levels (Figure 19). In OECD countries, higher urban population shares are associated in most cases with higher per capita GDP than their national average. In part, such higher per capita GDP can be attributed to metropolitan areas. The "OECD Competitive Cities in the Global Economy" report shows that the acceleration of urbanisation has strengthened the weight of large cities or metropolitan regions in the national economies of OECD countries (OECD, 2006f). ${ }^{9}$ In many OECD countries, one single metropolitan area produces one-third (e.g. Oslo, Auckland, Prague, Tokyo, Stockholm, London, Paris) to one-half of the national GDP (Budapest, Seoul, Copenhagen, Dublin, Helsinki, Brussels). Thanks to the benefits of agglomeration economies, most OECD metropolitan regions with more than 1.5 million inhabitants feature a higher GDP per capita, a higher labour productivity and higher employment levels than their national average.

Figure 19. Urbanisation and income

Urban share of total population (PU) and per capita GDP in OECD countries

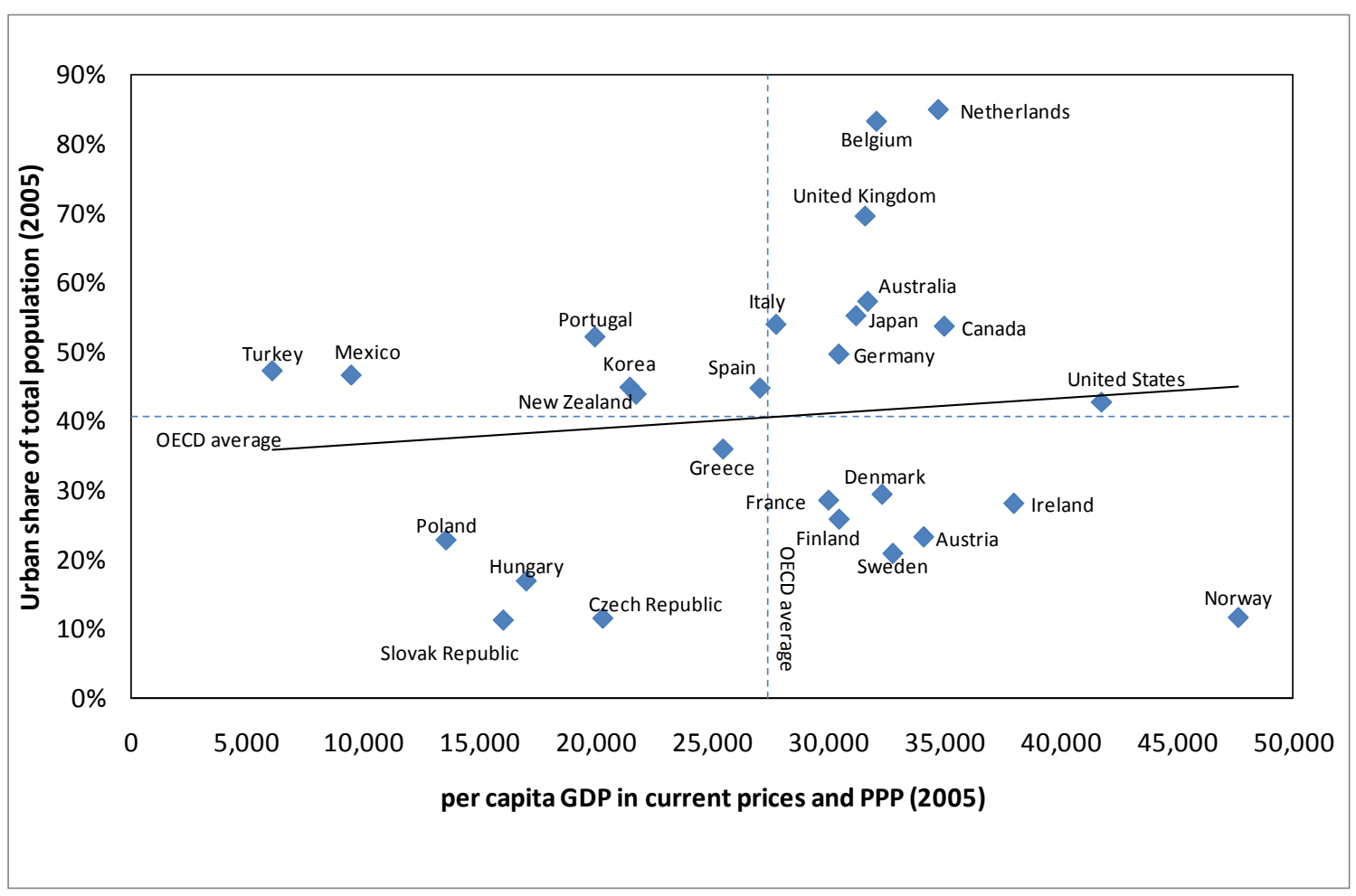

Notes:

Urban share of total population by country refers to population in urban regions as a proportion of total population.

Iceland and Luxemburg were not included in the sample as the OECD Regional Database does not identify predominantly urban (PU) regions in those countries.

Switzerland was not included as GDP figures at sub-national level in that country are not available.

Mexico's per capita GDP data refers to 2004; New Zealand's per capita GDP data refers to 2003; Turkey's per capita GDP refers to 2001.

Source: Author's calculations based on data from the OECD Regional Database.

9. The size of metropolitan regions varies widely among OECD countries from small growing monocentric metro-regions in Europe (Dublin and Helsinki with less than 2 million inhabitants) to megacities in Asia such as Tokyo (34) and Seoul (23.5), and in North America metro-regions such as New York (18.7) and Mexico City (18.4). Some other European metro-regions also largely outstrip the OECD average (around 5 million people) such as London (7.4), Paris (11.2), Istanbul (11.4), and the polycentric metro-regions of Randstad-Holland (7.5) and Rhine-Ruhr in Germany (13.4). 
Similar trends can be observed in China. As a group, metropolitan regions have become the principal engines of China's fast-growing economy ${ }^{10}$. Holding just under $30 \%$ of China's population, the 53 metropolitan regions produced 64\% of the country's GDP in 2004, up from 55\% in 1998 (Figure 20). While China's production was largely decentralised before the mid-1990s, the country became a predominantly metropolitan economy by the late $1990 \mathrm{~s}$, a trend that has accelerated such that almost two-thirds of China's economic output is now concentrated in the 53 metropolitan regions. Perhaps more significantly, these metropolitan areas accounted for $77 \%$ of China's overall growth in GDP from 1998 to 2004.

Figure 20. Growing economic importance of China's 53 metropolitan regions

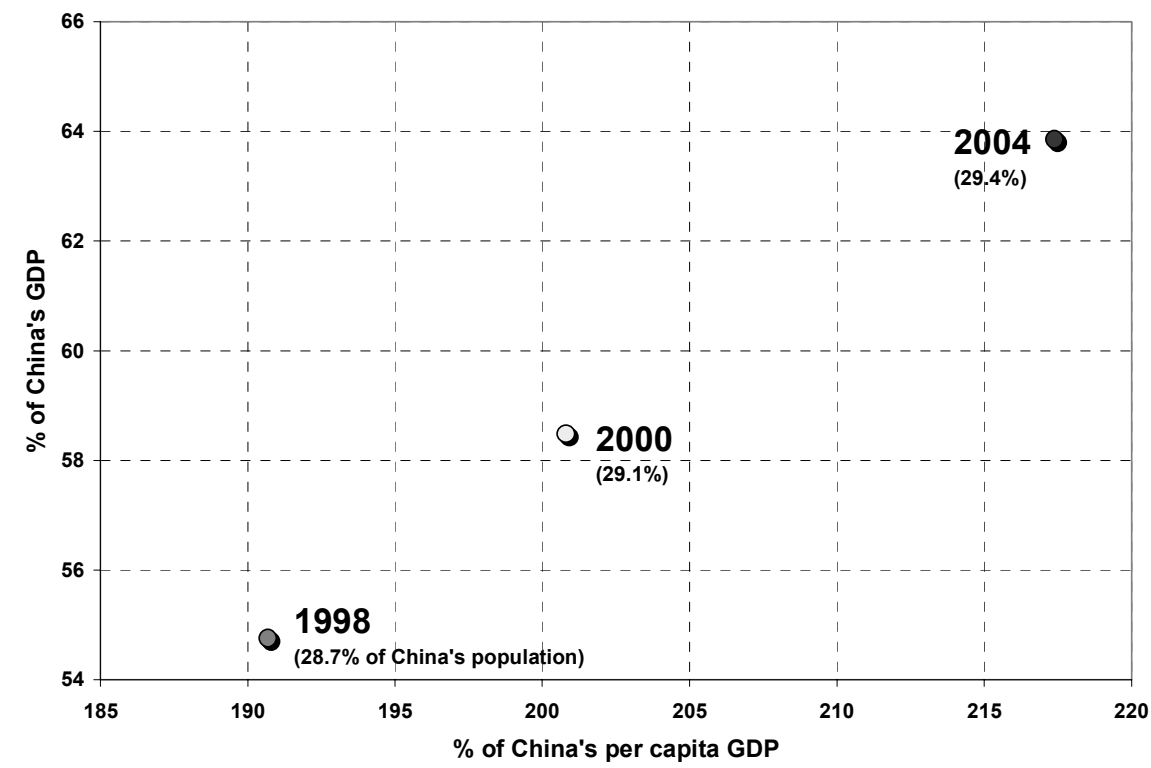

Source: Calculation from aggregated county- and city-level data, 1998, 2000, and 2004, adapted in OECD Metropolitan database.

However, the benefits associated with economies of agglomeration are not unlimited. Cities can reach a point where external diseconomies outweigh centripetal forces and become less competitive (OECD, 2006f). Among the 78 OECD metro-regions with 1.5 million inhabitants and more, one-third ranks systematically lower than their national average for almost all indicators, such as income, growth, productivity, skills, employment and unemployment. Similar findings emerge from an EU report on 258 metropolitan areas of 250,000 inhabitants and more which shows that between 2000 and 2006 more than half experience growth rates that are below their national average (EU 2009). It can be argued that lower growth rates are a normal result of development and convergence (the neo-classical expectation). However, in 41 metros out of 258 such a decline was for more than 5\%. This suggests that a number of metropolitan areas are confronted with a stronger development issue than merely a reduction in the benefits of agglomeration economies, due to higher overall levels of development. The EU report found that metropolitan areas that also function as national capitals tend to have the highest per capita GDP whereas smaller metropolitan areas and some of the second tier metros scored lower (EU 2009); similar findings were highlighted in the OECD Competitive Cities in the Global Economy (OECD, 2006f). In general, in the less developed EU countries, the capital city holds a large

10. The metropolitan region definition is based on Chreod. 
share of GDP. It can be argued that as development takes place, growth will tend to emerge in other urban areas as well -as it has happened in many Western European countries.

In the same vein, although metropolitan economies in China have in aggregate grown significantly, there are wide differences in productive capacities among them. Figure 21 shows the change in share of China's GDP produced in each of the 53 metropolitan regions from 1998 to 2004. Not surprisingly, Shanghai, Guangzhou, and Shenzhen have grown in national importance, each producing almost 1\% more of China's GDP in 2004 than in 1998. Significantly, the eight metropolitan regions in the Yangtze Delta Megalopolis ${ }^{11}$ produced 17\% of China's GDP in 2004, up from 13\% in 1998. This compares with the three metropolitan regions in the Pearl River Delta Megalopolis which grew from producing 5.3\% of China's GDP in 1998 to $7.5 \%$ in 2004. Figure 21 also illustrates divergent economic dynamics of China's metropolitan regions in recent years: six of 28 coastal metropolitan areas experienced declines in their share of China's production from 1998 to 2004; four of six in the northeast also had declining shares; only one of seven metropolitan regions in central China experienced a drop; and, perhaps significantly, only two of 12 in the West declined.

11. Shanghai, Hangzhou, Ningbo, Suzhou, Wuxi, Changzhou, Nanjing, Taizhou. 
Figure 21. Change in metropolitan region's share of China's GDP, 1998-2004

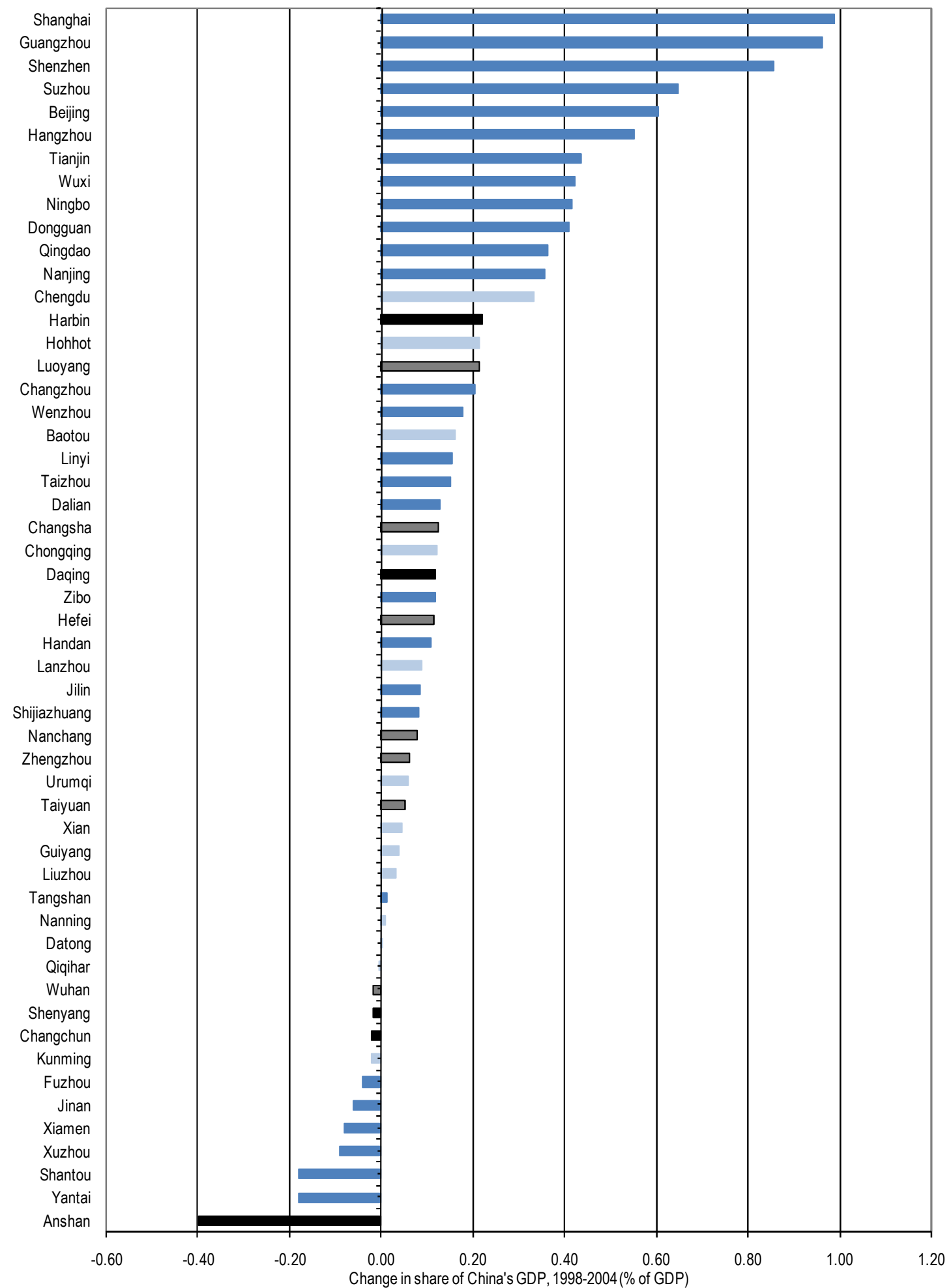

Coastal

Northeast

Central

Western

Source: Calculations from city and county-level data from Chinese Provincial Statistical Yearbooks, adapted in OECD Metropolitan database. 
One of the main explanations of such mixed outcomes is linked with the existence of negative externalities, including congestion costs. ${ }^{12}$ Negative externalities associated with large concentrations in urban areas raise the question of whether the costs borne by society as a whole are becoming unsustainable. As externalities, these negative attributes are not internalised by firms and households, and may only show up as direct costs in the long term. They include, for instance, high transportation costs (i.e. congested streets) and loss of productivity due long commuting times, higher health costs, higher carbon emissions and environmental degradation. Taking into account the costs and the benefits of agglomeration, it has been argued that urban concentration may entail a "privatisation of benefits and socialisation of costs" (OECD, 2009i).

Agglomeration economies are significant and important but public policy is needed to maximise their positive effects. Recent estimates suggest that doubling the size of a city-region is associated with a 3.5 to $8 \%$ increase in total factor productivity (Rice et al., 2006; Graham, 2007 and Graham and Kim, 2008). A recent survey concludes that these agglomeration economies apply as strongly in developing countries - such as India or China - as they do in OECD countries (Quigley, 2009) ${ }^{13}$ But in the absence of public policy neither effect will influence decisions about urban growth so we can have no expectation that individual cities will reach or exceed their 'optimum' size. ${ }^{14}$ Successful policy would ensure that urban expansion maximised the positive agglomeration gains from growth but minimised the impact on space costs and congestion.

Moreover, although agglomeration economies emerge with urban concentration and are crucial to improve productivity levels, economic performance of cities is not only a function of city size. Agglomeration economies arise because workers and firms agglomerate and interact producing gains related to sharing, matching and learning. Such agglomeration economies can arguably be internalised by firms in the form of higher productivity levels. Among all OECD predominantly urban (PU) areas, the richer the city, the fastest it grows (Figure 22). Small, medium and large cities can grow slower or faster than the urban average (see size of the bubble in Figure 22). Other growth determinants such as physical capital -among which infrastructure-human capital and innovation might be behind performance differentials.

12. These can be thought of as centrifugal forces

13. Such agglomeration economies, too, are a form of externality not taken into account by our hypothetical 'additional' city resident. It could be that the gain in productivity and incomes generated for the existing inhabitants by the addition of one more resident more than offsets the increase in congestion and space costs imposed.

14. It is most important not to conceive of there being a single 'optimum' size for all cities. Each sector and activity is subject to varying agglomeration economies; preferences for living in cities of varying sizes are likely also to vary across households and with age. As emphasised in section 1.2 cities of a great range of sizes should be expected to be the optimum pattern and there is a vast literature on the structure of city sizes as well as ample empirical confirmation of the existence of a more or less predictable urban hierarchy - sometimes referred to as Zipf's law. Nevertheless, given its economic structure, it may be useful to think of a particular city having an optimum size. 
Figure 22. Economic performance in OECD urban areas

GDP per capita growth and levels in predominantly urban areas

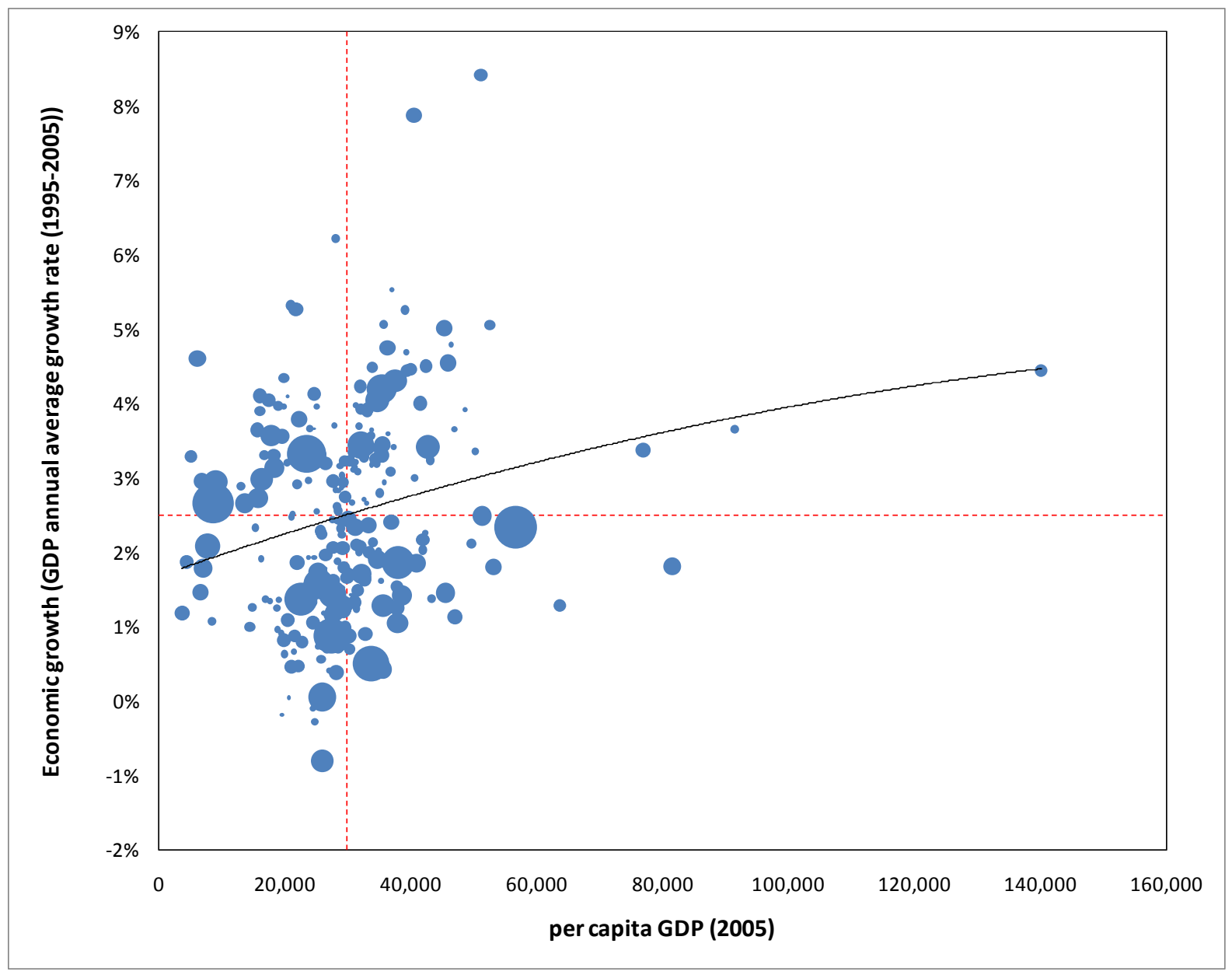

Source: Author's calculation with data from the OECD regional database.

City size seems to be related to economic performance up to certain level where perhaps diseconomies of scale can start to play a role. The OECD report "Competitive Cities in the Global Economy" (OECD, 2006f) shows that the association between income and city size turns negative once a threshold is reached and diseconomies of scale become more important than agglomeration economies. In general, very small and very large cities tend to have lower economic growth rates than the average urban area in the OECD (Figure 23).

Although population grows faster the larger the urban area, within urban regions, it is mediumsized cities that outperform the rest in terms of economic growth. Medium-sized cities are half the economic size (GDP) of large ones and less than one-third of those with more than 1.5 million people. Yet, over 1995-2005, they grow by half a percentage more every year. Over time such growth differentials can compound to yield significant development gains and increase inequality across urban areas. 
Figure 23. Economic performance and city size

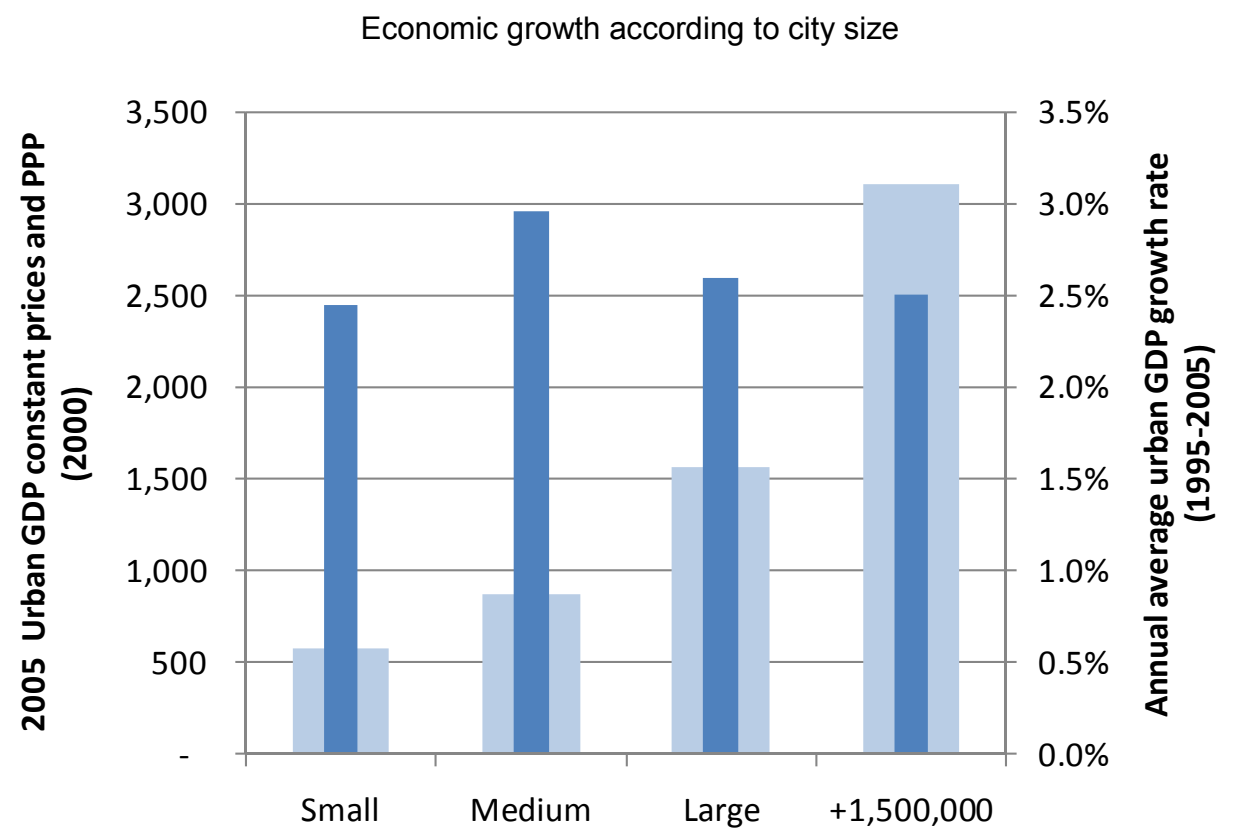

1. This analysis was carried out using only predominantly urban (PU) areas.

2. Small cities are PUs with population between 100000 and 500000 people. Medium-sized cities are PUs with population between 500,000 and 1 million people. Large cities are PUs with population between 1 and 1.5 million people.

3. GDP expressed in PPPs.

Source: Author's calculations based on OECD Regional Database.

There is no single optimum city-size, but rather an efficient city size which depends on local specialisations. ${ }^{15}$ Figure 24 illustrates how city size in a completely unregulated world might tend to be too big. It should be stressed that since the significance of agglomeration economies varies strongly by sector (Graham, 2007; Ioannides and Overman, 2000) and preferences for different sized cities are likely to vary between households there is no single 'optimum' size for cities: but for any given city, given its economic activities and the preferences of households living within it, there is likely to be a particular efficient size. Cities will attract both firms and workers and will continue to do so given the benefits involved in terms of higher wages, productivity and employment. However, each particular city given its own specific specialisations will stop being attractive to either firms of workers if the costs of agglomerating become higher than the actual benefits (Box 2).

15. See Carpello and Camagni (2000). 
Figure 24. City size and economic performance

Population size and economic growth

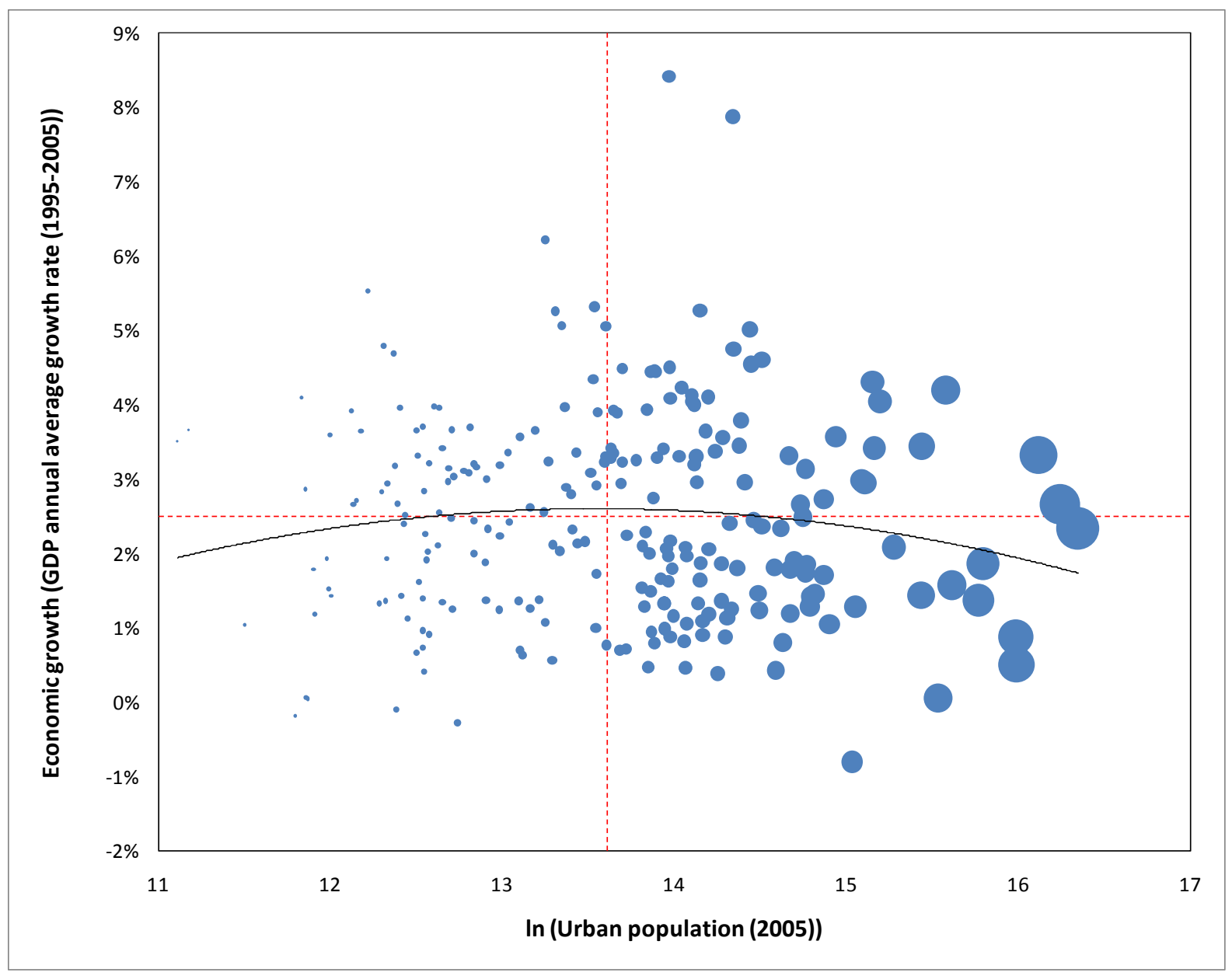

Source: Author's calculations with data from the OECD database.

\section{Box 2. Explaining the efficient city size}

Cities' grow as benefits for firms and workers drive both to agglomerate up to a point where the costs of such agglomeration become greater than the benefits. From a theoretical point of view, the efficient city size can be explained by an increase in labour productivity, employment, wages and housing prices until a point where the cost of agglomeration exceeds the benefits. In Figure A, adapted from Coombes et al., (2005), city size is measured as $N$, the number of workers within it. In both the upper and lower halves of the Figure wages $(w)$ and costs $\mathrm{H}$ - housing costs - rise moving away from the origin. Both wages - because of agglomeration economies - and housing costs rise with city size. The reason for housing costs rising with size is consistent with basic urban economic theory and competition for space and accessibility to jobs. In Figure B net real wages rise and later fall with city size as labour productivity rises but rising 'gross' wages are eventually offset by rising costs; and the labour supply curve - in the sense of the number of workers wanting to live in/move to the city - also rises with city size. The city is attractive to individual workers to the point where the labour supply curve crosses the net wage curve at a size of $N^{*}$ - which will be the equilibrium size for the city. But the 'social' optimum from the point of view of existing residents would be at $N_{B}$ where the net wage is maximised. The discrepancy between optimal and equilibrium size arises because new migrants to the city are motivated by whether their own expected net

wage exceeds the supply price of their labour but their arrival triggers a cost to all existing residents - it drives up 


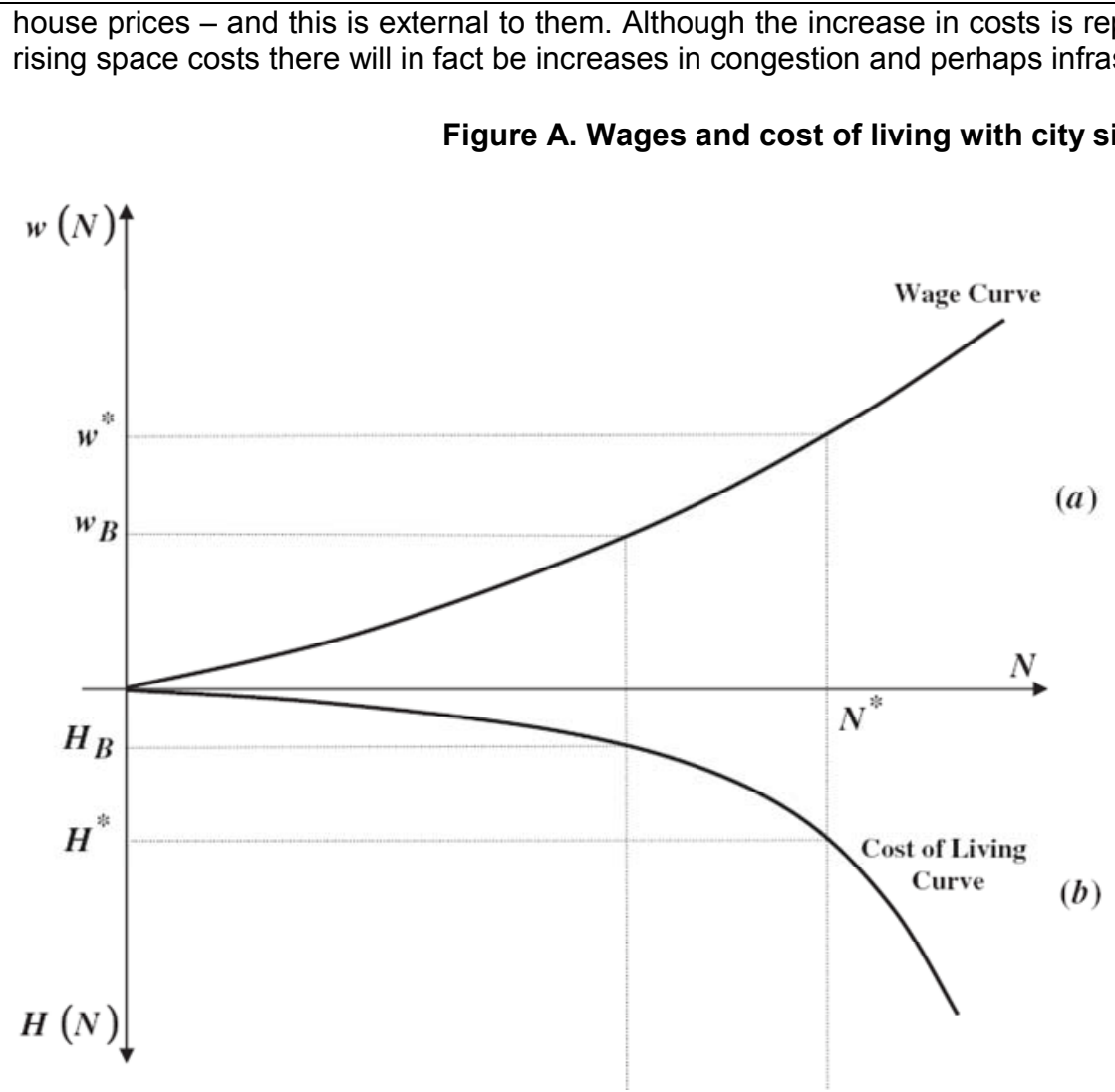

Source: Adapted from Coombes et al (2005).

Figure B. Efficient city size

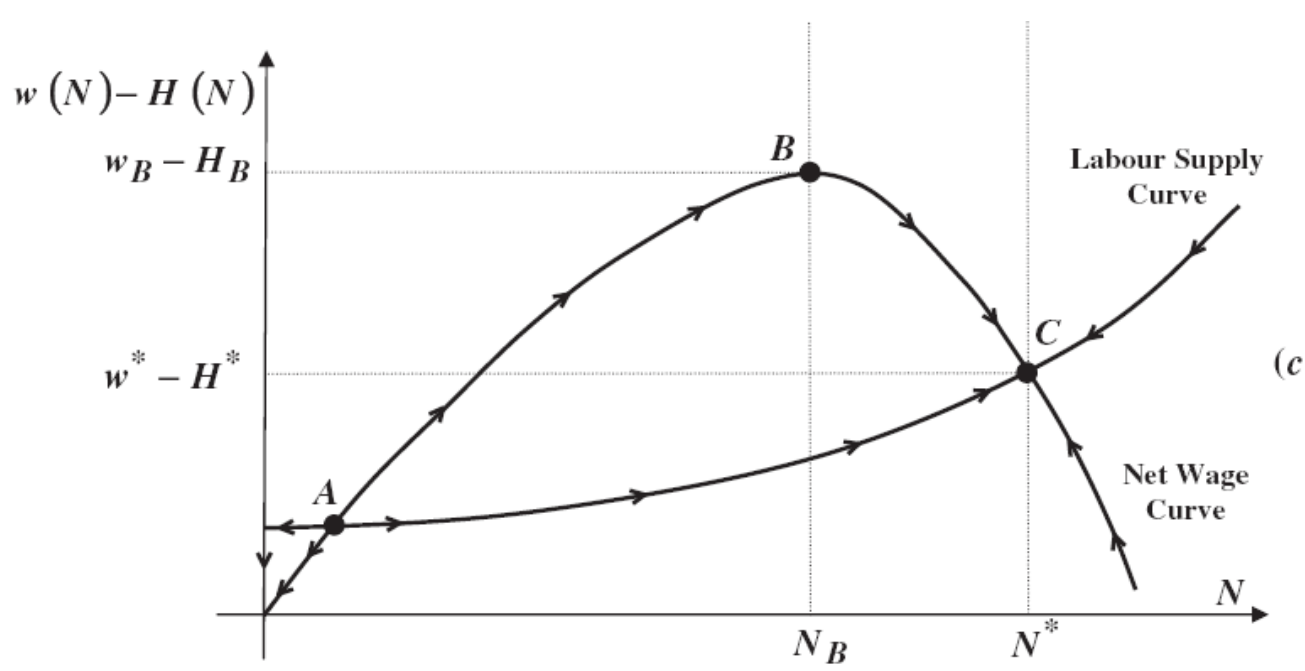

Source: Adapted from Coombes et al., (2005). 


\section{Main factors of growth and decline}

\subsection{What are the main drivers of economic growth in urban areas?}

Regional competitiveness depends on both national and regional factors. On the national side, macroeconomic environment and structural reforms have a large impact on the regions' economic performance. However, whilst a sound macroeconomic environment, efficient products and factor markets as well as performing regulatory and taxing environment are crucial elements to ensure productivity and growth, competitiveness (and decline) of the business sector increasingly depends on factors related to the regional business environment. This section will focus on the regional factors of growth and decline.

OECD work on metropolitan regions has showed that productivity levels are a main explanation of regional performance. ${ }^{16}$ Disaggregating GDP into four main factors reveals that, for the most part, higher income in metropolitan areas can be attributed to higher labour productivity levels (Figure 25). In turn, performance in the productivity level of metropolitan areas is strongly linked to their association with certain economic specialisation (high value-added), as well as human and physical endowment (OECD, 2006f). The effect of labour productivity can also be nuanced -or aggravatedby demographic or labour-market factors. In particular, the size of the pooled labour market (workingage population as a proportion of total population) and the way in which labour markets function (depicted for instance by employment rates) are important factors in determining how GDP in metropolitan areas diverge from the national level. The highest GDP differentials with respect to the national level can be found in metro-regions such as Warsaw, Monterrey, Washington DC and Paris to a great extent due to higher labour productivity, but they could also be held back by poorer performance - when compared to the national level — in labour market indicators such as participation rates. The size of the labour market thus, is a relevant factor in determining agglomeration and performance of metro-regions. At the other end of the ranking, metro-regions with below national average GDP levels such as Daegu, Naples or Berlin are lagging behind precisely due to lingering productivity, participation and employment rates and only marginally helped by demographics. However, mid-ranking metro-regions such as Chicago, Hamburg or Puebla are mostly being held back by the size of the labour market.

16. A cross-country comparison model has been developed to examine which factors explain a given region's gap in GDP per capita with other OECD metropolitan regions (OECD Competitive Cities, 2006). These are productivity per worker, efficiency of the local labour market expressed in terms of employment/unemployment, and the relative size of the labour force with respect to the population, i.e., the activity rate. Greater productivity per worker translates into a higher level of GDP per worker, an efficient labour market results in better labour utilisation (more employment, less unemployment), while a larger labour force relative to population implies that more of the region's human resources are being used in production. This methodology has been applied within the framework of the $O E C D$ Territorial Reviews to assess competitiveness of some metro-regions. Productivity emerges as a key factor in metro-regional performance among the three explanatory factors, in turns explained by the industrial mix (specialisation in high value added sectors) and human (skills) and physical endowment (capital). 
Figure 25. Factors determining per capita GDP differentials

Labour productivity, employment and participation rates, demographic factors among OECD metro-regions with respect to their national average (2005)
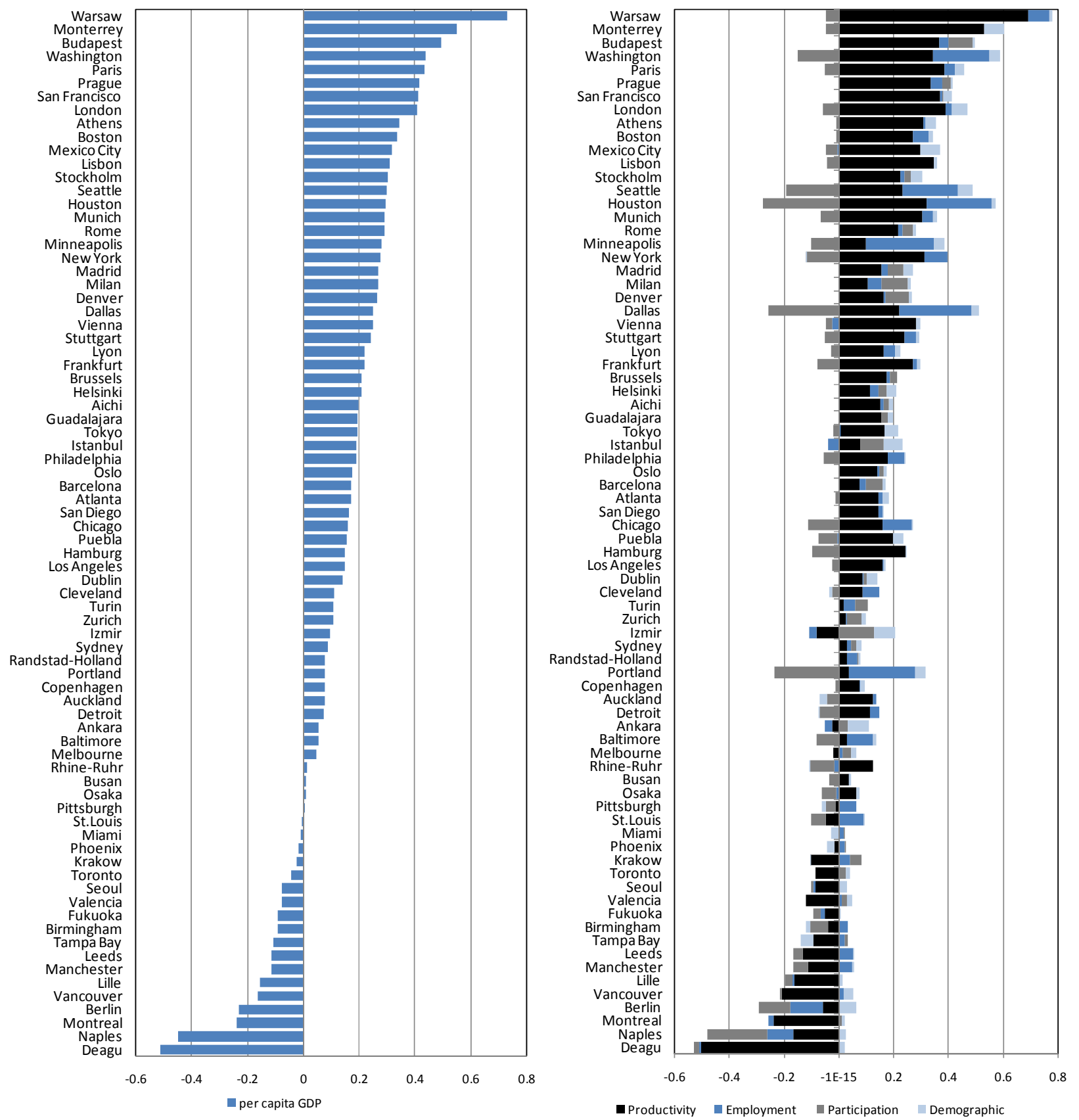

Notes: Per capita GDP can be disaggregated into four components: Productivity, Employment, Participation and Demographic. The Demographic component represents the size of the pooled labour market of each metro region compared to the national average. Labour market pool is calculated as the proportion of the working-age population over the total population.

Australia, Germany and US data refers to 2004; New Zealand data refers to 2003; Switzerland data refers to 2002; Turkey and Mexico data refers to 2000 .

Source: OECD Metropolitan Database, 2009. 
Economic growth in urban areas is driven on endogenous factors such as human capital, physical capital-among which infrastructure - and innovation, but also spatial factors such as agglomeration economies and proximity to markets. Using a number of econometric techniques, the OECD has developed a regional economic growth model that takes into account endogenous factors and new economic geography elements (OECD, 2009d). Among the results are:

1) Human capital is the most robust factor - mainly tertiary educational attainments, and takes about three years to have an impact.

2) Infrastructure has an impact as long as other factors are also in place (e.g. human capital, innovation, agglomerations etc...).

3) Innovation has an impact on growth, but is a longer term process and takes between 5-10 years.

4) Agglomerations in services (measured by a region's specialisation index times the size in financial intermediation) has a positive impact on growth. This result can have particular implications for urban regions since financial intermediation (or knowledge-intensive services) is mainly present in metropolitan areas.

5) Accessibility to markets has a positive impact on growth, but this result is not very robust since in only one model it is statistically significant.

6) Urban regions with low employment rate can generate growth if they can manage to mobilising their labour force.

Although neither urban nor concentration are necessarily synonymous to success, in many cases these endogenous growth factors tend to locate in urban areas. A more favourable industrial mix with high value-added activities is closely linked to the capacity of urban regions to concentrate R\&D activities and generate innovation. Usually infrastructure and private capital agglomerate in cities and attract human capital. In turn, these factors allow for the exchange of ideas and for innovation to appear. For instance, more than half of all patenting activity takes place in PU areas (Figure 26). In fact, the more urban a country becomes, it is more likely that innovation will become also urban (Figure 27). That is, as the share of total population that resides in urban areas increases, innovation increases. This is however, not tantamount to economic growth as this can take place in rural and intermediate regions alike depending on a number of other factors such as human capital, physical capital, as well as congestion costs (e.g. land-rent prices, immobile factors and diseconomies of scale). In fact, patenting activity increases with city size so that growth in large cities is driven by innovation whilst it is specialisation in medium-sized cities that drives agglomeration economies. More than three-quarters of patenting activity that takes place in urban areas are carried out in cities of more than 1.5 million people (Figure 28). 
Figure 26. Innovation and urban areas

Shares of PCT patents by regional type (2005)

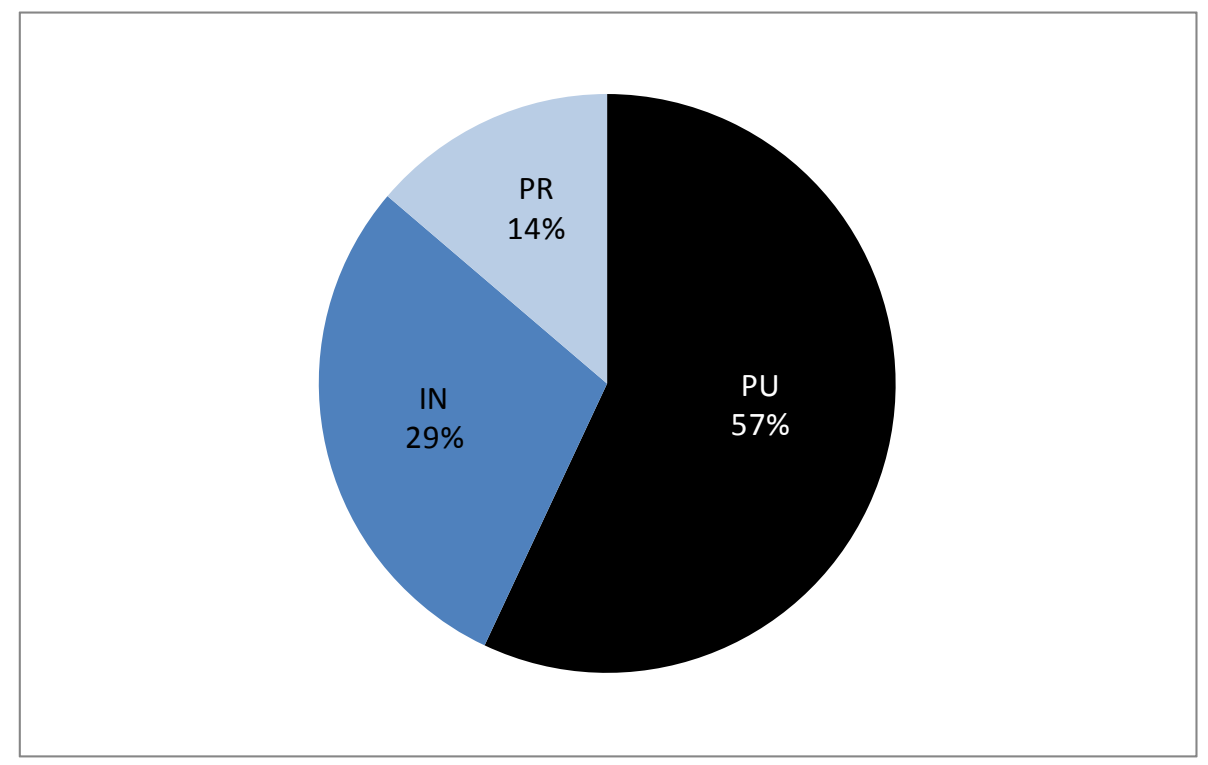

Note: Iceland was not included in the sample.

Source: Author's calculations based on OECD Regional Database.

Figure 27. Innovation and urbanisation

Patenting and urban population shares

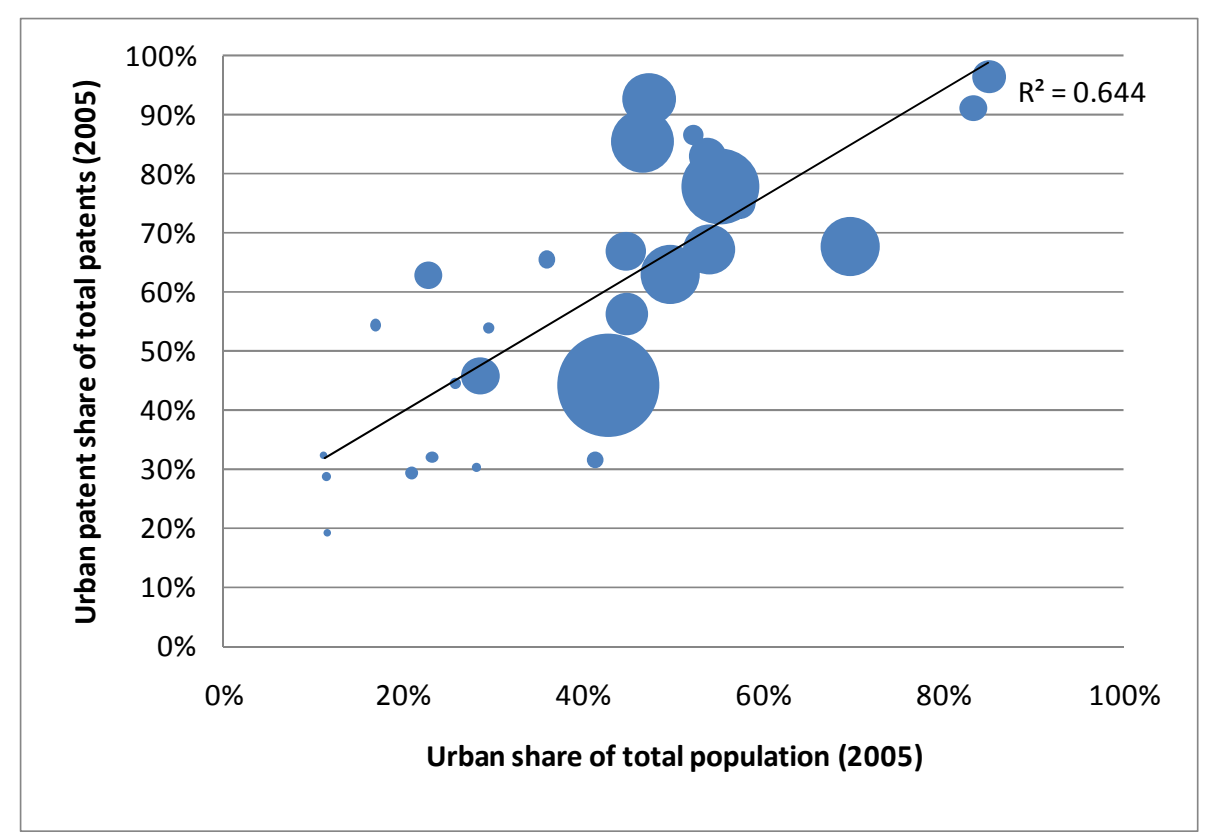

1. Urban share of total population by country: population in urban regions / total population.

2. Urban patent share (2005): proportion of urban patents over the total patents in each country

3. Iceland and Luxemburg are not included in the sample because they don't have PU regions

Source: Author's calculations based on OECD Regional Database. 
Figure 28. Innovation by city size

Patenting activity according to population size in PU areas

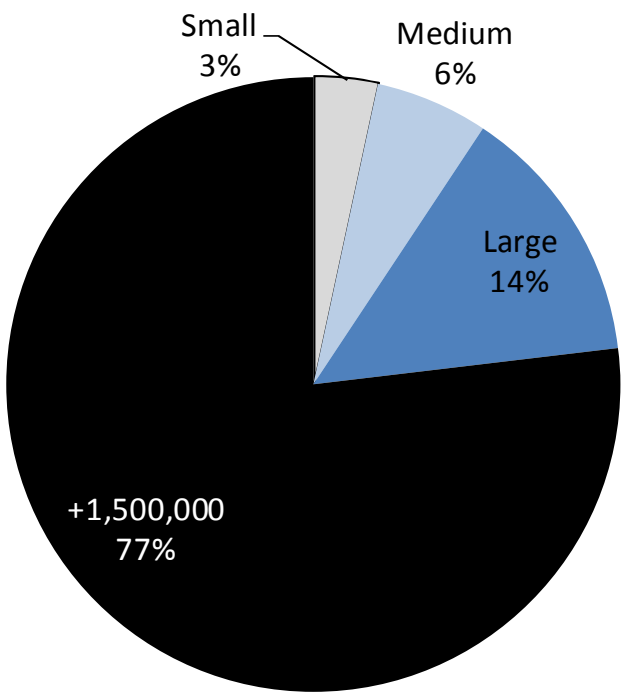

Source: Author's calculations based on OECD Regional Database.

Skills in metro-regions strongly influence their productivity level. In Montreal, for instance, which belongs to the category of metro-regions that have specialised in high value-added sectors, relatively lower productivity was partly caused by lower educational attainment (OECD, 2004d). In less advanced metropolitan areas, such as Mexico City and Istanbul, productivity level is highly inhibited by the relatively lower skills of the working population and the extent of the informal sector where adult education and skills training are difficult to provide (OECD, 2004c and 2008f). In general, lower productivity seems to be related to lower skills, not only in Turkish and Eastern European metro-regions, but also in metro-regions from more advanced countries such as Athens, Lille, Lisbon and Valencia. In Copenhagen, the general level is skills is high but there are significant shortage in some specific functions that impact on the labour market and on the level of productivity (OECD, 2009h).

One of the key challenges for continued economic growth and productivity increase in many OECD cities is how to retain more qualified people and attract others. In 1990s, the Newcastle city region has experienced continued decline of manufacturing base and relocation to lower cost locations outside UK (a particular threat for the city region's relative dependence on these sectors), and loss of call centre jobs due to offshore relocation and technology. As a consequence much expertise and skill was lost through outwards migration to Southern England and London. From 1991 to 2001 there was a declining population in all but four of the districts in the city region, while the UK as a whole experienced population growth. The beginning of the $21^{\text {st }}$ century witnessed the end of Newcastle's decline economy, yet the growth is from a lower base, at a lower rate and supported by lower productivity. The task of upgrading to higher value added and higher productivity level is further challenging (OECD, 2006c).

Similar issues can be observed in China. The central and local governments have spearheaded a massive drive to merge universities and colleges across the country, to expand university facilities (including through the construction of 'university towns' in the suburbs of many metropolitan regions), and to expand enrolment. While university enrolment is up, the delivery cycle for highly- 
trained technical and professional graduates is 6-10 years. A combination of new graduates and a reported increase in Chinese graduates returning from overseas institutions represent a potentially important addition to the human capital and innovation capacities of metropolitan regions. Given increased labour mobility in China over the past few years, and growing competition among metropolitan regions to attract highly-qualified graduates, most of this segment of the workforce will be able move to where career opportunities are highest. This suggests that the large and advanced metropolitan regions shouldering the biggest shares of China's GDP are likely to attract the most qualified workforce; i.e., Shanghai, Guangzhou, Shenzhen, Suzhou, and Beijing and correspondingly putting more pressure on the attraction of talents of inland and less developed metropolitan regions, i.e., Chongqing and Xi'an.

Regions with the highest concentration of economic activity tend to have greater endowments of infrastructure and physical capital, thus a higher stock of capital per worker that can positively impact productivity. There are no data available at the local level to establish the link between the stock of capital and the level of productivity. However, a positive correlation between regional productivity and the stock of infrastructure has been detected in eight out of 15 OECD countries, (i.e. the Czech Republic, Denmark, Germany, Hungary, Japan, Sweden, United Kingdom and United States) (OECD, 2005f). From a theoretical perspective such a link could be easily supported. For instance R\&D infrastructure (e.g., laboratories) and allocation of adequate spaces in metro-regions allow for the exchange of ideas and cross-fertilisation of innovative activities. In other words, capital provision in urban areas will not only increase the ratio of capital per worker, but can also allow R\&D activities within firms and innovation arising at the production site to take place.

\subsection{Social disparities, exclusion and poverty: the urban paradox}

Although urban areas tend to be characterised by high concentration of wealth and employment, they also tend to concentrate labour market exclusion and poverty. OECD work on metropolitan regions demonstrated that wealth creation in urban areas was not always adequately translated into job creation. According to the OECD Regional Database, about $47 \%$ of unemployment in OECD is concentrated in predominantly urban regions, but this figure reached $60 \%$ in the United Kingdom, Japan, Korea, the Netherlands and the United States. Overall, unemployment rates are lower in metroregions than in their national context but for almost one third of metro-regions unemployment rates are higher than their national average. The Urban Audit of the European Commission reaches similar conclusions (European Commission, 2004). Although its data refer to a wider size range of cities and not to metro-regions, the areas that fall within many metro-regions are included within this generalisation. While employment and employment growth are typically higher in cities, they also contain disproportionate numbers of people who are either unemployed or inactive (or who work in the informal economy). Among the main explanations advanced by the Urban Audit are the lack of affordable child care facilities, larger proportions of immigrants who generally have lower skills and who may be discriminated against, and in some cases, the presence of a sizeable informal economy, typically large in large cities.

Exclusion and poverty in most OECD countries have become urban phenomena. These issues are prominent not only in less-advanced metro-regions like Mexico City (about $50 \%$ of the population are in a situation of poverty), partly due to rural migration, but also in cities that have faced strong industrial restructuring (Rotterdam, Lille, Detroit) as well as in the suburbs of some of the richest metro-regions (Paris, London, New York). Exclusion does not, of course, take the same form or intensity in every city but most metro-regions, including the wealthiest ones, have pockets of population with low standards of living and which experience social problems. The precise patterns vary from country to country and from city to city, partly depending upon national economic trajectory, labour market policies, welfare state policies and citizenship rights. Exclusion from the urban labour market is a drag on a region's competitiveness as limits the opportunity from the 
availability of a labour force, but it also generates costs from higher social assistance benefits, weak social capital, lack of trust, crime and degradation of public infrastructure. Related to that, even in the most dynamic metro-regions, there are increasing socioeconomic inequalities between high-income people working in high value-added services, and those engaged in servicing them and even more with those that have not found jobs. Among the main consequences of urban poverty is a higher level of criminality in urban areas (on average $30 \%$ higher than the national level).

A particular vulnerable segment of the population excluded from urban labour markets in OECD countries is the foreign immigrant which creates a need for integration strategies in relation to urban services, job opportunities, housing, and the like. Many of them have lower skills but even skilled immigrants find it difficult to integrate into economic networks. In Stockholm only $40 \%$ of foreignborn university graduates from non-EU countries have a qualified job compared to $90 \%$ for native Swedes (OECD, 2006d). In Toronto, after two years only $41 \%$ of immigrant, Torontonians have a job in their intended occupation (OECD, 2010b). Appropriate skills might be an issue in some OECD cities, but other obstacles include the lack of recognition of foreign credentials and language barriers. ${ }^{17}$ This exclusion is regrettable given how foreign migration can contribute to regional labour markets by (i) increasing local working age population and so the size of the local labour market, (ii) constantly increasing the supply of labour (this keeps pressure on wages low, so economic growth does not generate inflation (as long as there are immigrants coming into the region) and (iii) differentiating the range of skills available in a given region. ${ }^{18}$ There are indeed several positive economic impacts linked with the presence of foreign immigrants.

Social exclusion in urban areas is generally associated with strong residential segregation between the prosperous and deprived populations that concentrate in deprived neighbourhoods. Far from being solved, the situation has worsened since the 1980s, both in countries with strong employment growth and in those where unemployment remains high. Even Nordic countries, which generally have comprehensive benefit systems, have not been able to prevent the emergence of inequalities in some urban areas. An OECD report on ten countries surveyed - containing around half of the total population of the OECD - shows that the proportion of the population of major urban areas in relative distress ranges from 7 to $25 \%$, representing up to $10 \%$ of the national population. In those countries surveyed, approximately 20 million people live in deprived areas, out of a total metropolitan population numbering 185 million (OECD, 1998). In many urban regions today, problems have now become chronic with patterns of social exclusion - unemployment, dependency, crime and violence perpetuated from one generation to the next in the affected areas. Problems are also becoming more pervasive, affecting the wider urban region, including to the spread of decline to hitherto reasonably well-functioning areas (such as the inner ring of suburbs in US cities), or the crossing of jurisdictional boundaries through higher levels of city-wide crime and violence, more widespread pollution, traffic congestion, and derelict sites in the suburbs and/or the inner city.

17. The costs of the lack of appropriate recognition of immigrants' qualifications and skills has been estimated between CAD 4 billion and CAD 15 billion, according to what estimate is used (Bloom and Grant 2001, Reitz 2001 in OECD Territorial Review of Toronto, 2009).

18. The first point can be verified in the case of the Madrid metro-region. Madrid is the largest recipient of foreign migrants in Spain, accounting for $19.3 \%$ of total foreigners in 2006. Foreign migrants originally clustered in the City of Madrid (67\% of the total immigration of the region in 2006), but in recent years the immigration has spread out to the metropolitan rings of the metro-region. Foreignborn made up almost $18 \%$ of Madrid metro-region population. Madrid attracts mostly relatively young people, so the influx of immigrants has had a positive impact on the age structure of the region and on the size of the local workforce. For instance, in 2006 the city of Madrid was home to more than 420 000 FWs, almost $50 \%$ of the local labour market (OECD Territorial Review of Madrid, 2007). 


\subsection{Negative externalities of urbanisation}

There are various negative externalities associated with large concentrations of population in urban areas. As externalities, they are not internalised by firms and households, and may only show up as a direct cost in the long term. They include for instance (i) congestion costs (heated property, high transportation cost and long commuting time implies a loss of productivity) and (ii) environmental costs (impacts on health and human capital, on cities' attractiveness and beyond cities, on global warming).

A first type of negative externality is over-heated property, i.e. under particular conditions urbanisation leads to high land prices compromising a city's competitiveness. If land prices are especially elevated, firms may choose to rent or purchase office space outside of a city, which in turn, reduces a city's tax base. High land prices may also make it more difficult for firms to recruit highly qualified workers. To attract and/or retain workers, firms may be forced to subsidise the housing costs of their employees. Recent real estate developments in the "edge cities" encircling metropolitan areas may take advantage of lower property values; consistently researchers have illustrated an inverse relationship between the distance from city centre and land prices (Bertaud, 2004). The trend, however, may not always have deleterious effects: high real estate prices may encourage real estate development and increase the property tax base of local governments.

The most notable negative externality of urban concentration is traffic congestion. It is difficult to find statistical data assessing the costs of traffic congestion and available data follow different methodologies.

- In Seoul, Korea, traffic congestion costs increased over the years 1999-2002 from KRW 4.18 trillion to KRW 5.31 trillion (OECD, 2005e).

- Traffic congestion in U.S. cities of all sizes has created a USD 78 billion annual drain on the U.S. economy in the form of 4.2 billion lost hours and 2.9 billion gallons of wasted fuel, the equivalent of 105 million weeks of vacation and 58 fully-loaded supertankers (Texas Transportation Institute, 2007). The 2007 Urban Mobility Report notes that congestion causes the average peak period traveller to spend an extra 38 hours of travel time and consume an additional 26 gallons of fuel, amounting to a cost of USD 710 per traveller.

- One estimation of the total economic losses due to traffic congestion in Istanbul, Turkey, is USD 7.2 billion per year, assuming that 1 million cars travel per day with an average two hour idle period in traffic, and considering gasoline losses, manpower losses, and depreciation. Another calculation of indirect economic losses by traffic congestion at the two bridges of the Strait of Istanbul is USD 5.6 billion per year (OECD, 2008f).

- In Randstad-Holland, the Netherlands, annual congestion costs were found to be around EUR 1.6 billion per year; this represents around $0.8 \%$ of the regional GDP (OECD, 2007h).

- In Toronto, Canada, high car-usage rates have led to traffic congestion, with annual costs for commuters in 2006 estimated at around CAD 3.3 billion per year and the annual economic costs at CAD 2.7 billion for the Greater Toronto and Hamilton Area (OECD, 2010b).

Congestion not only impacts on productivity but also generates environmental costs. Congestion in urban concentration produces different forms of pollution, such as reduced air and water quality, but also high noise levels and degradation of green areas.

Air quality is increasingly affected by car traffic. 
- In Istanbul, Turkey, the transportation system, which depends heavily on motor vehicles, has caused a lot of $\mathrm{CO}_{2}$ emissions (a 52.6\% increase from 1990 to 2000) as well as other damaging emissions including CO and NOX (OECD, 2008f).

- As a city surrounded by mountains which give rise to temperature inversions, air pollution is an increasingly visible problem in Cape Town, South Africa. In 2007, the air quality monitoring stations recorded 128 days of poor air quality when the levels exceeded international World Health Organisation air quality guidelines. Vehicles contributed $65 \%$ of pollution, followed by industry (22\%), wood (11\%), and other causes $(2 \%)(\mathrm{OECD}, 2008 \mathrm{e})$.

Water pollution has become a major concern for many cities.

- In Chongqing, China, growth in urban population expansion and industrial activities has made the metropolitan area the largest source of water pollution upstream of the Three Gorges Dam. In 2004, 58\% of monitored sections of key rivers in Chongqing had water quality of IV or lower. ${ }^{19}$ Industrial discharges from many metallurgy and chemical installations add to water problems as many plants employ older technologies and lack pollution prevention and abatement equipment (OECD internal OLIS doc on Chongqing, 2007).

- The Capital Region of Copenhagen, Denmark, contains several contaminated soil and water areas. Field investigations conducted by environmental specialists in the regional government have identified water contamination in at least 3000 sites. Of these, the regional government identified 50 heavily contaminated areas where costs of cleanup would exceed 10 million Danish crowns (approximately 1.35 million euro). If the contaminants in these sites leak into underground aquifers, water quality will be compromised especially given that $75 \%\left(80\right.$ million $\left.\mathrm{m}^{3}\right)$ of the total annual water consumption in the Capital Region is extracted from the region's ground water aquifers (OECD, 2009h).

- Inadequate water quality is a key issue for the Venice city region, Italy. It lagoon is affected by the drainage basin, untreated sewage, atmospheric deposition and the release of contaminants sequestered in sediments originating from industrial activities, especially petrochemical processing in Port Marghera. Seventy percent of monitoring points in the lagoon are classified as "bad"; "poor" in $27 \%$ of the rest and "unattributed" for the remaining $3 \%$. Currently sewage in the historic centre is untreated, and flows directly into the lagoon, which receives an organic and pathogen loading equivalent to more than 400000 persons during the tourist season. Significant levels of Hepatitis A and enteroviruses have been detected in Venice's canals. The quality of the Lagoon is still mired by the legacy of Port Marghera's discharge of mercury, dioxins, and hydrocarburants (OECD, 2010c)

In many OECD countries, urbanisation and suburbanisation went hand in hand with urban sprawl, generating greater capital costs related to building more schools and extending roads, water and sewer lines and storm water drainage systems. Sprawling cities tend to be characterised by low economic efficiency and high environmental stress. Essentially sprawl is characterised by $i$ ) leapfrog or scattered development, ii) commercial strip development, and iii) large expanses of low-density or single-use development. This entrenches an urban form of poor accessibility: residences may be far

19. The pollution streams are derived from different sources: households, industrial discharges and agriculture run off, and the impact has been compounded by sluggish investment in water pollution treatment. Untreated wastewater from households and agriculture run-off are the largest sources of organic pollution with high social impacts. The proximity of the Three Gorges Dam reservoir area makes water pollution particularly acute as its ecological balance is directly influenced. 
from out-of-home activities (residential accessibility) or out-of-home activities may be far from one another (destination accessibility). Both types affect the efficiency of household transport patterns and tend to increase daily vehicle miles travelled per capita which leads to greater air pollution/ozone levels. The most complete empirical work on sprawl in the US "The Cost of Sprawl -2000" found out that sprawl would result in USD 227 billion in additional costs in the U.S. over a 25-year period (Burchell et al., 2002).

In China, sprawling associated with the rapid expansion of the major metropolitan regions has become a serious issue (Kamal-Chaoui et al. 2009). More than $12 \%$ of this (cultivated) land has been lost in the last decade due to industrialisation and urbanisation (Warburton and Horn, 2007, cited in Kamal-Chaoui et al. 2009). The result is consumption of agricultural land and growing urban sprawl that is causing inefficiencies in land use, land markets, goods transport, public transport, and public services all of which undermine agglomeration benefits. This is occurring not only in the major coastal metropolitan regions, such as Shanghai and Guangzhou, but also inland in smaller regions such as Chengdu. For example, time-series analysis of satellite imagery shows that built-up land areas in large parts of suburban Chengdu grew by 300\% in a six-year period (1996-2002) and built-up parts of large areas of suburban Shanghai expanded by $350 \%$ from 1988 to 2002 (Kamal-Chaoui et al, 2009). From 1990 to 2000, built-up land area in the Inner PRD grew by over $300 \%$ in a pattern of sprawl that was hitherto unknown in China (OECD, 2010a). Concerns over rampant conversion of agricultural land have triggered periodic inspections and clampdowns by the Ministry of Natural Resources and Lands, but the basic problem remains that, under the current fiscal system in China, leasing of land use rights accounts for a large proportion of local government financing.

Urban sprawl has been identified as one of the major driver of greenhouse gas emissions (KamalChaoui, L. and Robert, A., 2009). OECD data demonstrate that urbanisation greatly increased carbon emissions (Figure 29). Half of Turkish people live in urban areas and produce around $250 \mathrm{mt}$ of $\mathrm{CO}_{2}$ whereas the urban share of population in Britain is $70 \%$, accompanied by nearly double the $\mathrm{CO}_{2}$ emissions of Turkish urban areas. To take another example, Germany has almost twice the urban population of France, and German cities have twice the pollution levels as those in France. However, not all urban areas pollute equally. As density increases, $\mathrm{CO}_{2}$ emissions from transport go down (Figure 30). Austria's urban areas are more than four times denser than Australia's, and generate only $60 \%$ of the amount of $\mathrm{CO}_{2}$ emissions that Australia's urban areas generate. Therefore, while urbanisation levels might bring about an expansion in carbon emissions, these are reduced with higher density (Figure 31). 
Figure 29. Urbanisation and carbon emissions

Urban population (according to $\mathrm{PU}$ areas) shares and $\mathrm{CO} 2$ emissions

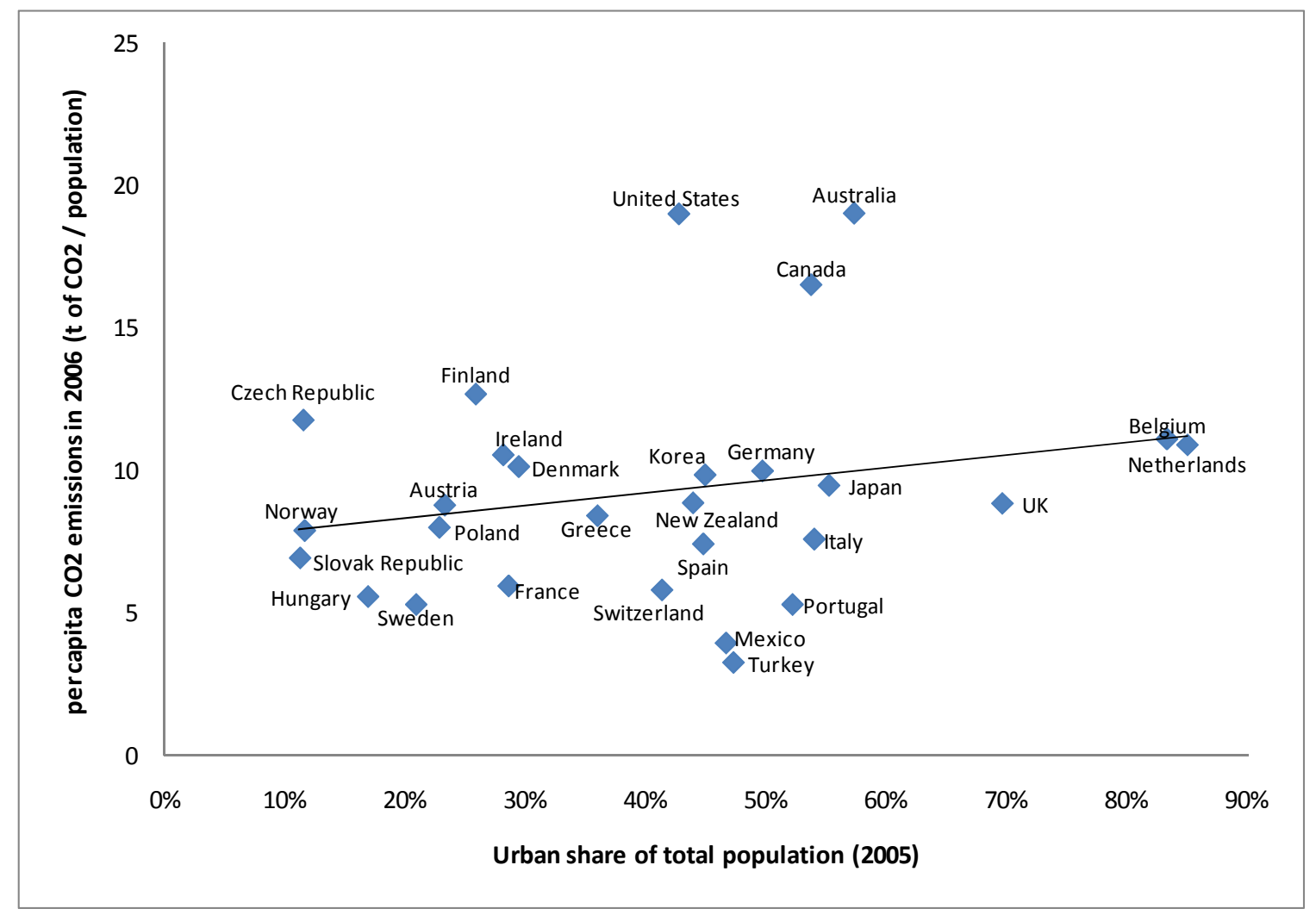

Notes: Urban shares were calculated on the basis of PU areas.

Finland, Norway and Sweden were taken out of the sample as they were considered outliers.

Iceland and Luxemburg were not included in the sample as the OECD Regional Database identifies no predominantly urban (PU) regions in those countries.

Source: Author's calculations based on data from the OECD Regional Database and IEA (2008), CO2 Emissions from Fuel Combustion, OECD Publishing, Paris. 
Figure 30. Urban density and carbon emissions in transport

Per capita carbon emissions produced by transport activities and urban (PU areas) density

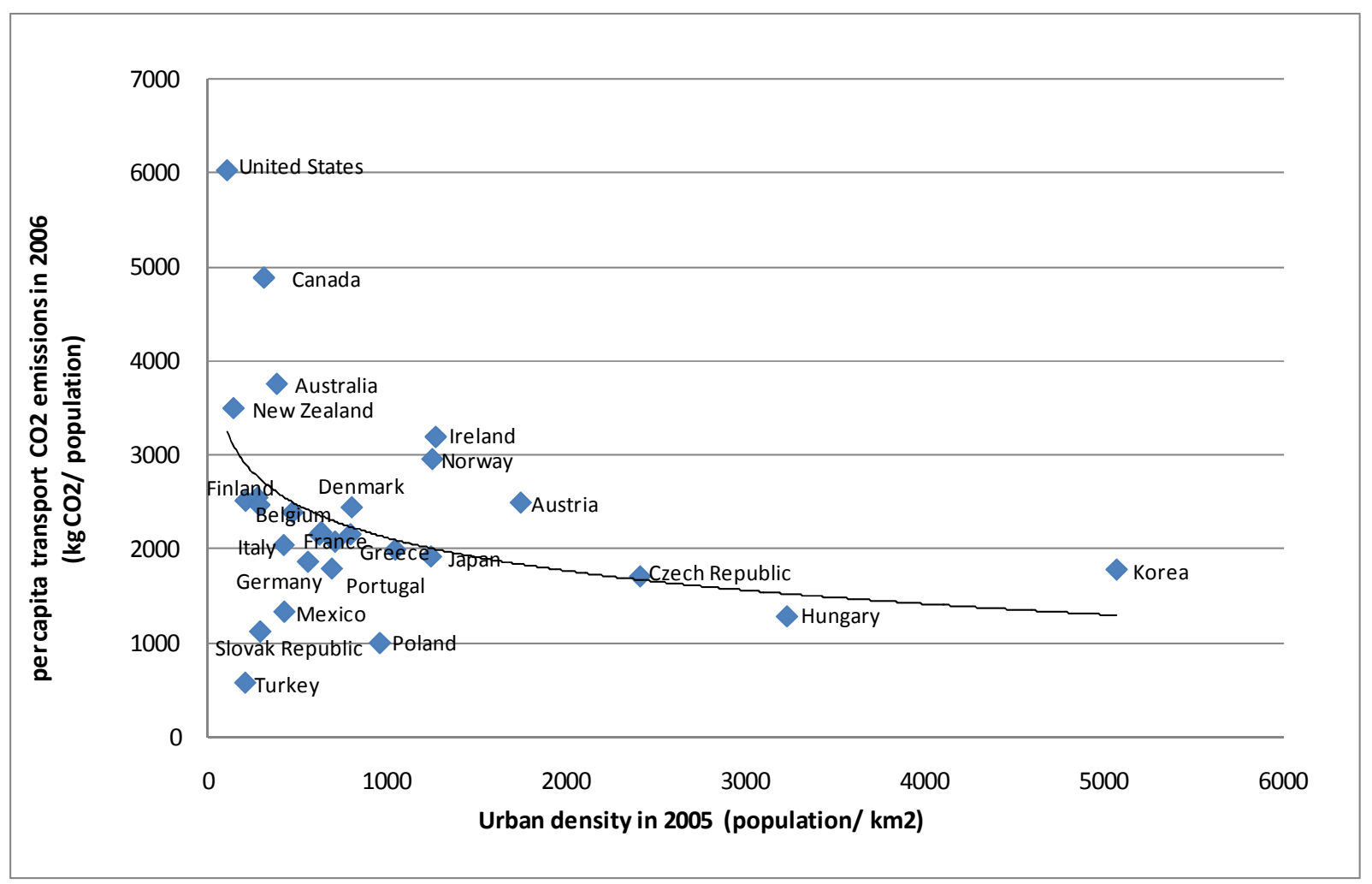

Notes: Urban density was calculated on the basis of PU areas.

Iceland and Luxemburg were not included in the sample as the OECD Regional Database identifies no predominantly urban (PU) regions in those countries.

Source: Author's calculations based on data from the OECD Regional Database and IEA (2008), CO2 Emissions from Fuel Combustion, OECD Publishing, Paris. 
Figure 31. Urbanisation, density and carbon emissions

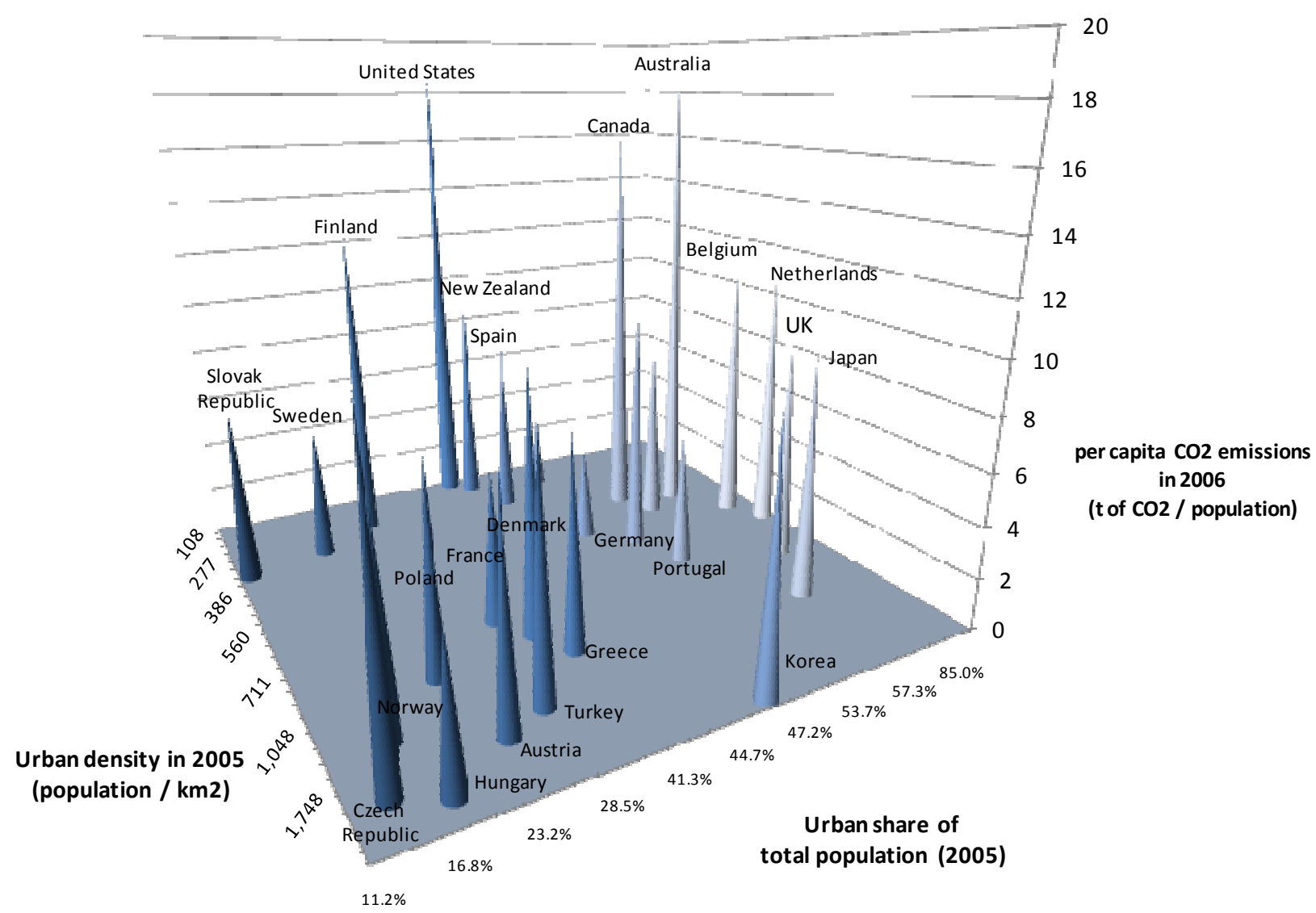

Notes: Urban density and urban share were calculated on the basis of PU areas.

Iceland and Luxemburg were not included in the sample as the OECD Regional Database identifies no predominantly urban (PU) regions in those countries.

Source: Author's calculations based on data from the OECD Regional Database and IEA (2008c), CO2 Emissions from Fuel Combustion, OECD Publishing, Paris.

Lifestyles, in particular the way in which people commute, are crucial in the generation of $\mathrm{CO}_{2}$. As urban areas become denser and rely more on public transport, carbon emissions are reduced. Not surprisingly, among OECD member countries, North American countries produce $50 \%$ more $\mathrm{CO}_{2}$ emissions than the Europeans; while European countries pollute twice as much as the Asian countries. Similarly, not all cities in the same country have the same lifestyles nor do they contribute to carbon emissions in the same way. Although the USA is the OECD country with the most flows of carbon emissions, internally cities like Los Angeles are noticeable for the concentration of $\mathrm{CO}_{2}$ emissions (Figure 32). Even smaller cities like Houston produce much more $\mathrm{CO}_{2}$ than New York -the largest city in the country. The Toronto region is one of the metropolitan regions in North America with the highest share of public transit (around 23\% in 2006) only surpassed by New York. The public transit share of the Toronto region is comparable to those of many European metropolitan regions, such as London, Munich and Amsterdam, but falls well below public transit shares in Japanese cities like Tokyo. Despite the high use of public transit within the North American context, the Toronto region has one of the highest rates of car use among OECD metro-regions (71\% in 2006) (OECD, 2010b). 
European metropolitan regions have been able to lower car use through a more extensive use of public transit, as well as development of other transportation modes including walking and cycling.

Figure 32. Concentration of carbon emissions in the USA

CO2 emissions at county level for 2002

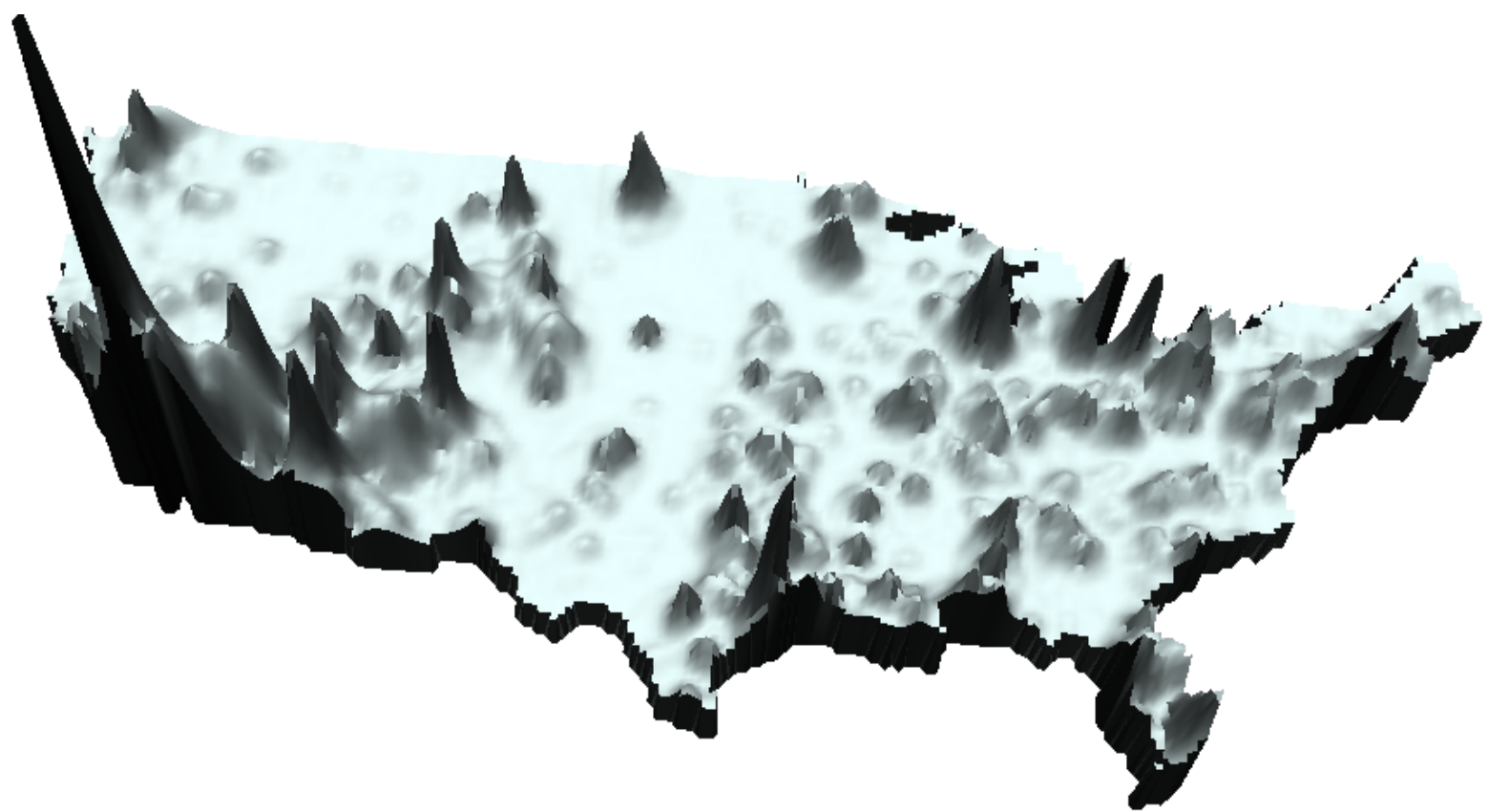

Source: Author's calculations based on data from the Vulcan Project (2009) and the OECD typology of regions. The Vulcan Project is a NASA/DOE funded effort under the North American Carbon Program (NACP) to quantify North American fossil fuel carbon dioxide (CO2) emissions at space and time scales much finer than has been achieved in the past.

It is not necessary to make tradeoffs between urban economic growth and environmental and health priorities. Findings from an OECD regional growth model disaggregated at the metropolitan level demonstrate that policies to reduce urban sprawl and congestion can be implemented without having a detrimental effect on long-term economic growth. ${ }^{20}$ These simulations, using the spatialised version of the IMACLIM-R CGE framework (Crassous et al., 2006), show that the trade-off between economic growth and climate policy can be actually lower when local dimensions are taken into account. Specifically, congestion charges and urban densification policies can have a significant effect on greenhouse gas emissions levels while allowing the local economy to grow (Figure 33). Underlying these results is the fact that technology-support policies embodied in the IMACLIM-R model can reduce and even offset the economic cost of curbing carbon emissions. In other words, the prospects of economic growth can actually be improved by providing incentives to innovation and growth. Assessed at the regional or local level, policies to reduce carbon emissions are less opposed to economic growth than policies designed at the aggregate level. The reason for this lower trade-off at

20. Note that, in the IMACLIM-R model, the explicit representation of technologies through reduced forms of technology-rich bottom-up sub models allows for an explicit description of agents' decisions that drive the pace and direction of technical change. Moreover, consumption and investment choices in IMACLIM-R are driven by agents' imperfect foresight and explicit inertias on the renewal of equipments and technologies. The combination of these two features is the underlying explanation for moderate carbon abatement costs in IMACLIM-R's policy scenarios when compared to those in other general equilibrium models. 
the urban level lies in the fact that more complementarities among policies and economic activities can be observed at the local than at the aggregate national level.

Figure 33. Economic growth with local policies

Changes in GDP comparing densification and congestion charges vis-a-vis baseline scenario)

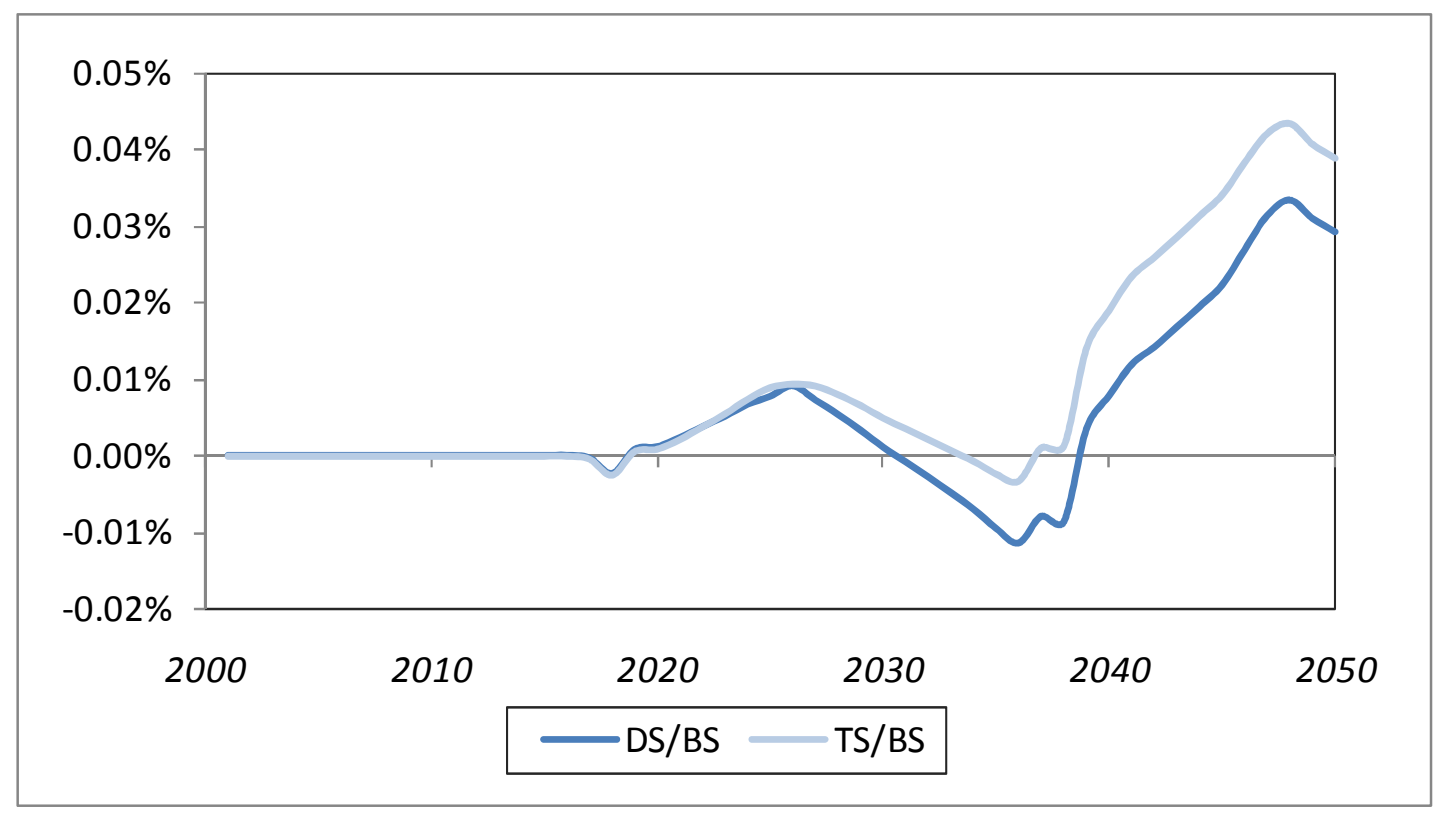

Note: DS refers to Densification Scenario; BS refers to Baseline Scenario; TS refers to Tax Scenario (in turn refer to the application of congestion charges).

Source: Simulations from IMACLIM-R model based on the OECD Metropolitan Database.

Low pollution levels will increasingly be a factor driving the attractiveness of urban areas. In the next two decades, cities that could become more attractive will do so while also curbing local pollution. According to the results of the IMACLIM-R model, and if current trends are sustained, cities that could experience improvements in attractiveness by 2030 include Ankara, Auckland, Barcelona, Krakow, Lille, Melbourne, Montreal, Monterrey, and Toronto; they will do so while also trimming down local pollution (Figure 34). Conversely, metro-regions could lose attractiveness if they continue to pollute, as in the cases of Chicago, Los Angeles, New York, Osaka, Paris, Philadelphia, Seoul and Tokyo if current trends continue. If local pollution is related to attractiveness, and the latter associated to population and firm creation, higher incomes, productivity and wages, then an environmental policy at the local level could generate economic gains. In particular, changing the urban structure by increasing cities' density and intensifying the use of public transportation may induce both improvements in attractiveness - and therefore economic performance - and in cities' responsiveness to climate change. Densification policies to respond to climate change can take the form of removing tax and development disincentives in the urban core, actively pursuing compact spatial form, and increasing mass transit networks and urban amenities in areas targeted for higherdensity growth. These issues should be at the heart of the ongoing debate about a green growth strategy. 
Figure 34. Changes in attractiveness and local pollution emissions across metro-regions

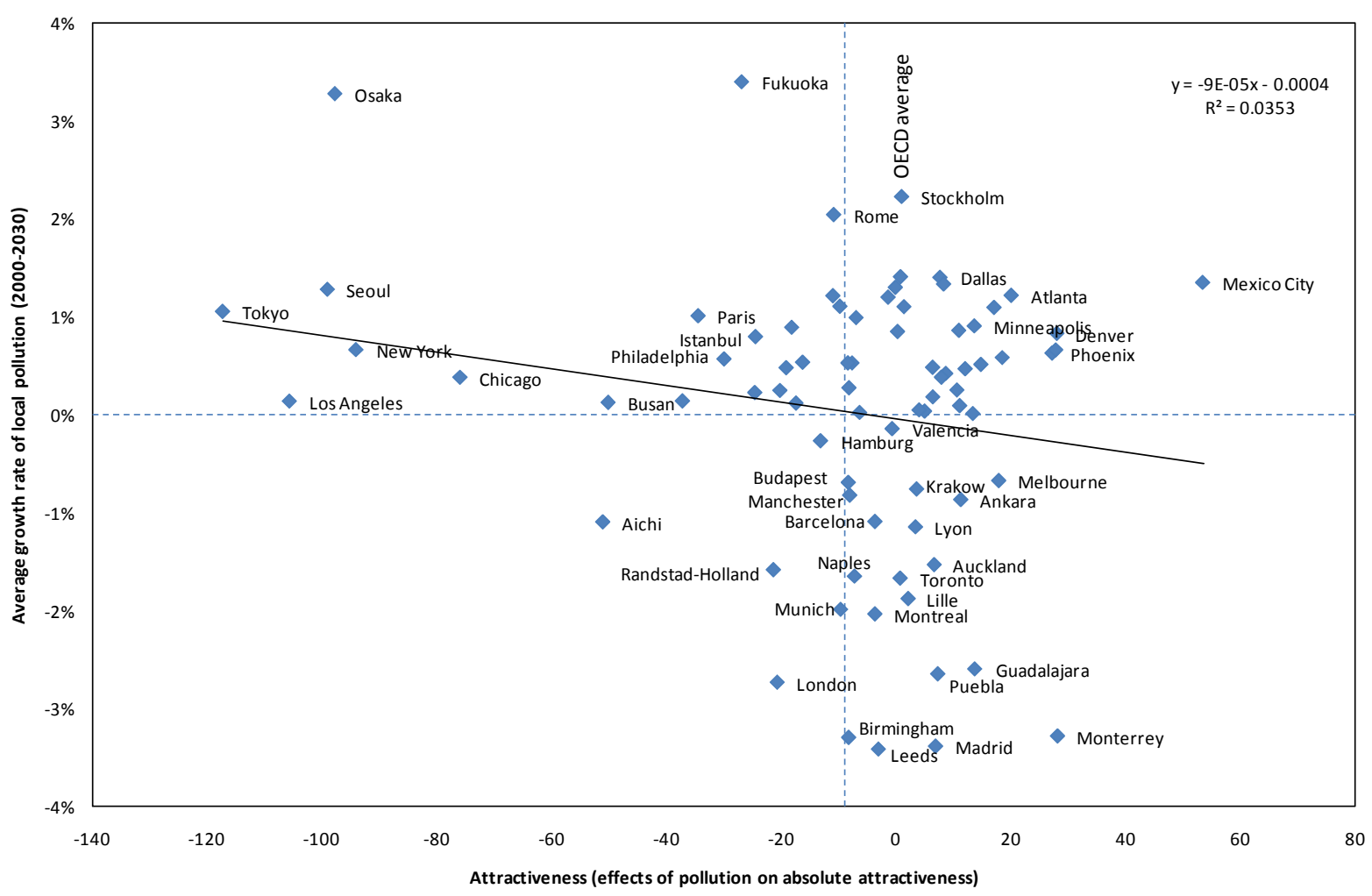

Source: Calculations based on the IMACLIM-R model and the OECD Metropolitan Database.

\section{Strategies and trends in urban policies}

\subsection{Urbanisation, market forces and strategic planning}

\section{Urbanisation: a planned trend?}

In most OECD countries, urbanisation trends have first mainly occurred as market forces not as a result of intended public policies. Very few countries have implemented specific urbanisation targets. Some countries like Poland however, have made urbanisation targets a national policy objective (OECD, 2011). Urbanisation is the result of economies of scale in firms located in urban areas. As they become more productive they are able to pay higher wages which in turn attract workers from rural areas. When policies have been introduced to limit urban sprawl, the installation of firms or the attraction of rural migrants, markets always find a way. For instance, in Korea, restrictions for setting up firms in Seoul have led the private sector to locate just outside the core of the larger functional area, driving out economic activity not very far away and having little impact on congestion.

Although there is not much record among OECD countries about explicit urbanisation targets, there is evidence that certain policies, often with other objectives, had important effects on urban areas. Prudhomme (2008) identified four main public policies implemented in France as of the 1950s1960s that pushed the development of medium sized cities. First with the creation of the DATAR in the 1960s, France developed strong and active regional policies targeting the less developed areas (based on large scale infrastructure investment and public subsidies for firms) whilst implementing discouraging measures to set up business in Paris. Second, strong housing policies, which consisted in 
various forms of subsidies or reduced rates loans for private construction, and in highly subsidised public housing construction for low income renters (HLM programme), although no being explicitly spatial, benefitted both medium sized and large cities. Third, massive redistribution policies were developed, with explicit social goals, have had a key unintended spatial impact as the equalisation scheme favoured the development of small and medium-sized cities. In general, experiences in OECD countries suggest that besides market forces, some indirect policies may have impact urbanisation outcomes. They include for instance housing, transport, fiscal and industrial policies.

\section{From spatial to strategic planning}

In many OECD countries, a long term national vision for urban development is reflected in the national spatial planning frameworks. Many OECD member countries have 5-10 years long term plan (e.g. EU member countries (2007-13), Japan (roughly ten years), Korea (20 years)). National spatial planning serves as a policy tool to address the distribution of economic activity and social welfare between regions, which may be termed as national-regional planning. Japan and Korea appear to place relatively great emphasis on the role of central government in spatial planning. The case of United Kingdom is somewhat different. Until relatively recently there has been little co-ordination among relevant sectors. Different central Departments have had responsibility for land-use planning, transport planning, economic development and business support, agriculture, tourism and other relevant policy areas. Denmark, Finland and Norway share the characteristic that spatial planning focuses on land use and land use-related matters and thus exists somehow alongside regional development policy. More generally, spatial planning priorities are being taken into account within regional development goals in a growing number of countries. This has long been the case in the Netherlands and has been highlighted in recent years in countries like Greece and Portugal, in part in response to broader EU policy supports.

Addressing the long term strategic planning for urban areas within national spatial framework is essential to enhance synergies between sectoral policy measures and avoid duplication and conflicts within and between regions. Spatial planning can be seen as one means by which to manage demand for future public investment, emphasising trajectories that maximise growth opportunities without overstretching public investment requirements. As countries, regions and cities strive to improve their competitiveness with respect to other places, so the (local) inputs that contribute to economic success, including the quality and functioning of infrastructure and public services, are being closely scrutinised. In this context, spatial planning, as both a means to reduce factor costs and to reduce public investment needs, should have an important role to play.

Spatial planning is practised at various levels of government, and the level has a major influence on the objectives and scope of the planning process. The highest level of plan is usually the macrolevel plan - usually at national level but also in some countries at large region level (e.g. for US states). Many countries, for example the UK, no longer have a national spatial development plan as such. In many federal governments, such as the US and Canada, the national constitution limits federal government involvement in urban affairs, and they tend to approach spatial issues a-spatially and sectorally, even if they no longer subsidise inefficiencies to reduce regional disparities. Others are exclusively conceptual (e.g. France) or have become increasingly conceptual (e.g. Japan), concerned with economic development issues in the aggregate but not with allocative or land-use decisions directly.

OECD work on spatial planning however shows that the effectiveness of current spatial planning approaches needs to be improved. The nesting of plans at different levels has become less and less straightforward. In the past, macro plans were specific and directive, which made it somewhat easier to disaggregate them into regional and local plans. Recently, these national development plans have become broader and more conceptual, combining physical development objectives with less tangible 
goals such as sustainable development. A principal challenge facing spatial planning today is, therefore, how to reconcile the diversity of roles that spatial planning is expected to play at different spatial scales. In particular, the middle level plans - examples include the Schéma directeur in France, the structurplan in the Netherlands and regional spatial strategies in the UK - have become more important as expressions of a regional development strategy.

Despite some variations, the planning systems of OECD countries can, in general, be said to encompass the following fundamental functions:

- Spatial planning provides a long or medium-term spatial strategy in pursuit of agreed objectives, often controlling regional disparities and working towards sustainable development.

- Spatial planning is also frequently a tool to co-ordinate various sectoral policies in pursuit of these spatial development objectives.

- Spatial planning is increasingly understood as a mechanism of co-ordination and interaction which enables sub-national governments to shape their own spatial development policies in conformity with national or even international policy goals, and facilitates the regional and local adaptations of national policies.

With globalisation, strategic planning has progressively replaced spatial planning. Spatial development has always been a primary policy objective in urban policy because in a physical space where population and activities are densely concentrated, provision of basic functionalities of space, such as shelter, mobility and sanitation, have been an important prerequisite for public welfare. In fact, during the period of massive urban expansion, urban policy meant, above all, policies to cope with rapidly expanding public demands for urban space and services. Since economic globalisation and the subsequent intensification of inter-city competition placed urban economic competitiveness on the top ladder of urban policy agenda, increasing attention has been paid to the profound change in the governance of cities and urban regions, particularly in the field of urban spatial development. The change is often described as a shift from a managerial mode of governance, which is primarily concerned with effective provision of social welfare services to citizens, to that of entrepreneurialism, strongly characterised by a pro-economic growth strategic approach, risk-taking, innovation and an orientation toward the private-sector. This shift opened up a new policy dimension in urban spatial development, created numerous policy innovations, and produced results in successful cases. However, policy experience over the past decades has shown that challenges exist for policy planners to realise the full potential of entrepreneurial approach in urban spatial development and prepare their cities for the knowledge economies in the 21 st century (OECD, 2007b).

\section{The risks of strategic planning in a market context}

Strategic planning for urban areas can however run the same risk as that policy of setting goals and visions that are not supported by the market. There are limits to public intervention in a market context. There are two issues here:

- Markets can become distorted and resources wastefully deployed. Public policy sometimes prevents diminishing returns from limiting the size of large cities, through such measures as subsidies to transport costs or special help with housing costs.

- Market forces may not support a city's pursuit of a particular economic activity.

(i) Diminishing returns and city size 
If market forces were allowed to operate, cities that reached a certain size would become so congested and expensive that investors and developers would start to avoid them and move elsewhere; there is a therefore a danger that public policy aimed at sustaining the quality of life in such cities enables them to continue growing long after they have become uneconomic, preventing diminishing returns from setting in. This raises the general issue of the relationship between planning and markets in the new urban policy. ${ }^{21}$ In a pure market, increasing returns are a temporary phenomenon. In the case of cities, costs of travel congestion, increasing land values for commercial and residential property, high costs of living, labour shortages, and deteriorating environmental quality reduce the attractiveness to investors of a favoured city. This leads to the establishment of new investment locations in cities where these costs and disadvantages do not exist. In the long run there should be relatively even development across cities. The policy conclusion to which this leads is that governments should not subsidise the construction of transportation structures, rents or other land costs, high costs of living, skills training or infrastructural and environmental improvement in dynamic cities, as these activities only prolong the period of increased returns, leading to symptoms of urban imbalance discussed before.

It is however extremely unlikely that governments will take the risk of waiting for this long- term outcome to arrive, if in the meantime they see their champion cities declining in relation to those in countries where governments are not following the same market principles. Very few governments in the OECD subsidise land costs as part of urban policy, but they are highly active with measures ranging from the location of major cultural centres in favoured cities to cost-of-living supplements to public employees' pay, usually in capital cities. The current emphasis on supporting and sustaining these cities makes it less rather than more likely that diminishing returns will set in. However, the economists' arguments cannot be ignored, and policy-makers need to consider the implications of policies that prevent diminishing returns from inhibiting extreme geographical imbalances in development. This may require ensuring the advance of a number of dynamic cities spread more or less evenly around the national territory, to produce a more level playing field of competition among the country's cities.

\section{(ii) Market forces and strategy for urban areas}

A wider issue raised by the confrontation of new urban policy by market forces concerns the impossibility of urban policy makers and spatial planners determining that particular economic activities will thrive in a particular region, without being guided by market signals. If policymakers try to establish visions for cities without reference to market forces, the likely outcome will be an oversupply of some kinds of urban economy and an under-supply of others, with firms that have benefited from urban policy assistance but with products not well targeted on the market eventually failing and wasting resources. In particular, national and city governments currently have a strong desire to succeed in very high-value, future-oriented industries like information technology, bio-technology and financial services. This could lead to an over-supply of the products of these industries, and consequent failure of those firms who owed their presence on the market to favourable public policy rather than to the quality of their products and an understanding of markets. Here national policy makers can do something to appraise coolly the unrealistic aspirations of individual cities.

Strategic visions for cities must develop with close attention to market signals. In general, policy will be most successful where it seeks to advance new developments which, while perhaps small, are clearly demonstrating a capacity to survive in the market; or developments which, while new, build on past specialisms and acquired knowledge in an area. To take a strong but perhaps surprising example,

21. See Fujita, Krugman and Venables 1999; Fujita and Thisse 2002 for a discussion of the problems experienced by economic theory in dealing with the increasing returns of the contemporary urban economy. 
Chicago's global role in commodities futures trading is based on expertise deriving from its agricultural and industrial past (Sassen in OECD 2007a).

There is an important role for national governments in helping local authorities identify potential new economic activities at times of rapid change. In periods of economic stability, local economic policy making is relatively straightforward for national and local policy-makers alike. Working in conjunction with the leading firms in a sector, they can develop infrastructural and other policies that support existing, successful sectors. In a period of rapid change representatives of existing industries may be speaking for interests that have no future; considerable sums were spent in the 1980s in many countries on attempts to prevent the decline of doomed industries. Assessing the claims of new local entrepreneurs or potential foreign direct investors is a difficult task. At the level of individual cities, capacity to make sound judgements may well be lacking.

While much growth takes place in the so-called 'new' economy, there is a continuing role for many traditional activities. Sassen (OECD, 2007a) has drawn attention to the fact that the new growth poles of the knowledge economy are not so disconnected from the more mundane activities of their regions as the language of newness and distinctiveness might imply. A whole series of ordinary services in the distributive sector cluster around the new activities, and the wider regions in which they are located also contain manufacturing and even agricultural activities. For this reason she advocates planning on a very wide scale, at the level of what she calls 'mega-regions': geographical spaces including a number of important cities and possibly extending beyond the boundaries of national regions, sometimes crossing national borders themselves. Conceiving of global city regions in this way dilutes the obsession with activities with very high value added only, and reminds public authorities of the inter-dependence of the various components of the economy.

There is considerable evidence of two unsuccessful kinds of approach to this problem: a downmarket one, relying heavily on the attraction of FDI through subsidies of various kinds; and an upmarket one, positing unrealistic objectives for cities. The former approach leaves cities vulnerable to investors primarily interested in low costs, who, either when the subsidy runs out or when cheaper parts of the world enter the global market for attracting FDI, move on, leaving little behind them in terms of acquired competences and local collective competition goods among the local population. The latter runs the risk of deciding that cities should try to develop prestigious high value added activities, usually in information technology or biopharmaceuticals, with no prior experience or local entrepreneurial base in the sectors concerned on which future expansion might reasonably expect to be able to build. There is experience of both strategies in North-East England (Box 3). There is also room for doubt over the viability of Madrid's approach to science parks and technology poles. These involve policy following emergent clusters. Links between SMEs and Spain's universities are structurally weak, and it may be it is unrealistic for the city to try to break into global biotech competition, a field where so many cities are trying to establish themselves (OECD, 2007g). 


\section{Box 3. Towards an innovation policy for North East England}

For two decades since the 1980s, the Regional Economic Strategy of the English North East concentrated on positioning of the region as a production site for multinationals. Economic development initiatives focused on subsidies for investors, providing investors with cheap land and infrastructure, and emphasising the region's absence of congestion, affordability of housing and availability of relatively cheap labour. Policy interventions focused on the development of supply chains around significant investors, and innovation policy focused on process and productivity enhancement initiatives to ensure that the region retained its competitive advantage. Property development was a key part of economic development, which has continued through to the present. The most recent strategies, however, signal a move away from a foreign direct investment strategy towards the development of a knowledge economy. Much greater emphasis is given to the role of the universities in the region, and innovation policy generally, in particular to large iconic innovation policies such as "Science City". The strategies have gone from an almost singular focus on the region as a production site to a strong focus on the region as a knowledge hub.

It is essential that such ambitions are strongly grounded in current realities, or the likelihood of disillusion is high, and with it the risk of significant changes in strategy. In considering how far the region takes a focus on priority sectors, policy makers will need to manage carefully the region's capacity to engage on a sector basis. The process would be resource intensive, and it is unlikely that there would be the capacity for engagement with more than two to threesectors at any one time. Factors which may limit the region's ability to take an active sector strategy approach very far, and which would need to be considered, include: the absence of a critical mass of companies, research and development establishments, co-operative actors, as well as existing and extendable starting-points for local (regional) production chains; a similar absence of a critical mass of private sector leadership in every sector; and, given the absence of a regional tier of democratic government in the UK, the region's limited ability to influence and bring to the table the national policy environment and national agencies.

All the plans and strategies being made for Newcastle identify specific initiatives, albeit often at a very general level, and they seek to show the link between the initiatives and high level results (outcomes). They are also supported by considerable efforts to measure and evaluate the expected outputs and outcomes. There is a cost to all of the institutions and strategies. Considerable time and effort is expended on producing the strategies, and then on ensuring (or trying to ensure) that they are reasonably consistent. In reality they are not all consistent, and this affects perceptions of their worth and believability. The large number of strategies and institutions also raises co-ordination costs, provides opportunities for institutions to pull in different directions, and inhibits common understanding and the maintenance of a common vision.

Source: OECD (2006c), OECD Territorial Review of Newcastle, UK, OECD Publishing, Paris.

There is also scope for the central governments to identify cases of metropolitan regions that are not making the most out of their potential because of a lack of appropriate public policy. For example, the Randstad is a high growth area, but the fact that its productivity is lower than in some other parts of the Netherlands suggests that it is not taking full advantage of polycentricity. Few firms locate their $R \& D$ there - though there is a strong public infrastructure of knowledge - due to issues such as transport inefficiency. Rather than find means of exploiting the innovative capacity of this knowledge infrastructure, municipalities are concentrating on building low quality office blocks to get rates income (OECD, 2007h). There is a similar lack of co-ordination in Milan, with many of the city's large numbers of SMEs being poorly informed of development possibilities, with no true innovation policy, a lack of interaction among firms, and with the city's two major universities not being involved in the city's urban policy (OECD, 2006h).

\subsection{Recent trends in urban policies in OECD countries}

Comparative analysis of national urban policies among countries is difficult to conduct for several reasons. 
First, urban policy is a broad based concept. Indeed, it transcends the confines of narrow definitions given that nearly all public policies directly or indirectly affect urban development. Central governments have a large impact on urban living conditions through a variety of policies, programmes and projects that are being implemented by a wide range of national ministerial departments and agencies. At the most basic level, national governments directly contribute to the operating budgets of metropolitan areas. National programmes affect cities in myriad ways: national housing programmes often determine density, patterns of urban growth, and the efficiency of energy use; national support of transportation infrastructure may change the built environment and accessibility of entire cities and neighbourhoods; and a nation's investment in education and local R\&D facilities can greatly improve the environment for innovation and entrepreneurship. While particular programmes channel funds directly to cities, a national government may also support regional programmes where it becomes difficult to disentangle rural and urban impacts. This is particularly challenging when urban policy also applies to very small towns in rural locations.

Many policies that are not seen as constituting urban policy have considerable differential effects on different locations, favouring development in some areas rather than others. Some of these are clearly spatial, such as the location of airports or major research institutes, but may not always be seen as affecting cities as such. Others are only implicitly spatial, though their implications for cities and their economies can be very strong: regulatory decisions that advance or hinder specific economic sectors, which are located in some areas rather than others; constitutional arrangements that bring political prominence to some areas rather than others, for example under schemes of devolution, or through the geographical basis of governing majorities. It is important when assessing urban policy that these -implicitly urban policies are recognised as such.

Second, urban policy objectives differ across countries. They are contingent on the specific challenges facing cities; for example, the approach used for cities undergoing industrial restructuring will differ from that used for high-growth cities. Some countries, such as the United Kingdom, the United States and France, are facing more serious spatial segregation issues in their cities than in Nordic countries, and their policies need to target specific neighbourhoods. The importance of urban development also varies across countries. This is due to differences in the urbanisation rates in OECD countries, ranging from above $90 \%$ (Iceland, Luxembourg, the Netherlands, Australia, United Kingdom) to below $60 \%$ (Finland and Ireland).

Third, urban policy must take into account varying levels of political centralisation among federal and national governments. In federal countries, intermediate levels of government, whose responsibilities are comparable to the national government of unitary countries, tend to be in charge of urban development. However, recent examples point to a growing interest in urban issues on the part of federal government: in Canada, the Federal Government created a Secretariat for Cities under the aegis of the Prime Minister (later merged within Infrastructure Canada); in Switzerland, the Confederation inaugurated a policy for agglomerations (OECD, 2006e); and the central government of Spain passed legislation that confers a special regime on large metropolitan areas (Rodriguez Alvarez, 2004). In more decentralised countries, the national government has often restructured its administrative and technical machinery at the sub-national level. For example, some national administrations have re-organised authorities into metropolitan regions, supra-municipal authorities to which certain powers (mandatory and optional) have been transferred. In other circumstances, national-level reforms are less explicit and are limited to the subsidisation of existing regional councils and infrastructure projects.

Table 2 summarises the current state of urban policy across OECD member states. 
Table 2. National urban policies in a sample of OECD countries

\begin{tabular}{|c|c|}
\hline Austria & $\begin{array}{l}\text { No explicit urban policy at federal or regional (Land) level. The Lande are more driven } \\
\text { by concern with the effects of suburbanisation and the 'weak' position of regional } \\
\text { peripheries rather than 'strong' urban centres. Strong fiscal equalisation mechanisms } \\
\text { mean that there is a high degree of 'home rule' amongst municipalities and intense } \\
\text { inter-municipal competition. }\end{array}$ \\
\hline Belgium & $\begin{array}{l}\text { No specific urban policy until 1990s when the salience of urban issues rose, reflecting } \\
\text { the rise of right wing political parties at local level, urban rioting and the growth and } \\
\text { segregation of minority ethnic urban communities. A strongly federalised governmental } \\
\text { system and the differential economic experiences of Belgium's three regions has } \\
\text { produced a divergence of policy approaches with an initial focus upon physical urban } \\
\text { renewal in Wallonia, urban safety and poverty in Flanders and a mixture of the two in } \\
\text { the Brussels region. The policy focus in the latter two regions has shifted recently } \\
\text { towards an emphasis on quality of life issues (on one hand social control, on the other } \\
\text { the attraction of high income residents and high value firms). }\end{array}$ \\
\hline Canada & $\begin{array}{l}\text { As in the US, Canadian federal government support for sectoral programmes whose } \\
\text { main beneficiaries were urban areas has dwindled since the } 1970 \text { s. The key } \\
\text { relationship in urban policy development is therefore between provincial and municipal } \\
\text { levels of government. The provinces, which are constitutionally superior in this } \\
\text { relationship, have tended to pass responsibility for addressing key urban issues (sprawl, } \\
\text { declining city centres, homelessness, transport, cohesion) to the municipalities and in } \\
\text { some cases have led processes of metropolitan government re-organisation in the } \\
\text { attempt to create new 'units' that can do so more effectively. There remains an } \\
\text { unresolved debate, however, about how greater sharing of urban policy responsibilities } \\
\text { between levels of government could improve the competitiveness and liveability of key } \\
\text { urban areas. }\end{array}$ \\
\hline Denmark & $\begin{array}{l}\text { A good example of the importance of implicit rather than explicit urban policies. The } \\
\text { latter remain relatively weak, with limited support from national government for } \\
\text { programmes of urban renewal, focused upon tackling neighbourhood decline and social } \\
\text { fragmentation. The former, traditionally based upon redistribution and the development } \\
\text { of local government's role in the national welfare state, began to shift in the 1990s with } \\
\text { a series of initiatives (airport development, strategic use of state land assets, creation of } \\
\text { bridge/tunnel link between Copenhagen and Malmo in southern Sweden) that had the } \\
\text { effect of strengthening the competitive position of the capital city-region. }\end{array}$ \\
\hline Finland & $\begin{array}{l}\text { Little in the way of specific, overt urban policy but urban areas have been seen as key } \\
\text { to a strong technology-orientated spatial policy that has been especially successful in } \\
\text { the Helsinki city-region and is now being used to try and promote balanced spatial } \\
\text { development across the country as a whole. Relatively lightly funded. Fits into a system } \\
\text { of inter-governmental relations in which there is strong local authority 'home rule' }\end{array}$ \\
\hline $\begin{array}{l}\text { Czech Republic, } \\
\text { Hungary, Poland, } \\
\text { Slovak Republic }\end{array}$ & $\begin{array}{l}\text { Little in the way of explicit urban policy as yet. Policies for urban areas dominated thus } \\
\text { far by need to manage the transition to market economies, deal with its economic, } \\
\text { social and physical consequences, build the professional and representative capacities } \\
\text { of sub-national authorities and cope with the delayed but rapid growth of } \\
\text { suburbanisation and the depopulation of certain urban centres (particularly their low } \\
\text { quality residential areas). }\end{array}$ \\
\hline France & $\begin{array}{l}\text { Focus of urban policy has been on institutional innovation and the creation of } \\
\text { institutional capacity, in a highly fragmented local government system, through (a) } \\
\text { statutory encouragement of various forms of inter-municipal co-operation, (b) the } \\
\text { provision of national government incentives through central-local contracts, and (c) the } \\
\text { development of additional mechanisms for citizen and stakeholder engagement in local } \\
\text { governance. Depending upon local conditions, the strengthening of governance is seen } \\
\text { as a means to address issues of urban unemployment, economic development and } \\
\text { segregation. Urban policy innovation has occurred in parallel with a sustained } \\
\text { programme of governmental decentralisation and the progressive abandonment of } \\
\text { regional policy initiatives that previously sought to encourage greater economic balance } \\
\text { between the capital city-region and provincial centres. }\end{array}$ \\
\hline
\end{tabular}




\begin{tabular}{|c|c|}
\hline Germany & $\begin{array}{l}\text { Urban policy developed in a context characterised by a highly federalised governmental } \\
\text { structure, strong fiscal equalisation mechanisms, a deep national commitment to the } \\
\text { preservation of a balanced urban system, the need to manage the consequences of } \\
\text { German re-unification and, recently, relatively late (by European standards) processes } \\
\text { of de-industrialisation. Urban policies as a result have focused upon experimental 'state- } \\
\text { down' and 'bottom-up' attempts to improve competitiveness and manage the physical } \\
\text { and social consequences of industrial decline and depopulation through the } \\
\text { repositioning of cities and city-regions to attract public and private funding within a set of } \\
\text { well-established institutional relationships that are difficult to reform. }\end{array}$ \\
\hline Greece & $\begin{array}{l}\text { Little in the way of explicit urban policy. Urban programmes dominated mainly by the } \\
\text { need to deal with the consequences of poorly-regulated patterns of market-driven urban } \\
\text { development and the demands it generates, e.g. in terms of the provision of } \\
\text { infrastructure. The limited financial capacity of local authorities to support urban } \\
\text { development programmes has been eased to some extent by EU funding but Greece }\end{array}$ \\
\hline Ireland & $\begin{array}{l}\text { Weakly developed overt urban policy, focusing mainly upon commercial and residential } \\
\text { urban renewal. EU programmes have been instrumental in supporting these efforts but } \\
\text { their effects have been overshadowed by high rates of national economic growth, the } \\
\text { impetus this has given to rapid and lightly regulated suburbanisation and associated } \\
\text { growth in housing costs, congestion and segregation. }\end{array}$ \\
\hline Italy & $\begin{array}{l}\text { No formal urban policy until 1990s. Weakly developed since then as statutes for } \\
\text { metropolitan reform remained unimplemented or partially implemented. Lack of co- } \\
\text { ordination between national, regional and local levels of government means that urban } \\
\text { programmes are piecemeal and dependent upon individual municipal efforts, hence } \\
\text { dependent upon unevenly-developed institutional capacities. }\end{array}$ \\
\hline Japan & $\begin{array}{l}\text { Traditional focus in spatial and industrial policy on reducing inter-regional differences } \\
\text { and relieving pressures caused by agglomeration in core urban areas. With the } \\
\text { economic crash of the later } 1990 \text { s, this policy regime has been revisited and the } \\
\text { importance of key metropolitan areas to national economic recovery both recognised } \\
\text { and supported, for example through an Urban Renaissance programme. }\end{array}$ \\
\hline Netherlands & $\begin{array}{l}\text { First formal urban policy developed in mid-1990s in response to de-industrialisation and } \\
\text { economic crises/related social difficulties in the major cities. Initial focus on the } \\
\text { 'gateway' functions of Randstad cities, especially Amsterdam and Rotterdam. } \\
\text { Subsequently extended both geographically (to other urban centres in the Netherlands) } \\
\text { and functionally (to social as well as economic/physical renewal). Resulted in } \\
\text { strengthening of 'compact city' strategies of major cities but dilution of spatial focus. } \\
\text { Ambitious programme of metropolitan governance reform failed but push for greater } \\
\text { strategic, inter-governmental policy integration carried through. Subsequent national } \\
\text { economic recovery and renaissance of major urban centres, along with high profile } \\
\text { breakdown of social harmony in Dutch cities resulted in more recent urban policy focus } \\
\text { on social order, integration of minority ethnic communities, education and citizenship }\end{array}$ \\
\hline Portugal & $\begin{array}{l}\text { Urban programmes largely driven by EU funding and priorities. No explicit urban policy } \\
\text { until late 1990s and the introduction of the National Spatial Planning and Urbanism Act } \\
\text { and the subsequent establishment of a Ministry of Cities, Territorial Planning and } \\
\text { Environment. Policies for cities nonetheless remain fragmented, horizontally (between } \\
\text { different sectoral policy areas and municipal jurisdictions) and vertically (between } \\
\text { different levels of government). }\end{array}$ \\
\hline South Korea & $\begin{array}{l}\text { Spatial policy in Korea has largely focused upon trying to decentralise population and } \\
\text { economic activity from the overwhelmingly dominant capital city-region (around Seoul) } \\
\text { through various controls upon and/or incentives for industrial and commercial } \\
\text { development and the sitting of higher education institutions and activities. The fact that it it } \\
\text { has been largely unsuccessful in reducing Seoul's influence upon the national economy, } \\
\text { combined with debates about its importance in linking Korea into international circuits of } \\
\text { trade and commerce, however, are beginning to trigger a rethinking of this approach. }\end{array}$ \\
\hline
\end{tabular}




\begin{tabular}{|c|c|}
\hline Spain & $\begin{array}{l}\text { Little in the way of formal, national urban policy. Urban initiatives given momentum by } \\
\text { EU programmes and, to varying degrees, the devolution of powers and responsibilities } \\
\text { to the regional scale. Complex division of responsibility between national, regional, } \\
\text { metropolitan and municipal levels has meant that recognition of urban potential and } \\
\text { problems has been dependent upon the development of joint programmes of activity } \\
\text { between levels of government. }\end{array}$ \\
\hline Sweden & $\begin{array}{l}\text { First specific national urban policy introduced in 1998, focusing upon problems of social } \\
\text { segregation in the country's three main metropolitan areas (around Stockholm, } \\
\text { Gothenburg, Malmo). } 1^{\text {st }} \text { phase focused upon housing. } 2^{\text {nd }} \text { phase focusing upon } \\
\text { localised economic growth and development. Fits into a highly decentralised local } \\
\text { government system and a lively, but as yet unresolved, debate about the extent to } \\
\text { which the capital city-region around Stockholm is being 'drained', through the operation } \\
\text { of fiscal redistribution mechanism, of resources that could be used to support its } \\
\text { development. }\end{array}$ \\
\hline United Kingdom & $\begin{array}{l}\text { Forty-year history of explicit urban policy, initially focused upon 'filling holes in the } \\
\text { welfare net' but subsequently, from the late } 1970 \text { s, concerned primarily with the } \\
\text { economic, social and environmental consequences of industrial restructuring. Mainly } \\
\text { focused upon 'problem' areas within the larger conurbations. Constant changes in area- } \\
\text { based initiatives and delivery arrangements; little continuity, sustained investment. With } \\
\text { recent urban renaissance, signs of a longer-term, less problem-focused approach in } \\
\text { which inter-governmental approaches to the development of city-regions may play a } \\
\text { larger part. }\end{array}$ \\
\hline United States & $\begin{array}{l}\text { Federal urban policy in long term decline since the high point of the War on } \\
\text { Poverty/Great Society programmes of the 1960s. Strongly federalised systems of } \\
\text { government, high degree of 'home rule' for municipal governments and the reliance } \\
\text { upon labour migration and low welfare entitlements to overcome spatial economic } \\
\text { 'shocks' mean a highly fragmented and competitive system of government in which } \\
\text { urban policies are unevenly developed and largely dependent upon state-municipality } \\
\text { relationships. Recent debates about 'the new urbanism' and the potential benefits of } \\
\text { 'regionalism' (i.e. metropolitan inter-municipal co-operation) for overall quality of life } \\
\text { have encouraged a focus upon the need for dedicated, bespoke urban policies but } \\
\text { seem unlikely to trigger fundamental change. }\end{array}$ \\
\hline
\end{tabular}

Although there are clear limits to assess and compare national urban policies, OECD studies conducted to date allow identifying key emerging trends:

The first trend is that regional development policies increasingly endorse a more pragmatic approach to the concept of balanced territorial development which tends to benefit urban regions. For a while, many national governments have tended to perceive excessive urban concentration as negative. The main arguments were that the impact of such concentration of population and output in metro-regions on the overall development of a national economy was negative because it was draining skills, capital and physical resources from other regions, thus compromising balanced territorial development. Moreover, the fact that this high concentration was generating a number of negative externalities gave more legitimacy for taking action.

Based on this argument, many OECD countries have implemented (and are still implementing) specific policies to restrict the development of their largest metropolitan areas. These include for instance France, the Netherlands, the United Kingdom and Korea (Box 4). Policies include both incentive or deterrent measures to contain the development of large cities such as specific regulations and taxes (new or higher taxes) to set up new offices (France, United Kingdom, Korea), direct subsidies for the relocation of firms to other areas (United Kingdom), restrictions on housing supply (the Netherlands), or relocation of public functions and universities (France, Korea). These policies did not produce expected outcomes. The UK has some of the strongest via urban containment, Greenbelt and densification policies. While these do have a substantial impact on the physical form of cities (and the cost of buildings) they do not seem greatly to influence the overall growth of cities 
viewed in functional terms. London just jumps across the Greenbelt increasing average commuting times. Past work on New Towns showed that they had little impact on overall trends driving decentralisation of industry. Investment in rural industry and restrictions on urban-rural migration may have more impact on rates of urbanisation.

\section{Box 4. Examples of OECD countries that tried to monitoring the growth of their largest metro-regions}

France has attempted to achieve "controlled growth" in the capital region around Paris, which expanded so rapidly compared with the rest of the country that scholars worried early about "Paris and the French desert" (title of a 1947 publication by French geographer Jean-François Gravier). Since 1955, both public and private firms seeking to expand within Paris are required to apply for an administrative authorisation. Regulations on offices were considerably loosened in 1985 but restored for larger offices in 1990. The government also started to levy taxes (redevance) on new offices locating in the lle-de-France region to discourage new firm creation after the 2 August 1960 law. The scheme was toned down in 1982 when it was restricted to specific zones with a regressive pricing mechanism. Evaluations show that industrial employment in the capital region decreased extensively but mainly due to sectoral shifts rather than to the efficiency of the government's deterrents (DATAR, 1999).

In Japan, the Industrial Relocation Promotion Law (1972) introduced direct subsidies from the MITI and long-term loans for businesses willing to relocate to designated areas. The results of this policy are mixed. On the one hand, the volume of industrial output from Tokyo and Osaka declined from 18\% to 15\% between 1985 and 1992. On the other hand, there was less success in fostering dynamism and creative capabilities in Japanese localities outside of the Tokyo-Nagoya-Osaka agglomeration. Although many prestigious technology-oriented buildings were constructed, the lack of venture capital and of other soft infrastructure made it hard for entrepreneurs to take the risk of launching start-ups (OECD, 2005d).

In the Netherlands, the Randstad is above all a spatial planning concept that was born shortly after the Second World War and refers to the position of a belt of cities, in particular four large cities (Amsterdam, Rotterdam, The Hague and Utrecht) encircling a green open area named the Green Heart in the western part of the Netherlands. National spatial development policies have in recent decades switched back and forth between promoting and discouraging the development of the Randstad into a metropolitan region. Repeatedly, fears of the Randstad growing together into one "amorphous" metropolis have led to policy initiatives to limit expansion of the large cities and urban sprawl around them. This approach had two main consequences until the 1990s: within the Randstad, planning policies focused on the preservation of the green heart, seen as a key asset for the region, and the restriction in housing policy; and policies were focused on dispersing growth out of the Randstad towards more peripheral regions of the North and the East of the Netherlands. In reality, however, population growth continued to be concentrated in the Randstad and have led to urban sprawl. Despite explicit policies to concentrate population growth in designated areas and to keep the Green Heart an area unaffected by urban construction, the whole Randstad area has gradually become more urbanised, including the Green Heart (OECD, 2007h).

In the United Kingdom, both deterrents and incentives were used to limit London's high concentration. From 1965 to 1979, the Greater London Council required firms to apply for office development permits (ODPs) before establishing new offices in the London area. A Location of Offices Bureau was set up and helped companies move away from the capital city. However, evidence of slowing expansion in London remained quite mixed. For example, the rate of office floorspace development increased from $14.6 \%$ in the decade before ODPs to $20.4 \%$ in the decade after.

In Korea, since at least the 1964 enactment of "Special Measures for the Restriction of Population Growth in Seoul", there have been efforts to control the growth of Seoul and the larger capital region in order to ensure balanced national development. These efforts include relocation of government offices outside of Seoul, the relocation of university branches outside Seoul and financial incentives to relocate firms and regulations to curb the expansion of industrial establishments and academic institution in Seoul (OECD, 2005e). The nature of the policies has gone through numerous changes over the years, as various measures proved ineffective and encountered criticism that curbing the growth of Seoul was undermining Korea's competitiveness on the international stage. Even so, there are many indirect, economic disincentives against locating in Seoul. For example, the Capital Region Readjustment Planning Act (1982) divides the area into three main categories: congestion restraint zones, growth management zones and nature conservation zones. According to the category, the central government prohibits or controls the construction of new factories and buildings, levies overconcentration taxes, and bans or administers the creation of new universities (except for smaller and vocational colleges). In addition, the registration tax is five times higher in Seoul than in the rest of the country because of the Capital Region Planning Law (OECD, 2005e). 
The debate over urban concentration has also been linked to that which has opposed urban (including the largest cities) versus rural regions. National governments in OECD countries have for a while opposed - rich urban regions with - lagging rural regions so that distribution of funds for regional development policies went mainly to what used to be classified as -rural. OECD analysis on regional trends has demonstrated that this generalisation was unfounded, as rural areas were not synonymous with decline and there were a number of urban regions experiencing decline and which were systematically lagging for a number of indicators. Moreover, focussing only on lagging regions, and thus excluding de facto the champion urban areas, did not produce a positive outcome. It did not solve the issue of concentration nor help to meet the balanced territorial development objectives as champion urban areas in many cases have continued to attract people and firms, but with increasing difficulties in facing the challenges of global competition and the associated social, economic and environmental costs.

In the same vein, it is interesting to note that the acceleration of the urbanisation process in China, occurred despite a successive implementation of anti-urban policy measures from the central government. As many OECD countries, the Chinese government's approach to urban policy has changed over the years. Economic development of rural areas is a priority, but the central government understands that the prosperity of different types of regions is closely interlinked, and therefore the government is paying greater attention to the development of cities, including that of the major urban clusters (Pearl River Delta, Yangtze River Delta and Pan Bohai Metro region) that were, for the first time, explicitly mentioned in the last Five Year Development Plan (Kamal-Chaoui et al. (2009)) 3 and OECD, 2010a).

Several factors have forced national governments to rethink their policy approaches to urban areas. First, countries have now endorsed the idea that economic performance depends on their capacity to maintain the competitiveness of their urban regions. The role of large cities on the international marketplace has clearly impacted the way national governments perceive high urban concentration. While in many cases stemming from market forces, the process of establishing or reinforcing urban areas as a preferred location for advanced economic activities has quickly become a major field for public policy.

In this context, countries that have so far oriented their regional development policies towards the objective of balanced territorial development are now also increasingly taking into account the role of their champion cities. In France, for instance, concerns have been expressed about the competitive position of the Paris metro-region on a global scale. The OECD (2006b) Territorial Review of France highlighted the fact that the region recently fell behind its major EU competitors for its innovation capacity and competitiveness, partly explained by the decision to relocate some public research centres outside the region. Since the 1960s, France has indeed implemented a succession of redeployment policies towards other urban poles of growth to meet its objective of more balanced territorial development. These policies have led to the emergence of eight major provincial - although not global - metropolitan areas (Toulouse, Lille, Nancy, Strasbourg, Lyon, Nantes, Bordeaux and Marseille), to the detriment of Paris as the unique global city of the country, the unique international competitor. Recently, however, the Ministry for the capital region was given the mandate to come up with a strategy to enhance the city's international competitiveness. In a similar vein, the Randstad-Holland region has also been endowed with a National ministry, while the national government focuses mainly on sustaining other regions.

Many members are increasingly developing a more differentiated approach to urban areas, acknowledging the principle of regional diversity. In Nordic countries, such as Finland or Sweden, which are dominated by one single metropolitan area and a large number of smaller urban regions 
(also called city-regions), national governments have started to develop differentiated urban policy approaches to preserve the growth capacity of their champion cities while enhancing the development of a number of subsidiary urban poles. In 1994, Finland introduced a specific urban policy to foster the innovation and growth of its eight largest city-regions (excluding Helsinki), initially called the centre of expertise programme (CoE), and restructured in 2001 under the name Regional Centres Programmes (RCP). This policy had a regional focus, with balanced territorial development as a key objective. It also recognised that a certain degree of concentration was needed to reach a minimum critical mass, and included as a main objective for the allocation of funds more collaboration (and thus economic integration) between a core city and its neighbouring municipalities (OECD, 2005c). Meanwhile, a policy package has been prepared for the major urban regions, including Helsinki. In Sweden, which like Finland, was focused only on regional equity objectives, the national government has, since the beginning of the decade, paid greater attention to Stockholm supporting the initiative to foster the integration of the larger Stockholm Malar region through public infrastructure investment, social support in distressed areas (called "metropolitan policy") and a well designed regional innovation policy strategy (OECD, 2006d). German spatial planning policy also sought to link the eleven most developed -European metropolitan regions (europäische Metropolregionen) with smaller centres - via secondary road networks is one example.

The second main trend is that national urban policies are becoming more pro-active and forwardlooking. Urban policies in the past have tended to be remedial (addressing negative externalities) and not pro-active (addressing negative externalities and fostering agglomeration economies). Concern with remedying the decline of industrial cities and managing issues of decay, crime and social welfare were often automatically associated with the term - urban policy in the 1980s and even the 1990s. Today, in most member states, urban development policies are no longer solely preoccupied with the regeneration of declining areas but with programmes for creating large urban spaces capable of being such nodes and competing in the most innovative and dynamic sectors of the global economy. Such policies are resulting in forward-looking programmes which attract firms and their associated highly skilled work forces to the most innovative and dynamic sectors, are providing the high-quality urban infrastructures that these highly mobile firms and workers demand. The change in approach has not occurred because the negative issues associated with declining urban structures and aggregations of social problems in large cities have been resolved. On the contrary, these issues continue to loom large among those addressed by urban development policies. However, a number of governments, including those of Japan (OECD, 2005d), Germany (Bundesministerium für Verkehr, 2006), Finland (OECD, 2005c) and Norway (OECD, 2007f) have recently re-oriented their national spatial strategies in order to come to terms with the changing geography of economic dynamism. For example, Japan abolished Industrial Allocation Promotion Law in 2006 and abolished subsidies for factories moving out of metropolitan areas. Japan also deregulated universities and factories for relocation into metropolitan areas. They are developing national policy for regional innovation systems in metropolitan areas, building universities as strategic hubs and launching major infrastructural projects.

Concern with addressing negative externalities associated with urbanisation remain high in the national urban policy agenda but is increasingly part of a forward looking approach. The negative externalities mentioned previously tend to exacerbate over time so that national governments are increasingly concerned with taking a more active role in such issues as infrastructure maintenance and development or social cohesion, distressed areas, crime and so on. In light of the experiences of the major OECD agglomerations, it seems that economic growth at the metropolitan level depends on economic interdependencies as well as other factors such as social cohesion and the physical environment. Areas which are isolated from the economy and labour market of the metropolitan region are, in a sense, hindering the competitiveness of the region as a whole and compromising the achievement of collective goals. Competitiveness is only one contributing factor to improving quality of life and social cohesion; however, without a competitive urban economy, it is difficult to raise living standards and improve the environment. 
While urban policies are becoming more pro-active and forward-looking, national governments cannot overlook the negative externalities associated with urban concentration (pollution, declining infrastructure, social distress, crime, and inequalities). Ensuring a clean and attractive urban environment is increasingly recognised as an integral aspect of the creation of dynamic cities rather than a mere compensation of their consequences. There are limits to the dynamism that can be sustained by cities with increasing traffic congestion and pollution. As will be developed later, the introduction of a congestion charge has generally been perceived as an effective measure to limit traffic and improve the use of public transportation (e.g. London). While policies aimed at distressed neighbourhoods have produced mixed outcomes, there are some successful examples of urban regeneration policies (e.g. Bilbao, Kitakyushu, and Glasgow) which have led to the development of tourism and creative industries. Some metropolises that experienced massive urban sprawl have, at times, resorted to quite revolutionary measures with spectacular results (e.g. converting a motorway into a water stream via the Cheonggyecheon project in Seoul).

\subsection{Urban areas and the new paradigm for regional development in OECD countries}

Recent trends in national urban policies reflect the implementation of some principles of the paradigm shift in regional policies that have been observed in OECD countries.

Regional policy began in most OECD countries in the 1950s and 1960s, a period of relatively strong economic growth, fiscal expansion and low unemployment. The principal objectives of the measures introduced were greater equity and balanced growth in a period of rapid industrialisation. The main instruments used were wealth redistribution through financial transfers by the national government, accompanied by large-scale public investments. During the 1970s and early 1980s, successive economic shocks and changes in the global economy led to the emergence of geographical concentrations of unemployment in many countries and regional policy evolved rapidly to address this new challenge. The earlier focus on reducing disparities (in income, in infrastructure stock, etc.), was widened to include employment creation. The assumption was that public policy could alter supply conditions (essentially by changing production cost factors through production subsidies and incentives) and thereby influence industrial (re)location decisions for both existing firms and new investments. Overall, the results were disappointing. Regional disparities were not significantly reduced, appearing as entrenched as ever in many countries despite significant public investment. At a regional level, there was only limited success in restructuring the economic base of the target areas. ${ }^{22}$

In response to these poor results, OECD countries have over the past few years promoted a new paradigm of regional policy that aims at helping each region, whether wealthy or not, to maximise its own comparative advantages in a positive sum game that contributes to national objectives (Table 3 ). Regional policy has therefore been evolving from short-term subsidies into a much broader family of long-term development policies designed to enhance regional competitiveness (OECD, 2009i). These can be characterised as follows:

22. The case of inward investment illustrates the limitations of these regional policies. Many governments attempted to attract foreign direct investment (FDI) into target regions in order to create employment, but also on the assumption that spillovers would benefit local enterprises, increasing their technological and organisational capacity. However, experience suggests that in many cases the facilities brought into the region generate few productivity gains among local enterprises. Often, these branch plants are weakly integrated into the local economy with few links to local suppliers. Most foreign-owned subsidiaries show low levels of innovation and very few conduct R\&D locally or link into local centres of innovation, preferring to retain their R\&D in their main country of origin (e.g., Pavitt and Patel, 1991). 
- a development strategy covering a wide range of direct and indirect factors affecting the performance of local firms;

- a greater focus on endogenous assets rather than exogenous investments and transfers;

- $\quad$ an emphasis on opportunity rather than disadvantage;

- a collective/negotiated approach to governance involving national, regional and local government along with other stakeholders, with the central government taking a less dominant role.

Table 3. Old and new paradigms of regional policy

\begin{tabular}{|l|l|l|}
\hline & Old paradigm & New paradigm \\
\hline Objectives & $\begin{array}{l}\text { Compensating temporarily for } \\
\text { location disadvantages of lagging } \\
\text { regions }\end{array}$ & $\begin{array}{l}\text { Tapping underutilised potential in all } \\
\text { regions for enhancing regional } \\
\text { competitiveness }\end{array}$ \\
\hline Unit of intervention & Administrative units & Functional economic areas \\
\hline Strategies & Sectoral approach & Integrated development projects \\
\hline Tools & Subsidies and state aids & $\begin{array}{l}\text { Mix of soft and hard capital (capital } \\
\text { stock, labour market, business } \\
\text { environment, social capital and } \\
\text { networks) }\end{array}$ \\
\hline Actors & Central government & Different levels of government \\
\hline \multicolumn{2}{|l|}{ Source: OECD (2007b), Competitive Cities: A New Entrepreneurial Paradigm in Spatial Development, OECD Publishing, Paris. }
\end{tabular}

The rationale of the new regional approach is based on the principle that opportunities for growth exist in the entire territory, across all types of regions, as documented in the OECD report "Regions Matter" (2009). The aim is to maximise national output by assisting and encouraging each individual region to reach their growth potential endogenously, thereby departing from the old view of regional polices as a zero sum game. Evidence of this so-called "paradigm shift" in regional policy can be seen in recent reforms of regional policy in a number of OECD countries (OECD, 2009i). This new thinking in regional policy concerns not only the most developed countries, but developing countries as well. The challenge for non-OECD countries is often to manage rapid industrialisation and urbanisation through active regional intervention, but without repeating the mistakes made by some OECD countries in the period when there was an attempt to artificially redefine economic geography through major public investments. So, the new paradigm in regional policy - an emphasis on market mechanisms, endogenous growth and on collaboration across levels of government - has clear relevance for these countries.

The implementation of the new regional development paradigm addresses the question of the relationships between urban and rural areas. Contrary to what prevailed in the past, the opposition between different types of regions is unveiled by the principle that regional policy should "tap underutilised potential in all regions for enhancing regional competitiveness". For those who would critic the provision of economic assistance to less developed regions arguing that government expenditure in favour of lagging regions diminished performance in the growth poles of an economy assumed to be the wealthiest regions, the new regional paradigm advocates that where are underused resources in lagging regions, mobilising them will contribute to both equity and national development objectives (Box 5). 


\section{Box 5. The equity-efficiency trade-off}

Equity approaches aim to reduce financial disparities between people and places (where subnational authorities are responsible for basic public services).

Efficiency approaches aim to foster growth in places that may already be relatively wealthy. They are based on the increasing acknowledgment of agglomeration effects.

In practice, equity and efficiency policies can be complementary:

- "Increasing returns to adoption" (positive externalities associated with a growing number of users) is a characteristic of knowledge economics. This is obvious in the case of network technologies. It is also the case with education since the larger the number of diploma holders, wherever they studied, the better the national innovation capacity. Similarly, the greater the number of people receiving health treatment, the better it is for the whole population. Thus equity in public spending can increase efficiency

- "Decreasing returns on investment": an excessive concentration in the allocation of public spending will meet limits in its ability to produce additional results. For example, in France, Grandes Ecoles students are few in number, but they receive far more public spending per student than for university students. The average results are lacklustre. Again, more equity in public spending can raise efficiency.

- "Dynamic perspective": investment in already wealthy regions with favourable growth potential can lead to extra wealth which can then be redistributed. Similarly, efficiency in public spending (either by limiting the cost of public policy for the same results, or by improving its outcomes) could increase resources available for the equity objective.

Source: OECD (2009i), Regions Matter: Economic Recovery, Innovation and Sustainable Growth, OECD Publishing Paris.

Instead of being in opposition, there is a growing recognition that rural and urban areas are more strongly interlinked than has been thought in the past. Rural areas in close proximity to urban areas provide a flow of environmental and recreational services to urban areas. In some countries, virtually the entire rural territory is within easy reach of urban residents who commute to work on a daily basis. Because of such economic connections, regional development strategies need to take into account the cascading effects of policy decisions that link rural and urban regions, including policies related with human capital development. The issue is broad - covering issues such as accessibility and its influence on enterprise performance, equity and access to public services, environmental protection and the link between those who preserve amenities and those that consume them, as well as issues of territorial and social cohesion. This increasing inter-dependence of urban and rural regions has several origins, including for example:

- The diminishing share of agriculture in the economy of many rural areas: This may lead to the development of other activities such as tourism for city dwellers and the introduction of tertiary activities in rural towns, thereby modifying their socio-economic profile. Outmigration and ageing, consequences of the reduction of agricultural employment can thus be counter-balanced to a certain extent by these positive developments, witnessed in an increasing number of rural areas. 
- The expansion of urban areas into rural hinterlands: This creates mixed-use areas which are hard to define as either urban or rural. This land is often under significant development pressures which tend to compete with agricultural and horticultural activity.

- Lifestyle changes: The high cost of housing in major cities is fuelling a trend towards cheaper homes in rural areas and increased daily commuting over considerable distances, leading to large "functional urban regions" which also encompass lower density/rural areas. At the same time, shorter working hours and more flexible working arrangements are inducing people to live part of the week, month or year, in the city, and part in the rural area.

- Cities of all sizes exert a strong influence on their surrounding regions. In many cases, there are strong synergies in relationship between urban centres and surrounding. These appear particularly important where a large region is dominated by a single large urban centre, a socalled regional city or city-region. Employment opportunities and services such as banking, health care, education and training as well as shopping centres, cinemas and other cultural facilities are provided by the urban centre, while the rural regions possess lifestyle advantages are accessible to people working in the urban area and can also be residential locations for people wishing to commute (meaning that regional cities often have very large labour market areas).

- For a long time, these cities have been overshadowed by the demographic and economic expansion of capital cities and major metropolitan regions. Now, however, the importance of regional cities as sources of economic growth in their own right and as anchors for rural regions is becoming clear. In some cases regional cities can develop into important economic centres on the basis of good transport linkages such as regional airports, economic specialisation, greenfield development possibilities, dynamic entrepreneurial universities etc. The interest of policy makers in regional cities also stems from their ability to provide basic and some advanced services for large rural regions, which would otherwise be threatened by outmigration because of the lack of employment opportunities and low-quality public services. Strong regional centres provide the principal means by which to offer the kind of social and economic infrastructures that can maintain population and retain and attract investment.

The specific case of green belts around large cities illustrates how countries have tried to develop mixed use or complementary use areas, where rural and urban functions exist in close proximity. For example, the Randstad shows that it is possible for farming to be highly profitable in an urban environment, but, in the process, the commodity outputs of farming become separated from the provision of environmental services (See section 5.3).

\section{Land policy and strategic urban planning}

Unplanned urban growth can cause many problems, such as insufficient infrastructure and public services, and traffic congestion. In general, rapid urbanisation tends to prioritise short term land development and economic growth over long term strategic spatial planning (Table 4). These challenges include the conversion of farmland to urban use without consideration of the impact on employment, innovation and academic clusters, transportation networks, public service delivery, commercial trade, and value of undeveloped farmland. 
Table 4. Problem recognitions and expected policy effects of urban growth management

\begin{tabular}{|c|c|}
\hline Problem recognition & Expected policy effects \\
\hline $\begin{array}{l}\text { Economic } \\
\text { - Loss of farmland (decrease of agricultural } \\
\text { production) } \\
\text { - Wasted commuting time } \\
\text { Inefficient public service and infrastructure }\end{array}$ & $\begin{array}{l}\text { Economic } \\
\text { - Continued existence of farmland ( keeping } \\
\text { agricultural production) } \\
\text { - Decrease of commuting time } \\
\text { - Efficient public service and infrastructure }\end{array}$ \\
\hline $\begin{array}{cc}\text { Social } & \\
\text { - Social exclusion (e.g. residential segregation } \\
\text { between suburb and city centre) } \\
\text { - } \quad \text { Loss of farmland (food security) }\end{array}$ & $\begin{array}{cl}\text { Social } & \\
\text { - Harmonious community } \\
\text { - Continued existence of farmland ( keeping } \\
\text { agricultural production) }\end{array}$ \\
\hline $\begin{array}{l}\text { Environmental } \\
\bullet \quad \text { Increase of } \mathrm{CO}_{2} \text { emission }\end{array}$ & $\begin{array}{l}\text { Environmental } \\
\qquad \quad \text { Decrease of } \mathrm{CO}_{2} \text { emission }\end{array}$ \\
\hline $\begin{array}{c}\text { Value } \\
\text { - Loss of rural scenery and amenities }\end{array}$ & $\begin{array}{l}\begin{array}{c}\text { Value } \\
\text { - Continued enjoyment of rural scenery and } \\
\text { amenities }\end{array} \\
\end{array}$ \\
\hline
\end{tabular}

Source: OECD adaptation based on Milward (2006).

Land is a limited resource and should be carefully managed to both support economic activity and safeguard environmental resources. Land management underlies the creation of urban form, which in turn, may be responsible for producing a spatial layout that minimises congestion, increases productivity, the exchange of ideas, and raises the level of "attractiveness" of the area. Conversely, poor land administration may result in a disorganised city with high environmental costs, i.e. urban sprawl, along with traffic and an irrational allocation of infrastructure. As mentioned previously, a sprawling model often enshrines an inefficient and non-economical rationale for infrastructure extension, elevating capital costs related to building more schools and extending roads, water and sewer lines and storm water drainage systems.

Central governments in OECD countries play a key role in land use policies and strategic planning. Many OECD countries have developed land use regulation and land-related policies to address market failures linked with rapid urbanisation and unplanned growth. Higher levels of governments are generally responsible for basic legal and institutional infrastructure for a functional land market. Protection of private property rights, a litigation system, and a land registry (cadastre) are indispensableAs for land use, central government often prepares guidelines and basic rules for subnational governments without interfering with detailed regulation. Municipal governments, in turn, create detailed land use plans and regulation. Between the central and municipal level, a regional land use plan is also emerging in many metropolitan areas in the OECD countries (e.g. Canada, France, some states of the US), due to the expansion of functional areas over municipal boundaries.

This section will review three main tools used by national governments to optimise urban land use development, including (i) legal and technical tools for an efficient land market, (ii) using land values to finance urban development, and (iii) planning, policy and fiscal tools to control, and reorient urban development.

\subsection{Legal and technical tools for efficient land markets}

\section{Developing policies consistent with market forces}

In a globalising economy, territories are in competition with one another and require continual adjustment to external market forces and their impact on land. Cities throughout the OECD face serious challenges as they attempt to cope with unprecedented population growth. In the struggle to respond to development pressures, their local institutions, both public and private, are being overwhelmed by a multitude of concerns: Will there be enough land to support urban development? 
Do all income groups have access to land for housing, commercial, and industrial activities? Is infrastructure expanding fast enough to support urban development, and are services being deployed in areas where needs are the greatest? How can the government finance the construction of critical infrastructure? Is the land market operating efficiently? How can the efficiency of the land market be increased? Will the prevailing patterns of population and housing density continue into the future, or are there alternatives to urban development that require less land? How can agricultural lands surrounding cities be preserved without driving the price of land beyond the reach of low- and middleincome households? Should the government attempt to aggressively control land development (Dowall, 1995)?

Policymakers in the OECD have recognised that land-use policy is an important facet of national strategic planning and can improve the cost effectiveness of public investment. A clear property right protection system and transparent land registry are critical in reducing transactions costs and protecting the rights of landholders. Unregistered communal property and illegal tenure have often reduced the tax base of local governments and increased the vulnerability of residents in these situations. Informal land ownership implies weak or non-existing linkages with the formal financial sector and an illiquid financial asset. Informal land ownership may also lead to a costly and inefficient pattern of infrastructure provision, with additional negative effects on environmental and social cohesion (OECD, 2008f).

In the development of public land, lagging cities tend to ignore market forces in the design of housing or land development projects. This includes, for example, not considering the annual effective demand for housing or the competitive supply of housing in local markets. Without this assessment, governments tend to purchase far too much land than was warranted by market conditions or build housing that is too expensive for residents to purchase. The main reason most local governments are unable to cope with rapid urban population growth is that they are "flying blind;" they simply don't know what is going on in their local land market. These cities are not able to adequately measure urban land development, the number of housing units (both formal and informal) built in the past year, land and housing prices, rents for office buildings and factories, infrastructure deployment patterns, land subdivision patterns, and so on. Without this information, the private sector in turn, may overbuild in markets which do not have an appropriate demand (Dowall, 1995).

Land pooling or land readjustment (LP/R) programmes have been frequently applied to facilitate service provision and to promote an equitable distribution of infrastructure. ${ }^{23}$ As used in such countries as Germany, the readjustment method calls for all plots in an area to be amassed into a so-called "readjustment mass". Within this mass, the government can obtain the needed plots for land servicing to provide necessary public infrastructure, for example, roads, sewers, and green areas, from the landowners free of charge. The remainder of the mass is redistributed among the original landowners, according to their original contribution to it. Some of the best known examples of successful land readjustment are in cities throughout South Korea, Japan, and Taipei Chinese where the technique has been used as an effective planning tool for over 70 years (Box 6). ${ }^{24}$ In Korea between 1962 and 1981, $95 \%$ of urban land was delivered through land readjustment. Likewise, in Japan from 1977 to 2000, $40 \%$ of the total annual supply of urban building plots was secured through land readjustment (Povey

23. Few authors have studied the premium that residents pay to regularize their homes; an exception is the detailed work of Lanjouw and Levy (2002) who in Guayaquil calculated that the cost of obtaining a title represented $102 \%$ of household annual per capita consumption (cited in Donovan, 2007).

24. Luxembourg also provides another reference. In this country, a part of land for development is transferred to the communes for public facilities. After approval of the Specific Development Plan by the Minister of Territorial Planning and the communal council, the land reserved for public facilities must be transferred to the commune (free of charge, if they do not exceed $25 \%$ of the total surface area) (OECD, Territorial Review of Luxembourg, 2007). 
and Lloyd-Jones, 2000). Two caveats, however, should be addressed. First, land readjustment should be carefully designed in co-ordination with local communities and highly skilled community mediators. If done in a compulsory manner, LP/R may arouse resentment as a top-down compulsory acquisition exercise and fuel existing confrontation between municipal authorities and residents (Farvacque and McAuslan, 1992). Second, though such a strategy has the potential to integrate informal areas into the city and contribute to infill development, it should not be seen as a means to increase housing supply per se. Land readjustment should complement a range of more appropriate planning tools designed to increase housing supply.

\section{Box 6. Land Pooling/Readjustment in East Asia}

A typical LP/R process begins with the preparation of a zoning plan by the municipality. On the zoning plan, within the site blocks which formed by the streets, lots are allocated for private development. The area for public use are then determined by measuring the square meters in the planned streets, parks, and so forth and comparing it to the total area of project. In other words, all land parcels within a project area are grouped together and a percentage of each land parcel calculated to determine a contribution to public areas. This percentage depends on the size of the project area and the total size of required public-use areas. The remaining land is then reallocated within the blocks defined by the plan. Each site block is first subdivided into suitable new lots, then land re-distribution is carried out. The basic principle in the distribution is to keep land in its original location, at least in the same block. After the physical and legal subdivision of land into streets, parkland and sites for buildings, the government may sell some of the building sites to recover costs and repay the loan. Finally, the serviced sites are distributed to the landowners and they are allocated final cash adjustments proportionate to each landowner's precise share of the project (Doebele, 1982). A graphic below from Archer's (1983) research in Chinese Taipei visually presents the replotting of land due to LP/R.

Pattern of separate landholdings before pooling

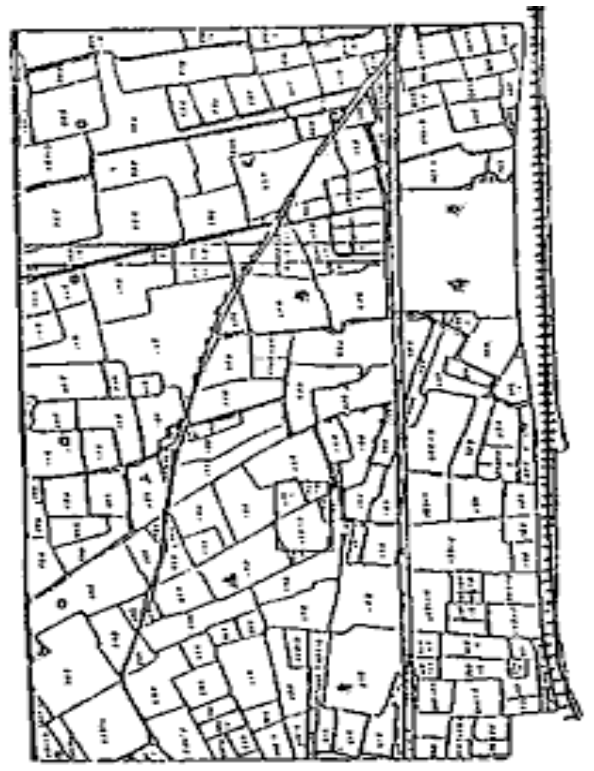

Pattern after pooling including the new street layout

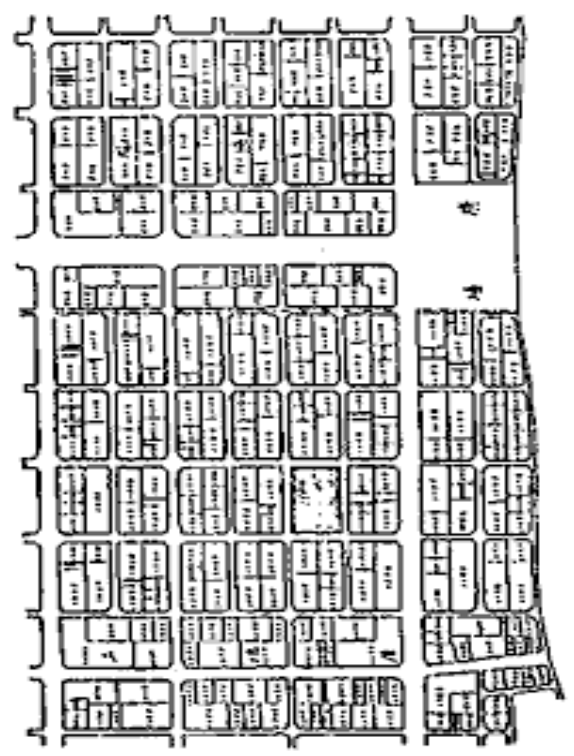

Source: Archer (1983), Doebele (1982), Farvacque and McAuslan (1992).

A land information system provides key information to market participants and the infrastructure to support a land market. Various investors need to know diverse information such as land values, transaction histories, ownership, regulations and environmental information. Basic infrastructure for the land market includes an accurate land map which clarifies lot size and coverage. Land survey in urban areas is generally more complex and may require more active involvement from the central 
government, as is the case in Japan (Box 7). For example, Japan funds a percentage of the cost for municipalities to conduct land surveys. Additionally, land transaction information can bring increased reliability of the real estate market, which will lead to increase of land buyer/seller (domestic and foreign) and speed-up land transactions. It contributes to the co-ordination function of market mechanisms, the fair allocation of benefits from land sales, and the corresponding expansion of the tax base, and help policy decisions in terms of not only land policy but also economic and other related policies. $^{25}$

\section{Box 7. Continuing cadastral surveys in Japan}

In Japan, just after World War II, the government began discussion about cadastral survey and the Law on Land Survey was enacted in 1951. Due to the slowness of the survey implementation based on the voluntary will of municipalities, the government amended the Act and enacted the new Special Law to Promote Land Survey to promote the survey based on the implementation plan. Since 1963, land survey has been promoted by 10-year plan. In spite of spending JPY 200 billion over more than 40 years, 52\% of land is still not surveyed as of March 2008. Current ten year plan (2000-2009) especially promotes survey in densely populated urban areas, which is late behind rural areas. Under the plan, when municipalities implement the survey, the central government and prefecture government contributes to the cost $(50 \%, 25 \%$ each). When prefectures implement the survey, the central government shares the half of the cost. The partial costs of prefecture and municipalities are later compensated by transfer of tax revenue system, decreasing their burden further. The most basic survey (focusing on geographic reference points) are directly implemented by the central government (Ministry of Land, Infrastructure, Transport and Tourism), while prefectures and municipalities develop land registration map based on the reference points. When land survey is implemented, a map based on the survey becomes the official map of land registration office. The official map will be digitised and shared among the related ministries.

Many OECD countries collect and disclose land transaction data such as land price information to encourage economic growth (Table 5). Accuracy of data is indispensable and the speed of information collection is an increasingly important factor. ${ }^{26}$ Policy makers use the information for various reasons. In the UK, financial institutions are required to offer real estate loan contract information to the Financial Service Authority (FSA). The FSA provides every data for Bank of England and part of data to Department of Community and Local Government (DCLG).

25. Because of the recent economic crisis linked with the housing bubbles, policy makers, especially macroeconomic policy makers feel it important to develop economic indexes to get a quick grasp at the change of real estate prices. OECD-IMF real estate workshop was held in Paris, November 6-7, 2006 to establish a guideline for standardise housing prix index. Though not reaching a conclusion, the workshop brought about a consensus about the importance of housing price index as risk management index in housing finance market, decision making index in finance policy, macroeconomic index, a kind of consumer price index and application to System of National Accounts (Dievert, 2007).

26. Usually mortgage information of the bank is the speediest information, but land registry is better in coverage. The reason is that every transaction does not necessarily goes through the bank for mortgage loan. 
Table 5. Collection and disclosure of land transaction price information

\begin{tabular}{|c|c|c|c|}
\hline & Information collection & Information disclosure & Internet use \\
\hline $\begin{array}{l}\text { Australia (State of } \\
\text { Queens land) }\end{array}$ & $\begin{array}{l}\text { Submit contract to land } \\
\text { registration office }\end{array}$ & $\begin{array}{l}\text { Ministry of Natural Resources } \\
\text { discloses the information on } \\
\text { the website of land information } \\
\text { system }\end{array}$ & Yes. AUD8.6/case \\
\hline France & $\begin{array}{l}\text { Submit contract to land } \\
\text { registration office }\end{array}$ & $\begin{array}{l}\text { Land registration office } \\
\text { discloses the contract as part } \\
\text { of the registry. }\end{array}$ & No \\
\hline Germany & $\begin{array}{l}\text { Submit a copy of contract to } \\
\text { land assessment committee. }\end{array}$ & $\begin{array}{l}\text { Land assessment committee } \\
\text { discloses the part of } \\
\text { information. }\end{array}$ & $\begin{array}{l}\text { Yes in the City of } \\
\text { Berlin. EUR7/case }\end{array}$ \\
\hline Japan & $\begin{array}{l}\text { Land assessment committee } \\
\text { collect information of new land } \\
\text { transaction from Ministry of } \\
\text { Justice (land registration office). } \\
\text { Based on that, committee sends } \\
\text { the questionnaire to the buyer } \\
\text { and dispatch the expert to the } \\
\text { site for evaluation. }\end{array}$ & $\begin{array}{l}\text { Ministry of Land, Infrastructure, } \\
\text { Transport and Tourism } \\
\text { discloses the arranged } \\
\text { information on the website of } \\
\text { land information system, so } \\
\text { that unique identification of } \\
\text { each transaction would be } \\
\text { impossible. }\end{array}$ & Yes, Free of charge. \\
\hline $\begin{array}{l}\text { UK (England, } \\
\text { Wales) }\end{array}$ & $\begin{array}{l}\text { Submit contract to land } \\
\text { registration office }\end{array}$ & $\begin{array}{l}\text { Land registration office records } \\
\text { price in land registry and } \\
\text { disclose it. }\end{array}$ & Yes. UKP 2/case \\
\hline $\begin{array}{l}\text { US (State of } \\
\text { Maryland) }\end{array}$ & $\begin{array}{l}\text { Submit contract certificate to } \\
\text { land registration office and tax } \\
\text { office }\end{array}$ & $\begin{array}{l}\text { Tax office discloses tax } \\
\text { information including } \\
\text { transaction price. }\end{array}$ & Yes. Free of charge. \\
\hline
\end{tabular}

Source: OECD adaptation, based on the Jutaku Shimpo (2006).

\section{Conducting land market assessment and monitoring land supply}

Land market assessments can determine how much land and infrastructure are currently available and project how much additional land and infrastructure need to be developed to accommodate urban growth. A wide variety of techniques have been utilised in OECD countries to conduct a land market assessment and monitor land supply. Effective land analysis has allowed policymakers to identify areas that are growing the fastest and given them accurate projections to inform infrastructure development. Without land assessments, policymakers may allocate infrastructure to areas that are not growing and make growing areas victims of their own "spontaneous urbanisation", which can create long-term patterns of congestion and an inefficient built environment. Similarly, monitoring land prices can give policy-makers the information of where land prices are the highest and where land prices are increasing the fastest, which are both critical to local property tax streams. At least four separate tools are at the disposal of land administrations. They include: (a) land inventory, (b) urban land conversion, (c) land supply monitoring tools, and (d) future land use analysis and scenario modelling.

a) Land inventory. All urban planning and monitoring systems must start with an initial inventory of land by type (e.g., vacant or developed; if vacant, developable or constrained; if constrained, relatively or absolutely; if developed, totally unavailable, partially unavailable, or redevelopable). The steps involved in conducting such an inventory include: identifying vacant land and those lands that cannot be developed due to environmental constraints; subtracting land needed for urban public services; adding land that can be redeveloped or developed at greater intensity though infill; identifying serviced land and estimating development capacity (Kaiser et al., 1995). Complex technical and conceptual difficulties arise at each step and relate to the multi-staged process of land development (Figure 35). 
Figure 35. Land development processes

$\underline{\text { States }}$

$\underline{\text { Transition Events }}$

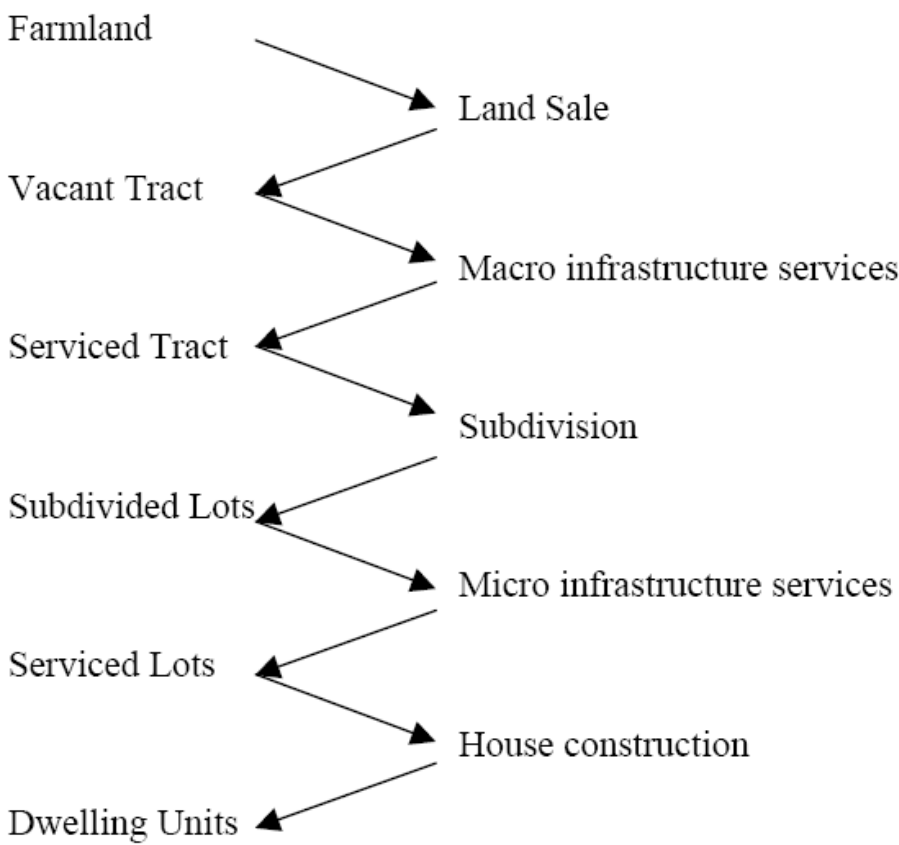

Source: Knaap and Moore (2000).

b) Urban land conversion: calculating the consumption of rural land. Using either aerial photographic survey or satellite image information, it is possible to identify the urban consumption of land and estimate annual requirements for land. Methodologies have been designed to ascertain (a) how the supply of urban serviced land is expanding to meet growing population and employment needs, (b) which land uses are growing the fastest, (c) where urban land conversion is taking place, and (d) where land prices are the highest and where land prices are increasing the fastest (Dowall, 1995). With this type information,

c) Land supply monitoring tools. Land supply monitoring seeks to account for the dynamic aspects of urban growth by estimating the current and future supply of developable land. ${ }^{27}$ To determine which lands are potentially developable, assessments of parcels according to physical constraints, governmental policies and the location of current infrastructure could be made. By combining this information with land use data on vacant parcels, the potential supply of serviced land can be estimated. By comparing the land supply estimates with future demand, assessments of future land market conditions can be made. For example, the number of years of supply of serviced land should be estimated by dividing the annual urban land requirements by the current supply of serviced

27. Developable land is defined as having reasonable access to roads and other critical infrastructure systems such as water and electricity, and is not constrained by physical impediments such as steep slopes, or by governmental limitations on development. Depending on the type of infrastructure and the cost required to extend services, land located within one-half to one kilometre of existing infrastructure should be classified as developable, assuming there are no physical and governmental constraints. 
land. ${ }^{28}$ This information can then be analyzed to determine the spatial patterns of land supply and whether there is sufficient land in high demand areas of the metropolitan region (Berke et al., 2006).

d) Future land use analysis and scenario modelling. Through a systematic land assessment, planning can create and assess alternative land use scenarios. These types of scenarios can be helpful for both master planning and for "envisioning exercises". Using geographic information systems (G.I.S.) modelling will help illuminate the possible effects of several land policies, which may include, but are not limited to:

- increases in the permitted density of existing residential land and in intensity of existing commercial and industrial lands in a zoning ordinance;

- financial incentives for higher density housing;

- reduction of on-site parking requirements in a zoning ordinance;

- reduction of space requirements in a zoning ordinance;

- provisions permitting additional density or intensity beyond that generally allowed in the particular zoning district(s) in exchange for amenities and features provided by the developer;

- minimum density or intensity requirements in a zoning ordinance;

- redevelopment, infill, or brownfields strategies;

- authorisation of housing types or site planning techniques in a zoning ordinance that were not previously allowed by the local comprehensive plan or zoning ordinance

- authorisation of changes in the zoning use classification, including the employment of mixed use zones; and

- changes in standards for public and community facilities or services, including transportation, that require the use of less land.

Sophisticated land use analysis can help policy-makers identify broad spatial trends, which can underpin planning strategies. This usually entails the development and application of planning support systems. This can be defined both broadly, to encompass a range of technology-based solutions useful to planners, and more narrowly as G.I.S.-based models that project urban futures and/or estimate impacts. They typical G.I.S. data set uses both vector data-representing features that have boundaries, such as landmarks, highways, countries, lakes, and watersheds - and raster data, which represents continuous data that has no well-defined shapes or boundaries, e.g. vegetation and terrain. Through this interface, G.I.S. is able to map several databases - employment, infrastructure, housing, etc.- onto particular spatial locations (Figure 36). On a more sophisticated level, G.I.S. is used to create scenarios that model the spatial impact of public policies and allow for the visualisation of data which can reveal relationships, patterns, and trends. G.I.S. is often used in tandem with a wide number of planning support systems to assess the impacts of urban policies. ${ }^{29}$

28. A table showing the annual increase in the stock of serviced land and the annual urban land requirements should be prepared to illustrate whether the current and future supply of serviced land is sufficient to meet urban growth requirements over the next five to ten years. The land supply inventory estimates should be tabulated for each zone.

29. The Land-use Evolution and impact Assessment Model (LEAM) integrates a grid-based cellular automata (CA) approach with regional socioeconomic models. UrbanSim simulates interactions through agents representing persons and jobs, and contains an urban land market at the parcel, zone, and grid-cell levels. Unlike many other simulation efforts, UrbanSim models real estate interactions and prices, and integrates directly with urban transportation models. It has been employed in a variety 
Figure 36. Geographic information systems: overlay analysis of urban poverty in Mexico City

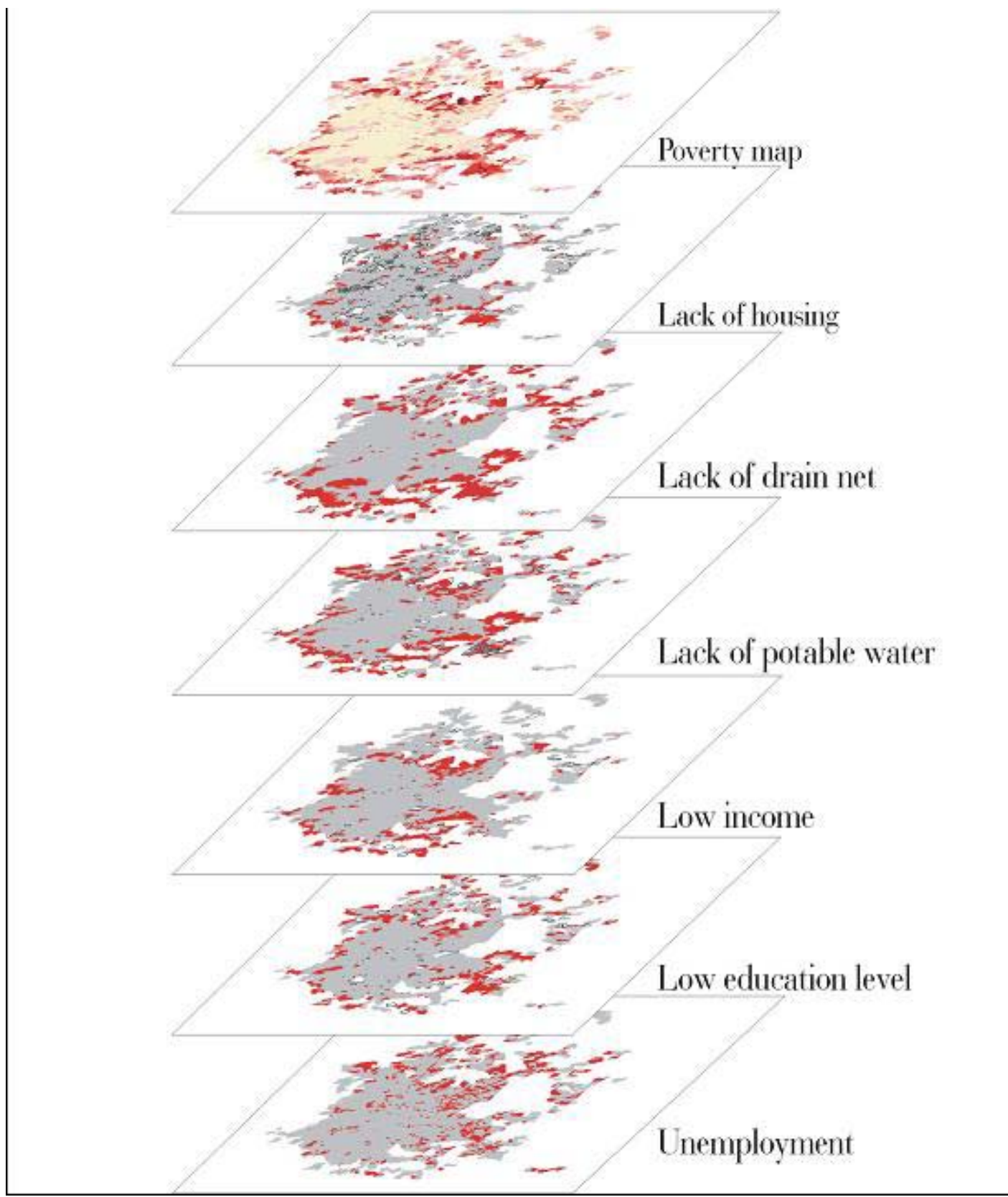

Source: Terborgh, C.J. (2005).

of city sizes and locales, including Brussels, Honolulu, Rome, Salt Lake City, San Francisco, Seattle, Tel Aviv, and Zurich. INDEX PSS contains a set of indicators that can be used to evaluate alternative land use designs in terms of their environmental and sustainable impacts. Coupled to this integrated 2D and 3D framework was an agent-based urban micro simulation model. The Policy Simulator ${ }^{\mathrm{TM}}$ represents an innovative attempt at simulating a city at the level of the individual activities of households and firms. Finally, the SiteBuilder 3D programme in the CommuntyViz software line offers a three-dimensional interactive viewing module (Brail (ed.), 2008). 


\subsection{Using land values for urban infrastructure financing}

Reliance on land revenues can be observed in some OECD countries, with mixed outcomes. For example, the land lease is the largest form of own-source revenues in Amsterdam. This dependence of local government on the land-related revenue causes inter-municipal competition for attracting development in the Randstad-Holland metropolitan area. The city of Amsterdam is reluctant to see new offices, industrial premises, retail construction and even housing go beyond its borders or to cooperate with nearby municipalities (OECD, 2007h). Other local governments in the Netherlands compete in attracting development by selling land at relatively low prices (OECD, 2008d). This competition hinders strategic co-operation among municipalities in peri-urban area and gives rise to unco-ordinated land use development. Municipalities in the peri-urban fringe of many German agglomerations compete with each other by developing new land to attract inhabitants and companies, thereby bringing in gains that are used to finance public services. This dynamic is made possible by municipal autonomy in land-use planning and large demand for undeveloped land; the result is an undermining of sustainable planning principles. In case of Poland, it is observed that because of the increase in land prices, especially around large cities, the surrounding municipalities tend to speculate on land rather than develop a strategic long-term vision on its best use (OECD, 2008g).

Well-designed local taxes on property can stimulate compact development and provide sustainable financing sources for local expenditures. The property tax is the pre-dominant local fiscal revenue source and it is the most important tool for the most of OECD countries to recoup the increased land value due to development. As such it provides a beneficial alternative to land sales or development rights. In most European countries and in the United States, property taxes provide local governments with nearly $70 \%$ of their tax receipts. It is even the sole local fiscal resource in the United Kingdom and Canada. When land values increase after development or infrastructure construction, the property tax also increases. ${ }^{30}$ In many OECD countries, the property tax is used as an effective instrument to link the real estate and public infrastructure finance and also to control land conversion.

The introduction of a property tax can reduce distortions on land markets and stimulate more efficient land use. The tax balance between owning and selling property affects real estate market and land use. For example, in Japan in the 1980s, low property ownership tax rates provided real property asset values with an advantage compared to other assets (e.g. stock or security), which did not encourage owners to develop the land they owned ("having land as asset, without using it"). The increased property ownership tax was effective to control ownership of unused land and the hike of property prices. In Korea, property taxation is based on the transaction rather than the possession of property, thereby acting as a barrier to a liquid property market and efficient land use territorial review (OECD, 2001c). Introduction of a property tax in urban areas, such as in the Guangdong province, could reduce distortions on the land market, reduce sprawl and stimulate compact urban development (OECD,2010a).

In order to finance infrastructure, local governments in OECD countries apply an array of instruments, including Tax Increment Financing (TIF), impact fees, development charges, land conversion fees and related instruments. All these instruments have in common that they use current or future increases of the land value to finance infrastructure in the area. Tax Increment Financing, mostly used in the United States, uses future gains in taxes to finance current improvements: it

30. However, economic growth does not translate very strongly into property tax revenue growth, compared to business tax or income tax. The strength of property tax is rather in its stability and predictability less affected of up down of economy. The drawback of property tax is that it is generally more unequally distributed than income taxes across regions. Metropolitan areas tend to receive larger property taxed due to the higher land prices. 
dedicates the additional tax revenue collected from properties in the district that benefited from the public investment to pay back the cost of public investment, usually over a period of 20 years. Both impact fees and development charges require developers to pay a contribution for the public infrastructure in a certain area: in the case of impact fees for the increase in land values due to infrastructure already in place, in the case of development fees for the construction of the infrastructure in the newly developed area. A land value increase also takes place when the function of the land changes (e.g. from agricultural to building land). Some countries, such as Denmark until 2004, have had taxes to recoup part of the windfall from this land conversion. In several countries however, skimming off these windfalls takes place via other mechanisms. In the Netherlands, municipalities can skim off windfall gains from land conversion through land exploitation agreements, the municipal gain tax and so-called "red for green schemes" (Box 8). ${ }^{31}$

\section{Box 8. Schemes to link land conversion profit to local finance in the Netherlands}

Landowners within a building location can negotiate a land exploitation agreement with the municipality. This agreement sets out which facilities are being developed by the municipality and the contribution that the land owners will pay to the municipality in exchanges for the public services. When owners and municipality fail to agree, the municipality can impose a municipality gain tax on these owners by means of contribution to the municipal services that are rendered. In practice, this gain tax is hardly used because of its complexity and mostly used as an instrument of last resort to avoid emergence of free-riders. Land exploitation agreements and the municipal gain tax can only recover costs of public services that are realised within or very close to the development site. Currently, based on the Land Exploitation Act, the municipality can list all the costs that can be recovered by the municipality and link the cost recovery to the building permit.

Red for green schemes are agreements in which land developers agree to contribute to the creation of green facilities, such as recreational or nature areas that are not in the immediate surroundings of the development site. Though this scheme made cost recovery at the regional level possible, there are several drawbacks to the schemes. First, there is no legal basis, which makes them vulnerable to judicial appeal. Second, as the level of compensation is determined by negotiation, considerable heterogeneity of compensation level exists. First drawback is somewhat solved by the Land Exploitation Act, though it is necessary to prove the relation between the compensation and the area where cost recovery takes place.

Source: OECD (2008d), OECD Rural Policy Reviews, Netherlands, OECD Publishing, Paris.

In addition to raising revenue, these different financing instruments can contribute to more compact urban development. Governments can discourage development through higher development taxes or impact fees in greenfield areas, and encourage development through lower fees in urban areas already served by public facilities. Split-rate property taxes, placing proportionally higher taxes on land than on built structures (described in more detail below), affect land use patterns as they make it more costly to hold on to vacant or underutilised, centrally located sites Development charges also provide the possibility to internalise the externalities caused by suburban sprawl, such as congestion and higher infrastructure costs. An important condition for this is that the charges correspond closely to real costs and externalities. This is often not the case, e.g. in most municipalities in metropolitan

31. There is also a commercial custom that private sector acquires farmland and then strategically sells it to the government at a lower price than normal market price. This is done in order to obtain exclusive building rights on part of the sold land after the government has serviced it. Through this process, the private sector can avoid the high risks $^{31}$ associated with land servicing (Tan et al, 2009). Municipalities also can sell the land to the private sector at the market price for "free" uses and at a controlled price for other uses, in particular social housing (OECD, 2007c). 
Toronto, development charges were levied for the whole municipality, rather than per developed area; the costs of sprawl were thus evened out among all inhabitants instead of charged to the development that was most sprawled (OECD, 2010b).

\subsection{Managing urban growth}

The need to align urban growth and timing of infrastructure building, along with the need to control urban sprawl for improving the environment and increasing efficiency of public infrastructure and service provision has justified the use of urban growth management in OECD countries. Growth management policies anticipate and incorporate the impacts of growth on local infrastructure and environment systems at the scale of both individual developments and larger areas (Pendall et al, 2006). These types of policies are generally classified into public acquisition, regulation, and incentives and fiscal policies (Table 6). The policies are also divided into two streams based on whether they approach the urban sprawl issue from urban policies or open space protection (rather rural policies). They are generally used in policy packages rather than individually implemented.

Table 6. Public Policies for managing urban growth and protecting open space

\begin{tabular}{|c|c|}
\hline Policies for managing urban growth & Policies for protecting open space \\
\hline $\begin{array}{l}\text { Public acquisition } \\
\text { - Fee simple public ownership of parks, recreation } \\
\text { areas, forests, environmentally sensitive areas etc. }\end{array}$ & $\begin{array}{l}\text { Public acquisition } \\
\text { - Fee simple public ownership of parks, recreation } \\
\text { areas, forests, environmentally sensitive areas etc. }\end{array}$ \\
\hline $\begin{array}{ll}\text { Regulation } \\
\text { - } \\
\text { - } \\
\text { regulations } \\
\text { Rate of growth controls (such as building permit } \\
\text { cap), growth-phasing regulations } \\
\text { - } \quad \text { Adequate public facility ordinances } \\
\text { - } \quad \text { zoning } \\
\text { - } \text { Mixed-use zoning } \\
\text { - Uransportation-oriented zoning (TOZ) } \\
\text { - Grban growth boundaries } \\
\text { - Urban service boundaries } \\
\text { - Comprehensive planning mandates (master plans) }\end{array}$ & $\begin{array}{cl}\text { Regulation } \\
\text { - } \\
\text { - } \quad \text { Cluster zoning (incentives often provided) } \\
\text { - } \quad \text { Down-zoning or large-lot zoning } \\
\text { - } \quad \text { Mitigation ordinances and banking } \\
\text { - } \quad \text { Non-transitional zoning } \\
\text { - Concentrating rural development }\end{array}$ \\
\hline $\begin{array}{l}\text { Incentives and fiscal policies } \\
\text { - } \text { Development impact fees or tax } \\
\text { - } \text { Real estate transfer tax } \\
\text { - } \text { Split-rate property tax } \\
\text { - } \text { - } \text { Brill and redevelopment incentives (reduction or } \\
\text { - Historic rehabilitation tax credits } \\
\text { - Location efficient mortgages } \\
\text { - } \quad \text { Priority funding for infrastructure in city centre }\end{array}$ & $\begin{array}{l}\text { Incentives and fiscal policies } \\
\text { - } \text { Right-to-farm laws } \\
\text { - } \text { Agricultural districts } \\
\text { - } \text { Transfer of development rights } \\
\text { - } \text { easemase of development rights, conservation } \\
\text { - Circuit breaker tax relief credits } \\
\text { - Capital gains tax on land sales }\end{array}$ \\
\hline
\end{tabular}

The arguments in favour of compact cities have convinced many authorities to curtail unplanned suburbanisation. Policies to limit urban sprawl seek to improve the attractiveness and the quality of urban core district. Examples of this approach include the French law of 13 December 2000 "Solidarity and Urban Renewal" or the implementation of the Rogers report in London, "Towards an Urban Renaissance" (October 2000). The European Commission (Commission of the European Communities, 1990, 1992) encourages European cities to move towards more compactness, on the basis of environmental and quality of life objectives. The British government has made urban compactness a central element of its sustainable development policy (Department of the Environment, 1993). The Dutch government has taken similar action (National Physical Planning Agency, 1991), as have Australian (Newman, 1992) and North American authorities (Wachs, 1990; Chinitz, 1990). 
Urban management policies have also been utilised to protect open space and farmlands in periurban area. For instance, the German government has advised the reduction of farmland-to-settlementand-traffic-use conversion from the current level of approximately 114 ha per day down to 30 ha per day by 2020 in the "goal-30-ha"plan (Tan et al., 2009). ${ }^{32}$ In peri-urban areas, pressures from the urban environment and industrial activities raise serious problems for the continuity and stability of agriculture, its economic vitality and rural community.

The evaluation of urban growth management policies is a challenging task. First, most policies lack an explicit goal. Very often, the policies have multiple objectives which cannot be easily quantified. Sometimes, the goal changes with socio-economic trends, e.g. from conservation of agricultural land to rural amenity to environmental improvement. Second, it is difficult to acquire data in appropriate geographic scales. The effect of policy sometimes impacts neighbouring jurisdictions. The scale problem is especially a challenge if we try to make an international comparison. Third, the effect of policies spans a long time. For example, usually land use regulation does not have a retrospective effect, which means existing buildings cannot be replaced quickly even when up-zoning or down-zoning is implemented. Fourth, there is a lack of knowledge regarding the counterfactual case. Because land use is affected by many factors (economic-social trend, value system etc), it is difficult to evaluate the effect of the growth management policy independent from those factors (Genaio et al., 2009; Bengston et al., 2004). Fifth, usually growth management policies are adopted in combination with land use regulation and incentives for infill development, which makes it difficult to delineate the effect of one policy from others.

Caution is warranted: inappropriate implementation of urban growth management may cause unexpected and undesirable effects on the region. First, geographical mismanagement may transplant leap-frogged development farther away from the city centre and beyond a controlled zone. Second, the lack of enough incentives to replace existing buildings for up-scaled buildings within strictly limited urban area is highly likely to cause rise of rent and housing price, i.e. affordable housing issue. Segregation by income might happen, with low-income people living in disadvantaged places. Third, growth control might decrease potential for economic development by limiting the physical place for investment. ${ }^{33}$ In sum, distributional effect and impact on economic efficiency should be taken seriously to achieve political consensus for the urban growth management policy.

OECD member countries have developed policy tools-development moratoria, rate of growth controls, and adequate public facility ordinances (AFPOs) - to control the speed of urban growth and complement it with infrastructure development. Development moratoria are usually implemented through a prohibition on the issuance of building permits. The regulation is generally temporary and used in rapidly growing communities to have enough time for thinking about solutions to growthrelated problems. Rate of growth controls or "growth-phasing regulation" are milder policy than development moratoria and are generally implemented by controlling the number of building permits, especially in rapidly growing communities. While rate of growth controls put an upper limit on the

32. Likewise, the European Economic and Social Committee on "Agriculture and peri-urban areas" stresses the opportunity to consider them as "rural areas that face specific and characteristic constraints that set them apart from other rural areas, and whose survival is seriously threatened" (EESC, 2003).

33. Strong regulation also has effect on limiting competition between existing and new business. Zoning's impact on retail market competition is widely discussed in policy and academic circles (in case of the United States and Finland, see OECD (2008a), "Working Party No.2 on Competition and Regulation: Competitive Effects of Regulations of Real Property-United States-“, presented at 18 February 2008, DAF/COMPM/WP2/WD (2008)11 and OECD (2008b), "Working Party No.2 on Competition and Regulation: Competitive Effects of Regulations of Real Property-Finland -“, presented at 18 February 2008, DAF/COMPM/WP2/WD (2008)3. 
number of building permits issued annually, growth-phasing regulation translates the availability of public facilities into a maximum number of building permits in a given year. AFPOs link the availability of public facilities to the speed of urban development and do not impose building permit caps. AFPOs require that developers demonstrate that adequate public facilities are available or will be available when the impacts of new development occur. The State of Florida in the U.S., for example, requires all local governments to adopt AFPOs for selected local services and facilities (Bengston et al, 2004). include:

Several tools have been developed to control "where" urban growth effectively occurs. They

(a) Public acquisition of land is often carried out for the primary purpose of protecting open space in and around urban areas. This is one of the strongest interventions of government and very often has quasi-eternal impact on urban forms. Nineteenth century urban planners advocated systems of regional urban parks, parkways, and nature preserves (e.g. Boston park system by Frederick Law Olmsted). The popularity of this approach in the United States is indicated by the fact that 30 of the largest 50 metropolitan areas have regional green space plans or are developing those (Brentston et al, 2004). This tool is also widely used across European countries. Public interest of acquisition should be assured in the acquisition process and compensation should be paid for landowners. Though acquisition is the most certain public policy instrument for protecting open space, but it is also the most expensive tool. Not only acquisition cost but also maintenance cost should be included in the policy decision.

(b) Comprehensive land use planning (master plan) has been used as an effective instrument to control disordered farmland conversion to urban land, among them, urban sprawl in many OECD countries. A comprehensive plan is largely a policy statement of the future land use and development goals of a particular jurisdiction. It serves primarily to mitigate conflicts between different land uses and also functions to co-ordinate such related issues as transportation, economic development, housing, parks and recreation (Pendall et al, 2006). The 1947 Finger plan of Copenhagen epitomises such an approach as it combines regulations for land use regulation and transit-oriented zoning. The Plan sought to control sprawl and maintain a compact urban form through a principle of accessibility, i.e. a rule that large office workplaces will generally have to be located within 600 meters of the closest public transportation station (OECD, 2009h). ${ }^{34}$ Such master planning is more popular and established in Europe than in North America or Asia. In France, Germany, and the UK where sustainable urban development is promoted, suburban development is generally strictly controlled by comprehensive land-use planning (Box 9). The common characteristics of the three countries are as follows:

- Authority of municipalities over city planning and land-use control

- Plot-by-plot detailed reviews of the land use

34. The 2007 Finger Plan intends to revive the principle of proximity to railway stations, which was weakened by a lack of regional political commitment during 1990s. It tries to accommodate regional expansion, setting out town fingers with potential for new urban areas and requiring municipal plans to contain provisions for phased development of the new urban zone. However, the plan does not show clear initiatives for concentrating activities and population in the palm area at a regional level. This conflicts with the reality of land use potential of the city of Copenhagen. An additional sixth finger has emerged, the Øresund Bridge to Malmö, Sweden, reflecting the continuing increase of commuting from Malmö (OECD Territorial Review of Copenhagen, 2009). 
- Emphasis on maintaining the status quo; general prohibition of new development in the suburbs

- New development in suburbs must be incorporated in the land-use plan, i.e., new development requires approval in the planning process.

- Regional planning at the regional scale beyond administrative boundary of single municipality, to which a city plan prepared by a single municipality should conform.

- Planning process with emphasis on governance, as consensus building mechanism between related levels of governments, in addition to strong public involvement in the process.

\section{Box 9. Land Conversion in France, Germany and the Netherlands}

In France, new construction is generally only allowed in built-up areas. Construction in areas other than built-up areas is prohibited in principle based on the "le principe de la constructibilité limitée (principle of limiting the possibility of construction)" of national Code de l'urbanisme (urban planning code). However, there are cases that construction in green fields is allowed based on municipality's land-use plan. Municipalities can choose the level of control among several methods. They have the authority to either formulate le plan local d'urbanisme (PLU, a local urban plan which includes detailed land use regulations and sets the zones where the construction is permitted ) or la carte communal (the municipality map demarcating areas where construction is permitted), depending on the context of the municipality. Construction in green fields is only possible when allowed by PLU or by la carte communal, otherwise, municipalities must comply with the national principle of limiting the construction. To set up the PLU and la carte communal, municipalities needs to go through public hearing and cooperational procedure with central government. When actual development does not conform to the plan, it can be legally not allowed to be connected to infrastructure such as electricity and water.

For integrating and co-ordinating policies regarding urban planning, housing, economic development, transport and commerce of multiple neighbouring municipalities, Establishments Publics de Co-operation Intercommunale (EPCl), and association of $\mathrm{EPCl}$ and municipalities can voluntarily formulate and approve Schéma de Cohérence Territoriale (SCOT) covering the area. SCOT is not for regulating land-use, but for setting strategic urban restructuring policy through formulating items such as housing demand analysis, proposal for alignment and sustainable development (plan d'aménagement et de développement durable, PADD), basic guideline for actualising PADD, built-up area maintained, general demarcation of natural and forest area and transportation projects. After taking necessary steps in the public hearing system, the SCOT must be approved by the coalition of municipalities. Municipalities cannot designate area which is open to new development through PLU or la carte communal unless they establish the SCOT and their plan comply with the SCOT. Therefore, the municipalities who want new development in green fields need to establish SCOT. SCOT is a tool for regional coordination while keeping the initiative of municipalities. Not only PLU but also local urban transport plans and housing plans must be compatible with the SCOT in order to be legally valid and binding, Central government (prefet of prefecture) provides support for municipalities by providing related information and checking if the plan (SCOT, PLU, and la carte communal) complies with national rules.

In Germany, The Federal Regional Planning Act (Raumordnugsgesetz, ROG) and Federal Building Code (Baugesetzbuch, BauGB) are the two legal bases for land use planning and development. The plans based on ROG (federal, state, municipal) do not have direct legal effect on the municipal level, whereas the BauGB lays the legal basis of development for municipalities. Municipalities judge the use of each site based on the system of $i m$ zusammenhang Bebauten Ortsteile (built-up areas) and Aus Enbereich (outlying areas), reflecting on the current land-use. According to the Federal Building Code, new construction is prohibited in the outlying areas and development projects in this area are only permissible when social conditions are met or Bebauungsplan (B plan or local development plan designating land-use, density, transportation area, green area etc) allowing the development is formulated. If a new land-use is expected to differ from those in the neighbouring areas, a Bebauungsplan (B plan or local development plan) must be prepared regardless of built-up areas and outlying areas. Municipalities need to go through many processes including approval of parliament and civil participation, and the development must conform to the plan. Alternatively, municipalities can enact a zoning ordinance drawing the line between built-up area and outlying area and when an outlying area has a certain volume of housings and does not have strong characteristics as agricultural land, the outlying area is treated as built-up area and building permit for the built-up area is applied to the area. Approval of the B plan and the ordinance by state government is not legally required but practically co-ordinated between the related levels of governments. Municipalities also 
should create $\mathrm{F}$ plan (Flächennutzungsplan, land-use plan) describing overall land-use policy of municipality area not directly regulating land-use of each plot, normally lasting ten years, and drafted at scale of 1:10 000. B plan is generally drafted at a scale of 1:500 or $1: 1000$ and theoretically its validity lasts forever. B plan must conform to $F$ plan while $\mathrm{F}$ plan practically needs to conform to the following Regional Plan as municipality requires approval of the $\mathrm{F}$ plan by state government.

For regional co-ordination, state government or regional planning association comprising of municipalities should establish Regional Plan. Regional plan generally includes desirable urban structure, desirable open space structure and desirable place or route of infrastructure, though each state defines the regional plan in a different way and has different contents and planning process. Typical examples are cases that state government plans over the functional area covering big city and the neighbouring municipalities. F plan of big city is also regarded as Regional Plan. In addition, multiple neighbouring municipalities can formulate common $\mathrm{F}$ plan (gemeinsamer Flächennutzungsplan) with approval of state government. Lower level plan needs to conform to upper level plan while lower level government needs to participate in the planning process of upper level plan. Co-ordination with the plan of neighbouring state or local government is also legally required. Land use planning at all levels should involve public participation.

In the UK, development rights have been nationalised, and all development needs permit from government. The National Planning Directorate (Office of the Deputy Prime Minister) issues planning policy guidance notes (PPG), to which local planning agencies must adhere. Under the PPG, there has been a two-tier system, with Structure Plans (from 2004 Regional Spatial Strategies in England) at the county or regional level, and Local Plans (from 2004 Development Frameworks) at the municipal level. The regional level Structure Plans set broad guideline for spatial development, and the municipality's Local Plans include detailed development proposals on a land parcel basis. The structure and local plans are evaluated and revised on a 5-year cycle and have a 10-year time horizon.

Three PPG notes were particularly relevant to the issue of urban containment. PPG3 (Housing) set a national target that by $200860 \%$ of additional housing should be on brownfield sites, thus greatly reducing greenfield development. In Local Plans, the search sequence for earmarking of housing sites must start with reuse of brownfields, followed by urban extensions, and then new or expanded settlements beyond the urban perimeter. PPG7 (countryside) asserts that "the countryside should be safeguarded for its own sake" and emphasises landscape character in addition to the more traditional concern with preservation of better agricultural land. PPG2 (Green Belt) expands on the need for wide and permanently designated belts and specifies inappropriate and disallowed development in them.

Source : Policy Research Institute for Land, Infrastructure and Transport, Ministry of Land, Infrastructure and Transport, Japanese Government (2006), Tan et al (2009), Milward (2006), OECD Rural Policy Reviews, Netherlands (2008c)

Unlike European countries, central government in Japan plays an important role in functional zoning, though the local governments strengthen the importance. The five acts ${ }^{35}$ are fundamentally important acts for territorial zoning, which are under the jurisdiction of three different ministries. As these tend to be managed by different departments of local governments, co-ordination has emerged as an urgent challenge. Responding to this situation, Japan's National Land Use Planning Act was enacted in 1974 to integrate the five regulations in comprehensive land use planning. ${ }^{36}$ Higher-level local government (prefecture government) designates Urbanisation Promotion Zone, Urbanisation

35. These include the City Planning Act of 1968, designating Urbanization Promotion Zone and Urbanization Control Zone; Agricultural Promotion Zone Act of 1969, establishing Agricultural Land Zone and Agricultural Promotion Zone where infrastructure building for agriculture is encouraged; Forest Act of 1951, Nature Park Act of 1958 and Nature Environment Conservation Act of 1972.

36. However, land use plan just added another legal procedure to the existing regulations and practically did not have much impact for change. The district which needs strict land use regulation such as Nature Environment Conservation Area is directly designated by the central government. 
Control Zone and Agricultural Promotion Zone in co-operation with municipalities. Co-ordination of urban and rural use in urban fringe is still a challenging issue in Japan (Saizen et al., 2006). ${ }^{37}$

(c) Zoning policies are core techniques to limit sprawl. On the one hand, up-zoning, small-lot zoning, minimum density zoning and mixed-use zoning encourage higher densities in urban areas. On the other hand, down-zoning, large-lot zoning, subdivision regulation, exclusive agricultural/ forestry zoning promote lower densities in rural areas. In rural areas, cluster zoning is also an option. Cluster zoning allows or requires houses to be concentrated together on small lots or a particular part of a parcel of land, leaving the remainder in open space. The undeveloped land may be owned by the developer, a homeowner's association, the local government or non-profit organisation, and may be protected under a restrictive covenant (Bengston et al., 2004). Related with zoning policies, there are more specific regulations regarding land use. For example, right-to farm laws protect farmers and ranchers in peri-urban areas from nuisance lawsuits that may arise from land use conflicts with new suburban residents (Bengston et al, 2004). Such a policy seeks to maintain agricultural activity and rural landscape in peri-urban areas. Policies which limit the establishment of new offices in particular zones provide another example of a zoning tool for urban growth management. ${ }^{38}$

(d) An urban growth boundary (UGB) is a dividing line drawn around an urban area to limit encroachment into surrounding rural areas. It can promote dense urban development within the boundary and restrict development of non-urban land outside the boundary. UGBs and green belt, which will be described later, are not intended to be static, but are adjusted according to new needs, usually every 10-20 years. ${ }^{39}$ UGBs have been instituted in some U.S. states such as Oregon, Washington and Tennessee. Similar zoning is implemented in many OECD countries such as Switzerland and Japan. The evaluation of the UGB depends on the size that UGB contains for urban use. If the containment area is too large, which often happened by political pressure (e.g. case of Switzerland and Japan in Box 10), there is actually no effect for limiting urban growth. If the containment area is too small to sustain development pressure, they may be associated with adverse effects, such as a rise of land prices, and affordable housing problem within the boundaries, and leapfrog type of development beyond the restricted areas.

37. In Japan, unused farmland is more political issue than farmland conversion. The background of unused farmland is that designated farmlands are strictly restricted for land use change, irrespective of the owner-farmer's will. Aging of farmer and unpopularity of agriculture as business increased abandoned farmland. Responding to this issue and need to increase food self-sufficiency, the central government deregulated to allow rental of farmland to individual farmers and corporations in 2009. Similarly, in the UK, landscape aesthetics seem to be the preeminent justification for protecting farmland. Reduced agricultural subsidies and protectionism, and increased free trade in farm products decreased the political and economic significance of the farmland in many OECD countries.

38. For example, from 1965 to 1979, the Greater London Council required firms to apply for "office development permits" before establishing new offices in the London area. In Paris capital region, since 1955, both public and private firms are required to apply for an administrative authorisation. Regulations on office were considerably loosened in 1985 but restored for large offices in 1990. Within specific zones, the government has levied taxes on new offices locating in the Paris Ile-deFrance region since 1982 .

39. Green belt is more often designed to be a permanent barrier to urban expansion. However, practically, green belt is adjusted in accordance with development pressure. 


\section{Box 10. Urban Growth Boundaries in OECD countries}

Portland, State of Oregon, United States: The UGB of Portland is the boundary delineating the urban area from the countryside and includes within its boundaries an adequate supply of land for 20 years of development. ${ }^{0}$ In the outer-boundary, the development is generally prohibited. The UGB is to promote effective use of built-up area, effective provision of public infrastructure and services, and conservation of good quality agricultural and forestry land. Land Use Act of Oregon State in 1973 required municipalities to set the UGB. The UGB of Portland was approved by the metropolitan area parliament in 1979 and State government in 1980. Organisation called METRO manages the UGB of Portland metropolitan area (the three counties and 24 cities). The expansion of the UGB is only allowed in the designated area called urban reserve. The necessity of expansion is basically considered every five years and must be approved by state government. Urban reserve contains developable land in future (30 years of land supply for development).

Switzerland: The Swiss Land Use Plan is mandated by the Federal Law on Spatial Planning and developed by each canton. The Cantons design a structure plan (Richtplan) that covers their entire area and vision future spatial development. The structure plan must be approved by the Federal Council. Land Use Plans, designed by municipalities and are subject to the above-level structure plan, regulate detailed land use and set the boundary between building zones and non-building zones. The boundary is evaluated and adjusted to new needs every $10-$ 15 years. Gennaio et al (2009)'s analysis on four municipalities in the metropolitan area of Zurich revealed that the building zones originally instituted in the 1960s were extremely large due to the optimistic population projections and political reasons. Reduction of the building zone is rare in Switzerland because the municipality is required to pay the landowners for lost opportunity caused by the increased land use regulation.

Japan: Japanese economy grew rapidly in the 1960s. People kept flowing into cities from countryside during 1960 s and such rapid migration brought about uncontrolled land use in the suburbs, especially in the three metropolitan areas of Tokyo, Osaka and Nagoya. Japan's City Planning and Zoning Act was enacted in 1968 to control the situation. The image based on the European and North American planning traditions, was to separate urban areas (Urbanisation promotion areas) from surrounding rural areas (urbanisation control areas). Urbanisation promotion areas included existing urban areas and areas that should be urbanised within ten years. Given pressure by landowners, vast urbanisation promotion areas were designated. Consequently, a number of fragmented farmland still remain in urbanisation promotion areas.

Note: Developable land estimation is based on not only density regulation but also infrastructure capacity and environment impact.

Source : Yokohari et al (2000), Gennaio et al (2009).

(e) Though the name is different, green belt policy is a kind of UGB. Unlike the UGB which is a line, a green belt is a zone which divides a city and its surrounding countryside. Strict regulation of land use change is enforced in a green belt, sometimes accompanied with public or non-profit acquisition of open space or development rights. Green belt has a long tradition as a planning notion since the breaking-up of most European city walls in the $18^{\text {th }}$ and $19^{\text {th }}$ century (Kühn, 2003). The greening of former wall areas constituted boundary zone between city and countryside. At the end of $19^{\text {th }}$ century when industrialisation of the UK has caused negative externalities in the UK cities, Ebenezer Howard created a famous urban planning model called "Garden City", a city surrounded by a Green belt, which consists of an agricultural and recreational zone. In the UK, Green belts have been integrated in national urban policy during the $20^{\text {th }}$ century. Many European cities such as Vienna, Barcelona, Budapest, and Berlin have followed the tradition. The concept was transferred to nonEuropean cities such as Hong Kong, Seoul, Tokyo, Toronto, Vancouver, Washington DC, Chicago, Boulder, Sydney and Melbourne (Kühn, 2003; Tang et al., 2007) (Box 11). The rationales for the designation, the significance, policy effect are diverse among cities. For example, Tang et al (2007) argues that Hong Kong green belt is a "transitional zone", where development permissions are given rather in ambivalent and flexible way. ${ }^{40}$ Buxton and Goodman (2003) analysed that the green belt in

40. Hong Kong's green belt policy is deeply affected by British planning tradition and dates back to a proposal by Sir Patrick Abercrombie, a proponent of the Greater London Plan. Green belt was first crafted as "recreation place", and then in 1965, it was formally adopted in Colony Outline Plan as "residential development space". Only after 1980s onwards, green belt was given the character of 
Melbourne was considered by many planners as a "holding zone for possible future urban development". In the Netherlands, the concept of green belt took a different shape where there is not only a sort of green belt policy around major cities, but a spatial plan for the whole country.

\section{Box 11. Green belt policies in OECD countries}

Ontario, Canada: In Canada, land use is a provincial responsibility and each province has its own legislation, policies and programmes regarding land management and use. Ontario, centred around Greater Toronto metropolitan area (GTA), is the most populous province in Canada. The Green belt Plan, which was established under the Green belt Protection Act of 2005, was initiated o address the following issues: urban sprawl; preserving agricultural land; and environmental protection. The plan limits development only in a designated portion of rural land in close proximity to the GTA. The designated land consists of approximately 1.8 million acres, consisting of designated protection land under the Niagara Escarpment Plan of 1973 and the Oak Ridge's Moraine Conservation Plan of 2001 and newly designated land to make a continuous band around the largest urban concentration in Canada.

Seoul, Korea: The Green belt surrounding Seoul is designated on a $15 \mathrm{~km}$ radius surrounding densely inhabited areas of the city. The land areas totals $1567 \mathrm{~km}^{2}, 29 \%$ of the National Capital Region. In the green belt, all development activities are prohibited in principle and only those limited projects listed in the regulations can be permitted only by the head of the related local authorities. It was largely imposed for military reasons rather than simply urban containment and countryside protection (Yokohari et al, 2000). The Green belt was supposed to serve as an "oxygen tank" to ensure minimum natural preservation and is regarded as one of few successful green belt experiences in Asian mega-cities. However, the evaluation of green belt policy in Seoul was controversial. It is assessed to have driven a part of the population out of the city but most of out-migrant seem to have simply leap-frogged into the surrounding capital region, creating the satellite cities. Due to higher commuter flows into outer suburbs, infrastructure costs increased while traffic congestion and air pollution were exacerbated. The Green belt also resulted in an artificial scarcity of developable land, which led to higher prices of land and housing. The government is progressively releasing land use regulations and Seoul is looking at its own ways to absorb negative externalities.

Randstad-Holland, the Netherlands: The Randstad is the most urbanised part of the Netherlands and contains the major cities of Amsterdam, Rotterdam, Utrecht, the Hague and Delft as well as a number of satellite urban areas. The green spaces surrounded by urban belt are often called as "the Green heart", embedded between several cities and are used for recreation of urban citizens. Dutch spatial policy established eight buffer zones in the region in 1958 as a way to control urban sprawl and maintain green space (Green heart). While there has been continual pressure for urban expansion, there continue to be considerable amounts of green space for a large urban population. A key factor to success is strong land-use controls accompanied by government purchase of land. On acquiring land, the government guarantees that its use will not be changed. This combined with a comprehensive land plan that originates at the national level and is reinforced at the provincial and local level, assures that development pressures are shifted away from land designated as greens space. The Green Heart has the status of a national landscape since 1998. The policy with respect to national landscape is that their natural and cultural/historic qualities should be maintained and if possible be strengthened, in combination with their significance for recreation. The three provinces concerned (North and South Holland and Utrecht) have come up with a Green Heart programme and the central government co-funds this programme. Symbolic and innovative development plans have been formulated that are essential for the Green Heart. Green Heart occupies about $1500 \mathrm{~km}^{2}$

Source: OECD Territorial Review of Seoul (2005), OECD Territorial Review of Randstad-Holland (2007), OECD Territorial Review of Canada (2001), Kühn (2003) and Yokohari et al. (2000)

"conservation place". However, the development control has been much more relaxed than "conservation area" and "country parks" where every kind of development is completely frozen. Under enormous development pressures, the town planning board had an incentive to approve landuse conversion on the green belt, provided that the development proposal is technically acceptable. Unlike the direct management of the country parks by the Country and Marine Parks Authority, the town planning board does not have the resources to provide, manage and maintain the landscape features and facilities on the green belt. The green belt takes up 13\% (13 900ha) of the land in the territory in a "compact and land-deficient city which is constantly under development pressure" (Tang et al, 2007). 
(f) Urban Service boundaries (USB), like urban growth boundaries, consist of a line drawn around a city or metropolitan area. A USB delineates the area beyond which certain urban services such as sewer and water will not be provided. They are often linked with adequate public facilities ordinances that prohibit development in areas not served by specific public services and facilities. Some metropolitan areas using USB adopts tiering systems that attempt to direct public infrastructure into new areas in a particular sequence (Bengston et al, 2004). Priority funding areas initiative in Maryland in the U.S. also reflects a concept of tiering systems of infrastructure services, focusing investment in the city centre.

(g) Split-rate property tax, placing proportionally higher taxes on land than on built structures, seeks to make it more costly to hold on to vacant or underutilised, centrally located sites. Distortions created by the property tax may result in the inefficient spatial expansion of cities, which makes the tax one possible causes of urban sprawl (Brueckner and Kim, 2003). Reducing the total tax burdens on land-intensive development and redevelopment could facilitate revitalisation and the replacement of obsolete buildings in older central cities. The effect is to reduce the tax burden on land-intensive uses (e.g. apartments) and increases the tax burden on land-extensive uses (e.g. parking lots) (Bengston et al, 2004). This form of tax is implemented in Sydney, Hong Kong, the U.S. cities of Pittsburgh and other cities within OECD countries such as Denmark and Finland. However, because the split-rate tax also might provoke premature land conversion in outlying areas, effective regulatory mechanisms should be designed to avoid unintended consequences.

(h) Use-value tax assessment in peri-urban areas provides landowners with an incentive to maintain agricultural use, because land is taxed at a lower value rather than the higher values associated with development uses. This policy typically includes requirements that the owner be actively engaged in farming (Bengston et al, 2004). In part of some Japanese metropolitan areas including Tokyo, designated farmlands are levied with a lower property tax.

(i) Brownfield redevelopment can facilitate the reuse of industrial lots in cities. Incentives for developers can encourage high-density urban development in city centres, but this development must still respond to demand. On the one hand, there are many barriers for redevelopment, such as expensive land prices, demolition cost of existing facilities, and limited land use by zoning regulation and cleanup costs. On the other hand, there are many benefits from brownfield redevelopment, such as urban revitalisation, increased asset value of the site and the surrounding site, increased tax base, increased employment, environmental protection, effective use of existing infrastructure and prevention of urban sprawl. Many OECD countries such as the U.S., Canada, EU countries actively promote brownfield redevelopment as an important policy that contributes to sustainable development (Box 12). 


\section{Box 12. Examples of Brownfield policies in OECD countries}

The US: The US classifies the Brownfield sites by externality (social and economic), contamination risk and degree of emergency. In 1980, the US government enacted the Comprehensive Environmental Response, Compensation, and Liability Act (CERCLA), commonly known as Superfund. This law created a tax on the chemical and petroleum industries, and the tax went to a trust fund for cleaning up abandoned or uncontrolled hazardous waste sites. The CERCLA established regulation regarding closed and abandoned hazardous waste and made clear the liability of persons responsible for releases of hazardous waste at these sites. Because of the strict regulation, developers and financial institutions preferred to remain hazardous site untouched and preferred Greenfield development. Many state governments responded to the problem by providing economic incentives and liability exemption to developers. Pushed ahead by the state governments, federal government enacted Brownfield Act in 2002 to support the activities of state governments. As shown in the Table A, Brownfield site usually does not have high contamination risk. The rationales of support come from not only environmental purpose but also economic impact on the region. According to EPA, EPA's investment in the Brownfield's Program has resulted in many accomplishments, including leveraging more than USD 6.6 billion in brown fields cleanup and redevelopment funding from the private and public sectors and creating approximately 25000 new jobs.

Table A. Classification of brownfield in the US policy

\begin{tabular}{|l|l|l|}
\hline & \multicolumn{1}{|c|}{ Large externality } & \multicolumn{1}{c|}{ Small externality } \\
\hline $\begin{array}{l}\text { Large contamination risk \& } \\
\text { high degree of urgency }\end{array}$ & Superfund sites & Superfund sites \\
\hline $\begin{array}{l}\text { Small contamination risk \& low } \\
\text { degree of urgency }\end{array}$ & $\begin{array}{l}\text { General brownfield site with } \\
\text { public investment for } \\
\text { redevelopment }\end{array}$ & $\begin{array}{l}\text { Site with small prospect for } \\
\text { redevelopment: environmental } \\
\text { control only }\end{array}$ \\
\hline
\end{tabular}

The UK: As the World's first industrialised nation, Britain experienced rapid urban growth. Scale of land contamination is large reflecting the past history of industrialisation in the city. Increasing housing needs in the city centre to protect rural landscape in peri-urban area increased the attention on brownfield development. The UK government increased the brownfield development targets for regional/local planning authorities from $50 \%$ to $60 \%$. In the UK, contaminated land has been dealt with primarily through the part IIA of the Environment Act of 1995 and the development permit process of land use planning. Similar to the US, the UK takes risk-based decision making approach by using a source-pathway-receptor pollutant linkage concept and soil guideline values as the standard for the decision-making about the need for remediation, and suitable use principle as the standard for remediation. The needs and level of remediation is decided case by case, taking into consideration the existence of harm and the possible impact of the harm on the other factors (e.g. human health, ecosystem). Government provides tax incentives and other financial aid (e.g. dereliction aid and gap funding scheme) to get rid of great barrier for brownfield development which usually needs higher financial development costs than green field development.

Table B. Classification of brownfield in the UK policy

\begin{tabular}{|l|l|l|}
\hline & \multicolumn{1}{|c|}{$\begin{array}{c}\text { Significant harm, } \\
\text { pollution of controlled waters }\end{array}$} & $\begin{array}{l}\text { Less than significant harm, no } \\
\text { pollution of controlled waters }\end{array}$ \\
\hline $\begin{array}{l}\text { No immediate prospect of } \\
\text { development }\end{array}$ & Part IIA sites & No action \\
\hline $\begin{array}{l}\text { Immediate prospect of } \\
\text { development }\end{array}$ & $\begin{array}{l}\text { Part IIA sites } \\
\text { Planning permit process }\end{array}$ & Planning permit process \\
\hline
\end{tabular}

Source : US Environment Protection Agency (http://www.epa.gov/brownfields), Luo et.al (2009).

(j) In peri-urban areas, transfer of development rights (TDR), purchase of development rights and conservation easements are often used as incentives to protect open space. These policies are based on the concept that ownership of land involves a bundle of rights that can be separated (for example, surface rights, air rights, and development rights). TDR allows for the sale and transfer of 
development rights from a particular parcel of land to other properties. Future use of the original parcel is then protected from development by means of a permanent conservation easement or deed restriction prohibiting development. This is a kind of compensation for the landowners for regulatory restrictions that reduce property values. Government, non-profit organisation for protecting open space are potential purchaser of development rights (Bengston et al, 2004). Administrative complexity is a drawback of this policy. In the U.S., federal government supports purchase of development rights of state governments.

\section{Building up competitive cities}

Cities in OECD have undergone important changes and registered high economic performance. However, not all cities are successful, a group of cities systematically falters for a number of socioeconomic indicators. This raised at least two main questions for national policy-makers:

- (i) What are the best policy instruments to foster urban competitiveness?

- (ii) How to build competitive cities while ensuring that others do not fall into neglect?

\subsection{Fostering competitiveness and innovation in urban regions}

The assumption of the new regional policy paradigm is that implementation of regional development policies involves integration of three core sectoral policies (OECD, 2009i):

- The capital stock dimension: essentially the level of past and present investment in a region's infrastructure. From a regional development perspective in OECD countries this has tended to mean transport infrastructure, while in less developed countries it also implies infrastructure for basic needs. More recently, ICT infrastructure has become a key target.

- The labour market dimension: this includes policies relating to both the labour market - for example, (dis)incentives for labour mobility and participation in the labour market - and human capital development.

- $\quad$ The business environment dimension: this covers a range of policies designed to support firms, such as cluster policies, policies to promote links between research and industry, and, in particular, promotion of innovation in regions.

Implementing this principle in the urban policy families require acknowledging diversity, i.e. differentiate among urban regions (metro-regions, smaller cities, cities in industrial transition, etc.) and recognising the regional dimension.

\section{The capital stock dimension}

Infrastructure investment in physical capital plays a crucial role in urban development. The expectation that improvements in physical infrastructure will generate productivity gains for local businesses and increase the attractiveness of an area for investment has been a recurring theme in OECD reviews. High quality infrastructure and services are accepted as being vital to a strong economy - locally, regionally and nationally. To take the example of transport, upgrading infrastructure changes access (travel times) which, in turn affects property prices and economic rents, influences decisions of households (residential location, patterns of consumption) and firms (production location, access to markets and investment decisions) and these, in turn, should have a net positive impact on the economy, increase tax revenues, create employment and generate resources for further investment. For business, the benefits could include: 
- Access to a wider labour market pool, with more diverse competencies;

- Faster access to suppliers and customers, which reduces transaction costs;

- Expanded market reach, including choice of suppliers, as well as expanded customer base;

- Reduction of land use constraints.

Accessibility plays a key role in urban growth. Poor accessibility prevents Ostrava, the third largest city in the Czech Republic, and more generally the region of Moravia-Silesia from attracting a more sizeable share of FDI in spite of its assets (human capital, excellent university and research centres) and strong financial and other incentives for investors.

There are however limits to put on infrastructure. OECD reviews suggest that the construction or upgrading of transportation infrastructure can undoubtedly have a positive influence on a region's economic development, but economic growth is not automatic. Growth effects are likely to appear only when positive externalities exist in the region. Faster transport connections can potentially incite positive externalities that exist in various markets - typically un-exhausted economies of scale, scope, agglomeration, density or network - and consequently improve (labour) productivity, enhance output, reduce production costs and promote more efficient use of resources. If such latent economies do not exist, however, improvements in accessibility could lead to changes in existing transport flows and spatial patterns without having long-term effects on growth.

Whether transport infrastructure becomes a link or a leak depends on a broader strategy - regional policy - that takes into account labour and business dimensions. Infrastructure provision is a response to a market failure: private agents will under-provide or not provide infrastructure. The type of infrastructure thus depends on the nature of market failure. If the infrastructure is a natural monopoly, the private sector would provide it at a lower quantity and at a higher price than the social optimum. The channels through which infrastructure can have an impact on growth are many. Besides new markets and increased competition, it can facilitate the division of labour and therefore specialisation, assist in the diffusion of technology, and complete value chains with intermediate inputs in other regions.

There are several examples of large infrastructure projects in urban areas that need to further take into account the regional economic system. The OECD review of the Öresund region (OECD, 2003c) underlines that the bridge between Copenhagen and Malmö is only one element in a wider strategy to build on the complementarities that have developed between the two regional economies. The challenge for policy makers explicit in the recommendations is to ensure that the potential in the labour market, research community, and enterprise systems is realised. The OECD Territorial Review of Vienna-Bratislava (2003d) provided a similar example: providing infrastructure to link the two centres will not necessarily generate sustainable growth unless policy challenges relating to economic specialisation, innovation and governance could be resolved.

\section{The labour market dimension}

According to the OECD Regional growth model, human capital is even more important than infrastructure as a determinant of regional performance, both as an advantage for regions with a highly educated workforce and as a competitive disadvantage in regions with low educational attainment. OECD analysis shows that in general lagging regions have substantial reserves of un-mobilised labour, indicated by high unemployment rates and low participation rates. Their labour markets function suboptimally over long periods of time without obvious adjustment in terms of either wage rates or outmigration. Hence, there is a structural problem with labour markets in a large number of regions. If the potential supply of labour is chronically higher than the average demand, this suggests that the price of labour is too high, or (what amounts to the same thing) that the human capital and skill sets of all those 
who would be willing to work is too low at the margin to interest potential employers. Moreover, even where incentives for individuals to move to regions with higher demand exist, they do not do so, or not in large enough numbers.

A major policy implication concerns the room for manoeuvre for labour markets to adapt to local conditions. Some level of constraint on the totally free workings of the labour market can easily be justified on social grounds, as well as on grounds of market failure and information asymmetries. Overall, however, the experience gained in the course of the OECD Jobs Study and its follow-ups shows that more flexible labour markets reduce unemployment and create jobs. Employers are more willing to hire, employees fear unemployment less because they are confident of getting another job, and more people at the margins of the labour market gain job experience that makes them more attractive to potential employers. Hence part of the solution for mobilising regional labour reserves in some countries must include reforms of national labour market legislation to make inactivity less attractive, and agreements that allow wages to more accurately reflect regional (and enterprise) conditions. Recent challenges brought by pressures of population ageing, changes in technological advances, globalisation and integration of the labour intensive countries have changed the policy priorities from cutting high and persistent unemployment to removing barriers to labour market participation. The main objectives in the restated OECD Jobs Strategy (Box 13) of reform is to raise employment by reducing unemployment but also by allowing people to move from inactivity into work.

\section{Box 13. The Restated OECD Jobs Strategy}

The sharp rise in unemployment rates in many European countries during the early 1980s presented a clear policy challenge to cut the high and persistent rates of unemployment. Initiatives such as the OECD Jobs Strategy in 1994 responded to this need with a list of ten policy recommendations. Fourteen years later the external conditions and trends in labour markets have evolved, and although rates of unemployment still remain high in several countries, labour market conditions face new challenges mainly the ageing population, changes in technological advances, globalisation and the integration of the labour intensive countries. The restated OECD Jobs Strategy proposes four main lines of actions or pillars to meet these new challenges.

1. Macroeconomic policies must ensure price stability and the sustainability of public finances. The stability of the macroeconomic framework must make it possible for reforms to produce their effects in terms of job creation as quickly as possible, while at the same time reducing the risks of permanent falls in employment in the event of recession.

2. The second line of action is to promote participation in the labour market of the least represented groups. To do this, it is essential to reform the rules on payroll taxes and welfare benefits. To be attractive, work must pay. Unemployment benefit systems and active labour market policies must also facilitate and support the quest for jobs, and lastly policies must be adopted to help the work/family life balance, by providing for child-care services.

3. The third pillar concerns the reform of the regulations on labour markets and markets in goods and services, since this plays an important role in creating jobs and mobility. Reforms in this area have proved difficult since they are often perceived by workers as a threat to job security.

4. The last line of action involves human capital, concentrating on promoting education systems which, beyond providing basic schooling, should also encourage close links between education and work. Such systems facilitate the transition between school and working life, and reduce youth unemployment. In addition the most highly-educated workers have the best employment prospects. Lifelong learning does not just promote growth and employment alone; it is also a factor for social progress.

The restated Jobs Strategy must be adapted to different national social preferences since there is no one path for reform: some successful countries, such as the United States, combine low welfare benefits and payroll taxes with fairly light job security legislation. Other countries such as Denmark and the Netherlands, offer generous welfare benefits while at the same time imposing strict obligations on job-seekers to actively look for work. In these countries, employment levels are high and income disparities low, but the budgetary costs involved are considerable.

Source: OECD (2006) Boosting Jobs and Incomes: Policy Lessons from Reassessing the OECD Jobs Strategy. 
Strengthening regional labour markets will normally be a more successful policy option than encouraging people to move. Labour is neither fully fixed nor fully mobile because there are systemic and personal barriers to migration. Standard neo-classical theory treats labour as mobile and in many theories capital is considered to be fixed. In reality, both factors are quasi- fixed in the short term, and in the long run it is not clear whether mobility is fully achieved in either case. Economic intuition says that labour responds to wage differentials among regions. In the US, traditionally the exemplar of high labour flexibility, labour mobility is positively associated with unemployment rates, implying that American workers respond to job opportunities elsewhere by moving, though even here mobility is sticky. In most other countries, labour mobility is relatively low and represents a very imperfect adjustor to changes in the labour market.

In recent years, there has been a shift in labour market policies from national-based to more active, area-based approaches. These reforms have widened the economic and social responsibilities of local government authorities and given more freedom to managers of local public employment services in the design and implementation of programmes. The local level has a particularly important role to play in addressing skills and productivity challenges. At this level it is also possible to focus on a limited number of industry sectors and clusters within a relatively homogenous economic environment. Regional or area-based labour market initiatives can lead to smarter prioritisation and sharper targeting of those more in need of support for employment search. Also on the demand side, it is at the local level that employers can determine some common needs, and where labour market authorities locally can have direct contact with employers and economic developers, while keeping track of local social issues and the situation of various vulnerable groups. An example of this shift to more spatially focused labour policies is Glasgow, which developed an Employment Zone and an Action Team for Jobs, followed by a Pathways to Work pilot and a Working in Neighbourhoods pilot. ${ }^{41}$ These initiatives can be regarded as positive developments, as they offer more personal advice and help to prepare people for work in a most effective way with respect to standardised national policies.

During the past few decades, national governments in several OECD countries have restructured their workforce development systems and economic development programmes in order to be more responsive to the needs of local businesses and workers. The United States provides workforce development services through a strong federal-state-local partnership. The UK's Regional Development Agencies offer another example of integrated workforce development policies, giving local authorities considerable flexibility in how they use their resources. The National UK Jobcentre Plus, for example, works closely with local partners through Local Area Agreements (LAAs), which are in charge of setting out priorities in agreement with other key partners at the local level, and represent the key vehicle for labour market policy delivery. In Italy, the Veneto Region is engaged in a series of educational projects to improve labour-market efficiency in the Venice city region (OECD, 2010c). It monitors labour market trends, run the Veneto employment information system and work on innovative projects both in the context of the enlarged Community market. The first nationwide online labour matching system, Veneto Job Exchange, has been put in place to improve employment prospects in the region.

Several cities in OECD countries face severe labour shortages. Two main types of policies have been implemented at the city-level to address these shortages: i) policies to raise labour force participation, targeting in particular women and groups with low participation or attempting to draw back older people into the labour force; ii) international recruitment. "Residents not in employment"

41. See the information on Glasgow and other UK cities on http://www.jobcentreplus.gov.uk/JCP/index.html 
represent a latent skill resource that several OECD cities are trying to harness. In Manchester, the new City Strategy is targeting 93 neighbourhoods in the city where economic activity is lowest, aiming to increase engagement with workless residents, and access to training and skills provision. The Open Cities initiative, involving the cities of Madrid, Bilbao, Cardiff, Belfast and Dublin, is helping cities to identify factors which can make them more attractive to skilled international migrants (OECD, 2009b). The City of Malmö has succeeded in attracting foreign population through a large number of investments in physical (the bridge connecting the city to Copenhagen, an underground system, new up-market residential developments) and knowledge (a new university) infrastructure (OECD, 2009h). Interestingly, some rapidly growing Chinese cities are also developing policies to attract and retain skills. For instance, the Shanghai municipality launched a detailed "Action Framework for Implementing Shanghai Talent Strategy" in 2004. The new action framework defined ten priorities to be addressed between 2004 and 2010, including expansion of tertiary enrolments and retention of highly skilled local and expatriate workers. A number of policy incentives and instruments, and new institutional setups were designed and managed in order to implement the Strategy. By 2006, Shanghai had issued 49 local regulations regarding the promotion of talent development.

Another major policy implication is that investing in human capital is a key element of public investment for regional development. For a long time, it has been neglected in regional policies in favour of investment in hard infrastructure. Now the situation has changed radically, with human capital development being a core component of spending within regional strategies. For example, in line with the Lisbon Strategy objectives, EU structural funds in Poland are being channelled towards improving human capital (education attainment and quality of education) through the Human Capital Operational Programme that accounts for $14 \%$ of the funding (OECD, 2008g). Similarly, the EU has approved Portugal's National Strategic Reference Framework which enables the country to allocate almost $30 \%$ of EU structural funds to human capital development (OECD, 2008h). Chile is another country that has made generalising access to quality education a national priority, including efforts to ensure that municipalities with limited fiscal resources are also able to improve educational provision (Box 14).

\section{Box 14. Generalising access to education in Chile}

The economic value of ensuring good access to quality education at all levels for all citizens has been recognised by the government of Chile, which has made improving Chile' $s$ human capital a priority in its efforts to encourage growth in the medium and long term. The section of Chile's population aged between 25-64 had, on average, benefited from less than ten years of schooling in 2002, compared with the OECD average of nearly 12 . In addition, the quality of education in Chile is also below OECD standards according to PISA international standardised tests. Tertiary education rates also remain below the OECD average. Overall income and territorial inequalities are closely tied to inequalities in access to education. Those in the top quintile of income earners have close to five more years of education than those in the bottom quintile. At the same time, standardised tests of education performance (SIMCE4 results for primary and secondary education) reveal that students from the poorest families perform worse than those from families with higher incomes. Close to $70 \%$ of the poorest students attend municipal schools and challenge the capacity of municipalities to provide adequate primary and secondary education, one of their main devolved responsibilities. Moreover reasonably qualified students from low and middle income backgrounds who could be successful in university have restricted access to higher education because of financial barriers to entry.

Source: OECD (2009g), OECD Territorial Review of Chile, OECD Publishing, Paris.

Often, however, the regional development dimension of educational provision has to address the concern that, by diffusing provision widely across the territory, quality is reduced and costs increase. If policy objectives are geared towards providing an equitable access, the system will find difficulties 
in replicating quality training everywhere. In addition, an equity-oriented system may run the risk of up scaling human capital in less favoured regions only to see a brain-drain towards more successful ones. In contrast, the result of a system oriented towards elite systems is likely to directly favour core regions. One possible solution to the problem is, in addition to setting up a system that is both equitable and qualitatively sound, it also takes into account part of the population that is highly attached to their regions of origin. Adult learners usually have links to a specific locality, and therefore are less mobile than younger students. Upgrading their skills will thus have a more direct effect on the region's economic performance. Programmes should be flexible enough to spur on-the-job learning such as in the French Conventions CIFRE or the British Knowledge Transfer Partnership, e-learning and distant learning frameworks, to take into account non-traditional learners, those who combine work and study, and the needs of the employers. The key question for urban regions is to find policies that can encourage, retain and attract human capital despite strong competition for increasingly mobile skilled workers. It is unavoidable, however, that spillovers from one region to another will dilute the direct impact of educational investment or job creation within the region making the investment. These spillovers can be quite large, and, where they favour core regions, can also sometimes run counter to policy aims such as that of reducing concentration or diffusing economic activity more widely.

\section{The business environment dimension}

If the regional business environment is not dynamic and innovative, economic benefits from infrastructure and human capital investments are unlikely to accrue in the target region: infrastructure will promote leaking and trained individuals will move to where more dynamic businesses are located. Therefore, this dimension is crucial for an effective regional policy. Regional policy has in the past often been focused on bringing in FDI and providing subsidised facilities for investors and/or for new firms. More recently, the focus has moved to making domestic firms more competitive, and this led to interest in cluster policies and similar instruments to build co-operation and exchange among firms, particularly SMEs. The focus has now shifted towards innovation, with the emergence of specifically regional innovation policies.

Although policies and research have tended to focus on innovation in research hub and success stories, there has been an increase in interest on promoting innovation in areas that are not core R\&D centres. Finland introduced a specific urban policy to foster innovation and growth of its eight largest city-regions (excluding Helsinki) in 1994 initially called the centre of expertise programme (CoE), and reshaped under the name Regional Centres Programmes (RCP) in 2001. This policy was a regional policy with a balanced territorial development objective but with a clear recognition that a certain degree of concentration is needed to reach a minimum critical mass in that it includes, as a main objective for the allocation of funds, more collaboration (and thus economic integration) between a core city and its neighbouring municipalities (OECD, 2005c).

Innovation through cluster policies remains a popular response. Despite a certain level of "cluster fatigue" in academic and policy circles, national programmes using a cluster model continue to be introduced, and in some cases are becoming more prominent on the policy agenda. The concept of clusters has been adapted and revised to a wide variety of new contexts and is often a bridge between regional policy and national science and technology or innovation policy (OECD, 2006f).

Policies for the encouragement of clusters have proliferated over the past decade, with manifestations ranging from policies to encourage low-resourced, small-group business networks without a particular sectoral focus to complex, large-scale programmes of co-ordinated measures that target a specific, geographically cohesive industry. There have been many examples, with varying success, of public policy targeted at the cultivation of clusters. Table 7 lists some examples implemented in different types of metropolitan regions and in some smaller urban areas. These cluster 
strategies vary in terms of their prioritised competitive industry, focus and policy tools. The table suggests that an industry approach has been widely accepted as an effective tool of local (and in the UK cases national) governments' targeting competitive industry groups as a way of building and strengthening metropolitan competitiveness. Specific cluster policies and focuses however vary. For example, given the differences (strengths and weakness) in their metropolitan clusters, the TAMA association in Tokyo stress the importance of fostering SME growth and building university-firm linkages whereas the Montreal metropolitan region takes a more comprehensive approach, ranging from identifying industry clusters, developing action plans and preparing a regional innovation strategy (Box 15).

\section{Box 15. Examples of different metropolitan cluster approaches and focuses}

TAMA (Technology Advanced Metropolitan Area) Association in Tokyo. TAMA is an association, founded with the encouragement of the Ministry of Economy, Trade and Industry (METI) (particularly through the Kanto Regional Bureau). The association focuses on the revitalisation and development of industries located in the western parts of the Tokyo metropolis, creating new technologies, products and businesses. Between 1996 and 1998, the TAMA association was created to link almost 200 enterprises and a large number of other actors in a range of joint activities designed to enable these small or medium sized enterprises to access new technology, market information, product development facilities and export information, among other things. In establishing TAMA, its industrial and governmental founders, considering the local circumstances and potentials, referred to models elsewhere, including the Greater Washington Initiative (a public-private regional development organisation in Washington DC and parts of Virginia and Maryland). The TAMA region, which stretches over three prefectures and 74 municipalities, contains more than 300000 small businesses and about 40 universities. Of these, about 300 area companies and 34 universities are members of the TAMA association. The association promotes industry interaction and seeks to strengthen traditionally poor industry-university linkages through exchange and joint R\&D projects, with the broader goal of creating synergies that will foster new technological development and commercialisation. TAMA has established a Technology Licensing Office to assist in patenting, licensing, and R\&D commercialisation. The TAMA region has significant strengths in mechatronics, instruments, and control systems. TAMA founders report that they have been successful in raising the concerns of companies in these sectors to policymakers, in catalyzing academic-industry links (important because many of the region's universities are small and not experienced in technology transfer), and in creating a unifying hub in an otherwise fragmented region.

Cluster Development strategy in the Montreal metropolitan region. The economic development of the Montreal metropolitan region, particularly its rebound in the $90 \mathrm{~s}$, has been based on its strong specialisation in a number of clusters. As the first step in developing its cluster strategies, the Montreal Metropolitan Community $2005(\mathrm{CMM})$ - the regional planning body serving 82 municipalities which covers the functional geographical area of the metropolitan region and which is responsible for the planning and the financing of economic development, transport and housing - examined the metropolitan economy and identified 15 clusters essentially based on their degree of development and interlinkages (Montreal Metropolitan Community 2005). These clusters are classified into four categories: (1) competitive clusters (aerospace, life sciences, information technologies, and textiles and clothing); (2) visibility clusters (culture, tourism, and services); (3) emerging technology clusters (nanotechnologies, advanced materials, and environmental technologies); and (4) manufacturing clusters (energy, bio food, petrochemicals and plastics, and paper and wood products). These clusters accounted for 1 280000 jobs (79\% of the total jobs in this area) in 2001 (Montreal Metropolitan Community 2005). The rest of the jobs in this region mainly concentrate in local services industries such as personal services, pubic administration and most health care and social assistance services. These regional clusters have stemmed from their ability to produce high-value added products and services and together created a hub of innovation in the rather diversified metropolitan economy. The first step was launched in the fall of 2003 and finished in late 2004.

The second and third steps involve developing an action plan for each cluster and preparing a regional innovation strategy and are carried out simultaneously. The point of departure in the case of Montreal is that the strategy should take a metropolitan-wide perspective to avoid the risks of heightening the tensions that exist between smaller municipalities in the region and the new largest city of Montreal (OECD 2004d). A second principle of the cluster strategy is that it should address problems of duplication among institutions, streamlining interventions according to an agreed set of priorities. The CMM cluster plan intends to ensure that the entire community is committed to the course of action. The CMM selected a bottom-up approach with the cluster development initiative coming from the firms involved and their institutional partners in development. In addition to building the competitive capital of the clusters, the CMM proposes giving an organisation the mandate to support 
the dynamics of innovation for all the firms, whether they belong to a cluster or not, and to improve the region's overall innovation performance.

In co-ordinating the cluster development plan, the CMM suggests assigning for each cluster a secretariat "to activate the cluster, safeguard the common vision, make good use of the competitive capital, see that the strategic plan is carried out and in the process, help improve the economic growth of the metropolitan area" (Metropolitan Community of Montreal, 2005). The secretariat will provide expertise in research and networking, cluster expansion, innovation and technology, education and training, commercial co-operation and policy action. Further, the CMM has decided to: (1) build an Integrated Transactional Information System (ITIS) to facilitate fast circulation of information among involved cluster partners; and (2) create a Metropolitan Competitiveness Fund through financing from the municipal, provincial and federal governments and the private sector primarily for value-added projects to stimulate and foster cluster development. The CMM, the Government of Quebec, the Government of Canada and the private sector are investing a total of CAD 6 million per year to finance the creation of industrial cluster initiatives as well as value-added projects to make these clusters more competitive and thereby make the metropolitan region internationally competitive. The cluster strategy has been developed with wide spread support and consultation from the CMM's Economic Development Commission (mayors and city councillors), the Technical Committee (Executive directors of the region's economic development corporations), elected officials on the CMM Board of directors and Executive Committee and the representatives of all the municipalities of the CMM, and the public.

Source: OECD (2004d), OECD Territorial Reviews: Montreal, Canada, OECD Publishing, Paris; OECD (2005d), OECD Territorial Reviews: Japan, OECD, Paris.

Table 7. Examples of industry cluster policies in metropolitan regions

\begin{tabular}{|c|c|c|c|}
\hline $\begin{array}{l}\text { Metropolitan } \\
\text { region }\end{array}$ & $\begin{array}{l}\text { Starting } \\
\text { Year }\end{array}$ & $\begin{array}{l}\text { Brand name of the cluster } \\
\text { strategies }\end{array}$ & Targeted clusters \\
\hline \multicolumn{4}{|l|}{ Regular regions } \\
\hline Boston & 2004 & $\begin{array}{l}2004 \text { Comprehensive Economic } \\
\text { Development Strategy by Boston } \\
\text { Metropolitan Planning Council }\end{array}$ & $\begin{array}{l}\text { Knowledge creation, IT, financial services, health care, } \\
\text { traditional manufacturing }\end{array}$ \\
\hline Montreal & 2003 & $\begin{array}{l}\text { Charting our international future: } \\
\text { building a competitive, attractive, } \\
\text { independent and responsible } \\
\text { community (overall metropolitan } \\
\text { strategy) }\end{array}$ & $\begin{array}{l}\text { Competitive clusters (aerospace, life sciences, information } \\
\text { technologies, and textiles and clothing); visibility clusters } \\
\text { (culture, tourism, and services); emerging technology } \\
\text { clusters (nanotechnologies, advanced materials, and } \\
\text { environmental technologies); and manufacturing clusters } \\
\text { (energy, bio-food, petrochemicals and plastics, and paper } \\
\text { and wood products). }\end{array}$ \\
\hline Munich & Various & $\begin{array}{l}\text { Loosely structured cluster policy } \\
\text { programs, including Bio }{ }^{\mathrm{M}}(1997) \\
\text { and Software-Offensive Bavaria } \\
(1998)\end{array}$ & $\begin{array}{l}\text { Mechanical engineering/automotive, } \\
\text { finance/insurance, medical, biotechnology, and aerospace }\end{array}$ \\
\hline \multicolumn{4}{|l|}{ Capital cities } \\
\hline Ottawa & 2002 & Innovation Ottawa & $\begin{array}{l}\text { Tourism, telecommunications, microelectronics, } \\
\text { professional services, life sciences, software \& } \\
\text { communications and photonics }\end{array}$ \\
\hline Seoul & 2002 & Seoul Digital Media City & $\begin{array}{l}\text { Digital media industry and related industries such as } \\
\text { software and IT-related service industries, IT } \\
\text { manufacturers, R\&D centres dealing with media and } \\
\text { entertainment technology, as well as industries distributing } \\
\text { and consuming digital contents. }\end{array}$ \\
\hline Stockholm & Various & $\begin{array}{l}\text { Various, including } \text { Stockholm } \\
\text { Bioregion (2003) and Kista } \\
\text { Science Park (2000). }\end{array}$ & $\begin{array}{l}\text { Biotechnology (life science), ICT and environmental } \\
\text { technology }\end{array}$ \\
\hline Tokyo & 2002 & $\begin{array}{l}\text { Regional Industry Revitalisation } \\
\text { Project (for Northern Tokyo } \\
\text { metropolitan area), Fostering } \\
\text { Bioventures, and IT venture forum } \\
\text { by Meti-Kanto }\end{array}$ & Transportation and electric machine, biotechnology, and IT \\
\hline \multicolumn{4}{|l|}{$\begin{array}{c}\text { Newer technology } \\
\text { centres }\end{array}$} \\
\hline San Diego & 2002 & $\begin{array}{l}\text { Community and } \quad \text { Economic } \\
\text { Development Strategy (FY 2002- } \\
\text { 2004) }\end{array}$ & $\begin{array}{l}\text { Telecommunications, biomedical/biosciences, software, } \\
\text { electronics manufacturing, financial and business services, } \\
\text { and defense and space manufacturing }\end{array}$ \\
\hline
\end{tabular}




\begin{tabular}{|c|c|c|c|}
\hline $\begin{array}{l}\text { Metropolitan } \\
\text { region }\end{array}$ & $\begin{array}{l}\text { Starting } \\
\text { Year }\end{array}$ & $\begin{array}{c}\text { Brand name of the cluster } \\
\text { strategies }\end{array}$ & Targeted clusters \\
\hline Phoenix & 2002 & $\begin{array}{l}\text { Turning Point: New Choices for } \\
\text { the Future by Greater Phoenix } \\
\text { Economic Council (GPEC) }\end{array}$ & $\begin{array}{l}\text { Aerospace and aviation, high technology, bioindustry, } \\
\text { software, and advanced financial and business services }\end{array}$ \\
\hline \multicolumn{4}{|l|}{ Inner cities } \\
\hline $\begin{array}{l}\text { Milwaukee, } \\
\text { Minnesota, US }\end{array}$ & 2003 & $\begin{array}{l}\text { The Initiative for a Competitive } \\
\text { Milwaukee (ICM) }\end{array}$ & $\begin{array}{l}\text { Manufacturing, business process service centres, } \\
\text { construction and development, and health services; and } \\
\text { Additional two business environment issues to be addressed: } \\
\text { workforce development and entrepreneurship }\end{array}$ \\
\hline $\begin{array}{l}\text { Lousville, Kentucky, } \\
\text { US }\end{array}$ & 2002 & $\begin{array}{l}\text { The West Louisville Competitive } \\
\text { Assessment and Strategy Project } \\
\text { ("The Strategy Project") }\end{array}$ & $\begin{array}{l}\text { Automotive cluster, transportation and logistics cluster, and } \\
\text { life sciences (biomedical research and health care) }\end{array}$ \\
\hline $\begin{array}{l}\text { Newark, New Jersey, } \\
\text { US }\end{array}$ & 2004 & $\begin{array}{l}\text { Opportunity Newark: Jobs and } \\
\text { Community Development for the } \\
\text { 21st Century(Opportunity Newark) }\end{array}$ & $\begin{array}{l}\text { Education \& knowledge creation, entertainment, arts \& } \\
\text { retail, health services transportation, logistics \& light } \\
\text { assembly }\end{array}$ \\
\hline $\begin{array}{c}\text { Reading, } \\
\text { Pennsylvaina, US }\end{array}$ & 2005 & $\begin{array}{l}\text { Initiative for a Competitive } \\
\text { Greater Reading (ICGR) }\end{array}$ & $\begin{array}{l}\text { Entertainment, hospitality and tourism; food processing; } \\
\text { and professional and shared Services and cross-cutting } \\
\text { issues: innovation in manufacturing, economic development } \\
\text { co-ordination, and inner city entrepreneurship }\end{array}$ \\
\hline United Kingdom & 2001 & $\begin{array}{l}\text { City Growth Strategies (CGS) } \\
\text { Pilot areas include St. Helens, } \\
\text { Nottingham, Plymouth and four } \\
\text { areas of London }\end{array}$ & $\begin{array}{l}\text { Various clusters identified, for example, prioritised clusters } \\
\text { in Plymouth includes advanced engineering, business } \\
\text { services, creative Industries, marine industries, medical and } \\
\text { healthcare, tourism and Leisure. }\end{array}$ \\
\hline
\end{tabular}

Source: Biotech Region Munich (1997), City of Ottawa (2002), City of San Diego (2002), Montreal Metropolitan Community (2003), Greater Phoenix Economic Council (2002), OECD (2006d), OECD (2005f), Metropolitan Area Planning Council (2004), Inoue, H. (2003), Newark Alliance (2004), as well as other local development strategy reports.

Cluster policies are most likely to be effective when they constitute a holistic approach, bringing together separate policy instruments. Different from traditional sectoral policies or regional (or metropolitan) policies which focus on building physical infrastructure, these policies pay particular attention to building linkages between local actors and more broadly developing social capital. The cluster approach requires policy consistency across local actors. In particular, facilitating inter-firm linkages and linkages between private sectors and research institutions involves many actors, such as different industry sectors, higher education and research institutes and development agencies. Policy co-ordination and consistency are necessary in order to make the approach effective. This entails new partnerships between government, business and communities with business and communities playing a more direct role in the formulation of strategy and economic development process (Stimson, Stough and Roberts 2002).

Identifying niches of excellence or competitive industry clusters is the first step before designing and implementing cluster policies. Public authorities tend to develop clusters around knowledge-based industries (information technology and communications and biotechnology etc.) without going through a well defined cluster identification process (i.e. carefully checking the cluster size, structure and competitive advantages). Policy makers need to be in a position to map industry clusters, better understand their potentials and obstacles, and design and implement effective development policies.

Once industry clusters are identified, tailor-made cluster development approaches should be adopted to accommodate cluster and metropolitan peculiarities. The logic underlying clusters discussed earlier suggests the importance of exploring the specific characteristics and capacities of individual areas in order to determine what is most likely to build and enhance their competitiveness. Currently much effort in this field concentrates on building high tech clusters (e.g. ICT) and science parks irrespective of these factors. There are no effective 'one size fits all' policies: tailor-made approaches are necessary. Regional differences not only refer to different socioeconomic contexts but also to different types of cluster (manufacturing versus services, knowledge intensive versus capital intensive etc) and their development stages (young versus mature, existing versus potential (embryonic)) etc. These differences have to be factored in when designing policies. Similarly, there are limitations to the possibility of applying successful lessons (or very specific policy instruments) 
from other regions to a particular case. If they are applicable, they have to be tailored to accommodate the differences. This is especially true for cluster policies which focus on building subtle relational assets.

Policies should also fit clusters at different stages. Different policies are needed for reviving old clusters, upgrading established ones or encouraging or assisting embryonic ones. Partnerships or networks remain important for sectors in decline, to help firms face challenges or potential threats on the market. For example, as the focus of the competition in the clothing industry shifts from production factors and costs to creating designs and brands, the fashion and clothing industry cluster in the Seoul metropolitan region faces challenges of how to stay responsive to market demand. Partnership and networks among member firms may enable them to pool resources in order to access expertise for this. For the emerging digital content cluster in the region however, growth potential lies in the fusion of traditional content industry and advanced information technologies, and networks would aim at furthering this. Research is needed on the possibly different forms that should be taken by clusters and policies towards them in these different circumstances.

Industry cluster policies should be accompanied by diversification policies for a well balanced industrial growth environment. The issue of diversity versus specialisation has always been a debate in urban development and the popularity of industry clustering in metropolitan regions has further stimulated this ${ }^{42}$. There are concerns that the general focus on the creation of high technology clusters tends to leave other economic activities in obscurity and therefore devalued (Sassen 2003). The debate on the role of industrial composition in the growth of cities is far from reaching a definite conclusion. There may never be one, as suggested by the coexistence of both specialised and diversified cities (Duranton and Puga 2000), but evidence tends to suggest that big metropolitan areas with much internal diversity spur innovation.

In addition, cluster policies can be significantly better tailored if government authorities understand how specific framework conditions work for different industries (or businesses). One important lesson learned from Danish cluster policy for metropolitan areas is the necessity of dialogue between the authorities and the cluster industries (Rasmussen 2003). Co-operation between different authorities is also a crucial part of the dialogue process. Co-operation between labour unions, professional associations, cultural and social organisations is also involved in the process of cluster formation and development. A dynamic network among public and private actors is essential for the development of the economic drivers of entrepreneurship and innovation (Parkinson in ODPM, 2004). Building and enhancing these linkages thus help create and maintain the dynamics of these driving factors in order to ultimately build competitive advantages. This issue demonstrates the importance of governance capacity and of new flexible forms of governance.

Important to the strength of clusters and other networked production systems is the existence of 'local collective competition goods' to favour business growth and help clustered activities flourish. Local collective competition goods are locally provided services and public goods that companies can use to develop their competitive strategies, but which they do not have to acquire through the market. Firms, especially SMEs, are dependent on the environment in which they are located to provide them with different types of these goods. Some of them are general (such as the transport infrastructure), but many are sector-specific (for example, links between particular university research departments and science-based industry). Local collective competition goods are not necessarily made available as public services or as deliberate products of public policy: they may be provided through local business associations, or even emerge informally and implicitly within the working community (as in the case of the tacit knowledge mentioned above). However, it is possible for policy makers to explore what

42. Jacobs 1969, Henderson, Kuncoro and Turner 1995, Romer 1986, Barro and Sala-i-Martin 1991. 
scope there may be for encouraging and stimulating the production of such goods within their regions. Particularly in the knowledge-based sectors of the contemporary economy, important sources of local collective competition goods are the networks that bring together entrepreneurs and those working on innovation within a region's higher education and research institutes.

Perhaps the most fully developed form of cluster development incorporating higher education and research alongside firms and other relevant agencies is the idea of a regional innovation system (RIS). This concept was introduced in economic theory during the early 1990s. It describes a "concentration of interdependent firms within the same or adjacent industrial sectors in a small geographic area" (Isaksen and Hauge, 2002). This systemic approach to innovation recognises that innovation stems from interactions within a network of different actors including firms and institutions, whereas it is seldom the result of efforts within a single firm. While national systems of innovation are invoked to explain differences in innovation performances between countries, regions are increasingly recognised as the cradle of networks of innovators, local clusters and cross-fertilising effects of research institutions (Lundvall and Borras, 1997). A RIS can stretch across several sectors and clusters as long as their constituent firms interact. At the same time, clusters can develop close links with knowledge organisation outside the RIS (Asheim, 2002).

A regional innovation system development strategy should follow a holistic approach. The concept is closely linked to that of industry clusters. In modern innovation theory, the strategic behaviour and alliances of firms, as well interaction and knowledge exchange among firms, research institutes, universities and other institutions, are at the heart of an analysis of innovation processes. Innovation and productivity capacity upgrading is considered a dynamic social process which evolves most successfully in a network where intensive interaction exists between those 'producing' and those 'purchasing and using' knowledge (Roelandt and Hertog, 1999). The exchange of knowledge and information in industry clusters is most important in updating firms' products or services and producing new products or services and thus maintaining their competitiveness on the market. This primarily Nordic concept has been applied in the most direct way in Finland, particularly in relation to the Greater Helsinki metro-region. At the heart of this is the Centre of Expertise Programme of the socalled 'Triple Helix Model' (Figure 37 and Box 16). 


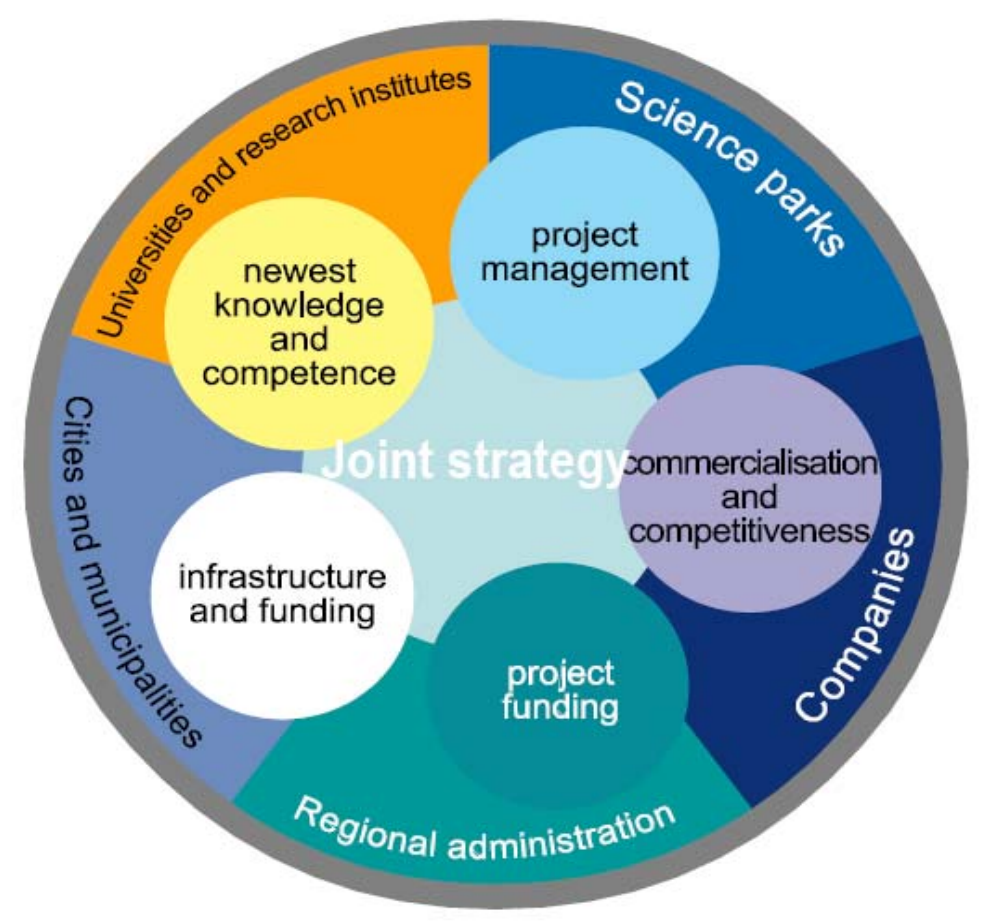

Source: Laurila (2005).

\section{Box 16. A well-functioning Triple Helix model: the example of the Helsinki Culminatum Ltd.}

For fifteen years, the City of Helsinki and the University of Helsinki have built up their co-operation, the most important ingredients of which are: promoting science-driven business enterprises with the aid of a common business incubator and science park, co-operating in urban planning and traffic planning to develop campuses and transport and logistics between campuses, creating a common Student City concept to increase international attractiveness, promoting urban research by creating initially six (today nine) professorships in urban research, and collaborating with the city's own think-tank Helsinki City Urban Facts.

Besides their international co-operation, the University of Helsinki and the City of Helsinki have been initiators in establishing the Helsinki Region Centre of Expertise Culminatum Ltd. This public-private organisation is based on the Triple Helix model, which means that one-third of its shares are owned by the local universities and research institutes, one-third by the City of Helsinki, its neighbouring municipalities and the Uusimaa Regional Council, and one-third by the business community, financers and science park companies.

Helsinki Culminatum forms a co-operation forum and a basis for the development of common projects. It focuses on two main missions, namely:

(i) Managing regional cluster building activities in six selected sectors of the knowledge-based economy. Development programmes and actions are funded mainly by the cities and by national innovation organisations. In sharing their knowledge, universities and polytechnics play a crucial catalysing role in development projects. One of the focus areas of Culminatum is to help university spin-off companies grow. Cluster building activities by Culminatum combined with the funding from the National Technology Agency (Tekes) have contributed to increased interaction between SMEs and higher educational institutions.

(ii) Developing the Helsinki Region as a world class innovation eco system - as an Ideopolis. Early 2005 saw birth of Yhdessä Huipulle (Together to the Summit), a common innovation strategy by Culminatum's owners presenting 26 common development projects of the universities, cities and the business community on four key issues: (1) to increase the international appeal of local research and education, (2) to develop strong clusters and 
create test beds and living labs for product service development, (3) to apply innovations to renew the welfare services provided by the cities and to consolidate the role of the cities in the R\&D, and (4) to support universitydriven business growth by, for example, developing a second generation science park concept.

Source: OECD Territorial Review of Helsinki (2003).

Regional cluster development policies are also being developed by national governments. In Japan, the development of SMEs is at the heart of a new approach to innovation and technology policy (Box 17). Norway began to adopt this kind of approach to planning in the mid-1980s; policy had taken on more of a market orientation, with an emerging focus on endogenous growth, knowledge-based development and the stimulation of entrepreneurship. In recent years Italian territorial competitiveness policy has moved away from attempting to divert, by means of financial incentives and subsidies, firms' investments towards less advanced areas, towards a programme of public investments and institution building, aimed at increasing the competitiveness of territories by enhancing their local potential opportunities.

\section{Box 17. Regional innovation policy in Japan, Norway and Italy}

Japan. At the heart of a new approach to innovation and technology policy, and one of the prime justifications for a regional emphasis, are Japan's small and medium-sized enterprises (SMEs). Enhancing the contribution of small and mid-size enterprises (SMEs) to regional innovation and competitiveness is a priority that requires ongoing consideration by Japanese policy makers. There are perhaps three key focal points for policy. A first policy thrust is to encourage existing SMEs to emphasise innovation. In the manufacturing sector, many Japanese SMEs have been organised into hierarchical vertical supply-chains led by larger companies. Long-term relationships in these vertical chains enabled SMEs to develop excellent technological and process capabilities in specific niches during Japan's rapid growth phase and build-up of mass production beginning in the 1950s. But a shift away from this system is already underway: for example, SME subcontracting rates in the general machinery sector have declined from nearly $85 \%$ in 1981 to under $60 \%$ today (Small and Medium Enterprise Agency, 2003). The challenge now is to encourage and support more existing SMEs to develop new "market-oriented" horizontal and lateral linkages, to increase investments in R\&D (non-subcontracting SMEs are twice as likely to undertake R\&D as subcontracting SMEs), and develop new products for a new era of increased international competition and innovation. A second policy thrust is to stimulate the start-up of new technology-based small businesses, for example through the spin-out of commercial ventures from regional university research or the spin-off of new firms from existing large companies or consortia of small companies. New technology-based ventures may be in emerging fields (such as life sciences), lack cash flow and reputation, require further product development support, and need to obtain intellectual property protection. A third policy thrust is to encourage the formation and growth of entrepreneurial knowledge-intensive small businesses in regions. Such firms may target evolving opportunities in such fields as business services, information services, logistics, tourism, health, social services, and other local community business markets. Again, the characteristics and needs of such businesses differ from those of the other two categories, for example, requiring entrepreneurial and service innovation and having lower entry barriers. This third category of policy is important to improve growth in high quality services employment in Japanese regions.

Norway. Norwegian governments have also established several programmes and instruments to encourage networking and the distribution of knowledge and competence in various parts of the innovation system. This is assisted by an increased effort on R\&D. Innovation and local cluster policies and programmes are to a large extent based on the triple helix model of regional development. They can be divided in two categories: core activity programmes focusing on developing clusters on the long term and in a holistic way; and support programmes which focus on specific problems, needs and/or challenges within a cluster and/or between the firms in the cluster and outside actors. Norwegian policy tools seeking to promote innovation and regional development are primarily based on a branch neutral support strategy. One key reason is the difficulty in picking winners among industrial branches; another is the flow of labour and capital resources between branches. This main picture must be slightly adjusted because the Research Council of Norway has several branch targeted programmes in prioritised areas like the marine, maritime and petroleum sectors. 
Italy. Some Italian regional policy makers have confronted the problem of how to support firms and networks of firms who have difficulty transforming the vague perception of a need into actual demand, through the creation of strong, autonomous and specialised centres that diffuse information, for the prevailing industries of the area in which they are located, until the industrial community understands its importance for itself, when the market may be left to operate. There are some key features in these experiences to be underlined. The first is the unit of intervention, which in this case is not as much the individual firms or the specific network in which they are organised. The aim is to increase the level of knowledge and the introduction of new skills within the whole local fabric. The second feature has to do with the nature of the measures. This strategy gives a clear priority to direct provision of services instead of financial incentives to buy services. This is not a secondary policy trait, given the traditional political practice that relies on monetary incentives and subsidies. The latter approach is unhelpful in circumstances where doubt can legitimately be cast on the ability of otherwise efficient firms to obtain information and make choices concerning the technology or services they might wish to buy. A third feature concerns the actors involved in the policy. Underlying this strategy is the conviction that success is linked to the direct participation not only of public but also of all relevant local actors who are expected to constitute a more or less formal policy network. Given that in local clusters, every structural change in organisation must be accepted and practised by many firms, new skills and services cannot be injected through commands, but must be diffused by means of consensus. Plans of action developed only by experts and the public sector and suggested without an actual participation of entrepreneurs and trade associations can face resistance in being utilised. For these reasons, centres have developed a specific institutional nature. They are quasi-public entities managed by a group of experts, knowledgeable people, officials from public organisations, but also representatives from local governments, trade associations, sometimes unions, and entrepreneurs who take an active part in the process.

Italian experience in the region of Lombardy, at the centre of which stands Milan, also demonstrates the need for policy-makers to break out from dependence on past successful clusters, which may have reached a point of lock-in and path dependence - the weakness of the cluster approach so often identified by its critics - and to develop policies that are open to use by entrepreneurs in a number of sectors. Clusters appropriate to hightech sectors are likely to be spread over much greater geographical distances than those associated with traditional Italian industrial districts - called 'meta-districts' by planners in Lombardy. This increased scale of districts is itself a part of the shift of contemporary economic dynamism towards larger urban centres that lies behind the new competitive cities strategy. These changes suggests at least two fronts for action: a) the appropriate diffusion of new skills among the whole economic actors of the local system as well as b) the provision of services that are not yet available (at least at the right quality and in time) at the local level.

Source: OECD Territorial Review of Japan (2005d), OECD Territorial Review of Milan (2006h), OECD Territorial Review of Norway (2007f)

Central to the new approach is for national authorities to find policy areas where they can see scope for targeted action in support of firms' existing, market-based strategies. In adopting such an approach, the Hungarian government has identified the following kinds of actions: Co-operation between firms supporting the establishment of sub-supplier networks and the joint production and market actions of SMEs within the same sector, of clusters, or of firms with similar business interests; a sub-contracting programme to strengthen the production, innovation and information ties of domestic SMEs with multinational corporations in Hungary; Business-related infrastructure and management culture and skills in SMEs: support will go to training and transition to working life programmes; major projects in business-related infrastructure will receive PHARE contributions; Research and innovation: a special catch-up development programme is carried out by the Ministry of Education to enhance science and technology infrastructures in less developed counties and to increase local demand-driven innovation programmes for SMEs. There is also support for the creation and development of regional networks of innovation and research institutions through non-refundable development grants. In the Hungarian case there are some doubts over the organisation of their delivery and their relationship to each other remains unclear. Before designing new programmes, it is wise carefully to evaluate the efficacy and efficiency of existing initiatives and the adequacy of links between programmes (OECD, 2001a).

Japanese policy makers have recently taken the view that regions have to be viewed from the perspective of the particular innovation systems that lie embedded in them, and concentrating such 
things as labour skills, research facilities, networks and advanced supply chains rather than physical production facilities and buildings. Since the 1980s there had been a concentration on developing high-tech centres in areas away from the existing urban agglomerations. As found in so many other countries, these attempts tended to succeed only where there was some existing strength in the activities concerned. Attempts to get firms to relocate design and research functions in cities outside the central Tokyo-Nagoya-Osaka concentration produced however only mixed results, as the lack of venture capital and soft infrastructures proved to be inhibiting factors. Hence the shift to a more 'bottom up' approach. As part of this, Community Renovation Grants have been introduced, which enable municipalities to select and undertake projects for themselves, subject to their coming within central guidelines and being evaluated. Locally available knowledge has replaced the firm as the centre of attention.

Another prominent way in which governments can provide general but targeted support for activities that are emergent rather than centrally planned is by building up universities as strategic hubs. There are several examples of this in the US, including the well known examples of worldleading universities in California and Massachusetts. Several cities in the USA have established Competitiveness Councils linking government, universities, business and trade unions. These take stock of a metropolitan region's existing capacities, identifying as yet unrealised potential in some infant sectors that could be encouraged by public policy providing appropriate infrastructures and linkages (OECD, 2006d). Within Europe prominent examples are the joint Danish-Swedish initiatives in the Öresund region, and the Finnish 'Triple Helix' and expertise policy (Box 18). As already noted, Finland in particular is a case where government identified several different types of town and city, trying then to give them appropriate development roles as hubs for their regions (OECD, 2005c).

\section{Box 18. Developing urban hubs by promoting innovation in Finland}

Three main rationales have driven Finnish urban policy: i) cities as nodal points for the creation of new jobs and the spread of economic growth; ii) promotion of innovation to enhance cities competitiveness; and iii) sustaining a large network of cities, including small and medium-sized, to ensure balanced territorial development. The main instruments to reach these objectives are the Centres of Expertise (CoE) programme launched in 1994 and the Regional Centre Programme (RCP) introduced in 2001. The CoE programme represents one of the main tools of Finnish regional innovation policy. The objective is to increase co-operation between universities and enterprises, develop top-level expertise, attract investments and talents to the region and improve regions' ability to raise R\&D funding. The programme is implemented by local development companies based on the Triple Helix model, i.e., partnership between i) universities and related institutions (research institutes); ii) the local business community (companies and science parks); and iii) public authorities (municipalities, regional councils, national government). The responsibility for the management of the Centres of Expertise is often assumed by the local science and technology park company. The CoE programme administered by the Ministry of the Interior functions efficiently as a programme crossing administrative boundaries. It is based on competition so that only the best local programmes have been awarded the centre of expertise status. These also have to compete for basic state funds annually. In 2003, the ministry's basic funds for the programme amounted to EUR 8 million and EUR 9.5 million in 2004. These funds are matching grants, as local actors, mainly cities, are also required to invest in the programme an equal amount of funding (so called 50/50 principle). In 2003, the total funding of the CoE projects was of EUR 40 million including various sources such as the EU (European Social Fund), private companies and national innovation organisations. The CoE, aiming to develop and consolidate international top-level knowledge within firms in particular by fostering connections with academia and research, is widely considered as a success story (Ministry of the Interior, 2003). A 2003 mid-term evaluation of the programme reported that modest public funding has successfully mobilised private resources in most cities involved. In 1998 and 2002, the national government decided to extend it to new regions so that by the end of 2006 , there should be around 22 Centres of Expertise operating in 45 branches. The programme, that initially targeted large urban areas, is thus progressively being extended to medium-sized city regions in coherence with the national objective to ensure a polycentric urban structure.

The principal objective of the Regional Centre Programme (2000-2006) is to ensure balanced territorial development by establishing cities of different sizes as strong regional or local centres, with the aim of boosting the competitiveness of the regions concerned. The programme also specifically stresses the development of sub- 
regional co-operation by bringing together in a joint network, municipalities, universities, research units and enterprises. On the basis of an agreement between municipalities, responsibility for the programme lies with the urban centres or the joint regional organisation of the municipalities, such as regional business development companies. The assumption is that urban regions are considered as functional entities for the development of which the core city and the surrounding municipalities must co-operate closely. The 34 cities that qualified for the RCP belong to the different categories identified in the typology of the Urban Network Study with the exception of urban regions in Uusimaa, which originally were excluded from the programme. They represent a total of 264 municipalities, i.e., 3/5 of total Finnish municipalities and $63 \%$ of total population. Ministry of the Interior funding for the programme amounted to EUR 10 million per year in 2001-2003, whilst the total expense amounts to EUR 20 million per year (2004-2006). In terms of policy actions, the main emphasis of the RCP is on competence and development driven by technology innovation within the functional regional centre area. Quality of the environment and culture are also focused as competitiveness factors.

Source: OECD Territorial Review of Finland (2005).

In some countries, it is difficult to pursue policies based on links between firms and universities, as the universities are often 'missing players' from such activities like in Milan or Madrid (OECD, $2006 \mathrm{~h}$ and $2007 \mathrm{~g}$ ). In some regions, universities may not be of adequate quality to play a part in true innovation-based growth, while firms may not have knowledge of how to work with university-based scientists. This may be the case in North-East England, where other than the chemicals sector there is also no critical mass of firms in any sector in the region which would be likely to be in a position to compete with other regions in the commercialisation of any research that was developed (OECD, 2006c). In such cases a key focus of technology transfer and commercialisation must be spin-off firms, and inward investment in specialist areas. In the short to medium term, initiatives which aim to increase the efficiency of existing businesses, making full use of best-practice processes, techniques and work practices may be more likely to make a difference than initiatives focused on radical new technologies. Similarly, rebalancing efforts to focus more on stimulating the demand for research and development and the capacity of firms in the region to participate in the technologies emerging from the region's universities rather than initiatives to push technology out of HEIs, may be merited.

With globalisation, OECD regions are confronting with innovation offshoring. The global dimension of innovation activity shows a clear rebalancing of resources with a West-to-East shift, indicating the reallocation of innovation-based resources towards specific regions, especially China. Chinese regions, and several others, have in recent years established a "virtuous circle" of innovationrelated development. In these "virtuous circle" regions, growing business-led investment in innovation is fuelling economic growth, which is being fed back into higher earnings and greater investment in education. Within leading regions in OECD countries, many regions which previously specialised in knowledge-based manufacturing have begun to shift towards more to service-related knowledge-based activities. This decline in manufacturing employment in technological sectors is not directly linked to a poor performance on innovation indicators, but it is likely that there will be some impact over the longer term on business R\&D investment. Conversely, some OECD regions such as Brussels, better known as advanced service centres, appear to be finding niches in high technology manufacturing sectors such as biotechnology. Despite offshoring, many of the less advanced regions in the sample, such as the southern regions of the US, are continuing to experience growth in their knowledge economies thanks to manufacturing-based employment in technology-intensive industries.

Looking forward, the concern of policy makers is to ensure that regional economies are innovative and thereby more resilient in the face of economic shocks and increased international competition. The tools available at the regional level vary considerably according to institutional frameworks and the focus varies according to the industry(ies) targeted. However, a number of policyrelevant findings emerge: 
- First, a clear and systematic analysis of the region's economy and assets in the context of global trends is the basis for any potential regional action. Quantitative and qualitative data is useful for the development of a clear analysis to appreciate what strengths are durable and where there may be new opportunities. This analysis also requires a clear understanding of the changing roles of different categories of firms (start-ups, SMEs, multinationals, etc.) and their role in global supply chains. However, the data are often at too large a scale and does not capture the very localised dimension of the knowledge spillovers that policy should be targeting (evidence from the US points to a rapid decline in the positive spillover effect with distance).

- Second, a common understanding of the problem facilitates the process for developing consensus on a strategy. Given the numbers of stakeholders, both public and private, this consensus is needed for a co-ordinated response. Often a compelling problem or crisis serves as the trigger for co-ordinated action, and there is a strong risk of complacency when regions fail to anticipate future trends because current indicators are positive.

- Third, perhaps the most important role for regional strategies is to favour adaptation to change. While public actors are not well-placed to predict the future of global product markets, they can play a clear role in developing an environment that supports private actors in their efforts to adapt and seize opportunities. Tools are needed both to understand and monitor how their research and educational assets interact with enterprises with the goal of designing policies to help build more systematic linkages across all actors.

- Fourth, it is important to reach consensus among all key public and private actors in the region on a vision, strategic outcomes and plans, and priorities for the region. Commonly developed strategies work better than top-down ones as they incorporate knowledge across sectors and among multiples levels of government.

\subsection{Fostering city competitiveness whilst ensuring that others do not fall into neglect}

Many OECD have tried to ensure that supporting champion cities does not compromise earlier policy goals of even-handed treatment of different regions. Experience suggests three potential ways out of achieving such a balance and those creatively resolving this question:

1. Subsidiary poles to counter-balance a dominant one. Even where a country has one clearly dominant metro-region, government and other policy actors can plan for a number of subsidiary strong regions, which, while they might not rival and may even be dependent upon the leading one, can have positive effects in parts of the country remote from the leading city.

2. Wider positive regional impacts of key growth centres. This approach will benefit even larger areas if potential wider positive regional impacts of key growth centres can be realised and encouraged.

3. From social casualty to pro-active urban policy. The policy of developing subsidiary growth poles can be extended to former deprived regions if the policy switch can be made from thinking in terms of regeneration and dealing with social casualty to a proactive and positive approach to urban economies. Emphasis should be put in particular on enhancing skills.

\section{Subsidiary poles to counter-balance a dominant one}

The concept of a number of subsidiary poles to counter-balance a dominant one has probably been most fully developed in Finland. It is notable that Finland did not start to have urban policy at all 
until the 1990s, and may therefore have escaped the path dependence of the 'social casualty' approach, even though the need for a policy was prompted by the major crisis in the Finnish economy precipitated by the collapse of its former markets in the former Soviet Union. The strategy began with a regional innovation strategy that envisaged Helsinki as a global high-tech centre and with subsidiary centres in the more distant cities of Tampere and Oulu. It is notable that growth in these two centres has remained strong, with the latter having the highest growth rate of all regions in Finland during the 1998-2003 period. Scientific innovation rather than investment has been the prime policy tool in Finland (OECD, 2005c). Though the central priority was a concern with competitiveness rather than the living environment and infrastructure, the 2002 Regional Development Act, while stressing competitiveness of the regions, also paid attention to safeguarding service structures throughout the country, and to developing a balanced regional structure. This produced, in 2003, a decision to extend the regional innovation approach to the whole country if possible, nine cities being selected as potential growth poles for their regions (Box 19).

\section{Box 19. Regional innovation policy in Finland}

Finland's programme for regional policy is very innovative but it remains a complex tool to manage because of its multi-faceted aspects and the wide sharing of responsibilities between different actors. The Ministry of the Interior, in co-operation with other ministries and the regional councils, is responsible for the formulation of national targets for regional development. In addition, the Ministry of the Interior is responsible for co-ordinating, monitoring and evaluating the preparation and implementation of regional strategic programmes and other programmes in accordance with the Regional Development Act. The Government decides on regional development targets for a fixed term (current period 2004-2007).

The nine Regional Development Targets adopted by the Government in January 2004 are: (1) Improving of competitiveness of regions in the global market by strengthening specialisation and promoting the Information Society. This relates to regional innovation policy and, more specifically, to the Centre of Expertise Programme; (2) Promoting of industrial development and entrepreneurship, with specific reference to the operating environment of companies; (3) Enhancing employment and reducing regional unemployment disparities in particular by improving the functioning of regional labour markets; (4) Providing better accessibility through adequate transport connections and fast, affordable ICT infrastructure and services; (5) Maintaining and improving the living environment and natural surroundings; (6) Safeguarding the availability and quality of basic services throughout the country, in particular by sustainable funding of services, implying support to supramunicipal and regional co-operation as well as to reforms in service structures and production methods; (7) Developing a polycentric regional structure based on a competitive Helsinki Metropolitan Area and a network of regional centres; (8) Mobilising sufficient financial resources for regional development programmes, with regional council's role to be strengthened in co-ordination of regional actions and allocation of resources; (9) Regionalising in the long run certain central government functions, with location of units and jobs (in particular vacated through retirement) outside of the Helsinki Metropolitan Area, primarily in regional centres.

State authorities are required to take account of regional development targets set by the Government in their operations, and promote their achievement. The Regional Development Act (602/2002) adopted by Parliament requires Government to draw up a Decision guiding and harmonising regional strategic programmes and development targets and measures across the administration and levels of governance (SEUTU and Kainuu projects). The Government can also decide on fixed-term special programmes drawn up in order to complement the Regional Programme. Recent Government Decisions mostly concern the continuation of existing programmes uch as the Centre of Expertise Programme, the Regional Centre Programme (to sustain small and medium-sized cities and foster intermunicipal co-operation), the Rural Policy Programme, and the Island Development Programme. More recently a Programme on "sub-regionalisation of business services" was launched under the responsibility of the Ministry of Trade and Industry to establish a network of at least 50 regional business service points. As an integral part of regional policy, ten key ministries1 must now define their regional development plans. The Ministry of Education was the first to compete its own plan at the beginning of 2004. This strategy defines and strengthens the role of Higher Education Institutions (Universities and Polytechnics) in regional programmes. The Ministry of Agriculture and Forestry emphasises urban-rural linkages and rural hubs qualified as "competence centres", in line with the Regional Centre Programme deployed by the Ministry of the Interior. The Ministry of the Environment focuses on communities' attractiveness. The Ministry of Labour's strategy is focused on the TE Centres servicing individuals and businesses. The Ministry of Trade and Industry is attentive to regional competitiveness: in particular, competences and enterprise financing. The Ministry of Transport and 
Communications will focus on the ICT infrastructure framework with implementation largely the responsibility of local government (regions, joint municipal boards and public-private partnerships) and on Information Society policy, aside from traditional missions (roads, increasingly a regional prerogative).

At the sub-national level, regional development policies are managed by the regional councils under the Regional Development Act. Each regional council draws up a "Regional Plan" (long-term strategic vision) referring to the regional development targets decided at the national level. "Regional Strategic Programmes", debated with the main public and private regional actors and also discussed with the national level to ensure overall coherence, are decided by the different regional councils. The "Annual Implementation Plans" detail financing from committed sources (EU, national, municipalities, and private sector), taking into account the regional development programmes defined at the national level. Each actor, at different levels of government can thus express views, with the regional council actively co-ordinating the preparation and elaboration of the strategic documents that it is to adopt, thus defining its regional development goals, measures and means of implementation. This responsibility extends to land use as the regional land-use plan, up-dated every fourth year, follows guidelines defined in the regional plan. The Lapland Regional Development Programme for 2004-2006 highlights the regional council's role in use of EU Structural Funds emphasising in this case with Interreg, the northern dimension.

Source: OECD Territorial Review of Finland (2005).

The German government clearly announced a change in its approach to spatial policy in its report Raumentwicklung in Deutschland (Bundesministerium für Verkehr, 2006). Since 1949 the Bonn Republic had successfully followed a policy of even development across its territory, setting such targets as minimum distances for all citizens from main modes of transport and access to education, health and other social services. The 2006 plan did not depart from these goals, but set their achievement in the context of a plan for concentrating growth on eleven 'European metropolregions' (Box 20). However, a denser network of a considerably larger number of smaller, regional centres was also envisaged, to be linked through such mechanisms as supplier networks and commuting patterns to the metropolregions. While this marked a move to a more concentrated approach to development than in the past, it sought to retain the geographical equality of the former model through seeking an even distribution across the country of major and subsidiary growth poles. For example, considerable attention is given to the construction of secondary road networks as a prerequisite of effective transregional motorways, providing accessibility to trunk lines.

\section{Box 20. Metropolitan regions in Germany}

German spatial planning is seeking to resolve the dilemma between furthering the most dynamic cities and ensuring that other areas are not neglected through a policy of co-operation and networking between the two kinds of area. At the heart of the approach is the concept of europäische Metropolregionen (European metropolitan regions) - an idea with close similarities to the OECD concept of metropolitan regions. These are the 11 most highly developed urban regions in the country, each with a population of at least one million, and containing centres of economic power (finance, media, etc) and of research and innovation capacity. They are seen as the motors of social, economic and cultural development. They have good international connections and are well served by transport infrastructures. They are surrounded by inner and outer areas linked to them by commuting and other networks. But each of them has within its reach regions that are not linked to its existing networks. These include two types of area: those that show strong signs of autonomous development and innovation themselves, potential new growth poles; and those, often rural, that remain without current dynamism.

It has been agreed by the Ministerkonferenz für Raumordnung (MKRO, Ministerial Conference for Spatial Order) that authorities and institutions in the metro-regions have a responsibility to work with their counterparts throughout their wider regions to develop networks and collaborative projects that will start to include these less favoured areas in processes of dynamism and innovation. The MKRO consists of ministers at federal and Land level who have responsibilities for spatial order and planning. 
The policy of metropolitan regions was first developed in 1997, when the MKRO identified an initial seven regions: Berlin/Brandenburg; Hamburg; Rhein-Ruhr; Frankfurt am Rhein-Main; Stuttgart; Munich; Halle/LeipzigSachsendreieck. In 2005 it was extended to include: Nürnberg; Hanover-Brunswick-Göttingen; Rhein-Neckar; Bremen-Oldenburg. The whole of Germany is now connected one way or another to one or more of these regions.

Source: Bundesministerium für Verkehr, Bau und Stadtentwicklung (2006).

While there are successful examples of urban policy approaches that manage to preserve the growth capacity of their champion cities while enhancing the development of a number of subsidiary urban poles (such as the Finnish policy, mentioned earlier), governments are often forced to make tough choices and identify priorities. Urban policy must avoid wasting resources by trying to help cities continue growing long after they have become uneconomic, or by supporting the expansion of particular economic activities that are not guided by market signals. For example, there is room for doubt over the viability of heavy subsidies to attract FDI or to build science facilities in Newcastle, in the absence of prior experience or local entrepreneurial base. Missing linkages between firms and universities can also hamper the development of effective cluster policies, even in wealthy cities (such as Milan and Madrid). Some OECD countries have therefore identified scope for better targeted action in support of firms' existing, market-based strategies (e.g, emphasis on SMEs in Japan's new approach to innovation policy, building up universities as strategic hubs in the Danish-Swedish region of Öresund).

\section{Wider positive regional impacts of key growth centres}

The dynamism of an ostensibly vigorous region is often concentrated in a small number of actual locations, the rest of the region benefiting as its population commutes to work in the centre, or as supplier firms to firms in the centre locate more widely. It is important that policy makers are aware of these wider effects, as they may be well advised to give up trying to create high-growth points throughout a region and concentrate on strengthening public transport links between the dominant city and the rest of the area.

- For example, in Italy, the work on the role of Milan in the north-west Italian economy has identified a so-called Lombardy meta-district, a large prosperous region, the wealth of which is based primarily on activities in the city. This leads regional planners to consider whether the transport networks linking Milan to the rest of the meta-district are adequate.

- Existing Finnish, and planned German new territorial policies seek a resolution of the dilemma over positive or negative spillovers from concentrating development in a number of favoured locations by encouraging a kind of hierarchy of cities. Rather than see a small number of locations that will receive concentrated attention while the rest of the country receives nothing, they see a chain running from a very small number of global cities through those of regional and local importance, all engaging in high value added activities and linked to each other. The issue of positive versus negative spillovers is then played out again at these lower levels, providing support for the arguments of the German planning authorities that a localised growth point can benefit rather than weaken the wider territory around it (BVBS 2006).

- An example of such a regional centre is Newcastle in the North East of England, a region lagging beyond most of the rest of the country. A recent reassertion of the role of Newcastle in the city region's economy reflects a range of positive agglomeration effects 
derived in the urban core of the city region. From the perspective of maximising productivity, it also suggests the benefit to be derived from concentrating economic development in the urban core of the region. The evidence is clear that Newcastle is important to the overall performance of the region, and the need to support its continued competitive success should be recognised. This also indicates the importance of business location and the spatial pattern of economic development which can impact significantly on journey times and, in turn, productivity (OECD, 2006c).

- There has been a similar experience in Japan, which long-maintained a regional policy objective of reducing disparities by developing peripheral and less developed regions while alleviating the pressures caused by agglomeration in the major urban/industrial areas. The policy has in several respects been successful, in that Japanese regional disparities are relatively low compared to other OECD countries (OECD, 2005d). However, a decline in disparities in recent years has been mainly due to the fact that Japan's more dynamic regions have been declining, a case of 'downward convergence'. A reprise of growth in very recent years seems once again to be favouring the growth of Tokyo at the expense of most other cities. Meanwhile, policy will now have to turn to establishing the future of former major industrial cities that are now in decline, through the development of new sectors. Now Japanese policy is shifting to building up previously neglected regional cities outside the main agglomerations, encouraging them to discover their competitive advantages.

\section{From social casualty to pro-active urban policy in lagging cities}

The policy of developing subsidiary growth poles can be extended to former deprived regions if the policy switch can be made from thinking in terms of regeneration and dealing with social casualty to a proactive and positive approach to urban economies. Emphasis should be put in particular on enhancing skills. Implementing this principle in urban areas means that shifting from a 'social casualty' approach to 'pro-active urban policy' involves, inter alia, a change in mentality towards local labour supply from seeing it as a burden to a positive asset. An example of this is found in the approach to labour supply in Newcastle in North East England, for decades a relatively depressed economy (OECD, 2006c). Historically the focus of policy in the region has been on attracting investment as a means of utilising what has been regarded as a surplus of labour, and the region still has relatively low participation rates. Local planners are now coming to realise that the region's problems may lie rather in a shortage of appropriately skilled workers that the region needs to attract and retain more skilled and talented people in addition to younger people. There is evidence of an inability to absorb innovation among the region's firms. This is partly explained by the remarkably high proportion of the workforce in the North East (and many other parts of the UK) with few or no formal qualifications beyond compulsory schooling. Those that do have qualifications then move away from the region because local firms cannot absorb them. Improving educational standards is therefore a possible route to breaking this vicious spiral.

\section{Problems of the social environment}

Social cohesion is not incompatible with territorial competitiveness. On the contrary, regional strategies with economic, social and, increasingly, environmental ambitions represents one of the strengths of regional policy, but makes its implementation more challenging, and as such is strongly influenced by a variety of policy interdependencies. OECD work on urban areas have identified the existence of particular problems posed by the social exclusion and loss of cohesion that follow the creation of socially segregated zones of poor people, often immigrants or ethnic minorities. While these immigrants sometimes move into rural areas (as with North Africans moving into southern Italy or Spain), these immigrations most often concentrate on big cities, metro-regions, as it is here that the 
typical low-productivity jobs available in urban agglomerations will be found, often in the shadow economy. Moreover, as mentioned in previous sections, cities in OECD, including successful ones, have tended to become sites for extreme inequality, sometimes trapped in more general criminality.

It is apparent from major cities across the OECD that regional wide economic growth depends not only on economic interdependencies but also on social cohesion, for which policies have to be designed. In other words, areas that are detached from the economy and labour market of the urban region constitute a drag factor that reduces the competitiveness of the region as a whole. For these reasons, regional economic and social development policies need to be elements of a single coherent strategy. Very frequently it is economic dynamism itself that creates this detachment and lack of cohesion. For example, cities which have faced strong industrial restructuring processes, like port cities such as Rotterdam, have experienced rapid losses of many basic port-related industries in the 1980 s, contributing to increase significantly social cohesion problems in the area, in particular for ethnic minorities with little education. Dynamism produces losers as well as winners, such as those whose skills are made redundant by sectoral change. Further, dynamic areas attract population from other parts of a country or from other countries, who often have difficulty in adapting to a new life and making social connections. In many respects, Chinese cities are confronted with similar issues, with increasing inequalities in its cities and social challenges raised by in-migration from rural areas.

This section will discuss policy responses in OECD countries to deal with (i) Affordable housing, and (iii) the integration in the labour market, especially for immigrants. In addition to specific policies to foster the integration of excluded people in local labour markets, address social exclusion and poverty, OECD countries have also developed (iv) integrated urban development projects in distressed areas.

\subsection{Affordable housing}

National governments have a key role to play in promoting standards of housing affordability and housing quality across urban regions. This section explores local, regional and national policies to monitor housing affordability, address and improve the elasticity of the housing supply, promote affordable housing for low-income households, and address problems of social cohesion.

\section{(i) Monitoring housing affordability}

The affordability of the housing market is often defined based on the relationship between housing prices and household income. Affordability concerns securing a given standard of housing (or a range of standards) at a price or rent which does not impose an unreasonable burden on household incomes, as defined by a third party (usually government) (Maclennan \& Williams, 1990). It is important to note that a housing affordability "crisis" means that housing is expensive relative to its fundamental costs of production - not that potential residents are poor (Glaeser \& Gyourko, 2003).

In order to measure housing affordability, two indexes are often used. The "house price-toincome ratio", as is defined by United Nations Human Settlements Program (UN-HABITAT), is the ratio of the median free-market price of a dwelling unit and the median annual household income. The "house rent-to-income ratio" is similarly defined by UN-HABITAT as the ratio of the median annual rent of a dwelling unit and the median household income of renters. A high house price-to-income ratio indicates a general level of excess demand in housing markets. Larger values would indicate a substantial gap between demand and supply (and often indicate reduced consumption in relation to dwelling space). The house rent-to-income ratio should be small as well to achieve housing affordability, though a very low ratio may be due to rent control, which can distort the efficient operation of the market. Tables 8 and 9 indicate these indexes in selected OECD countries. 
Table 8. House price-to-income ratios and floor area per person owner-occupied

\begin{tabular}{|l|c|c|c|}
\hline & Year of the survey & Price to income ratio & Floor area per person \\
\hline Denmark & 2000 & 4.35 & 52.8 \\
\hline Finland & 2001 & 2.30 & 38.0 \\
\hline Greece & 1999 & 2.78 & 37.5 \\
\hline Japan & 1998 & 4.90 & 37.5 \\
\hline Norway & 2001 & 3.50 & 54.8 \\
\hline Poland & 2002 & 3.75 & 23.6 \\
\hline Sweden & 2002 & 4.38 & 49.0 \\
\hline United States & 2000 & 2.85 & 69.4 \\
\hline
\end{tabular}

Source: OECD (2006a), "Interim Report on Socially Sustainable Housing", presented to Working Party on Territorial Policy in Urban Areas, June 2006.

Table 9. House rent-to-income ratios and floor area per person rented housing

\begin{tabular}{l|c|c|c|}
\hline & Year of the survey & Rent to income ratio & Floor area per person \\
\hline Denmark & 2000 & 0.17 & 44.5 \\
\hline Finland & 2001 & 0.28 & 30.0 \\
\hline Germany & 2002 & 0.22 & 36.5 \\
\hline Greece & 1999 & 0.17 & 31.9 \\
\hline Japan & 1998 & 0.14 & 21.0 \\
\hline Norway & 2001 & 0.20 & 46.2 \\
\hline Poland & 2002 & 0.05 & 16.6 \\
\hline Sweden & 2002 & 0.26 & 40.0 \\
\hline United States & 2000 & 0.23 & 49.1 \\
\hline \\
Source: OECD (2006a), "Interim Report on Socially Sustainable Housing", presented to Working Party on Territorial Policy in \\
Urban Areas, June 2006.
\end{tabular}

Some countries use additional indexes in order to capture the neediest households more accurately. For example, Canada uses the percentage of households spending $30 \%$ or more of their income on housing cost as a benchmark of housing affordability (Table 10). In Australia, the National Housing Strategy defines households falling in the lowest $40 \%$ of the income range and who pay more than $25 \%$ of the income in housing costs as experiencing "housing stress". That measure - and the more conservative benchmark of $30 \%$ of income spent on housing - have subsequently been widely used as an overall measure of housing-related hardship in Australia (Berry \& Hall, 2001).

Table 10. Housing affordability in Canada

\begin{tabular}{|c|c|c|c|}
\hline & 1991 & 1996 & 2001 \\
\hline House price-to-income ratio & 3.40 & 3.00 & 2.80 \\
\hline House rent-to-income ratio & 0.21 & 0.23 & 0.22 \\
\hline $\begin{array}{l}\text { Home-owner spending ( } 30 \% \text { or } \\
\text { more) }\end{array}$ & 13.80 & 14.20 & 13.90 \\
\hline Renter spending ( $30 \%$ or more) & 30.80 & 36.90 & 34.60 \\
\hline
\end{tabular}

In addition to the relationship between housing prices (or rents) and household income, there are a number of key variables influencing housing affordability (Table 11) (Berry \& Hall, 2001). A regular monitoring of these valuables is essential to identify the neediest households and to prepare for necessary action. Developing and maintaining a reliable database on housing supply (e.g. new construction starts, number of stock, age, vacancy, etc.), and quality (e.g. size, etc.) and other problems related to housing (e.g. social segregation, crimes, illegal occupation, slums, etc.) is an important task for national and local governments. 
Table 11. Key variables influencing housing affordability

Inflation, interest rates and real interest rates (repayments required)

Incomes and earnings (capacity to pay)

Unemployment and employment conditions (market participation)

Dwelling prices and rents (payment requirements)

Mortgage and rent payments (savings capacity, ability to increase housing consumption)

Tenure (impact of market economics, housing choice)

Mobility or frequency of residential relocation (aggregate housing demand and price and rent impacts)

Source: Berry \& Hall, 2001

\section{(ii) Addressing housing supply unresponsiveness}

Housing is distinguished from other commodities by several unique characteristics. First, since land is used in the construction of housing, the relationship between developers, landowners and planning authorities is important; second, there is a lengthy time period between project initiation (investment) and completion (sale); third, dwellings are expensive relative to household incomes, and long-term loans are required; and lastly, provision of infrastructure is required during the consumption phase (Short et al., 1986).

Due to such characteristics of the housing market leading to lags in construction, and due to the relatively small effect of annual construction on the total stock of housing, housing supply responds only partially to cyclical movements in demand (Arnott, 1987). As a result, any positive demand shock will lead to a temporary increase in real house prices. If housing supply is highly elastic, unfettered new supply should prevent the price of housing from rising much above construction costs. Moreover, since an elastic housing supply helps create an elastic supply of labour, high demand in labour will not lead to large increases in wages. On the other hand, if housing supply is inelastic, then positive demand shocks will have relatively little impact on new construction, leading to a sharp rise in housing prices. High demand in labour demand will lead to increases in wages because workers should be compensated for increased housing prices.

Addressing housing supply inelasticity is a key action to take in order to cope with a growing housing demand. Figure 38 shows the relationship between the annual change in the average housing price and the annual change in the volume of house building in 13 European countries in the late 1990s. A sharp increase in housing price relative to an increase in housing supply (the case of Netherlands and UK) implies inelastic housing supply. In fact, in the Netherlands, while the demand for owner-occupied housing has been stimulated by increased maximal borrowing capacity and subsidies for low-income households seeking homeownership, the supply of housing has been restricted by spatial planning and urbanisation policies (Boelhouwer \& de Vries, 2002). As a result, housing prices rose sharply, especially in the late 1990s, and there has been no letup because housing supply failed to react. In the UK, the supply of newly built housing has not reacted to increased demand, leading to a sharp rise in house prices since the mid-1990s, which indicates low housing supply elasticity during that period. It could be attributed, to some extent, to the increased rejection of applications for residential developments and increasing number of dwellings held up after receiving planning permission (OECD, 2006a). 
Figure 38. Changes of the number of house buildings and the prices

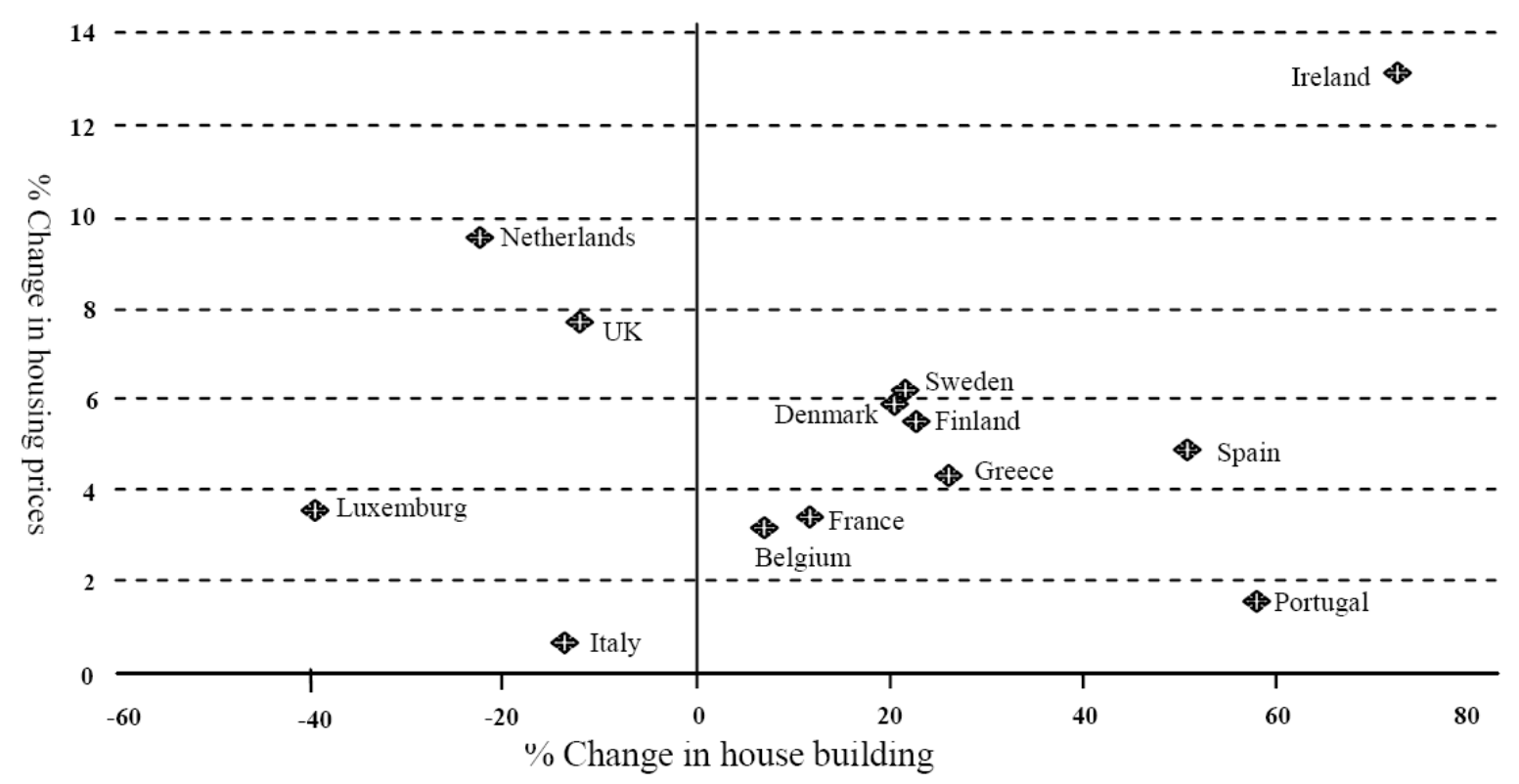

Source: Ball (2004).

\section{(iii) Policies to improve housing supply elasticity}

While regulations restricting supply of land (e.g. urban growth control policies) can directly undermine the elasticity of housing supply, regulations imposing additional costs on residential development can also reduce housing supply. Zoning and other land-use controls impose an "implied zoning tax" that discourages new housing construction (Glaeser \& Gyourko, 2003). Floor-area-ratio restrictions, restrictions on units per acre and height restrictions all can restrict high-density development. ${ }^{43}$ Box 21 presents the results of different studies in the United States regarding the effect of regulations on housing costs. In addition, regulations increasing housing construction and land costs may also lead developers to reorient their projects to higher-income customers as cost increases force them to build more expensive dwellings, which can aggravate disadvantaged households' exclusion from housing.

\section{Box 21. Effect of regulations on housing costs in the United States}

Various empirical studies show that housing prices are expensive in high-cost areas primarily because of government regulation, particularly regulations that limit supply of land such as growth management policies and regulations that induce additional delays and lengthen the construction process, both of which significantly undermine housing supply responsiveness.

Katz \& Rosen (1987) examined whether a jurisdiction that is small relative to the metropolitan area, would raise its house prices relative to those prevailing in the rest of the metropolitan area by the use of development restrictions. By analysing 1673 single family dwelling units from 63 suburban communities within the San Francisco metropolitan area, they found that housing units located within jurisdictions for which a formal growth management plan had been in effect for at least one year in the $1973-79$ period were about 17 to $38 \%$ more expensive than units located within jurisdictions without such a plan.

43. They can also limit opportunities to develop multi-family and connected housing, which typically is more energy efficient per capita. 
Glaeser \& Gyourko (2002) compared the data of housing prices from the American Housing Survey and construction costs from the R. S. Means Company and found that about half of the housing in the United States is priced less than $140 \%$ of construction cost. This indicates that a large share of housing in the United States has its price roughly determined by the physical costs of new construction. However, in certain areas the price of homes is much higher than the cost of new construction. If the driving force for the wedge between construction costs and housing prices is intense demand for land in high-demand areas, houses with bigger lots should be much more expensive than similar houses with smaller lots. When the lot is doubled, the gap between construction cost and housing price should be doubled as well. However, if planning regulation is driving the wedge, then the gap should be wider. Based on this assumption, Glaeser \& Gyourko (2002) compared the land values calculated by 1) comparing the price of comparable homes situated on lots of different sizes and using hedonic methodology to determine the marginal value of land to homeowners; and 2) subtracting the construction cost from the home value and dividing by the number of acres. They found that hedonic estimates produced land values that often were about one-tenth of the values calculated with the second methodology. This indicates the critical role that zoning plays in driving the wedge between construction costs and housing prices.

While most of the empirical studies focus on the impact of regulation on housing costs, Mayer and Somerville (2000) examined the relationship between aggregate market supply of housing and local government land-use regulation in 44 US metropolitan areas for the years 1985-1996. The results showed that Metropolitan Statistical Areas (MSAs) with 4.5 months delay in development approval and where growth management measures have been introduced will have about $45 \%$ less new construction than a MSA with a minimal 1.5 month delay and no growth management policies. Moreover, development fees were found to have a smaller impact on new construction than a two-month increase in the approval delay, even though the time cost of this delay is smaller than the cost of fees in many cities. Based on these results, they concluded that regulations that induce additional delays and lengthen the construction process impose a larger constraint on new construction activity than regulations imposing predictable additional costs on development (e.g. development fees, because the uncertainty associated with approval delays creates greater problems for the developers.

This conclusion seems to be endorsed by the study of Glaeser \& Gyourko (2003), in which they examined the correlation between housing prices and zoning measures in the central cities of 45 metropolitan areas. They focused on the average length of time between an application for rezoning and the issuance of a building permit for a modest size, single-family subdivision of fewer than 50 units. The index related to this length ranges from 1 to 5: a value of 1 indicates the permit issuance delay is less than three months, a value of 2 indicates the time frame is between three and six months, a value of 3 indicates a seven-to-twelve-month delay, a value of 4 indicates the delay is between one and two years, and 5 indicates a very long delay of more than two years. It was found that when the delay index increases by one, an additional $15 \%$ of the housing stock becomes quite expensive (i.e. more than $140 \%$ of the cost of new construction).

Source: OECD (2006a), "Interim Report on Socially Sustainable Housing", presented to Working Party on Territorial Policy in Urban Areas, June 2006.

The followings are measures of regulatory reform to improve housing supply elasticity, with policy examples in OECD countries:

- Increasing the flexibility of zoning regulations to allow various types of residential development including low-cost housing. German residential zoning is often more flexible than its American counterpart, for example, as it allows for doctor's offices, hostels, small hotels, and multi-story apartment buildings, which are generally prohibited in US residential zones (Buehler, 2009). The zoning scheme in the city of Christchurch, New Zealand, the Land Development Guidance System (LDGS) of the city of Fort Collins, US, and Australian Model Code for Residential Development (AMCORD), are among attempts to promote performance-based planning approaches (OECD, 2006a). Performance-based planning ensures flexibility of land uses compared to traditional zoning ordinances, although it faces significant challenges, as the process is unpredictable and not guided by clear and specific rules and procedures (Eggers, 1990). 
- Rationalising excess requirements related to housing, sites, development fees, etc., to reduce development costs. In the State of Minnesota, US, the Liveable Communities Act (LCA) aims to improve housing affordability by removing regulatory barriers that impede supply of affordable housing (Box 22).

- Making urban growth management policies compatible with housing policy objectives. Policies controlling urban growth by, for instance, establishing urban growth boundaries, could drive housing prices up and reduce housing supply by increasing residential development costs, mandating higher-cost building designs and limiting land available for residential development. Some critics even claim that urban growth restrictions that aim to prevent urban sprawl are mutually exclusive from policies to promote affordable housing (Downs, 1992; Fodor, 1999). Moreover, certain growth control policies (e.g. those that impose low-density requirements, require minimum housing size, or ban attached homes) are, in fact, specifically intended to make housing more expensive and thereby exclude lower income families. It is therefore important that urban growth management policies that aim to reduce sprawl and energy demand also incorporate measures to increase housing affordability. For example, urban growth management policies could incorporate policies that increase building densities, promote a mix of housing types, and improve access to jobs and services. These measures could offset the negative effects of increased land prices to some extent by reducing costs to residents and limiting the need for local governments to raise development fees or property taxes. ${ }^{44}$ In addition, growth management policies should ensure a certain flexibility in order not to impede local governments from achieving development goals related to housing affordability.

Since regulatory processes that induce additional delays and lengthen the construction process could undermine housing supply responsiveness more than regulations that simply add predictable costs to development, it is important to promote the following policies as well:

- Co-ordination of infrastructure and housing development policies to streamline processes related to new residential development. In Ireland, constraints related to capacity of infrastructure have caused serious bottlenecks for housing supply, which led to a sharp increase in housing prices a concentration of low-quality development in the 1990s (Evans \& Hartwich, 2005). As a result, in order to improve the co-ordination between infrastructure policies and housing policies, the Serviced Land Initiative (SLI) was introduced in 1997 to accelerate the provision of water and sewage schemes to open up land for residential development. Moreover, the strategic loosening of development regulations in priority development areas can be an effective tool. Streamlining the development process and providing "fast-track" approval processes for affordable housing projects can also increase affordable housing stock.

- Improvement of predictability, consistency, and simplicity of planning permit processes. It is important to reduce the uncertainty surrounding the planning permit process, which is a significant contributor to the costs of housing development.

44. Increased densities would reduce the material input necessary for constructing and maintaining infrastructure supporting each floor area of housing; promotion of collective housing would reduce lifecycle energy use of dwellings; and improved access to jobs and services would reduce transportation costs, which would all contribute to reduce the aggregate living cost of residents. 


\section{Box 22. Regulatory reform based on the Liveable Communities Act of Minnesota}

The Liveable Communities Act (LCA) of Minnesota, which was passed and implemented in 1995, promotes voluntary participation and incentives to increase the share of affordable housing development rather than imposing requirements and penalties (Orfield, 1997).

Programmes based on the LCA aim to improve housing affordability by removing regulatory barriers that impede the supply of affordable housing. Two studies related to metropolitan housing in Minneapolis-Saint Paul in Minnesota found that large lot sizes, minimum floor areas, development fees, and a variety of other exclusionary practices imposed significant barriers to affordable housing in the developing suburbs. For example the results showed: nine out of ten communities examined by the Centre for Urban and Regional Affairs (CURA) had lower multifamily density limits than recommend by the Metropolitan Council (i.e. a density level of 20 units per acre); $39 \%$ of the communities examined in the Minnesota State Planning study had a two-car garage requirement for single-family homes; and three cities examined by CURA required a conditional-use permit for any multifamily development (Orfield, 1997).

Municipalities participating in programmes based on the LCA negotiate affordable housing goals with the Metropolitan Council to become eligible to compete for funding provided under the programme. In the programme, financial assistance was combined with relief from government regulation, including zoning modifications and fee waivers. For instance, the Carver County Housing and Redevelopment Authority (HRA) collaborated with the city of Chaska to reduce costs related to its mixed-use building project. The city granted a zoning variance that allowed housing above commercial space and increased the allowable density three-fold to 64 units per acre, which reduced costs by USD 29000 per unit. The city also granted a variance that reduced the required number of garage spaces per unit from two to one. This reduced land acquisition, demolition, soil correction, and construction costs by an average of USD 24000 per unit. Finally, the city agreed to defer USD 40 000 in local fees, which reduced costs by USD 1250 per unit.

Although savings from regulatory relief were significant in some cases where municipalities were willing to co-operate with the LCA, in most cases, the savings were less than USD 3000 per unit (State of Minnesota, 2001). This indicates the necessity of measures to motivate local authorities to promote further regulatory reform.

\section{(iv) Policies to promote housing supply for low-income households}

In many OECD countries, the government has retreated from the role of directly supplying housing and the private sector now provides most dwellings. However, for-profit housing providers tend to build for the top end of the market because there is more profit in high-end homes than in economy homes, which leaves many communities with an inadequate supply of moderately priced homes (Foder, 1999). Thus, the public or non-profit sectors are often called upon to fill the gap of affordable housing. At the same time, creating efficient private rental housing markets is also important, because rental housing has always been the main housing opportunity for households that are unable to afford home ownership (Bramly et al., 1999) and because an efficient rental sector is very important for labour mobility (European Mortgage Federation, 2006). The following are major policy practices seen in OECD countries.

First, many OECD countries have introduced measures to ensure affordable housing provision by the private sector. Many cities have established mandatory quotas or voluntary targets for affordable housing production. In France, the national Solidarity and Urban Renewal ("Solidarité et renouvellement urbain") law requires that $20 \%$ of the housing in municipalities of over 3500 inhabitants and in agglomerations of over 50000 inhabitants be dedicated to public social housing. Those municipalities that do not meet the requirement must pay a fee based on the number of missing affordable housing units, which is then applied to the development of social housing (French Ministry of Ecology, Energy, Sustainable Development and the Sea, 2005). In the United States, the State of California requires local governments to adopt housing plans that meet existing and projected housing needs for residents of all economic levels and do not unduly constrain housing development (California Department of Housing and Community Development, 2009). Other US cities have 
enacted their own regulations to require a portion of new housing developments to meet affordability criteria (e.g. the 80/20 Program in the City of New York), or to provide incentives to developers who include a certain share of affordable housing units in their developments. Incentives can have unintended consequences, however. The US State of Massachusetts' affordable housing law known as Chapter 40B, which allows new developments with more the 20 percent affordable housing to bypass local zoning regulations, has been criticised for poor oversight and for encouraging urban sprawl (McConville, 2007).

Second, in some countries, governments have tried to enhance the housing supply through nonprofit organisations (NPOs). Whereas various measures have been introduced by governments to support NPOs, policy practices indicate the importance of improving the financial arrangements with these organisations (Box 23). They include for instance providing matching funds, increasing NPOs' access to capital markets and setting aside a share of national housing grants for NPO developers.

\section{Box 23. Supply of affordable housing by the non-profit sector}

In the United Kingdom, while direct supply by local authorities diminishes, the percentage of households living in social housing owned by Registered Social Landlords (RSLs) has increased significantly. RSLs are private sector, non-profit organisations that are regulated by the Housing Corporation in England, Communities Scotland in Scotland, and the Welsh Assembly in Wales. Developments by RSLs are partly subsidised by government funding, with RSLs expected to meet remaining costs. However, some RSLs with low credit ratings may experience difficulties in raising funds at favourable rates (Barker, 2003). It is necessary to enhance the ability of RSLs to add to their financial commitments (e.g. to increase their borrowing capacity) to promote the growth of the RSL sector as a whole.

In the Netherlands, Dutch housing associations are the principle supplier of social housing, and own over $99 \%$ of the social housing stock. The Social Rented Sector Management Decree, introduced in 1993, provides housing associations a lot of flexibility to determine their own asset management policies. Moreover, the "grossing and balancing operation", which involved cancelling all government loans against the current subsidy obligations, made the associations completely financially independent. This financial independence, and the associated professionalisation of the housing associations, reduced the amateurism in the Dutch social rental sector, which had been identified as undermining the sector's efficiency. As for financial arrangements for housing associations, the government ensures that housing associations have adequate access to the capital market. The guarantee fund for social housing construction, which was initially set up in the 1980's to guarantee loans for housing improvement, was expanded in the 1990s and covers all loans for housing associations (Elsinga et al, 2005).

In the United States, the HOME Investment Partnership Programme was introduced by the 1990 National Affordable Housing Act. The programme requires $15 \%$ of federal block grants to be set aside for communitybased non-profit organisations. The law on Low-Income Housing Tax Credit (LIHTC), which is the primary production vehicle for low-income housing in the United States, also required each state to set aside at least $10 \%$ of its grant allocation for non-profit organisations (Orlebeke, 2000). Moreover, the section 202 programme provides direct federal grants since 1990, to non-profit developers of housing for the elderly and handicapped (Wallace, 1995). In addition to these federal schemes, various measures, including housing trust funds targeting low-and moderate-income housing, have been introduced by state and local governments to support NPOs developing affordable housing. A problem of the NPO scheme is complexity and cost in arranging the finance. In order to improve the efficiency, it might be necessary, for instance, to standardise more of the elements of affordable housing finance, and reduce the number of finance sources that non-profit developers must assemble (Wallace, 1995).

Third, since land availability can present a serious constraint on the supply of affordable housing, some countries have tried to set aside land for affordable housing developments. For instance, in the United Kingdom, English Partnerships (EP) has established a register of public sector land under the Section 24 of Government Accounting, which gives EP and other agencies 40 days to consider ways of maximising the use of public-sector land to meet housing policy objectives before it is offered for sale to the wider market (Barker, 2003). In Ireland, based on the 2000 Irish Planning and Development 
Act, local authorities may dedicate up to $20 \%$ of land zoned for residential development in their jurisdictions to ensure the availability of housing at a range of income levels, particularly for those in need of social or affordable housing.

Fourth, some countries use fiscal incentives to promote the supply of rental housing. Fiscal treatment of rented housing can significantly affect investment. For example, as the fiscal treatment of rented housing is relatively unfavourable in the United Kingdom, when compared with other countries like Germany, ${ }^{45}$ the current mix of rental housing in the United Kingdom is distorted relative to the share of rental housing that a neutral rental market would produce, implying an inefficient allocation of rental housing overall (Barker, 2003). Norwegian policy could be an example of how favourable fiscal treatment can promote the supply of rental dwelling units. In Norway, where the owneroccupied sector accounts for more than $70 \%$ of the housing stock, private rental housing mainly serves certain niche groups (i.e. students, young single and childless people, mobile people, and poor groups). Such groups usually form households of a small size and do not need spacious housing. In order to meet the housing needs of such groups, the Norwegian government has been promoting the development and renting of extra apartments attached to existing housing. Premium loans from the Norwegian State Housing Bank and favourable taxation have promoted the supply of single-family houses with an extra apartment for rent to those with weaker credit, particularly where apartment blocks were scarce. According to interviewees from the Norwegian Ministry of Local Government and Regional Development, the increase of rental housing between 1988 and 1995 (from 256000 to 362 000 ) is mostly due to this system, and according to a living conditions survey in $2001,32 \%$ of the rental housing units were owned by private persons who had utilised this system (OECD, 2006a).

Finally, some countries have addressed the housing supply for households with special needs, such as the elderly. It is estimated that by 2030 , the proportion of people aged 65 and over will have more than doubled compared to 1960: the elderly population will represent more than $20 \%$ of the total population (as opposed to 10\% in 1960) (OECD, 2003a). It is important to address the unique needs of elderly homeowners and renters. Elderly homeowners, who often lack resource to invest in housing, may suffer from their homes' lack of accessibility to those with limited mobility, while elderly renters may face difficulty in finding appropriate rental dwellings (OECD, 2006a). In Japan, for example, the Act for the Stable Living of the Elderly was enacted in 2001 to promote housing supply for the elderly and to help the elderly find appropriate rental dwellings. The measures include special loans to elderly homeowners for renovations to make their homes more accessible to those with limited mobility, guarantee of rent payment to landlords, establishment of lifetime lease contract system and registration of rental housing stock with adequate quality for the elderly (Building Center of Japan, 2008).

\subsection{Integration in the labour markets}

In OECD countries, the concentration of immigrant and disadvantaged communities in rapidly growing, peripheral suburbs have created new needs for additional infrastructure in these neighbourhoods. The case of the highly diverse city of Toronto is a relevant one. In the past, immigrants benefited from social services that were mainly concentrated in the city centre where they resided. Several social service organisations operating in the Toronto region, such as the United Way of Greater Toronto, have called for the construction of additional community infrastructure - early learning and child care, social housing, English and French language training, accessible recreation

45. While rented dwellings are subject to a tax on capital gains and there is no form of depreciation allowance in the United Kingdom, rental housing investment is treated like other investments in Germany, in that interest, depreciation, and management and maintenance costs are deductible for income tax purposes and losses may be offset against other income. Moreover, in Germany, there is no tax on capital gains for private persons holding real estate assets for more than two years (Bramly et al., 1999). 
programs - in these diversifying neighbourhoods. Rapid population growth in cities calls for flexibility and visions in urban planning, as continuous adjustments in the infrastructure and in service provisions are required to avoid exclusion in urban fringes. Public transport should be leveraged to better facilitate inter-urban mobility and to improve access to jobs and social services for residents living in suburban communities.

While immigration applications are likely to be dealt with at the national level, migrants ultimately settle in local communities, and require support from local stakeholders when integration proves difficult. A wide variety of local stakeholders have stepped in OECD cities to fill this policy gap. Local activities to support integration are carried out by local and regional authorities, nongovernmental organisations (NGOs), colleges, trade unions, not-for-profit enterprises, and employers. Regional branches of the employment services, particularly in Canada, have also developed innovative solutions to supporting immigrants into work. However the most important stakeholders are arguably employers, or organisations such as colleges which help to provide a "bridge" between unemployed immigrants and local employers. As the Stockholm Territorial Review showed, even a welfare state as strong as the Swedish one is inadequate for immigrants' needs. New and innovative public policies at urban level are clearly needed, as recent examples from Stockholm shows (Box 24).

\section{Box 24. Policies for integrating immigrants into the labour market in Stockholm}

Sweden has invested heavily in programmes aimed at integrating immigrants and is one of the only countries in the world where immigrants are entitled to social assistance immediately upon arrival. However, better immigrant labour market integration requires a paradigm shift from a model of assistance and entitlement to a model that recognises the social, cultural and economic value that comes from diversity. Tackling discrimination, forging partnerships with the private sector for programmes aimed at immigrants and creating incentives for early labour market participation need to be part of this paradigm shift.

The Swedish government has taken several useful steps to promote better labour market integration of foreign-born workers. Sweden has increased protection against discrimination in employment such as the Act of 1 July 2003. In 2004, Sweden established a foreign diploma equivalency and validation board. This measure should assist immigrants upon arrival to find employment that matches their qualifications. Vocational training in fields where there are labour shortages has also been offered to skilled foreign-born workers who hold jobs for which they are overqualified. One successful programming facilitating labour market entry is the Job Centre Southwest in the Skärholmen district in the Stockholm County. This Skärholmen model has generated national and international interest because the number of households receiving social welfare benefits has dropped by half since the programme started six years ago, the best results of any Local District Council in Stockholm. However, it has been reported that this experience has provided short-term solutions, with some people coming back to unemployment in some cases after six month. The Kista matching is another example of an area that offers an opportunity to move forward on the issues of integration and inclusion. The area's robust business sector and concentration of immigrant and ethnic minority residents makes possible a unique synergy between business development and an under-utilised labour force. However, housing in the area is segregated and local residents have relatively high rates of unemployment. Services, for example those provided by the Kista Science City Information Centre (Motesplats), have focussed on labour market, such as improved placement services and career enhancement.

To improve coherence and co-ordination of actions among central government and the municipalities, county councils and regions, Sweden launched in 1998 a Metropolitan Policy aiming to 'end the social, ethnic and discriminatory segregation in the metropolitan areas and to work for equal and comparable living conditions for people living in the cities'. The initiative focuses on 24 housing districts in the three major urban areas reaching 250000 individuals. The main policy tools for achieving these objectives are the local development agreements (LDAs) elaborated by the state, the municipalities and the districts but implemented primarily by municipalities. First evaluations of the programme suggest success increasing employment rates and reducing benefit dependency. Tangible results in reducing segregation, a phenomena based on a complex set of issues, have not yet been observed despite improved neighbourhood conditions. Furthermore, there are still several distressed districts within the Stockholm Mälar region that have not benefited from LDAs, including those located in Västerås and Uppsala.

Source: OECD Territorial Review of Stockholm (2006). 
Despite a general lack of resources to deal locally with the challenges of migrant integration, there has been much local innovation in this field. In Paris, a city that has been experiencing several social tensions from poor integration of the migrants, a town councillor has been given the responsibility for migrant inclusion and integration policy. Employers are leading partners in the Toronto based Region Immigration Employment Council (TRIEC), for example, which has the mandate to improve access to the labour market for skilled immigrants. The Council includes government representatives, professional associations and NGOs and sees itself as a "solution seeking machine" running a number of different programmes which link employers with immigrants. Their "Career bridge" scheme requires local employers to pay a fee to access a pool of pre-selected graduates, who then carry out paid work experience with the company for up to twelve months. 300 internships have already taken place with $85 \%$ receiving offers of full employment. In London, skills shortages in the education, engineering and construction sectors have led to the development of a citywide partnership involving the London Development Agency and five Learning and Skills Councils, to assess the qualifications of a 1000 immigrants and broker relevant ongoing training. In the west of the city, a partnership known as Renewal has also been developed to link local employers with a more specific migrant group, refugees. This partnership funds and co-ordinates a wide variety of community based projects and is led by a major public sector employer.

One of the reasons why migrants are often observed to have worse labour market performances in the cities is the fact they tend to form "enclaves". Enclaving is a process of residential and labour segregation that slows down migrant assimilation, perpetuating inequities in social mobility across ethnic groups. The physical disconnection from jobs can exacerbate unemployment among low-skilled minority workers (the so-called "spatial mismatch" hypothesis). Segregation often extends to the education market, adversely affecting school performances and raising drop-out rates among minorities. For example, despite comparatively good earning performance of migrants, ethnic segregation in Copenhagen's schools comes close to the high segregation levels of many US cities. The dropout rate of immigrants from vocational education is almost $66 \%$ - compared to less than $30 \%$ for persons of Danish origin. These inequities generate efficiency losses, as creative and talented individuals do not develop the capabilities to contribute to the local economy according to their potential. The city of Copenhagen has responded to this challenge by developing a programme for stimulating more mixed schools: the Copenhagen Model for Integration ensures that schools reserve places for students from catchments with high ethnic concentration.

Immigrant inclusion in OECD cities benefits from increasing use of labour matching services. Though a wide number of employment centres have been built to provide information to immigrants and employers, it is likely that these services are not being taken advantage of and used to their highest potential. This was found to be the case in Milan, which has more development employment centres and a higher number of immigrants. There in 2005 only $10 \%$ of businesses and $2 \%$ of immigrants used the services of employment centres for immigrants (Chaloff in OECD, 2006f). Both businesses and immigrants need to be made aware of these advantages of using these services.

Experience from OECD cities shows that the involvement of professional associations can expedite immigrant integration. As more highly skilled immigrants arrive to OECD countries as a result of skill-biased migration policies, the accreditation of foreign qualifications and experience will be of increasing importance. The example of Toronto provides a useful reference for more engaged professional associations. For example, Professional Engineers Ontario (PEO), a professional association with regulatory authority for the engineering profession, allows written examinations to be taken prior to immigration and issues provisional licenses to applicants who have satisfied all the licensing requirements except for the minimum 12 months of acceptable engineering experience in Canada. Professional associations also have a role in providing "bridge-to-work" programmes, which 
help immigrants to get work experience in Canada. Most of these programmes are funded by provincial and federal governments and facilitated by professional associations, education institutions and not-for-profit organisations (OECD, 2009h).

Immigrant workers are often found to be more entrepreneurial than locals in OECD cities, so immigrant entrepreneurship could become a vital economic force for employment creation. However, little resources are generally dedicated to confronting problems immigrants face in establishing businesses. The problems faced by immigrant entrepreneurs include unfamiliarity with the culture and economy of host city, poor access to information, poor credit, limited business language skills, difficulty in obtaining recognition of professional skills, and lack of involvement in professional associations. In the city of Turin, the chamber of commerce published in 2003 a guide in the nine principal foreign languages spoken in the region, providing information on laws and authorisations, and on services available (health, educational, etc.), which would be useful for immigrants wishing to start a business. Similar initiatives exist elsewhere in OECD regions. In Bologna, the National Artisan Confederation opened a special office for immigrant entrepreneurs, which provides a wide range of consulting, orientation and mediation services for the more than 500 immigrant entrepreneurs. The service supports the development of business plans and runs training courses for entrepreneurs. Other institutions, such as banks, have been less quick to adjust to change (Chaloff in OECD, 2006f).

There are several monitoring tools that have been developed to evaluate the implementation and outcome of integration programs. Improved monitoring and accountability would be achieved through adopting the metrics developed by the INTI-CITIES' "Benchmarking Integration Governance in European Cities" project. ${ }^{46}$ Co-financed by the European Commission, this programme developed a rigorous assessment model that includes indicators for assessing integration governance structures at the local level The benchmarks questions on the performance of inter-departmental committees for migrant integration, public reporting of results of its migrant integration policy, and the costeffectiveness of inter-departmental work on integration, can help identify the bottlenecks causing the current fragmented organisation for integration services: housing, education, and employment tend to be tasked in different departments. It is increasingly clear that the complexity of the integration process requires dedicated resources and a multi-agency approach. A strategic approach to assimilation has been pursued by the city of Helsinki, which adopted in 1999 an inclusive integration strategy: migrants should be treated as citizens of Helsinki and potential citizens of Finland. The goal of the Integration Programme is to encourage the integration of immigrants by supporting Finnish language training, education, employment and their participation into cultural and voluntary activities and by promoting immigrants' participation in planning of issues concerning their own affairs.

\subsection{Integrated urban development for distressed neighbourhoods}

Urban decay is a problem in many high-density areas that were built as recently as $30-40$ years ago in response to migration pressures. The poor quality of the buildings and the lack of proper maintenance, along with insufficient space to respond to growing demands (in particular for social infrastructure and green spaces) have degraded living conditions. Moreover, such neighbourhoods are often associated with abandoned industrial sites that constitute an environmental hazard. Recurrent events in urban areas in France, the US, Denmark and the UK reflect the dangers to community life that can be caused by poor living conditions, and the negative impact that a lack of confidence in their environment can have on the expectations and behaviour of residents. Social cohesion and equitable access to urban amenities and opportunities, such as education and jobs, are critical challenges for urban sustainability because urban structure dynamics are generally characterised by segregation

46. See $w w w$.integrationindex.eu for more information. 
trends. Many OECD countries have developed place-based policies to address exclusion and foster the integration of people living in distressed neighbourhoods.

In order to avoid the concentration and spatial segregation of the urban poor and, it becomes important to appropriately integrate and disperse housing for different household income categories within the same neighbourhood. Design quality and integration with market-rate housing are important factors for minimising negative perceptions of affordable housing projects. Moreover, once spatial segregation becomes evident, promotion of a greater social mix could be done in two main ways: to attract a certain household category missing in the neighbourhood (e.g. attracting better-off households to a low-income area), and to relocate households from a homogeneous area (e.g. low-income area) to a better mixed area or an area where such households are missing (e.g. middle-income or high-income areas) (Holmquist, 2005).

In addition, in order to maximise the positive effect of dispersal programmes that integrate disadvantaged households into better-off areas, it is necessary to enhance the upward social mobility of integrated households and to avoid negative effects on integrated neighbourhoods. It is also necessary to ensure an appropriate jobs-housing balance and the quality of transportation to make integrated households increasingly participate in social and economic activities.

A "negative competition" among local municipalities to reduce services for disadvantaged households impedes less-distressed jurisdictions from promoting dispersal programmes. In order to enhance social cohesion at a regional level, there is a role for national and regional governments to address negative competition and ensure achievement of fair social distribution in each jurisdiction. Practices in OECD countries demonstrate that institutional or legal arrangements promoting intraregional co-ordination of housing policies as well as negative economic incentives (e.g. fines on jurisdictions according to the level of non-compliance with distributive targets) can be effective in managing negative competition (OECD, 2006f).

Different policy approaches have been experimented to tackle urban poverty and spatial polarisation within metropolitan areas. An instance can be taken from Mexico City, where, as elsewhere, the problems are metropolitan-wide, but the solutions are often top-down and organised according to political jurisdictions (OECD, 2004c). There, the federal government launched the Habitat programme in 2003 that intends to improve public infrastructures and services in nearly 60 cities. A more integrated approach that will include other social measures is currently being developed. In the Netherlands, the City of Rotterdam has focused rather on making it more difficult for poor people, particularly recent immigrants to live in the city, and on attracting wealthy residents. In France, there has been an attempt to reduce the social isolation of these areas (mainly through large urban renovation projects) and to attract economic activity to them (mainly through the 'urban free zone' policy). However, it has proven very difficult to link the two objectives - social cohesion and economic development - in a single comprehensive policy package led by a single ministry (Box 25).

\section{Box 25. Fighting urban poverty and distressed neighbourhoods in Mexico, France, and Rotterdam}

\section{The Mexican federal policy in urban areas.}

Recognising the need to foster the fight against urban poverty, the Habitat programme, launched by the federal government in 2003 was essentially designed to combine federal and local budgetary resources to finance physical infrastructure (streets pavement, construction of sidewalks, expansions of networks for water, drainage and electricity, and also building of community centres, day-care centres for the elderly, shelters for victims of family violence, etc.), in well defined zones (poligons) within cities, that concentrate large shares of urban poverty.

A more coherent and integrated approach to urban poverty alleviation has recently been launched to complement the existing Habitat programme with other types of poverty alleviation measures and better 
involvement of local actors. The SUMA con Habitat programme seeks to articulate the objectives of social policies with those of territorial and urban development in a framework that includes all regional and local government actors and joint funding responsibilities between federal, state and municipal governments, as well as private investors. More specifically, the new programme will combine existing measures to improve physical and social infrastructure and public services delivery with subsidies or income transfers for poor households for basic consumption of private goods (food, healthcare, etc.), as well as more longer term policy actions such as basic education and labour training for adults, financial supports to small businesses and self employment and other types of measures to support capital accumulation (family dwellings, etc.). In terms of implementation, innovative governance mechanisms would be developed to secure both horizontal co-ordination among programs from different sectoral authorities and vertical collaboration between different levels of government that have distinct responsibilities at the local, regional or national levels. A particular focus would be put on providing adequate schemes of social participation around the design, monitoring and evaluation of the programs. Two surveys will be conducted, at the beginning and at the end of the pilot test, to assess the impacts of this co-ordinated strategy and compare its effectiveness (impacts) relative to those obtained in other local contexts where policy interventions are not integral and are not co-ordinated.

\section{French policies for urban distressed areas: the city contract and Urban Free Zones policies}

Until the 1970s, France's urban policy goals were essentially quantitative. They sought to promote the construction of as much housing as possible. This approach led, to some extent, to problems of spatial segregation which had to be addressed in the 1980s with targeted initiatives. In some areas these took the form of new infrastructure and social and environmental measures (rehabilitation of large estates, neighbourhood social development). The rationale behind urban policy today is to progress beyond merely renovating problem neighbourhoods and, using comprehensive development plans, foster genuine social and urban development in these "disadvantaged" areas that are home to 5 million people. As a result of the French urban policy - territorybased and contractual initiative - specific procedures have been developed since the 1990s leading to the creation of: 247 city contracts for the 2000-2006 period, 751 sensitive urban zones (ZUS), 416 urban revitalisation zones (ZRU), 85 urban free enterprises zones (ZFU).

City contracts (which reflect a commitment on the part of one or more local and central authorities to jointly implement a multi-annual programme, designed to deal with the most disadvantaged neighbourhoods areas at urban area or municipal level) were introduced under the 1993 Urban Revival Plan, with the aim of promoting a comprehensive strategy rather than the previous sector-specific policy. City contracts are first and foremost viewed as contributing to urban social development. More than 1300 neighbourhoods and six million inhabitants are now benefiting from the initiatives introduced under the 247 city contracts. ${ }^{47}$

The urban "free zones" (ZFUs). The 1996 Urban Revival Pact (1996-1998), introduced as part of a programme of affirmative action on behalf of specific urban areas in difficulty, was a more significant effort to tackle their disadvantages from an economic perspective. In particular, it set up the mechanism of the urban "free zones" (ZFUs). The 44 ZFUs (0.8 million inhabitants in 1999) were designated by decree by the Conseil État, "taking account of the factors that will attract enterprises or foster the development of economic activity". The principle is to offer reductions in taxes and social contributions to businesses that set up in these zones and recruit at least $20 \%$ of their personnel from those living in the ZFU (or in other sensitive urban zones (ZUS) in the same urban area).

Several reports give a favourable assessment of this policy, in terms of enterprise and job creation and of achievements in terms of investment. ${ }^{48}$ They also emphasise the technical problems involved in precisely gauging

47. Following criticism of the earlier programme of grands projets urbains (GPUs) a programme of 110 more numerous and ambitious city projects and urban renewal schemes designed as an integral part of city contracts was introduced in 2001 . These seek, among other things, to promote social revitalisation and upgrading, in order to restore the economic value of the areas. They include schemes to introduce public and community services, make certain districts less isolated and incorporate them into the urban area (improving transport, improving the distribution of urban functions across the area) and breathing new life into the economy (reinforcing the existing fabric, assisting local people with business creation).

48. Including the report to Parliament by the Minister for cities in July 2001, the urban policy report by the Audit Office in 2002 and the information report by the Senate Commission for Economic Affairs and Planning in July 2002, 
the specific impact or cost-effectiveness of the attendant tax and social exemption measures. However, it should be noted that the latest enterprises to set up in the ZFUs are most often concentrated on the edges of the zones, because of the lack of sites available in the more central districts. It is therefore on the periphery of these areas that economic development is the most marked, and the impact of the ZFUs on the more central areas is limited.

The generally favourable assessment of the first generation of ZFUs prompted the government in 2003 to give the current list of 44 free zones a five-year extension and broaden the scheme further. As from 1 January 2004, a regime of tax and social exemptions for 41 new free zones was created under the framework law of 1 August 2003 on urban renewal. It grants five year tax exemptions to small enterprises with fewer than 50 employees that set up business in ZUS districts, provided that one-third of the jobs created go to people living in problem neighbourhoods in the larger urban area. Opinion remains divided about their value. According to one study by Ernst and Young, the average cost of tax and social exemptions for one job in a ZFU (whether created, transferred or already existing) ranges from FF 33753 (EUR 5 158) to FF 44832 (EUR 6 838). However, the ability of ZFUs to create jobs in the long term is regularly questioned. To date, urban policy has not markedly closed gap in development and inequality between the ZUS areas and the rest of the country.

In addition, an urban renovation programme, comprising 52 major city projects (GPV), three of which are located in the overseas territories, and 70 urban renewal operations that will soon be extended to over 165 sites has been launched. To complement its action, the government has created recently the National Urban Renovation Agency, a public corporation that allocates substantial grants to local communities planning to carry out urban renovation projects. A far-reaching five years nationwide urban renewal programme has been launched to improve housing and environmental conditions in priority areas. It includes the building of 200000 new subsidised rental housing units, the rehabilitation of 200000 rental housing units, the demolition of the same number of run-down housing units and a programme to rehabilitate common areas.

\section{Urban redevelopment in Rotterdam}

The city of Rotterdam is forming a logistic centre in Europe, with the first European port for the transportation of goods. The area has faced since the 1980s strong pressures, linked to structural changes which resulted in decline and loss of many basic port-related industries. This transition had a greater impact on low skilled labour, largely consisting of immigrants with little education. The decline of the area expelled middle-class residents, which resulted in the concentration of poverty and important increase in social problems. To face these challenges, Rotterdam has adopted since the 1990s strong - often controversial - policies aimed at improving social cohesion and conducting urban redevelopment. Poor housing stocks have been demolished and replaced by more expensive housing to attract middle-and high income people. The municipality has also decided to pursue a stricter population policy, focused on retaining and attracting the better-off who have a more solid socioeconomic position in the districts where the quality of life is under pressure. At the same time, there is the desire to stem the influx of underprivileged to Rotterdam. The municipality of Rotterdam has submitted a request to the central government to amend the Housing Act. This would allow Rotterdam to require a minimum socio-economic level for households from outside the Rotterdam urban region who wish to reside in Rotterdam. The long-term plan is to reduce social housing from $72 \%$ to $60 \%$ over 15 years. Rotterdam has also reduced tax rates in certain areas. This policy has contributed to attract new entrepreneurs by providing high quality building environment and lower tax rates. The comprehensive urban redevelopment plan is also placing a priority on education and giving schools a broader role of educational and community development (vocational training, social skills, etc.).

Source: OECD (2006b), OECD Territorial Review of France, OECD Publishing, Paris; OECD (2004c), OECD Territorial Reviews: Mexico City, OECD Publishing, Paris; OECD (2007h), OECD Territorial Reviews: Randstad Holland, Netherlands, OECD Publishing, Paris.

\section{Climate change and environmental damage}

How cities develop matters to greenhouse gas emissions levels, vulnerability to climate change impact, and environmental damage. As consumers of a great majority of energy production worldwide - between 60 to $80 \%$, cities are primary contributors to $\mathrm{CO}_{2}$ emissions. Climate change also poses a real threat to cities' development and competitiveness, as rising coastal waters, more severe storms, and urban heat island effects threaten to damage infrastructure, reduce efficiency, and exacerbate urban poverty. Cities across the OECD have begun to take action to mitigate their contribution to greenhouse gas emissions and adapt to expected climate change impacts through urban sectoral policies and through co-ordination with national and regional governments. Urban action on climate 
change is supported by the recognition that climate change mitigation and adaptation are closely linked to competitiveness, and that cities that reduce their emissions and their vulnerability to climate change are more likely to attract economic activity than those that do not.

Urban planning decisions about how cities grow lock society into development patterns that persist for decades to come. The right choice of urban policies is particularly important to ensure that long-lived infrastructure is designed to withstand the expected increase in climate hazards while simultaneously improving the energy and emission performance of the built environment. Especially in countries where urbanisation is still rapidly occurring as in China, a shift to climate-friendly urban development patterns offers enormous opportunity for cost-effective action. Urban centres may also be particularly vulnerable to some of the distributive impacts of climate change. Poor populations in both rich and poor nations are expected to be the most vulnerable to climate change in part due to the lack of resources and capacity to respond in a timely manner. Integrated urban planning is central to land use decisions and zoning that may exacerbate or limit the exposure and vulnerability of urban dwellers and infrastructure to the growing threat of climate change. Action is needed to address simultaneously both adaptation to potential climate change effects and mitigation of cities' impact on climate.

\subsection{Urban policies to address climate change and urban sustainability}

Cities and metropolitan regions across the OECD provide examples of taking action on climate change - even in the absence of national policy or commitments - not only out of recognition of cities' contributions to and risks from climate change, but also of the opportunities to lower the potential tradeoffs between economic growth and environmental priorities. Cities and regional governments both small and large - are well positioned to tackle certain types of policies, particularly those relating to spatial development and the built environment, transportation, natural resources management, building and urban utilities. While some local and regional governments have taken action independently, others have benefited from guidance provided by national and transnational networks of local governments. These include the Nottingham Declaration in the United Kingdom (signed by 300 local authorities ${ }^{49}$ ) and transnational networks such as ICLEI, the METREX EUCO 2 80/50 project, and the Covenant of Mayors. ${ }^{50}$ Urban climate action has also developed in response to national government mandates, such as Japan's Act on Promotion of Global Warming Countermeasures, which requires local governments to formulate climate change action plans. ${ }^{51}$

The context for urban policymaking and programme implementation often involves multiple levels of governance. Cities in the OECD often need to collaborate with other cities and higher levels of government - as well as private sector and non-governmental stakeholders - to gain the authority, technical expertise and funding needed for their climate policy goals. This can require vertical coordination among local, regional and national governments, and horizontal co-ordination among the range of agencies engaged in climate policy within a local government, as well as among the local governments within a region. In some cases, the role of local governments is to administer national

49. www.energysavingtrust.org.uk/nottingham, accessed 18 November 2009.

50. ICLEI's Cities for Climate Protection was one of the first net works established, and counts over 680 cities as members from over 30 countries worldwide (www.iclei.org/climate-roadmap). The EU $\mathrm{CO}_{2}$ 80/50 project, organised by METREX: The Network of European Metropolitan Regions and Areas, targets a reduction in GHG emissions by its member cities of $80 \%$ on 1990 levels by 2050 (www.eurometrex.org/ENT1/EN/Activities/activities.asp?SubCat1=EUCO2). The Covenant of Mayors is a commitment by signatory towns and cities to exceed $\mathrm{EU} \mathrm{CO}_{2}$ emissions reduction targets (www.eumayors.eu/).

51. Response to OECD "National-Local Climate Change Governance Practices Questionnaire" by Naoto Nakagawa, Japanese Ministry of Foreign Affairs, 10 August 2009. 
programmes or apply for and redistribute national funding. In other cases, urban areas act independently of outside programmes and may even innovate policy solutions that get scaled up to the regional or national levels (OECD, 2009a). Urban areas in general engage in at least four modes of governance through which they can design and implement climate change policy responses. These modes (adapted from Kern \& Alber in OECD 2008c and 2009a) are: self-governing (e.g. municipal operations management and purchasing); governing by provision (e.g. by influencing infrastructure development, programme administration and service delivery in the provision of urban services); governing by authority (e.g. by climate enacting regulations where cities have legal jurisdiction); and governing through enabling (e.g. facilitating co-ordination with private sector and civil society actors).

City and regional governments may more easily identify and combine complementary climate policies within and across sectors than higher levels of government, given the interconnectedness of urban policy sectors. The existence of a policy complementarity signals a benefit in the form of the return generated when one policy is enacted along with another (De Macedo \& Oliveira Martins, 2006). Identifying the impact and benefits that policy sectors can have on each other is essential to designing policy packages that enhance the effectiveness of each individual policy. Some urban sectors are particularly interlinked to others, and thus can enhance or undermine the effectiveness of other sectoral policies. For example, land-use zoning, i.e. the decisions regarding the location and density of residential, commercial, industrial land uses, among others, has the widest influence on other sectors. Transportation policies are also interlinked with land-use zoning, natural resources management and use of renewable energy, as they affect the amount and type of energy required to travel between activities within a metropolitan region as well as the impact and vulnerability of transport infrastructure relative to the surrounding environment. Policy complementarity within each sector is also crucial, and more easily co-ordinated at smaller scales. For example, transportation polices to limit personal vehicle use are enhanced by policies to increase mass transportation options.

\section{Land-use zoning policies}

Land-use zoning policies have a wide-ranging, long-term and yet underlying effect on sectoral policies to address climate change. Spatial planning affects the placement of the built environment, and therefore the distances required for urban travel, the energy required to heat and cool buildings, and the vulnerability of the built environment. Urban master plans and land-use zoning policies determine the set of land uses that are allowed in a particular zone - at the most basic level these include residential, commercial, industrial, open space and mixed uses - and the degree to which land uses are separated from one another. These decisions shape the built environment and determine longterm travel patterns, building placement, access to amenities and exposure to natural hazards.

Land-use zoning policies impact transportation policies that aim to reduce GHG emissions by determining the degree of segregation among land uses and therefore the energy required to travel between home, work, shopping and other activities. The degree to which these uses may be segregated varies within the OECD. For example, German residential zoning is often more flexible than its American counterpart, as it allows for doctor's offices, hostels, small hotels, and multi-story apartment buildings, while most residential zones in the United States are restricted to single-family dwellings (Buehler et al., 2009). The establishment of mixed-use zones, which allow for the development of a combination of business and residential uses, is one way of providing alternatives to segregated zoning. However, where mixed use zones are not the norm, they are typically only applied in specially designated districts where their impact is limited (Hirt, 2007).

Land-use zones that allow for transit-oriented development can facilitate increased use of public transportation. While it may not change trip distances or frequencies, it can decrease the distances between mass transit stations and residences, places of work and retail. The City of Toronto has created policies to encourage or require mass-transit oriented development, in addition to policies to 
facilitate density in the urban core and mixed-use (residential and commercial) development. ${ }^{52}$ The City of Toyoma, Japan, is pursuing transportation-oriented growth by concentrating city functions such as residential, commercial, business, and cultural facilities along a newly established light rail line, built over an underused long-distance rail line (Mori in OECD, 2009c). Arlington County, Virginia, promotes transit-oriented development around the light rail system by providing density credits, increasing parking requirements and improving infrastructure around transit stations. As with mixed-use zones, transit-oriented development zones are often exceptions to traditional land-use zones and therefore can be limited in their reach. Comprehensive reform may require an overhaul of residential zoning codes to systematically allow non-residential uses rather than the piecemeal designation of mixed-use zones (Hirt, 2007).

Land-use planning tools also have a fundamental impact on natural resource management. They present a primary means for cities to adapt to potential climate change impacts, including reducing vulnerability to flooding and extreme weather events. Local government disaster management plans are being updated to take into account potential impacts and vulnerability assessments. The Municipality Plan for Hedensted, Denmark, focuses on flooding by prohibiting new development areas at risk under 100-year IPCC flood scenarios (Local Government Denmark, 2009). The Finnish cities of Espoo and Helsinki have mandated that new planned areas be 2.6 metres above sea level, and that the lowest floor level of new buildings be 3 metres above sea level. ${ }^{53}$ Planners in the United States have introduced the concept of "rolling easements" to discourage development of coastal areas by granting a public right-of-way to a narrow portion of coastal property, which migrates inland as the shore erodes. This prevents coastal land owners from erecting structures to block sea level rise and transfers the impact of sea level rise to the private land owner (Titus \& Narayanan, 1996). The most immediate impact of the policy would be to discourage new coastal development in areas vulnerable to coastal flooding (U.S. Global Change Research Programme, 2009).

Land-use policy can also support building policies that increase energy efficiency. Residential zones restricted to single-family dwellings, common for instance in the United States, can greatly restrict the availability of multi-family and row housing, both of which typically are more energy efficient per capita than detached single family dwellings. Land-use policy tools that promote multifamily or compact housing zones can also facilitate the use of district heating and cooling systems by allowing service to a greater number of customers in a given area than would be possible in a singlefamily residential zone. Land-use policies can also aim to reduce urban heat island effects, as the cities of Stuttgart, Freiburg and Mannheim, Germany have demonstrated. These policies include regional plans that provide minimum standards for open spaces, including a minimum width of 500 metres for "green corridors" and 250 metres for "green breaks". Mannheim is also taking thermal impacts into account when pursuing infill development.

Many metropolitan regions in the OECD have created "sustainable neighbourhoods" or "econeighbourhoods" that combine transportation, natural resource preservation, building, waste and water policies to respond to climate change and reduce the urban environmental footprint. Common principles include increasing energy efficiency, using sustainable building materials, and reducing personal vehicle use. The most notable "eco-neighbourhoods", either completed or currently under development, are located in western and northern Europe, including in Sweden (Bo01 and Augustenborg in Malmö and Hammarby Sjöstad in Stockholm); Finland (Viiki in Helsinki); Germany

52. Response to OECD “Local Climate Change Governance Practices Questionnaire” by Mark Bekkering, City of Toronto, Environment Department, 11 August 2009.

53. Voutilainen, O. (2007), "How do Finnish cities respond to climate change", presented at the OECD Workshop on Competitive Cities and Climate Change: Challenges and Opportunities, Paris, France, 30 November 2007. 
(Vauban and Rieselfeld in Freiburg; Kronsberg in Hanover); Denmark (Vesterbro in Copenhagen); the Netherlands (Leidsche Rijn in Utrecht); and Great Britain (BedZED in Beddington, zero-carbon communities). Eco-cities are also under development in China, as well as in Korea and Abu Dhabi. Residential density varies among sustainable neighbourhood projects, although most could be described as low-rise high density; towers or high-rise apartments are rare. Sustainable neighbourhoods shape development beyond residential density; cars may be restricted or prohibited (such as in Vauban) and waste collection policies that are more restrictive than elsewhere in the city may be imposed.

The urban policies discussed above intersect with the question of urban density. Many cities have begun pursuing policies to increase the density of residential neighbourhoods and favour concentration at the centre of the urban agglomeration as a means to facilitate the climate change mitigation and adaptation measures. The concept of the "compact city" as a spatial development strategy has become popular in many OECD countries, particularly in Europe and Japan. The European Commission (Commission of the European Communities, 1990, 1992) encourages European cities to move towards more compactness, on the basis of environmental and quality of life objectives. The British government has made urban compactness a central element of its sustainable development policy (Department of the Environment, 1993) and the Dutch government has taken similar action (National Physical Planning Agency, 1991). Most recently, the Japanese government has introduced the concept of "Eco-Compact City" as one of its top-priority urban policies (Ministry of Land, Infrastructure, Transport and Tourism, 2009). The compact city strategy aims to intensify urban land use through a combination of higher residential densities and centralisation, mixed land uses, and development limits outside of a designated area (Churchman, 1999). Compact cities also typically involve concentrations of urban services and transportation options and high degrees of land-use planning controls (Table 12) (Neuman, 2005). While some associate compact cities with high-density development, the concepts are distinct. Compact development prioritises development close to and radiating from an urban core, where the definition of high-density development is based primarily on the concentration of dwelling units, regardless of proximity to an urban core or urban amenities. In some metropolitan regions, compact development may apply to polycentric development, where two or more cities in a region share complementary functions (Nordregio, 2005), in which case compact development strategies radiate from each urban core.

Table 12. Compact city characteristics

- High residential and employment densities

- Mixture of land uses

- Fine grain of land uses (proximity of varied uses and small relative size of land parcels)

- Increased social and economic interactions

- Contiguous development (some parcels or structures may be vacant or abandoned or surface parking)

- Contained urban development, demarcated by legible limits

- Urban infrastructure, especially sewerage and water mains

- Multimodal transportation

- High degrees of accessibility: local/regional

- High degrees of street connectivity (internal/external), including sidewalks and bicycle lanes

- High degree of impervious surface coverage

- Low open-space ratio

- Unitary control of planning of land development, or closely co-ordinated control

- Sufficient government fiscal capacity to finance urban facilities and infrastructure

Source: Neuman, Michael (2005), "The Compact City Fallacy", Journal of Planning Education and Research, Vol. 25, No. 1, Sage Publications, pp. 11-26. 
While compact development presents advantages for low-carbon development, its impact on urban economic and social priorities is complex. On one hand, high-density residential areas have been associated with a more economically efficient use of high-priced land and a greater mix of housing types, which may facilitate a more diverse mix of residents than areas dominated by singlefamily housing (Churchman, 1999). On the other hand, high residential densities can lead to increased traffic congestion and pollution, and the value of land may also rise significantly as a result of highdensity developments, which can discourage the preservation of open space and limit residents' access to in high-density areas (Churchman, 2003). Higher housing prices and smaller dwelling sizes, both associated with high-density areas, may lead families with children to leave for areas with lower prices, larger dwellings, or opportunities for outdoor space. This can lead in turn to economically and socially heterogeneous high-density areas. Spatial planning strategies are needed to manage these potential issues, which point to a need for development plans that respond to rapid growth and demand for undeveloped land while taking into account the environmental and climate impact of urban activities. To effectively reduce GHG emissions, it is critical for spatial policy tools to reduce distances between residential, employment, shopping, and leisure activities, which is not necessarily achieved increasing residential densities alone. Transportation and resource efficiency, and open space preservation can be facilitated by spatial development that is planned to maximise transportation linkages, prioritise areas adjacent to public utilities services, and preserve open space. The Ile-deFrance region provides a key example of combining these elements in the new SDRIF (Master Plan for the Île-de-France Region), which encourages higher density in existing urban spaces, prioritises development around a network of structured urban centres and areas served by public transportation, and strengthens the network of open spaces in the region. The SDRIF aims for urban "intensity", or the linking of dense neighbourhoods to quality public transportation, parks and open spaces, services, and jobs (Fouchier in OECD, 2009c).

\section{Transportation policies}

Many cities in the OECD have focused on achieving urban climate goals through the transportation sector. The transport sector is a significant and growing contributor to GHG gas emissions. Transport activity is responsible for $23 \%$ of world $\mathrm{CO}_{2}$ emissions from fossil fuel combustion - this share rises to $30 \%$ in OECD countries. Key transportation policies to reduce GHG emissions or adapt to climate change impacts aim to: increase use of public transportation systems; decrease personal vehicle use and manage traffic demand; support non-motorised means of travel; increase vehicle fuel efficiency and use of alternative fuels; prevent disruptions to transportation system due to flooding; and prevent disruptions to transportation system due to extreme temperatures. A key distinction should be made between policies that impact accessibility, or the ability for people in urban areas to gain access to employment, retail, services and activities, and policies that impact mobility, or the ability to travel a given distance. Policies to reduce GHG emissions from vehicles may reduce mobility by discouraging personal vehicle use and increasing mass transit use, while land-use policies to increase proximity to urban amenities and a mixture of commercial and residential land uses can improve accessibility.

As providers of public transit, local and regional governments in the OECD have increased the use of public transit systems by focusing on improving quality, increasing linkages with multiple modes and expanding service. To improve linkages between multiple modes of travel, multiple local agencies often need to co-ordinate service delivery, which requires effective regional co-ordination on transportation planning. There has also been a growing focus on better management of existing public transport networks in order to increase ridership through improving their quality and reliability. Many local transportation agencies, including those in Stuttgart and Paris, have implemented real-time signage systems to communicate expected arrival times to mass transit customers. In China, the City of Beijing aims to achieve a $40 \%$ share of public transport use, which would build on an increase in 
market share from $30 \%$ to $39 \%$ over $2005-2008$, by expanding public transit service, improving quality and providing linkages to other travel modes (Liu et al., in OECD 2009c)

Local governments have used their authority over the design and management of a city's road system to increase the share of non-motorised means of travel, particularly biking and walking. Local governments can eliminate traffic lines lanes or use "traffic calming" strategies, such as replacing intersections with traffic rotaries and enlarging sidewalks, to both discourage driving and encourage foot travel. Local governments can also make structural improvements to encourage travel by bicycle. While city-operated shared bicycle rentals, such as Paris' Vélib', Rio de Janeiro's Samba and Montreal's Bixi have been highly promoted for their potential to reduce GHG emissions, the corresponding efforts to facilitate bicycling, including the creating of protected bicycle lanes and clear signage of bicycle routes, may have a more significant impact on the attractiveness of bike travel.

Local governments can also decrease personal vehicle use by enabling alternatives through programme co-ordination and technical assistance. Cities can facilitate the use of alternatives to personal vehicle use through programmes such as the City of Toronto's Smart Commute Programme, in which the city works with large employers to develop plans that encourage their employees to utilise alternate forms of transportation. ${ }^{54}$ Some cities have also begun to provide shared-car services through concessionaries, including the City of Hanover. While cities influence individuals indirectly when they work with employers to create employee travel plans, Cambridge Systematics, Inc. (2009) estimated that employer-based commute strategies (including vanpools, employee parking pricing and tele-work policies) can result in an up to $1.7 \%$ reduction in baseline GHG emissions, similar to their estimates for congestion pricing. The actual impact of employer-based strategies on GHG emissions depends of course on the scale at which they are implemented (Cambridge Systematics, Inc., 2009).

Cities can also take the lead on promoting use of renewable fuels for transportation and discouraging fossil fuel use by increasing the share of renewable energy used for mass transit systems and supporting the development of new technologies. Some local or regional governments directly fund development. For example, the Eindhoven metropolitan region, in the Netherlands, was at the centre of the development of a low-emission public transport vehicle, the Philias - an advanced, guided bus that is controlled by a magnetic system built into the road-and that connects various communities within and around Eindhoven to major regional facilities, including the airport ${ }^{55}$ (OECD, 2009a; Broaddus, 2007). Others provide funding, such as the City of Paris' programme providing EUR 400 to purchasers of electric motorcycles (City of Paris, 2009).

Reducing infrastructure vulnerability to climate change impacts poses a key challenge for local and regional transportation authorities. Preventing disruptions due to flooding is chief among these concerns. It is vital for cities to clearly assess and plan for sea-level rise, storm-surge and other storm impacts that exceed existing 100-200 year plans. Below-ground transportations systems are particularly susceptible to water damage. Effects from extreme temperatures can also disrupt mass transit systems if they exceed the heat thresholds for which roadways and public transportation systems have been designed. Currently, most transit system agencies have not yet started making improvements to infrastructure, although some cities have developed plans for protecting underground transit systems from coastal flooding. Concern about climate change impacts is also beginning to shape future infrastructure development. For this reason, nationally funded local infrastructure projects in Switzerland have to submit to climate change standards mandated by the Swiss Federal Department

54. From response to OECD "Local Climate Change Governance Practices Questionnaire" by Mark Bekkering, City of Toronto, Environment Department, 11 August 2009.

55. Philias Bus Rapid Transport Eindhoven, Part I, Video. http://www.youtube.com/watch? $v=S t N$ $4 x d z h z 4$. 
of the Environment, Transport, Energy and Communications. ${ }^{56}$ While adaptation plans and taking climate change impacts into account in new infrastructure are important steps, system-wide vulnerability assessments and large-scale retrofitting are needed to respond to impacts that are expected to exceed existing worst-case infrastructure planning scenarios.

Transportation policies can enhance policies in other sectors as well as within the transportation sector. Transportation policies can be designed to support strategic territorial plans by prioritising service in compact and high density Policies to reduce personal vehicle use such as through restrictions on travel and parking are most effective when combined with policies to increase transportation quality and options for bicycle or foot travel. Taking advantage of policy complementarity requires transportation decision making to become more multi-sectoral and to coordinate with other local and regional, and in some case national, policy makers. Transportation policies have an impact on land-use zoning policies and natural resource policies as transportation networks can increase the value of the properties they serve and can improve the perceived quality of high density developments. On the flip side, expansions in road and rail services can also lead to demand for suburban land. These measures can provide co-benefits in the form of a wider set of sustainability objectives, such as congestion mitigation, improved air quality and better accessibility.

\section{Natural resources and environmental management}

Local governments are making use of their jurisdiction over environmental features within their boundaries to protect developed land from potential climate change impacts. For coastal cities, public investment for flooding protection is a primary adaptation tool. Examples include Venice, New Orleans, Helsinki and Rotterdam. These investments are not without controversy, however, as they can lead to the destruction of ecological resources in order to protect the built environment. Parks and natural spaces can also be used as an adaptation measure, by planning new parks in areas that are most vulnerable to flooding. A number of cities and regions including the City of Dresden, Germany and the Dolnoslaskie Region, Poland are implementing adaptation programmes to prevent flooding, minimise and manage rain water and storm water. ${ }^{57}$ Through national hydraulic engineering and forestry legislations, the Swiss federal government is providing funding at the canton level for protective measures against natural hazards, which is matched by funding from cantons, municipalities, and infrastructure owners. ${ }^{58}$ Other cities are increasing their capacity to assess potential impacts. In China, the city of Shenzhen has developed a network of 2,000 automatic meteorological data collection stations, to provide a monitoring range of $250 \mathrm{~km}$ (OECD, 2010a). Because environmental zones do not often fall within city boundaries, adaptation planning and management often requires horizontal co-ordination with multiple local governments within the same region as well as vertical co-ordination with regional and national governments.

The natural environment of the urban landscape is also often included in climate plans as a means of absorbing $\mathrm{CO}_{2}$ and reducing overall urban GHG emissions, as well as reducing potential urban heat island effects. The City of New York's PlaNYC Climate Plan includes a goal of planting an additional one million trees by 2030, and filling all available spaces for trees. The plan sets a goal of planting 23,000 additional trees annually (City of New York, 2007). Sejong City, a new city in Korea that will

56. From response to OECD "Local Climate Change Governance Practices Questionnaire" by Barbara Jeanneret, Swiss Federal Statistical Office, 17 August, 2009.

57. From response to OECD "Local Climate Change Governance Practices Questionnaire" by Wolfgang Socher, City of Dresden, Department of Urban Ecology, 26 August, 2009; and by Maciej Zathej, Dolnoslaskie Region, Poland, Regional Bureau of Spatial Planning, 28 August 2009.

58. From response to OECD "National-Local Climate Change Governance Practices Questionnaire" by Barbara Jeanneret, Swiss Federal Statistical Office, 17 August, 2009. 
be completed by 2014 with an expected population of a half million by 2030, plans to reduce average city temperatures by $2.5^{\circ} \mathrm{C}$ by devoting over half of its total surface area to parks, greenbelts and waterfronts and operating a water circulation system that draws on natural water resources (Sejong City, 2009). Tokyo has initiated policies for Greening Projects that include tree-lined streets and rooftop greening. In São Paulo, the development of Linear Parks along waterways has served to minimise flooding effects, reduce water pollution, and contribute to the planting of more than half a million trees in over four years (Sobrinho in OECD 2009c). Improvements to the urban environment to reduce $\mathrm{CO}_{2}$ can provide an opportunity to capitalise on carbon offsets through cap and trade systems.

\section{Building policies}

Energy demand from buildings represents a significant share of cities' energy emissions in OECD countries; at the same time, the built environment is vulnerable to climate change impacts. The share of energy demand from residential and commercial buildings is much higher in OECD cities than in worldwide figures. For example, GHG emission from buildings in the City of New York accounted for $79 \%$ of the city's total emissions in 2005 (City of New York, 2007). While contributing to climate change, the built environment is also vulnerable to anticipated climate impacts, including urban heat-island effects, flooding, and related extreme weather events. Building location and design can add to the negative outcomes of urban heat-islands. The increased frequency and severity of flooding will threaten buildings that were located in areas previously believed to be at lower risk of flooding. National, regional, and local governments can deploy a range of building policies to assist local authorities, reduce GHG emissions and adapt to climate change impacts, including those that: increase building energy efficiency through design, placement and retrofitting with energy-saving devices; increase local share of renewable and captured energy generation; adapt to flooding and extreme storm events by requiring minimum ground clearances; and reduce urban heat island effects by requiring or encouraging "green roofs". Measures that have the potential to reduce $\mathrm{CO}_{2}$ emissions from building heating and cooling also provide benefits in the form of reduced energy prices for energy consumers, reduced risk of blackouts during extreme heat events, and health benefits associated with reducing air pollution from unnecessary electricity and heat generation.

Building codes are the primary means for increasing building energy efficiency. Through building design and placement criteria, they can require reducing the demand for energy to light, heat and cool buildings. Their regulatory approach can be seen as an effective way for achieving a given goal of energy efficiency of new buildings (OECD, 2003b). For example, because they are applied equally to owner-occupied and rented buildings, they can pre-empt the disincentive that owners and renters of rented buildings face in making energy efficiency investments. ${ }^{59}$ They can also facilitate the meeting of specific targets. For example, the city of Shenzhen became in 2006 the first Chinese city to establish building energy efficiency regulations, and has since set targets of $20 \%$ energy reductions for retrofitting existing buildings and 50\% reductions for new construction (OECD, 2010a). On the other hand, the effectiveness of building codes is often constrained in several ways. First, as building codes typically apply only to new construction and renovations, their benefits are only felt over the longterm (IEA, 2005). Second, while most of the OECD countries now include national energy efficiency requirements in their building codes for all new buildings, city or regional building regulations to

59. Known as a "principal-agent" problem, owners of rented buildings have little incentive to make investment because they usually do not have to pay the energy bills, and renters do not have incentive, either, because they are not likely to benefit from the investment over the long term. Under such circumstance, economic instruments and information tools may not function effectively (OECD, 2003). 
apply more stringent efficiency standards often apply only to projects over a certain size. ${ }^{60}$ Third, due to strong opposition of stakeholders, it is often difficult to set energy efficiency requirements strict enough to effect significant reductions in GHG emissions or real protections against climate change impacts (OECD 2003b). Fourth, building codes may discourage innovation because developers rarely have an incentive to exceed efficiency standards (IEA, 2008a). Performance-based codes, which set a total requirement for the building based on the supply of energy or the resulting environmental impact, may provide more incentives for innovation, but require a comprehensive and reliable method for calculating the energy performance of a building (IEA, 2008a). Finally, and perhaps most importantly, the effectiveness of building codes can vary significantly due to difficulties and resulting differences in compliance and enforcement (UNEP, 2007).

Supporting building retrofitting or the installation of energy-efficient technologies has also been an effective instrument for local governments in some OECD countries to reduce the GHG emissions from existing buildings. The City of Berlin has pioneered a model for improving energy efficiency in buildings in which the city project-manages the retrofit of public and private buildings by contracting with energy service companies to implement efficiency retrofits to achieve an average of $26 \%$ reduction of $\mathrm{CO}_{2}$ emissions (C40 Cities, 2009); the City of Toronto has provided technical support for owners of large buildings to retrofit their buildings for energy efficiency through its Better Buildings Partnership and Sustainable Energy Funds. ${ }^{61}$ The benefits of such projects are greatest where heating and cooling loads are high. While retrofit programmes present an opportunity to have an impact on the energy demand of the built environment, governance of such programmes can be more complicated. They are less well suited to implementation through building codes, given that uniform performance requirement by building codes could be too much burden for some existing buildings, but rather are more appropriate for policy instruments such as public private partnerships and grant programmes. They also require a good monitoring system and a competitive energy performance contracting industry (IEA, 2008a). Energy efficiency technical assistance programmes are a key vehicle for national assistance on the local level. Public private partnerships can also result in the construction of buildings that are energy efficient by design, such as in the case of the Kronsberg Passive House Estate in Hannover, Germany. ${ }^{62}$

Building retrofitting, or the installation of energy-efficient technologies in local governmentowned properties have become widely adopted into local climate action plans (Wheeler, 2008), and are often easier to implement than policies for private buildings. Depending on the scale of the intervention, self-governing and purchasing policies can have a wide impact on city building efficiencies; they can also serve as a model for privately funded energy efficiency projects. These projects can require co-ordination among multiple local government agencies. For example, cities in Japan provide matching funds to public schools that have made energy efficiency improvements, in

60. For example, the City of Boston approved a green building zoning code in January 2007 that requires all construction projects exceeding 50000 square feet to be designed and planned to meet the U.S. Green Building Council's (USGBC) LEED “certified” level standards (City of Boston Redevelopment Authority, 2009). the Flemish Climate Policy Plan for 2006-2012 sets out comprehensive requirements for new or significant additions to dwellings, schools and offices, as well as major renovations of schools and offices exceeding 3,000 m3 (Flemish Ministry of Public Works, Energy, Environment and Nature, 2006).

61. From response to OECD "Local Climate Change Governance Practices Questionnaire" by Mark Bekkering, City of Toronto, Environment Department, 11 August 2009.

62. From response to OECD "Local Climate Change Governance Practices Questionnaire" by Astrid Hoffmann-Kallen, Ute Heda and Rainer Konerding, City of Hannover, Climate Protection Unit, 1 September 2009. See also www.passivhaustagung.de/zehnte/englisch/texte/PEPInfo1_Passive_Houses_Kronsberg.pdf 
the amount of half of the projected annual cost savings (Sugiyama \& Takeuchi, 2008). Many governments have undertaken retrofitting local street lighting, including Graz, Austria, Gwalior, India and Stockholm, Sweden. While not typically subject to building policies, efficient street lighting programmes reflect the focus on improving the energy efficiency of government-owned properties. In the case of Graz, investments were pre-financed and refinanced from the energy cost savings, which are paid off over 15 years, while in Stockholm an investment in light-emitting diode (LED) traffic signals is expected to pay off within ten years (IEA, 2008b).

Programmes to require or enable use of renewable or captured energy sources can have a largescale effect on demand for low-emissions energy sources. Barcelona's "Solar Thermal Ordinance", which requires all new buildings and major renovations to use solar thermal collectors to supply at least $60 \%$ of the energy used to heat water, led to similar ordinances in over 60 other Spanish municipalities. In the Greater London area, building codes requiring renewable energy generation have expanded to communities across the UK. District heating and cooling systems, which capture heat produced in energy generation to heat or cool water for all buildings connected to the systems, have the added benefit of being able to be applied incrementally at appropriate scales. Moreover, given that district energy systems connect to both new and existing buildings, they are an effective way of altering the energy demand of existing building stock. One of the earliest district heating systems, in Copenhagen, provides $97 \%$ of the city's total heating needs. The Cities of Stockholm, Sweden and Mannheim, Germany provide other examples of district heat generation, including through the use of biofuels. The City of Toronto, Canada, has enabled the creation of a district cooling system by establishing a corporation that has connected most of the major downtown office buildings to a deep lake water cooling system and which has resulted in a significant decrease in electricity demand for air conditioning. ${ }^{63}$ Regulatory changes requiring buildings within a designated zone to connect to the system allow district heating and cooling projects to realise energy efficiency gains for a large number of energy consumers. For example, MVV Energie in Mannheim, Germany, makes more money selling hot water than it does electricity, due to the efficiencies of its system. However, potential price inefficiencies may exist if the projects receive significant government subsidies (Agrell \& Bogetoft, 2005).

Local governments face the challenge of revising local building regulations to address potential climate change scenarios, particularly those that expose the built environment to flooding and extreme storm events. Building codes that require minimum floor height requirements in new developments located in areas at risk for flooding and extreme storms represent an underutilised adaptation opportunity. The challenge for local governments is assessing the nature of the threat compared to existing metrics such as the commonly used 100-200 year flood measurement. In the Netherlands, for example, 1,000-year flood metrics are now being used for development planning. Building codes are however not sufficient to address flood vulnerabilities because they typically only affect new construction and major renovations. They therefore must be combined with additional flood mitigation measures, such as retrofitting and infrastructure investments.

Local governments can also address the threat of increased urban heat island impacts by implementing building codes that require "green roofs". Green roofs may take the form of roofs planted with vegetation, which can both increase building insulation from heat and cold as well as reduce storm water runoff into local waterways. Green roofs planted with vegetation do consume additional water and therefore are not suited to areas facing the risk of increased drought or water shortages. Other types of green roofs may be painted white or composed of materials that allow them to reflect sunlight and minimise the amount of heat they absorb, which makes them well suited to

63. From response to OECD "Local Climate Change Governance Practices Questionnaire" by Mark Bekkering, City of Toronto, Environment Department, 11 August 2009. 
warm climates but could work against efforts to reduce heating energy consumption in colder climates. Toronto has made it mandatory for almost all new buildings to include a green roof. ${ }^{64}$ Stuttgart currently subsidises $50 \%$ of all costs to retrofit existing roofs to become "green" roofs, and Chicago provides grants of USD 5000 to residential and smaller commercial building owners to help with the planning and installation of a green roof (Velasquez, 2003; City of Chicago, 2005). Building codes that mitigate urban heat islands provide co-benefits by reducing the demand for energy to cool buildings. As green roofs reduce cooling bills, they provide an economic incentive; however, like other energy efficiency measures, the upfront investment may need to be surmounted by local governments.

\section{Waste policies}

While urban waste contributes to climate change through methane $\left(\mathrm{CH}_{4}\right)$ and to a lesser extent $\mathrm{CO}_{2}$ released by landfills and emitted by waste incinerators, heat and energy capture from waste incineration can provide an efficient energy source. Methane, which represents the largest share of GHG emissions produced by the waste sector (IPCC, 2007), presents a key concern for local GHG emissions reduction because $\mathrm{CH}_{4}$ has a significantly greater impact on climate change than $\mathrm{CO}_{2}$ emissions and continues to be released for decades after waste disposal.

Local governments across the OECD have reduced the quantity of waste that ends up in landfills by providing recycling and composting services and setting fees to discourage waste. Many cities divert waste from landfills through recycling and composting programmes. ${ }^{65}$ The City of San Francisco's recycling and food composting efforts have allowed it to divert from landfills $70 \%$ of all waste consumed (Kamal-Chaoui in OECD, 2008c). The actual amount of non-recyclable and noncompostable waste provided to collectors can be reduced through incentives in the waste collection rate structure. The City of Zurich restricts the amount of waste that residents can generate, and sets fees for additional amounts. Local governments also have opportunities to reduce waste by improving waste management systems. To meet its target of recycling 35\% of the waste stream in 2009 and $51 \%$ in 2011, the province of Rome, with financial support from the Lazio region, provides economic grants to municipalities in its jurisdiction to establish waste collection systems that enable them to quantify individual household waste and thereby create fiscal incentives for waste reduction recycling (Kamal-Chaoui in OECD, 2008c). Waste quantities can also be reduced through education campaigns, which are already common in many urban areas in OECD countries. In order for efforts to reduce the amount of non-recyclable and non-compostable waste through fees or information to be effective, they need to be coupled with collection services that offer recycling and composting for a wide range of consumer waste products. The EU Landfill Directive requires reductions in the volume of biodegradable municipal waste it sends to landfills.

Local government agencies that use waste as an energy source can increase the net energy efficiency of incinerators and reap economic benefits from energy savings. Even when incinerators do not generate energy, they emit a significantly smaller amount of GHG emissions than landfills. The amount of other pollutants they emit depends greatly on their cost and design; many European countries have adopted stringent emission standards for incinerators (IPCC, 2007). Cities are also capturing methane gas from landfills to be used as a source of energy. The city of Monterrey, Mexico, which has been active in generating electricity by harvesting methane, constructed using public and private funds a 7-megawatt energy plant that captures and converts enough landfill gas into electricity

64. From response to OECD "Local Climate Change Governance Practices Questionnaire" by Mark Bekkering, City of Toronto, Environment Department, 11 August 2009.

65. The South Waikato Region, New Zealand; Christchurch, New Zealand; Dolnoslaskie Region, Poland; Darmstadt, Germany; and Toronto, Canada also provide examples of municipal composting. 
to power the city's light-rail transit system and its streetlights (Kamal-Chaoui in OECD, 2008c). In China, the City of Guangzhou in Guangdong province has undertaken one of the largest landfill energy capture projects, which is expected to generate more than $50 \mathrm{Gwh}$ of electricity, or enough for 30,000 households (OECD, 2010a). Other cities investing in landfill methane gas capture include Amman, Jordan (Freire in OECD, 2009c), Christchurch, New Zealand and Nelson, New Zealand.

The waste services sector provides an opportunity for local government to reduce GHG emissions economically because they can build on services they already provide and capitalise on economic benefits. Policies to reduce waste through expanding recycling and composting services and raising the price of non-recyclable waste recycling programmes have been shown to consume less energy than disposing of the waste in landfills or by incineration, even when taking into account the potential energy that may be captured at either landfills or incinerators (Morris, 2005). It is therefore important that policies to support waste-to-energy capture do not compete with recycling programmes. Policies that support waste incineration and landfill gas capture complement recycling and composting policies by increasing the energy efficiency of disposal of non-recyclable or non-compostable waste. Incineration or landfill programmes that capture heat and energy can reduce net GHG emissions while offering economic benefits.

\section{Water policies}

While many cities' do not prioritise urban water policies as part of their climate policy goals, they deserve attention because water service provision both consumes energy and is also vulnerable to climate change impacts such as increased droughts and rising sea levels. Water services provision contributes to GHG emission because of the energy demanded by water treatment, pumping and other water provision activities. For example, approximately $5 \%$ of all the electricity used in California is related to water provision, while an additional $15 \%$ is related to end uses of water, such as heating and pressurising (California Natural Resources Agency, 2008). Local governments respond to a variety of climate change impacts scenarios with four key water policy goals that aim to reduce water consumption; reduce energy demand of water delivery systems; prevent water system infiltration due to flooding; and prevent water system disruption due to drought.

Empirical evidence emphasises that using prices to manage water demand is more cost-effective than implementing non-price conservation programmes, and they also have advantages in terms of monitoring and enforcement. For example, on average, in the United States, a ten percent increase in the marginal price of water can be expected to diminish demand in the urban residential sector by about 3-4\%. A recent study of 12 cities in the United States and Canada suggests that replacing twoday per week outdoor watering restrictions with drought pricing could achieve the same level of aggregate water savings, along with welfare gains of approximately USD 81 per household per summer drought (Mansur \& Olmstead, 2006). Toronto's WaterSaver Program helps businesses that use a lot water to identify areas that may be 'wasting' water and offers solutions and cash incentives. Industrial, commercial and institutional facilities that successfully reduce water use can receive a rebate (CAD 0.03 per litre of water saved). The programme allows Toronto to buy back water or sewer capacity that has been freed up by participants who have reduced water use in their operations (Raissis in OECD, 2009c). Local and regional governments have also enacted regulations to increase the use of recycled water. For example, more than 40000 homes in Melbourne, Australia, are required to use Class A recycled water, metered and delivered separately in a distinctive purple pipe, rather than potable water for toilet flushing, washing cars and watering outdoor landscaping.

Cities have also begun incorporating adaptation strategies into their water supply planning processes. New York City has started to adapt its water supply, drainage, and waste water systems to account for climate change and sea level rise. The City of Crisfield, USA has incorporated sea level 
rise and storm surge into its comprehensive plan and is using land elevation to guide future land use planning. Many other cities are assessing vulnerabilities of water supplies. In the East of England plan (one of nine Regional Spatial Strategies in England), clear policy guidance on water planning is incorporated at the regional level to inform the next stage of the spatial planning hierarchy (Hickey in OECD, 2009c). Adaptation and mitigation policies in the water sector are interconnected, as increased water shortages increase the energy required to provide water. Water scarcity can require greater pumping and greater travel distances from water source to consumer. Desalinisation, a possible solution for water scarce areas, requires a significant amount of energy. Policies to reduce consumption complement adaptation policies by reducing vulnerability to fluctuations in water availability and the need for energy intensive delivery methods.

\section{Renewable energy policies}

Some cities and regions in the OECD have undertaken the provision and production of renewable energy, in addition to pursuing goals of increasing renewable energy consumption through land-use zoning, transportation, natural resource and building policies. Local governments can develop their own sources of renewable energy by capturing and converting energy from one or more renewable energy sources that exist in many cities and towns (IEA, 2009). A distinction can be made between distributed energy options (e.g. rooftop solar or solar water heaters) and centralised power production. Cities are generally better placed to incentivise distributed energy technologies, in part through zoning laws such as Barcelona's Solar Thermal Ordinance, as discussed earlier.

Some cities in the OECD also own and operate power generating facilities, which provides them with more options for increasing local use of renewable energies. The City of Los Angeles' GreenLA Climate Action Plan sets targets for the Los Angeles Department of Water and Power to increase its renewable fuel sources to $20 \%$ by the end of 2010 and to $35 \%$ by 2020 , in part by developing four new renewable energy projects. These new projects build on $\mathrm{CO}_{2}$ reductions of $3 \%$ achieved over 20042008, which resulted in an estimated reduction of 524000 metric tons of $\mathrm{CO}_{2}$ (City of Los Angeles, 2008). The City of Seoul, Korea, aims in its new climate change master plan to expand its renewable energy share from $1.5 \%$ in 2007 to $20 \%$ by 2030 , with nearly half of this share to come from hydrogen energy (Seoul City Government, 2009). Cities and regions that are not municipal power producers can still use their regulatory authority to remove obstacles to local renewable energy production and their self-governing authority to purchase renewable energy for city or regional operations (IEA, 2009).

\subsection{National-local policy frameworks}

National governments have several reasons to better engage with local governments and stakeholders on the issue of climate change. First, local authorities serve as a vehicle for the implementation of national strategies and policies. Second, local governments may be able to build resilience to climate change and low-carbon performance into urban infrastructure and development patterns. Third, urban scale action may allow for greater social and technical innovation than is possible at broader scales. In this context, local authorities become a power base for experimentation, action and learning that can over time lead to climate-friendly development patterns. There is significantly greater potential for experimentation at local scales, which in turn can be a testing ground for national governments. Where successful, such experiments can provide an essential evidence base with new forms of policy and open the possibilities for broader diffusion in other urban areas or possibly nationally. A key aim of national policy may usefully be to encourage, enable and possibly finance experimentation that goes above and beyond nation-wide action. In this way urban policy can be a testing ground for broader scale efforts.

National policies are a central enabler of local action on climate change adaptation and mitigation. To avoid a patchwork of unco-ordinated targets, goals, and programmes, national 
governments can and should take the lead with design and implementation of broad cross-cutting instruments. National policies may also advertently or inadvertently constrain the ability of local authorities to act, leading to mal-adaptation or mal-mitigation. In some cases a problem may arise because authority is not devolved to local governments on key issues, such as transportation planning. Where authority is devolved there is a need to ensure the availability of financial resources to design and implement local climate policies. More generally there is a need to ensure that national policies appropriately incite action at regional and local levels, and help to build capacity at sub-national levels to address climate change in a timely way. In OECD countries, national-local policy co-ordination on climate change has taken three main forms: i) nationally or regionally led policy that enables and influences local action; ii) local or regional action that informs national policy; iii) a hybrid approach in which national priorities are adapted locally (Cities, Climate Change and Multi-level Governance, OECD 2009).

Nationally or regionally led policy frameworks in many OECD countries require or enable local or regional authorities to take action on climate change. National policies that influence local action on climate change take a range of forms, but are generally characterised by support in terms of funding, programme assistance, or knowledge dissemination. National regulations can provide the foundation for local and regional activity on climate change by setting price signals (e.g. through a national carbon tax or cap-and-trade programme), providing national emissions and adaptation targets, and setting standards in urban sectors, such as building codes. This can have the effect of advancing action in municipalities and regions that have not taken the lead on climate change action and can prevent competition among regions due based on climate policies. Some countries in the OECD have also put into place non-regulatory frameworks that allow authorities discretion in adapting national policy goals to local contexts.

Funding is a key issue in national-local co-ordination. For example, Norway provided technical assistance and NOK 7 million (USD 1 million) in financial support for the development of local climate plans targeting carbon emissions reductions and forestry projects. While non-financial support included a web-based information portal and emissions calculation tool, funding was key to plan development: only one municipality developed a climate plan without grant support, and action on the climate plans stalled when funding was not made available to support implementation (OECD MLG; Aall et al., 2007). France responded to the need for local funding by providing a funding programme through the Agence de l'Environnement et de la Maitrise de l'Energie to support the development of carbon emissions inventories. The agency provides up to $50 \%$ of the cost of the development of local emissions inventories and also provides expert input (Cities, Climate Change and Multi-level Governance, OECD 2009).

National policies to provide technical assistance have also led to local climate action in Portugal and the United Kingdom. The United Kingdom's Regional Development Agencies have helped to develop regional approaches to climate change, while the Carbon Trust and Energy Savings Trust have helped England's core cities to pilot energy savings programmes. The UK Climate Impacts Programme has generated local and regional knowledge about potential climate change impacts and to build local capacity for cost-effective adaptation. The project "Climate Change in Portugal: Scenarios, Impacts and Adaptation Measures" (SIAM) convenes scientists and disseminates knowledge about potential climate change impacts to local governments. Sintra (near Lisbon) is the first Portuguese municipality to create $\mathrm{n}$ adaptation strategy in collaboration with the SIAM team (Cities, Climate Change and Multi-level Governance, OECD 2009).

Locally developed climate change programmes in the OECD have also influenced policies at higher scales of government. In these cases, successful local practices inform policymaking at regional or national levels. For example, the City of Portland, United States, developed innovative green building policies that eventually influenced state-wide policy. Funded through solid waste fees and 
grants, the city's Green Building programme provides policy development, demonstration projects, technical assistance and education, and Green Investment Fund, which provided more than USD 2.5 million in funding over 2002-2008. The State of Oregon, where the City of Portland is located, built on the city's experience by developing a network of institutions to support a state-wide effort to regulate building energy performance and promote green buildings across the state. The State of California, United States, provides another example of policy making influencing national levels of government. The State of California's policies on air pollution control have created a base of knowledge and political will that has disseminated to other states (OECD, 2009a).

A third type of national-local co-ordination on climate policy consists of national support for and dissemination of local climate policy innovations. In this case, national or regional governments collaborate with regional or local policymakers to support experimentation on locally adapted climate activities and to share best practices with other local or regional governments. For example, Finland's Regional Environment Centres (RECs) and permit authorities, whose mission and goals are defined by the Ministry of the Environment, make decisions on environmental permits for large and mediumsized enterprises and can assist cities and regions to develop capacity and design and implement locally tailored climate policies. RECs provide voluntary guidelines for cities on environmental and land-use planning, which have begun to influence how cities are addressing the issue of climate change (OECD, 2009a).

Sweden has provided a framework in which local communicates compete for funding for mitigation or adaptation activities. The national government provides financial, legal and technical assistance, as well as an investment programme, KLIMP, to support the implementation of climate change activities. To compete for funding under the investment programme, local governments must develop a locally adapted climate strategy with primary and intermediate objectives and an evaluation component. Funding from the national government ranges from $25 \%-85 \%$ of total project costs, which requires local governments to mobilise funding as well. The KLIMP programme resulted in roughly 125 local climate investment projects between 2003-2008, representing an investment of EUR 214.9 million and an estimated 1.1 billion tonnes of $\mathrm{CO}_{2}$ reduction per year (Cities, Climate Change and Multi-level Governance, OECD 2009).

Although in Japan environmental and energy policies are under national government jurisdiction, the national government has also provided a framework, the Kyoto Protocol Target Achievement Plan, to encourage local and regional governments to pursue climate change initiatives related to energy efficiency, transport and regional planning. Local and regional governments can also develop climate related policies in areas that the national government does not take action, and they are also responsible for implementing and monitoring their plans. For example, the City of Kyoto introduced a labelling system aimed at reducing local household energy use (responsible for $23 \%$ of city greenhouse gas emissions in 2000) by providing information on the impact of air conditioning appliances and televisions. The success of this programme, which resulted in an increase in the efficiency of air conditions purchased in 2003, resulted in a national energy efficiency labelling system in 2008 (OECD, 2009a).

Beyond explicit co-ordination, national policy can facilitate local climate change action by removing national policy barriers that may impede local initiatives. Many national policies that affect local climate change initiatives were developed before climate change was recognised as a policy priority. For example, in Norway, large-scale flood-defence projects have in some cases made it harder for local authorities to develop more locally adapted flood protections. In the United Kingdom, short-term budget cycles may impede the development of long-term local initiatives (Urwin \& Jordan 2008 in OECD, 2009a). It is therefore important that national-local co-ordination on climate change policy include an examination of national policies that may restrict local climate initiatives. 


\subsection{Incorporating climate change into existing national, regional and urban development frameworks}

A main challenge for national climate strategies is how they are integrated within existing regional and urban development policies frameworks that most OECD countries have had in place now for decades. Within the OECD, application by national governments of regional policy using a "green" lens, or the pursuit by central governments of climate change strategies using a regional development policy filter, is uneven. Japan and Korea currently appear to have developed the most comprehensive of approaches to green urban development strategies of the OECD countries (Box 26). However, a brief review of practices in OECD highlights a number of challenges in other OECD countries. ${ }^{66}$ First, only a minority of OECD countries is applying a climate change lens to the implementation of regional/territorial/spatial economic development policy frameworks. What appears to be the norm are the parallel application of regional development policies on the one side, and the pursuit of targeted sectoral strategies directly or incidentally addressing climate change on the other side. Second, sectoral strategies may be applied without regard for regional or local strengths and assets. A regional development policy lens may not be used at all when designing sectoral strategies to address climate change. Third, cross-sectoral, holistic regional approaches to address climate change by central governments appear to exist in only a few instances (e.g. Japan, Korea, Sweden), while in most countries, a significant co-ordination challenge exists in the implementation of the various climate-change and regional development spatial plans: little if any co-ordination exists between the various scales of regional and local planning instruments. Finally, the most effective cross-sectoral strategies appear to be those where climate change mitigation and adaptation is seen to be a potential source of regional economic development/growth. By contrast, strategies based on adding a "green" component in a more isolated manner to sectoral regional development policy drivers (e.g. infrastructure development), seem less likely to successfully sustain regional economic development and tackle climate change over the longer term. This assumes that national governments accept that economic development and environmental sustainability are not an either/or proposition but rather are synergistic.

66. These are the findings from the answers to the questionnaire and the discussion that followed at the OECD Ministerial Meeting on Regional Development, March 30, 2009. These were compiled by Adam Ostry, Chair of the OECD Working Party on Urban Areas. 


\section{Box 26. Regional Policy and Climate Change: examples from a selection of OECD countries}

In Japan, the central government is currently pursuing a "Compact City" urban greening policy because of the positive externalities on the environment. Under the Compact City policy framework, the central government is focusing on generating a more compact urban structure with its 2006 revisions to its City Planning Act. A related initiative, the Comprehensive Urban Transport Strategy, aims to ensure that citizens in urban areas can live with less dependence on the automobile, by targeting investments at light rail/light rapid transit and by zoning to combine functional activities related to commerce, housing and industry around LRT stations. The Japanese government has also introduced the recognition of an "Environment-Friendly Model City" as a means to share best practices relating to the promotion of compact urban form and lower GHG emissions among urban centres across Japan.

What Korea calls its "Korean-Style New Deal" to address the current economic crisis aims to contribute simultaneously to creating new jobs and respond to climate change. The project aims to support the construction sector in supplying energy-saving, eco-friendly "green" homes and building transfer nodes for low-carbon, masstransit infrastructure such as high-speed rail. The government of Korea has explicitly underscored in its "New Deal" that it seeks to counter the conventional view that economic growth conflicts with environmental protection. On the contrary, a principle at the core of its approach is the synergy between economic growth, job creation and environmental protection and enhancement.

In France, the current round of regional development plans (CPER) (for 2007-2013 now contains carbonneutrality objectives: any infrastructure project financed under a CPER that leads to the generation of emissions (a highway, for example) must be offset by other projects that will reduce emissions (like public transit, for instance). The French government's national climate change framework is also being planned using an urban lens: the "Grenelle de l'Environnement" provides for the extension of the existing climate-energy plans, the strengthening of environmental assessment components in urban planning, and the inclusion of anti-urban-sprawl objectives, measures to limit greenfield development and the development of eco-friendly districts/neighbourhoods in urban planning approaches. Article 26 of the Grenelle II text lays the groundwork for mandatory GHG inventory reporting for urban areas greater than 50,000 people, public entities larger than 250 employees and private entities with more than 500 employees.

In Mexico, the federal government explicitly recognises the link between urban competitiveness and urban attractiveness and liveability, including environmentally friendly urban development. The government has begun to base policy on the premise that future urban competitiveness will depend on the adoption of climate-change policies and strategies. The Ministry of Social Development is pursuing its urban development policy framework using a climate-change lens, with a focus on public transport corridors and urban mobility, maximising urban public green space and more effective waste disposal technologies to reduce GHG emissions.

Other OECD countries are also shaping regional policy to respond to climate goals. Austria has identified climate-change adaptation and mitigation as key priorities for implementing its regional policy framework. The United Kingdom's Regional Development Agencies provide a new performance framework for local authorities incorporating climate objectives. Australia has recently introduced a Climate Change Action Fund to assist regions and communities in adjusting to a low-pollution. The Czech Republic has identified the improvement of the economic and environmental potential of its regions as one of the top priorities for its regional policies, while Germany will focus part of its regional policy approach to implementing the EU cohesion policy on reconciling climate-change objectives with its goals for regional economic growth. Greece also identifies climate change as a key emerging issue in its regional development policy framework.

A "paradigm shift" is required to move away from perceiving growth and sustainability as an either/or proposition to defining the two policy objectives as linked and mutually reinforcing (OECD, 2009a). This paradigm shift is already happening in many responsibility centres across OEC governments. At issue, however, is whether national governments accept this premise whether national agencies with authority over issues related to climate change and regional economic development fully understands the need for change. What follows from this is the challenge of intragovernmental co-ordination and coherence in developing and implementing cross-sectoral approaches aimed at pursuing regional development objectives using a climate-change or more broadly a sustainability lens. 


\section{Innovated urban governance}

\subsection{Main rationale for improving urban governance}

Urban governance emerges as a key issue for managing urban growth and for the implementation of policy actions and strategies in pursuing competitiveness objectives. Cities have to cope with negative effects of urbanisation and international division of labour (urban sprawl and spatial disparities, congestion and pollution, social issues and distressed areas) but they also have to produce proactive actions to improve and sustain their competitiveness position and foster agglomeration economies. Although market forces have contributed to shape the development of urban areas, public policies addressing physical infrastructure (transport and communication, education and research centres) as well as soft measures (the animation of clusters, universities and firms linkages, human capital, etc.) are also increasingly important for cities to maintain their competitiveness. Yet, in a context of increasing strain on fiscal/financial capacities, local governments have to constantly "perform better with less". Providing more efficient and effective public services, making economies of scale, and dealing with infra-metropolitan equity issues (positive or negative territorial spillovers and externalities) are a particular challenge for urban areas.

The main rational to address urban governance include:

- The need for a strategic planning framework

- The need to deliver public services in the most effective and efficient way, i.e. producing economies of scale

- The need to deal with internal tensions and imbalances within urban areas (which generates functional and social segregation and negative territorial spillovers

The main obstacles to face these challenges in urban areas include:

(i) The institutional fragmentation that characterises most urban areas and the lack of critical mass in medium sized cities which require innovative forms of inter-municipal co-ordination,

(ii) The lack of capacity of local governments (financial, legal, institutional).

(iii) lack of inter-municipal co-ordination within a single urban region both for strategy development and service delivery

In addition, effective urban governance needs to:

(iv) go beyond the public sphere and

(v) be aligned with central government public policies through an effective multi-level government framework.

(vi) be based on horizontal coherence between ministries in the central authority - breaking down central government silos is key to optimising the development and impact of spatial strategies.

\subsection{Horizontal co-ordination within urban areas}

A review of metropolitan governance arrangements experienced in OECD countries shows that there is no one single model for metropolitan regions. Differences between the different models contain tradeoffs in terms of benefits and costs (Table 13). These arrangements strongly depend on national politico-institutional framework, including the level of decentralisation, as well as local and regional context. Countries like France, Germany, Italy and Eastern provinces in Canada have the 
tendency to rely on institution-building, whilst Nordic countries, US and UK rather on association and co-operation arrangements. Even within countries, different solutions have emerged. In federal countries like Germany, governance models range from strong metropolitan governments in Stuttgart, Frankfurt and Hanover to purpose-oriented loose networks and state-run regional planning in Berlin, Munich and Hamburg (Walter-Rogg, 2006). Similarly, in a unitary country with a federal structure like Spain, Madrid and Barcelona have followed two completely different strategies to organise their metropolitan governance, relying on the creation of autonomous communities to build a strong metropolitan government in Madrid or developing coalitions of several actors from the civil society with the local and regional authorities in Barcelona (Tomas in Heinelt and Kübler, 2005). Even in a strong unitary country like France that provides a common legal framework for metropolitan wide cooperation, the success and level of co-operation largely differs from one region to the other. In fact, there are wide variations among sub-national authorities both in their capacity and their ability to transform this mobilisation into real impact and influence (Jeffrey, 2000 in Giordano and Roller, 2003).

There is also no best practice or one size fits all solution. Many cities have placed greater emphasis on voluntary instruments for co-ordination and co-operation and even the few examples of strong metropolitan governance through metropolitan governments and amalgamated cities coexist with other forms of network arrangements. In terms of efficiency, it may be second-best to rely on a co-operative mechanism rather than a self-financed and directly elected administrative organ, but it has its own merits of fostering communication and possibly limiting the tendency to bureaucratic mission creep. On the other hand, experiences of voluntary co-operation arrangements are most often difficult if not impossible to implement in context of conflicting relationships between different territorial layers or when there are high intra-metropolitan disparities. Paris is one of the richest municipalities in the Region Ile-de-France and has never accepted to engage in any urban or agglomeration communities. Similar is the city of Milan, which is not part of the Metropolitan Development Agency. Flexible and informal forms of co-operation are increasingly advocated as being the appropriate response for metropolitan areas, which evolve in space and time. Yet, in some cases, like mega-cities such as Mexico City or Istanbul, the problems seem so significant that any solutions require a governance structure that has a more permanent institutional status (Bird and Slack 2004). More generally, formal institutions might be in a better position to co-ordinate policy objectives throughout a metropolitan area and to deal with spatial disparities. Lighter forms of governance could be considered a first step towards the establishment of a more formal institution. The Italian cases of metropolitan conferences that aim at setting a metropolitan city instance have clearly demonstrated the limits of public policy that concentrates on the project (strategic vision) neglecting the procedure (institutions) (Pinson, 2006). In this respect, governance should be thought of as a process and not as a final outcome.

The question of a long term strategy is generally not well addressed in existing formal metropolitan governance arrangements. Due to the large number of actors involved in urban development policies, there is a need for a collaborative framework that will enable a clear and coherent strategy for the development of the whole metropolitan region that goes beyond short term objectives. Actually, most of the existing formal models tend to bring a response to the lack of cooperation among local jurisdictions focussing on improved economies of scale, reducing fiscal competition and disparities and internalising territorial spillovers within the area. In other words, they bring a solution to problems that would help to improve social, spatial and economic conditions and that would certainly contribute to improve the competitiveness and the attractiveness of the area. However, formal governance arrangements do not automatically provide an explicit 'proactive' approach that an overall development strategy for the whole area would require. All forms of fiscal arrangements simply ignore the issue. Both the metropolitan model and the amalgamation holds out the promise of increasing the political power of the metropolitan region, vis-à-vis the central government and internationally, but do not necessary holds the capacity to mobilise all stakeholders 
around a common strategic vision. Lighter and more informal forms of governance generally tend to better mobilise metropolitan wide stakeholders around a common vision but the implementation of such vision then requires an action plan and a critical mass of financing that might need a more formal arena for co-operation or collaborative tools. Elaborating a politically agreed commitment to the metropolitan concept is a key element for success. Any vision has to be backed by a political consortium including all of the different territorial governments and designed around an inclusive vision for the region, which without strong unifying action risked disintegrating into areas of relative poverty functionally and spatially segregated from areas of job growth and economic development.

Trends for horizontal co-operation in metropolitan regions tend to highlight a complex set of multi-layered metropolitan governance frameworks. This is consistent with the fact that the boundaries of a metropolitan area cannot be definitively fixed. In fact, rarely metropolitan governance models achieve a perfect match between functional and administrative boundaries. Moreover, the fact that the appropriate boundary varies according to the function or goal in question calls for different responses. For instance, promoting the development of clusters and enhanced inter-firm relations may require co-ordination within a territory whose boundaries differ from the functional region defined by commuting flows. Even metropolitan government models either built on existing administrative layers or created on purpose (metropolitan governments and amalgamation) generally coexist with either other administrative institutions or other forms of collaboration operating at different territorial scales. The amalgamation in Montreal has allowed a reduction in the number of municipalities, but the metropolitan region remains an intricate institutional mosaic, with 79 municipalities in addition to three largest cities (Montreal, Longueuil and Laval), 11 supra-municipal bodies at the fringe, provincial administrative regions plus the recently created Conseil d'agglomération that groups the recently demerged cities (OECD, 2004d). Yet, a main disadvantage for having multi-layer metropolitan governance is that might result in a 'spaghetti bowls of institutions and bodies', especially as it is most often easier to create new institutions than destroy existing ones. The French Urban Communities and Agglomeration Communities have not replaced any existing administrative layers but have been created as an additional layer leading to a patchwork of institutions and agencies within metropolitan regions. An extreme case is the Region Ile-de-France which includes 27 Agglomeration Communities in addition to a number of other forms of intermunicipal co-operative bodies (the city of Paris not participating in any). 
Table 13. Main purposes of a selection of metropolitan co-operative arrangements

\begin{tabular}{|c|c|c|c|c|c|c|}
\hline & \multirow{2}{*}{$\begin{array}{l}\text { Tax-base sharing } \\
\text { and redistributive } \\
\text { grants }\end{array}$} & \multirow{2}{*}{$\begin{array}{l}\text { Informal co-operation } \\
\text { networks } \\
\text { (association/platform/metr } \\
\text { opolitan conferences) }\end{array}$} & \multicolumn{2}{|c|}{ Metropolitan authority/agency } & \multirow{2}{*}{$\begin{array}{l}\text { Metropolitan } \\
\text { government }\end{array}$} & \multirow[t]{2}{*}{ Amalgamation } \\
\hline & & & Single-purpose & Multi-purpose & & \\
\hline Examples & $\begin{array}{l}\text { Minneapolis Saint-Paul } \\
\text { Stockholm County } \\
\text { Some municipalities within } \\
\text { Paris lle de France } \\
\text { Busan/Seoul }\end{array}$ & $\begin{array}{l}\text { Regio Randstad (Plateform) } \\
\text { Lyon Urban Region, Council of } \\
\text { Stockholm Mälar Region, Bilbao } 30 \text { - } \\
\text { Metropolitana, Torino Internazionale } \\
\text { (Associations) } \\
\text { Regional conference (Rhine-Ruhr) }\end{array}$ & $\begin{array}{l}\text { Many US cities } \\
\text { Mexico City (large number of } \\
\text { sectoral agencies) } \\
\text { Athens transport agency }\end{array}$ & $\begin{array}{l}\text { Montreal Metropolitan } \\
\text { Community } \\
\text { Greater vancouver District } \\
\text { Urban and Agglomeration } \\
\text { Communities in France }\end{array}$ & $\begin{array}{l}\text { Greater London Authority } \\
\text { Stuggart Verband Association } \\
\text { Portland } \\
\text { Communidad de Madrid and } \\
\text { Region lle-de-France (Paris) as } \\
\text { existing regional governments }\end{array}$ & $\begin{array}{l}\text { Montreal, Toronto } \\
\text { Busan/Seoul in the } 1950 \mathrm{~s} \\
\text { Madrid in the } 1960 \mathrm{~s} \\
\text { Melbourne in the } 1990 \mathrm{~s}\end{array}$ \\
\hline $\begin{array}{l}\text { Administrative } \\
\text { boundaries }\end{array}$ & No change & No change & Possible creation of a new laye & & $\begin{array}{l}\text { Building on a regional tier or } \\
\text { creation of a new a regional tier } \\
\text { with elected body }\end{array}$ & $\begin{array}{l}\text { Disappearance of } \\
\text { municipalities. Possible } \\
\text { creation of sub-local units }\end{array}$ \\
\hline $\begin{array}{l}\text { Economies of } \\
\text { scale (cost } \\
\text { saving) }\end{array}$ & No & No & For one public service only & $\begin{array}{l}\text { For certain public services } \\
\text { only }\end{array}$ & $\begin{array}{l}\text { For certain public service only } \\
\text { Expected (??) }\end{array}$ & Expected (??) \\
\hline $\begin{array}{l}\text { Sharing of } \\
\text { public } \\
\text { services }\end{array}$ & In a limited way & No & $\begin{array}{l}\text { Yes, for one public service } \\
\text { only }\end{array}$ & $\begin{array}{l}\text { Yes, for certain public } \\
\text { services only }\end{array}$ & $\begin{array}{l}\text { Yes, for certain public services } \\
\text { only }\end{array}$ & Common \\
\hline $\begin{array}{l}\text { Specific } \\
\text { advantage }\end{array}$ & $\begin{array}{l}\text { Reduce fiscal disparities } \\
\text { Still allow some variety }\end{array}$ & $\begin{array}{l}\text { Great flexibility. } \\
\text { Might provide impetus to further co- } \\
\text { operation }\end{array}$ & $\begin{array}{l}\text { Cost saving for a particular } \\
\text { service } \\
\text { Better management of a } \\
\text { metropolitan function }\end{array}$ & $\begin{array}{l}\text { Idem to single-purpose + } \\
\text { Integration and co-ordination } \\
\text { of sectoral policies }\end{array}$ & $\begin{array}{l}\text { Integration and co-ordination of } \\
\text { certain sectoral policies }\end{array}$ & $\begin{array}{l}\text { No fiscal disparities } \\
\text { Stronger political power } \\
\text { One decision centre } \\
\text { Better equalisation of costs }\end{array}$ \\
\hline $\begin{array}{l}\text { Specific } \\
\text { disadvantage }\end{array}$ & $\begin{array}{l}\text { Separate the costs and } \\
\text { benefits of local public } \\
\text { services }\end{array}$ & $\begin{array}{l}\text { Does not tackle issues such as } \\
\text { territorial spillover/negative } \\
\text { externalities/equity } \\
\text { Weak implementation capacity }\end{array}$ & $\begin{array}{l}\text { Emergence of sectoral } \\
\text { constituencies }\end{array}$ & $\begin{array}{l}\text { Emergence of the funding } \\
\text { and legitimacy issues }\end{array}$ & Democratic cost?? & $\begin{array}{l}\text { Lack of creative diversity } \\
\text { Democratic cost?? }\end{array}$ \\
\hline $\begin{array}{l}\text { Long term } \\
\text { strategic } \\
\text { vision }\end{array}$ & No & Yes, in many cases & $\begin{array}{l}\text { Yes, in many cases for } \\
\text { economic development } \\
\text { agency but risk of avoiding } \\
\text { the multi-sectoral aspects or } \\
\text { urban development }\end{array}$ & In some cases only & $\begin{array}{l}\text { Yes, will depend on the } \\
\text { administrative boundaries of the } \\
\text { new structure }\end{array}$ & $\begin{array}{l}\text { Yes, will depend on the } \\
\text { administrative boundaries of } \\
\text { the new structure }\end{array}$ \\
\hline
\end{tabular}

typology is not exhaustive. The selections of different options that it includes are not mutually exclusive, as some metropolitan regions combine several options (e.g. Montreal experienced an amalgamation of 27 municipalities whilst a multi-sectoral agency was created at the wider metropolitan level). 
Two main elements have proved to be crucial for the emergence of metropolitan governance. The first element is the incentive framework granted to area-wide co-operation established by higher levels of governments. For instance, fiscal and financial incentives largely explain the success of the French policy for Urban and Agglomeration Communities; other countries, such as Switzerland, are considering introducing such mechanisms in their policy to promote horizontal collaboration within their large metropolitan areas. Negative incentives could also see the emergence of a horizontal collaborative framework like the threat of a solution imposed by higher levels of government. A second element that is crucial to drive any collaborative process is leadership. Political leadership generally depends on whether the local government framework includes an elected mayor that could position himself as a charismatic and influential leader. The greater success of Urban Communities in Lyon and Bordeaux as compared with other metropolitan regions in France was achieved by strong leadership of local elites. In the same vein, resistance of local political leaders might block the process (Rotterdam and Amsterdam), reverse it (demergers in Montreal), or be not responsive to any financial and fiscal incentives (Paris Region-Ile-de-France). Leadership could be conducted or supported by area-wide coalitions as well. Although the creation of the Stuttgart Regional Association derived from a 1994 state law, it was largely advocated by the city of Stuttgart with strong support from the local industry including big business firms like Daimler-Chrysler, Porsche and IBM, and re-enforced by the local media. In Milan where political and institutional conflicts have prevented so far the establishment of a metropolitan region, the debate over the creation of metropolitan wide governance has been lively among socio-economic actors and spurred by private initiatives such as the Association of Metropolitan Interests (AIM) that brought together many large companies (Pirelli, Telecom Italia, Falk) and banks (Banca Intesa, Credito Valtinese) (OECD, 2006h).

The success of any metropolitan governance reform will largely depend on the public support that the new established structure is able to gain and therefore on the process that preceded and would be followed to establish such legitimacy for that structure to function properly. The democratic character of metropolitan governance is not limited to the involvement of citizens through voting and representation or accountability of decision-making process but also includes participation of nongovernmental groups in the decision making process (Heinelt and Kübler, 2005). In this respect, there are several interesting experiments among OECD metropolitan regions (Box 27).

\section{Box 27. Involving civil society in metropolitan governance}

In Germany, the Stuttgart Regional Association works closely with a series of economic and social groups on various initiatives. For example, it joined KulturRegion Stuttgart (an association set up in 1991 to promote the cultural identity of the Stuttgart region) and SportRegion Stuttgart (an association of municipalities, specialised sports associations and sports clubs) in 2001. It also produced a joint study with FrauenRatschlag Region Stuttgart, a feminist network of female experts and politicians, defending women's interests in regional transport planning. It incorporated this study's findings into its own regional transport plan. Broader and closer collaboration between public and non-public actors could also be facilitated by bringing together the metropolitan authority and the private sector through mutual participation of their respective bodies. For example, the metropolitan authority of Hanover $(\mathrm{KGH})$ in Germany is a member of several chambers of commerce (e.g. the bilateral German-Italian Chamber of Commerce). In Hungary, the Act on Regional Development and Planning imposed the legal obligation to involve voluntary associations and businesses in the consultation process preceding the planning process. The business sector is also represented through the local Chamber of Commerce in the Development Council of the Budapest Metropolitan Region.

Seoul's executive leadership in recent years has sought to encourage more citizen input into metropolitan city management. One example was to encourage direct public participation in controlling corruption through simple-to-use mechanisms for residents and non-profit organisations to request audits of agencies in the event that a breach of law or other harm to the public interest is suspected. The city has also made excellent use of Korea's very high rate of internet dissemination to craft an online system for handling civic affairs called OPEN (Online Procedures Enhancement for Civil Applications). By accessing the city's internet website, residents can monitor the progress of their applications and other business with the city. Seoul's administration has also 
bolstered the incentives to report suspected cases of corruption by offering financial inducements to residents. Finally, the city has encouraged direct citizen representation in the decision-making process through various oversight committees. Over $30 \%$ of the committee members are required to be women in order to increase female participation in social affairs. The use of committees needs to be accompanied with clear standards and guidelines for the committee members - especially the representatives from civil society - to use in determining whether there are problems evident in the area they are overseeing.

In France, the 1999 act on regional planning that established the Urban Communities and Agglomeration Communities provides the establishment of a conseil de développement. Those are mandatory councils which represent the economic and social actors at the metropolitan level which are supposed to assist the joint municipalities structures in the elaboration of their strategic projects and actions. However, they largely differ in membership and in place since the law does not provide for any rules in that matter (Lefevre, 2006). Generally speaking, chambers of commerce, business associations and higher education institutions take part in these councils. Sometimes there is direct participation of the population. In some areas, they are chaired by a member of the joint authority. Overall, they lack staff and budget but they contribute to strengthening relationships between the private and the public sector which are not so well developed.

Units of local governments that are close to residents become particularly important when the metropolitan region is represented by large scale local government. When amalgamation was implemented in Montreal in 2000, former municipalities were turned into simple administrative units called arrondissements (boroughs) with limited responsibilities. Some citizens therefore raised the issue of the democratic cost of the amalgamation and the implementation of a new law ended up with more autonomy for these boroughs ${ }^{67}$. In the case of mega-cities represented by a single city authority, the legal relationship between the upper and basic local governments remains very hierarchical. Yet, Seoul's 25 autonomous $g u$ (lower level of local governments) could be thought of as mid-sized cities, as they have a rough average of 400000 inhabitants (OECD, 2005e). Similarly in Istanbul, most of district municipalities have at least 200000 inhabitants far exceeding the average size of a municipality in the OECD countries (which is around 15000 inhabitants). In Tokyo Metropolitan area, the average size of the 23 special districts $(\mathrm{ku})$ is around 350000 inhabitants with the largest district (Setagaya) reaching almost 800000 inhabitants. Devolving more responsibilities and finances to these lower local governments units would facilitate the development and reflection of local character and better encourage participative democracy.

\subsection{Enhancing local capacity}

Local capacity varies widely among OECD countries and depends on national constitutional legal, and regulatory frameworks as well as the background administrative culture of countries.

Local capacity depends on service allocation and administrative responsibilities vary from country to country. Yet, there are some similarities (Figure 39).

- "Environmental" responsibilities are very often at the local level (water, waste, roads, urban planning). The share of sub-national spending in this area in total government expenditure

67. Draft bill 33, law modifying the Charter for the City of Montreal, approved on December 18 (Projet de loi 33, Loi modifiant la Charte de la Ville de Montréal, adopté le 18 décembre 2003") http://www2.publicationsduquebec.gouv.qc.ca/dynamicSearch/telecharge.php?type $=5 \& f i l e=2003$ C28 F.PDF. 
was $74.5 \%$ in 2005 and is the most devolved competence. It is a very important area as it requires important capital investments.

- Economic development, culture, tourism are often shared among levels of government; when regional authorities exist, they play an important role. Their fiscal weight in sub-national expenditure compared with total government expenditure has risen in the last years from $41.8 \%$ in 1995 to $46.8 \%$ in 2005 and this is the competence for which fiscal devolution progressed the most during the period;

- Education is frequently shared among levels of government (in 2004, primary and secondary school buildings were the responsibility of sub-national governments but remuneration of teaching staff was a central responsibility in half of European countries); education is amongst the most decentralised policy areas in OECD countries, with spending by subnational governments representing about $60 \%$ of education expenditure (while they represent on average $30 \%$ of public expenditure in OECD countries).

- Public health is also often shared (for example, in 2004, hospitals were a sub-national government responsibility in just six EU countries).

Figure 39. Share of sub-central government in general government spending by function in the OECD area

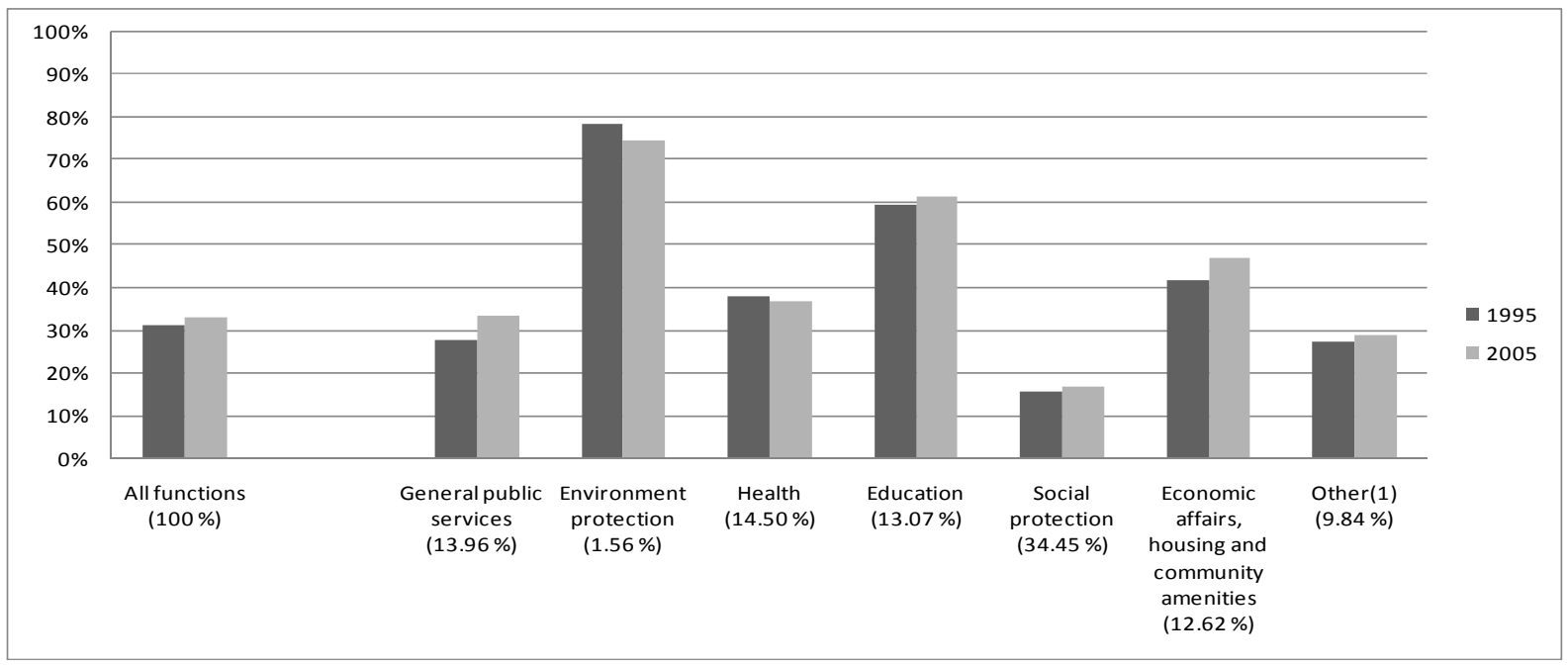

Note: The vertical bar on the figure represents the share of sub-central government in general government spending by function. Data in brackets show the share of the given function in total sub-national expenditure.

Source: OECD (2009).

A clear-cut allocation of competencies across levels of government is extremely complex to design, as many policy areas require shared interventions from different levels of government, including the central government. Municipalities are generally responsible for providing and managing basic community services, while higher-tier local governments are responsible for supra-municipal tasks such as health, roads or economic development. Some basic criteria relevant to the allocation of competencies are given in Table 14. However the weight given to each is more historical and political than economic and it is rarely possible to implement these theoretical principles. In addition, allocating responsibilities to sub-national authorities has been shown to have limited impact on the 
differentiation of strategies implemented in each place (as shown by Madies, 2001, regarding local aid to firms and "mimetic" choices about sub-national tax rates).

Table 14. Criteria for the allocation of competencies

\begin{tabular}{llll}
\hline & \multicolumn{1}{c}{ Criteria } & \multicolumn{1}{c}{ Decentralisation } & \multicolumn{1}{c}{ Centralisation } \\
\hline 1. & Preferences & Heterogeneous & Homogenous \\
2. & Scale economies & No & Yes \\
3. & Spillover effects & No & Yes \\
4. & Congestion effects & Yes & No \\
5. & Decision costs & If they increase in function & If they decrease in function \\
& of the size of the group & of the group \\
\hline Bernard Dafflon \& Thierry Madies, « Décentralisation dans les pays en développement: quelques principes issus de la
\end{tabular}

When determining the allocation of responsibilities among multiple levels of government, what matters most is the establishment of mechanisms for vertical and horizontal co-operation among government agencies as well as with private actors. As there is a clear trend towards devolving responsibilities to lower levels of government, it is essential to build strong capacities at the local level to design, implement, monitor and evaluate local public policies. Even within OECD countries, i.e. under the same national institutional framework, there are large differences among local governments in their capacity to both implement national policies and to define their own strategy for long-term development. These capacities might be related to the level of education of municipal staff, weaknesses in project management and budgetary practices, or difficulties in responding to local citizens preferences and firms' needs. Yet, these capacities are essential to design, implement, monitor and evaluate local public policies. Local governments need qualified public employees, as well as sufficient number of staff to be able to manage an increasing set of competencies. As a corollary, in certain cases in a decentralisation context, the number of public employees at the central government level might be reduced to decrease public expenditures - but this is not applied systematically. ${ }^{[1]}$ Several management tools have been implemented in OECD countries to build local capacity, by enhancing the performance of local public employment as well as improving the coherence of budgeting processes across levels of government. The quality and coherence of the multi-level regulation system is also crucial.

Most countries are looking for a trade-off between giving managerial autonomy to sub-national governments and keeping a certain degree of control and coherence over HRM systems at sub-national levels, both to help building local capacities and to avoid large heterogeneity in HRM systems and local performances (OECD, 2009i). However, the right balance is not easy to find, as too much involvement will discourage local governments from learning and diminish incentives for efficiency, as local governments can argue that substandard performance results from the actions of central government. At the same time, a lack of involvement can undermine the decentralisation process, increase disparities across managerial capacities between rich and poor regions, and lower the possibilities for mobility across local governments or levels of government.

Overall, central governments tend to keep a significant role in HRM management across levels of government in terms, except in federal countries (Table 15 and 16, Evans (2004)). Central governments use human resource management controls over sub-national governments for several

[1]. Decentralisation is not in itself a guarantee to reduce public employment at the central government level. In France for example, it is estimated that there have been 500000 new public employees since 1982 (and the beginning of decentralisation reforms), with no decrease in public employment at the central level, contrary to one could have expected (Pébereau, 2005). 
policy reasons: the first is to control the outputs of sub-national and agency bodies; the second is to retain control over budget aspects of HRM at the sub-national level (Stein-Holmes, 2007). What seems more important in a long term perspective is to ensure good coherence between central and local HR systems, in terms of level of wages for certain categories of posts and career opportunities, in order to ensure sufficient attractiveness of local public employment careers and to avoid a brain drain to the benefit of the central government.

Table 15. Autonomy in HRM at sub-national levels

\begin{tabular}{|c|c|c|c|c|}
\hline \multirow{2}{*}{$\begin{array}{l}\text { Largely centralised } \\
\text { system directed at } \\
\text { the national level, } \\
\text { and very little } \\
\text { autonomy }\end{array}$} & \multicolumn{3}{|c|}{$\begin{array}{l}\text { Mixed picture in terms of discretions of HRM authority. While } \\
\text { there is guidance from the national/federal level for conditions of } \\
\text { recruitment/dismissal... }\end{array}$} & \multirow{2}{*}{$\begin{array}{l}\text { Large discretions } \\
\text { for the sub- } \\
\text { national levels for } \\
\text { all domains in } \\
\text { HRM authorities }\end{array}$} \\
\hline & $\begin{array}{l}\text {... there is some } \\
\text { discretion for } \\
\text { career } \\
\text { management or } \\
\text { profile of skills, but } \\
\text { less for } \\
\text { establishment of } \\
\text { salaries }\end{array}$ & $\begin{array}{l}\text {... there is some } \\
\text { discretion for the } \\
\text { establishment of } \\
\text { salaries, but less } \\
\text { for career } \\
\text { management }\end{array}$ & $\begin{array}{l}\text {... there is some } \\
\text { discretion both for } \\
\text { profile of } \\
\text { skills/career } \\
\text { management and } \\
\text { for the } \\
\text { establishment of } \\
\text { salaries }\end{array}$ & \\
\hline Slovakia & $\begin{array}{l}\text { Czech Republic*} \\
\text { Hungary } \\
\text { Korea } \\
\text { Portugal* }^{*}\end{array}$ & $\begin{array}{l}\text { Spain } \\
\text { UK }\end{array}$ & $\begin{array}{l}\text { Netherlands } \\
\text { Norway }\end{array}$ & $\begin{array}{l}\text { Australia } \\
\text { Germany* } \\
\text { USA }\end{array}$ \\
\hline
\end{tabular}

Source: 2006 HRM survey $\quad{ }^{*}$ Recent trends towards more autonomy

Table 16. Autonomy in recruitment or in setting the average wage bill

\begin{tabular}{|l|l|l|l|}
\hline $\begin{array}{l}\text { Recruitments, wage bill } \\
\text { and salaries centrally } \\
\text { defined/bounded }\end{array}$ & $\begin{array}{l}\text { Entire discretion for } \\
\text { recruitment numbers, } \\
\text { but wage bill and } \\
\text { salaries are centrally } \\
\text { defined }\end{array}$ & $\begin{array}{l}\text { Discretion in workforce } \\
\text { and recruitment } \\
\text { numbers, and for } \\
\text { salaries, but top ceiling } \\
\text { are imposed for overall } \\
\text { wage bill }\end{array}$ & $\begin{array}{l}\text { Recruitments, wage bill } \\
\text { and salaries largely at } \\
\text { the discretion of sub- } \\
\text { national government } \\
\text { levels }\end{array}$ \\
\hline $\begin{array}{l}\text { Kungary } \\
\text { Sorea }\end{array}$ & $\begin{array}{l}\text { Czech Republic } \\
\text { Portugal }\end{array}$ & $\begin{array}{l}\text { Norway } \\
\text { Spain } \\
\text { UK }\end{array}$ & $\begin{array}{l}\text { Australia } \\
\text { Germany } \\
\text { Netherlands } \\
\text { USA }\end{array}$ \\
\hline
\end{tabular}

Source: 2006 HRM survey.

In most OECD countries - even federal ones-, the central government plays a role in enhancing local capacities, through a focus on staff mobility, training and performance management. A few examples are provided in Table 17. 
Table 17. Examples of national policies to support local capacity in OECD countries

\begin{tabular}{|c|c|}
\hline $\begin{array}{l}\text { Central government support to build } \\
\text { local capacities: policy objectives }\end{array}$ & Country examples \\
\hline $\begin{array}{l}\text { Enhancing staff mobility and avoiding brain } \\
\text { drain to the benefit of the central } \\
\text { government }\end{array}$ & $\begin{array}{l}\text { Interchange Canada is a national programme that involves the temporary } \\
\text { assignment of employees from one sector to another, including the federal } \\
\text { public service, other levels of government, private-sector organisations, } \\
\text { academic institutions and non-profit organisations. These assignments serve to } \\
\text { strengthen policies, programmes and services, share expertise and best } \\
\text { practices, and encourage employee development in line with strategic } \\
\text { organisational needs. } \\
\text { Interchange Canada is open to employees in all groups and at all levels of the } \\
\text { federal public service and to employees in business, other levels of government, } \\
\text { Crown corporations, unions, academic institutions and non-profit organisations } \\
\text { both within Canada and internationally. }\end{array}$ \\
\hline $\begin{array}{l}\text { Remuneration coherence across levels of } \\
\text { government }\end{array}$ & $\begin{array}{l}\text { If mobility across public administration and government levels is considered a } \\
\text { key element to promoting co-ordination, then differences in remuneration could } \\
\text { hinder such efforts. } \\
\text { Some countries have established laws and statutes to ensure remuneration } \\
\text { coherence in the public sector. This last tool is used by such countries as } \\
\text { France, Denmark, Iceland, Japan and Spain. }\end{array}$ \\
\hline $\begin{array}{l}\text { Building competences at the local level and } \\
\text { developing training programmes }\end{array}$ & $\begin{array}{l}\text { In Mexico the central government has provided numerous hands-on and } \\
\text { distance learning courses for sub-national actors. } \\
\text { In France, the national centre for territorial civil service (Centre national de la } \\
\text { fonction publique territoriale) is in charge of setting priorities in terms of training } \\
\text { and career in the local civil service. It is a public agency organised in } 28 \text { regional } \\
\text { branches and run by a board made of local governments and unions. It is in } \\
\text { particular in charge of training for local civil servants. } \\
\text { In Italy, the central government supports the regions through specific actions, } \\
\text { technical assistance and focused training, with the aim to develop policies of } \\
\text { high quality regulation at regional and local levels. These are addressed to all } \\
\text { the regions in the country, but also, and in particular, to the southern ones } \\
\text { (regioni del Mezzorgiorno), through the funds of the Inter-ministerial Committee } \\
\text { for the Economic Planning (CIPE). }\end{array}$ \\
\hline $\begin{array}{l}\text { Controlling and motivating: Introducing } \\
\text { performance management systems to better } \\
\text { monitor individual and team performances. }\end{array}$ & $\begin{array}{l}\text { The UK has developed ambitious approach to monitor performance } \\
\text { management at the central government level, but also across local } \\
\text { governments, through 'capability reviews'. In } 2006 \text { the performance of local } \\
\text { governments was assessed, along a precise set of criteria, for leadership, } \\
\text { strategy and delivery dimensions. }\end{array}$ \\
\hline $\begin{array}{l}\text { Enhancing efficiency and exploiting ICTS } \\
\text { and e-government tools to raise the } \\
\text { efficiency of public service delivery at the } \\
\text { local level, }\end{array}$ & $\begin{array}{l}\text { In Portugal, central government bodies like SEAM (the Cabinet of the Secretary } \\
\text { of State for Administrative Modernisation) and AMA (Agency for Administrative } \\
\text { Modernisation) play an important role in encouraging regions and municipalities } \\
\text { to share the vision of public sector reform through administrative simplification } \\
\text { and e-government. } \\
\text { A number of different simplification activities take place at the municipal level: } \\
\text { one example is Digital Cities and Digital Regions funded through UMIC with the } \\
\text { support of EU structural funds. It consists of more than } 32 \text { projects, covering } \\
96 \% \text { of Portugal, involving e-government solutions for local governments, } \\
\text { conditions for reinforcing the competitiveness of small and medium size } \\
\text { enterprises and a variety of citizen-oriented services such as health, education, } \\
\text { social support, culture, and safety. These projects have } \\
\text { been an effective instrument to mobilise local actors and enhance their } \\
\text { qualifications for managing joint local and regional development programmes } \\
\text { based on ICT. } \\
\text { The UK's national strategy for building e-government capacity at the sub- } \\
\text { national level succeeded in putting all government services on line between } \\
2001 \text { and } 2005 \text {. This is significant given the fact that } 80 \% \text { of all services } \\
\text { delivered in the UK are through municipalities. The transfer was not only of } \\
\text { competence - the provision of e-services - but also of fiscal resources. The } \\
\text { funding model was a flat-rate, grant-based model that rewarded smaller } \\
\text { municipalities. Funds were allocated over a five year period, and receipt of } \\
\text { funds from year to year depended on the results obtained from the } \\
\text { implementation of the e-government services. }\end{array}$ \\
\hline
\end{tabular}




\subsection{Beyond the public sphere: involving the private sector in the supply of public goods}

Beyond the relationships between central and sub-national levels of governments, there has been increasing acknowledgment that purely public intervention has its limits, and this has opened the way for greater co-operation between the public and the private sector (OECD, 2005b). In fact, the involvement of private actors in the supply of so-called local public goods is nothing new (even if there has been a recent increase in the use of these methods in the fields of social welfare, environmental protection, etc.) and there are some who regard it as the key element in the definition of governance.

Public-private partnerships (PPPs) are increasingly important for the financing of large public investment projects. PPPs are contractual agreements between a public agency and a private firm which can take different forms (Box 28). Through this agreement, the skills and assets of each sector (public and private) are shared to deliver a service or facility for the use of the general public. In addition to the sharing of resources, each party shares in the potential risks and rewards. From the public sector's point of view, there are two major attractions. First, PPPs enable an authority to lever additional finance without recourse to fiscal means. Second, they split the costs and risks of projects between the public and private sectors, tapping into the expertise and economies of scale available in the private sector that are rarely exploited for public policy. The key issue in assessing the use of PPPs is whether they bring about any increase in efficiency and effectiveness.

\section{Box 28. Forms of public-private partnerships}

Public-Private partnerships can take many forms, such as the following:

The private sector operates the facility for a fee. The public sector retains responsibility for capital costs.

The private sector leases or purchases the facility from the public sector, operates the facility, and charges user fees.

The private sector builds or develops a new facility, or enlarges or renovates an existing facility, and then operates it for a number of years.

The private sector builds the required infrastructure, operates the facility for some specified period of time, and then transfers it to the government.

The private sector builds and operates the facility and is responsible for capital financing. The public sector regulates and controls the operation.

The private sector builds the infrastructure and then transfers ownership to the public sector.

Source: Kitchen, Harry (2005), Delivering Local/Municipal Services. In Anwar Shah et al. Public Services Delivery. The World Bank: Public Sector Governance and Accountability Series, Chapter 5.

At the same time there are certain risks involved with PPPs, in particular asymmetries of information and of commitment between the different parties. The private partners need to participate at as early a stage as possible, so that they can suggest initial infrastructure development plans or alternative plans. On the other hand, early participation of the private sector may produce transparency and accountability problems. Plans proposed by firms may concentrate on their own returns rather than the overall socio-economic benefits to a region. It is therefore important for policy makers to 
ensure procedures of enhancing positive externalities of the projects without sacrificing the private innovations. The public sector should decide the prioritised lists of overall infrastructure projects and undertake feasibility studies for each project before the decision is taken as to whether anyone would be implemented with private participation.

However, beyond the advantages and risks associated with the co-financing of public investment with private actors, the main issue is the shared will of the different actors to improve their living conditions and the economic development of the territory. The economic dynamics of the regions require that all the actors at national, regional, and local level, from the public as well as the private sector, be involved in decisions regarding their future. In an economy that places very high value on knowledge, regional development policy cannot afford to disregard the cognitive resources available. The participation of private key actors in the very definition and implementation of regional development strategies is directly attached to the notion of leadership at the local level that varies significantly according to the institutional framework of OECD countries. Local and regional leaders are often responsible for making the financial arrangements when drawing up contracts between levels of government.

\subsection{Effective multi-level governance}

Many services and policy areas such as regional development often require the intervention of all levels of government. This happens because there are inherent interdependencies among levels of government, as many public policies require the intervention of various levels of governments. Besides, the assignment of responsibilities among level of governments can be "imperfect." This occurs either because there are overlaps leading to shared responsibilities and therefore the need for co-operation, or because some policy domains are not specifically assigned to any level of government and co-operation is thus required. However much effort is put into specifying the competences of each level, a large shared area will remain. The example of France is instructive in this sense. Hence the crucial importance of co-ordination mechanisms and multi-level governance arrangements, both vertically between the centre and the lower level, and horizontally among the constituent units themselves, to reduce transaction costs and asymmetries of information across levels of government.

Many OECD countries are confronted with the problem of overlap in competencies across levels of government, leading to unclear responsibilities, inefficient public spending and lack of evaluation mechanisms for certain policy fields. This is for instance often the case for the employment policy, and for the transport policy. For example in France, the central government sets the overall framework for the employment policy and decides on the amount of the unemployment benefits, while the departments fund the minimum salary - "revenue minimum d'insertion"-, and regions are responsible for adult training. Evaluation mechanisms are very hard to set in such a system. Germany faces similar problems, and one of the objectives of the Hartz reform in 2005 was to reinforce the coherence across employment and social policies, across levels of government. In Switzerland, many efforts have been conducted at the end of the 1990s to clarify allocation of competencies across levels of government and enhance public spending effectiveness.

The various experiments with metropolitan reform show clearly that the central state has played a dominant role in the reform process. Higher levels of governments (central government in unitary countries and state/province in federal countries) are increasingly involved in promoting horizontal collaboration among municipalities within metropolitan areas, often through the use of fiscal or legal instruments. Any modification of the administrative framework and any process of decentralisation is initiated or conducted under the aegis of the central state. Whether in the case of merging municipalities, creating sectoral or multi-sectoral co-ordinating bodies, or even metropolitan governments, rarely have the reforms of metropolitan governance emanated from purely local 
initiatives in the OECD countries. The state has played a leadership role either by imposing or by encouraging reform, in the conviction that the emergence of metropolitan authorities is necessary to promote the growth of cities and thus national growth.

Centrally instituted metropolitan governance reforms are typically implemented through a national law which legitimises the process. The law may be restrictive. Indeed, in certain countries, institutional reforms have been imposed unilaterally by central governments. In Korea, for example, the territorial framework was modified to reflect the growing degree of urbanisation in the country (OECD, 2001c). In 1995, metropolitan cities were granted the same status as the provinces from which they were detached. The municipality mergers in the provinces of Quebec and Ontario in Canada are another example of state imposed reform (OECD, 2002b). Even in countries with strong local autonomy, central governments may threaten to pass a national law to force inter-municipal cooperation. For instance, in Finland, a proposal for legislation has been prepared by the Ministry in charge of regional development to force collaboration within the Helsinki Region. No legislation was actually enacted but the debate brought new dynamics to collaboration among 14 municipalities which agreed on areas for voluntary and progressive co-operation in such fields as housing, land-use and transportation through partnership principles and decided as a concrete first, to prepare a common land-use strategy (OECD, 2005c).

Other countries opt instead for a national law to promote inter-municipal co-operation on a voluntary basis. This is the case of Italy with the 1990 law which provides for the creation of metropolitan cities (Città Metropolitana) or in France with the law allowing for the creation of Urban Communities or Agglomeration Communities. Generally, in the absence of any form of incentive, the laws rarely lead to any concrete reform in practice. In Italy, metropolitan cities are now specifically mentioned in the Constitution but in the absence of any incentives from above and in a context of political rivalries between the different sub-national tiers, no metropolitan city has been created so far (Giordano and Roller, 2003). The French experiment has worked better than the Italian proposal because the related laws involved fiscal incentives for the newly created supra-municipal authorities. These French laws promote voluntary co-operation by offering participating municipalities an incentive grant, in addition to their existing block grants entitlements. One of the conditions however is that the municipalities accept to devolve certain responsibilities (mandatory and optional) to the new supra municipal body and to adopt a unique business tax system within the area (the business tax is the main local tax in France).

In general, national laws which institute or encourage the creation of a metropolitan authority are universal and inflexible in that they envisage only one single framework for metropolitan institutions. They apply identically to all urban areas irrespective of their differentiating characteristics. Often only demographic criteria are taken into account, with minimal differences to the status or structure. However, in certain cases, institutions are created on an ad hoc basis, i.e. a specific law establishes a metropolitan institution without there being a nationwide policy for metropolitan areas. In Portugal, a law was passed allowing the creation of metropolitan authorities only for the cities of Porto and Lisbon. The Italian law also provides a framework for only nine metropolitan areas. Such frameworks are common in federal countries where the laws are enacted by the provincial/state government like the Quebec law for city amalgamation in Montreal, Quebec and Longueuil or the Baden Württemburg German state law that established the Stuttgart Regional Association.

Apart from institutional reforms, one of the principal modes of action of central government in cities is policy implementation. In many countries, intergovernmental negotiation and collaboration have progressively replaced the interventionist approach which previously prevailed. Urban partnerships have been widely used in two areas: to attack the multi-faceted problems of distressed urban areas and to redevelop urban brownfield sites. Whether this new relationship constituted an $a d$ 
hoc arrangement or an element of a long-term strategy, partnerships have stemmed from various rationales to: create synergy effects among the partners, spread the risks of a project among several actors, gain additional financial resources, reduce open conflict, and create a consensual policy climate. Now, it is increasingly agreed that such partnerships should be part of a more comprehensive process, i.e. included in a multi-sectoral and metropolitan area-wide contract that should meet the following criteria:

- Involve a multi-sectoral, integrated approach (public-public and public-private) to achieve desired outcomes (for example, more sustainable forms of urban development, regeneration of urban brownfields or distressed urban areas), and be handled at the metropolitan level even if they encompass neighbourhood or city-based partnerships.

- Result from a negotiated planning process among different levels of government.

- Promote participation via incentives.

- Require a structured round of negotiations, with clear objectives, a precise timetable, and with monitoring and assessment components.

- Establish a binding commitment and pluri-annual implementation.

- $\quad$ Tailor to local needs.

This type of tool would be better suited to a multi-sectoral contractual approach. The contract formula would allow government mechanisms to be adapted to local characteristics and replace traditional hierarchical relationships with contracts based on negotiation and a learning process. These mechanisms ensure a degree of sustainability of co-operation since they are pluri-annual. Several OECD countries use this type of mechanism for implementing their regional policy. State-region planning contracts in France or territorial pacts and programme contracts in Italy allow the central government to integrate the requirements of government action in the pool of knowledge and skills at sub-national government level (OECD, 2006b). Some countries have adopted this approach specifically to urban development. By concluding multi-level urban partnerships, both central and local governments have agreed on a list of common tasks and on sharing the responsibility of fulfilling them. In Canada, the federal government developed the Urban Development Agreements (UDA) in the Western provinces, which are innovative partnerships to improve the co-ordination of activities among the federal, provincial and municipal governments by addressing issues unique to each city (Box 29). UDAs have proven to be successful mechanisms, bringing stakeholders together and insuring that duplication of effort is minimised. However these agreements are subject to limitations because they are unfunded. In France, City Contracts have been signed between the municipalities and the central government for mutual commitment in distressed areas related matters. In Sweden, local development agreements (LDAs) have been created as the main tool of the Swedish metropolitan policies, focussing on 24 housing districts in the three major urban areas. The LDAs are elaborated by the state, the municipalities and the districts but implemented primarily by municipalities. First evaluations of the programme suggest success in increasing employment rates and reducing benefit dependency, but, as with the UDAs in Canada, uncertainty about a renewal of central state funding could well result in a halt of the activities (OECD, 2006d). 


\section{Box 29. Contractual arrangement in urban areas in France, Sweden and Western Canada}

The French City Contracts (contrats de ville) are a tool to enhance collaboration between municipalities and the central government. They were introduced in 1993 to foster cross-sectoral collaboration for urban policy. City contracts are for a period of several years, usually seven, and serve as development programmes for distressed urban areas at the scale of the city or larger urban communities. More than 1300 areas and 6 million inhabitants benefit today from the actions led under the framework of contrats de ville under 247 such contracts. Other stakeholders than the State and local government actors are involved in the process: such as housing and transportation agencies, as well as various associations and NGOs. In a 2005 report, the French Senate recognised that French city contracts have contributed to facilitate horizontal collaboration at the local level - and notably to involve civil society in the decision-making process concerning urban issues. However, the Senate also criticised in its report the complexity of these contracts and their lack of readability. The report also states that city contracts have reached only $50 \%$ of their objectives and recommends simplifying the procedure.

Local development agreements (LDA)s in Sweden are elaborated by the state, the municipalities and the districts, based on a bottom-up approach focusing on collaboration and management by objectives. The municipality is ultimately responsible for the neighbourhood's development. The LDAs cover over 1000 different projects in 24 housing districts, comprising 250000 residents. The districts have used different methods, ranging from the creation of new structures, working groups and sub-structures (ex: resident councils) to the organisation of large meetings open to all residents, so as to involve local inhabitants in the development of their neighbourhoods (Lukkarinen, 2004). State and the municipalities concerned decide which initiatives will be funded out of the remaining resources in disadvantaged housing areas (Commission on Metropolitan Areas, 2005). Between 1999 and 2003 the government allocated approximately EUR 230 million to the agreements, and metropolitan authorities and the municipalities committed themselves to the same amount. First evaluation of the LDAs concluded on important improvements such as increase in higher employment rates in the 24 districts that participated in LDAs as compared to other districts as well as a decrease in the number of residents dependent on social benefits. Crime has been reduced in some of the housing districts making them more attractive.

In the Western provinces of Canada, the federal government has participated in Urban Development Agreements programs that are specifically directed to cities along with the participation of the provinces. In Winnipeg, a five-year tripartite commitment of CAD 75 million has been implemented through seven programs in the areas of community development and security, labour force development, and strategic and sectoral investments. The Edmonton Economic Development Initiative (EEDI) was signed in September 1995 and designed to support the long term sustainable economic development of the city for instance through support for the Edmonton Capital Region Innovation Centre, the Edmonton Waste Management Centre and the Edmonton Competitiveness Strategy. The first Vancouver Agreement was signed for a five-year period in 2000 and renewed in 2005. The scope of the Vancouver agreement is broader and has three main components: health and safety (including primary health care, substance abuse, policing and justice), economic and social development (including housing), and community capacity building. Its main objective is to promote co-operation between the three levels of government to address local issues of poverty, homelessness, substance abuse, safety, and economic revitalisation, focussing on the Vancouver's Downtown Eastside. While the Vancouver Agreement is unfunded, it makes use of existing mandates, authorities and programs to fund initiatives. There is agreement by each party to use funding available from existing federal, provincial and municipal programs to finance projects and programs, and to strategically focus a portion of those expenditures on agreed activities.

Source: OECD Territorial Review of Canada (2002), OECD Territorial Review of Champagne-Ardenne, France (2002), OECD Territorial Review of Stockholm (2006).

While city contracts are valuable in their ability to address specific neighbourhood issues, there is also a valuable rationale for developing a metropolitan contract. A contract covering an entire metroregion would allow policy makers to increase policy coherence across the functional area and avoid costs and benefits from a city contract spilling over to the suburban areas. There are a number of cases where partnerships and contracts have been concluded with recently created metropolitan authorities, though largely as ad hoc sectoral partnerships. Some countries have begun to introduce or contemplate the introduction of contractual procedures at metropolitan level based on a more multi-sectoral 
approach. France created the agglomeration contracts that involve the central state, the region and the inter-municipal body of either the Agglomeration Communities or the Urban Communities focussing on human capital improvement and economic development initiatives (Box 30). However, the approach based on support for economic competitiveness is still too compartmentalised and piecemeal, especially because the contracts do not yet really cover the functional economic area as a whole and this limits their impact. The forthcoming introduction of Metropolitan contracts (as from 2007) will, however, be a major step towards recognising functional economic areas by fostering collaboration among municipalities around a commonly defined project for economic development, without creating a formal metropolitan body. Two tenders put out for metropolitan co-operation have already selected fifteen groups of cities, but the funds available are modest. The addition of a new layer of contracts also has raised some concerns about overlapping and transparency of urban policy in France, the complexity of which has been frequently criticised, notably by the Cour des Comptes in its 2002 report on urban policy. No provision has yet been made to articulate the different types of contract together (City contract, Agglomeration contract, Metropolitan Contract and the State-region planning contracts) (OECD, 2006f). The Swiss Confederation is also introducing an agglomeration policy which would better integrate large city problems in sectoral policies in particular by encouraging project implementation through policy incentives entitled the Model Projects. The Economic and Social Committee of the European Union, responsible for preparing policy recommendations, is in favour of creating a community programme METROPOLITAN. This would be along the same lines as the URBAN Programme ${ }^{68}$, which addresses the integration of city districts in difficulty (European Economic and Social Council, 2004).

\section{Box 30. Contractual tools used at the metropolitan level in France and Switzerland}

The agglomeration contract in France is a bottom-up method based on 'one territory - one project - one contract', which is proving increasingly successful and contributing to agglomeration-based governance, bringing together the central government, the region and the Agglomeration Community or the Urban Community. The county council (conseil general of the département) can be associated with the signature of the contract, in particular for questions related to social policies. This procedure involves four main stages. (i) The agglomeration project which is the basic document that contains a diagnosis of the functioning of the agglomeration. It identifies the issues, provides development policy options and an indication of the support areas for these choices as well as the policies and measures to implement these choices, with a phased timetable and identification of priorities. The project must focus on regional development (economic, social and human development) rather than infrastructure development and improvement. The project must be based on dialogue with the municipalities and the main actors in the area by mobilising non-public actors for implementation. (ii) The development board: that represents a variety of economic, social, cultural and association groups which must be consulted during the preparation of the project and on final delivery of the project prior to signature of the contract. They can also be associated with the drafting of the contract. (iii) The agglomeration contract that is the financial and programme document on the implementation of the project which identifies the partners, projects, pluri-annual financing and contractors. (iv) The regional coherence plan (SCOT) which is a spatial projection document of the agglomeration project that translates the project decisions into urban planning law (included in the State-Region Contract procedure).

The metropolitan contracts in France focus on actions which nurture and expand the development of the metropolitan areas: economic development, access to infrastructure, research, higher education, cultural development, etc. Particular attention is paid to poles of competitiveness, especially on actions which allow the development of synergies between the private sector, research and universities. Metropolitan contract is supposed to unfold in three phases: (i) a government call for proposals for engineering stronger metropolitan cooperation; (ii) a metropolitan plan, prepared by governments (2005/2006); (iii) introduction of a metropolitan contract as of 2007, based on very specific activities. Fifteen metropolitan areas were selected to compete for State financing in order to prepare a metropolitan plan. Six of these 15 metropolitan areas have the distinction of constituting cross-border territories (Aire métropolitaine de Lille, Région métropolitaine Côte d'Opale-Flandre occidentale, Sarrebrück-Moselle Est, Eurodistrict Strasbourg-Ortenau, Réseau Métropolitain Rhin-Rhône,

68. http://europa.eu.int/comm/regional_policy/themes/urban_en.htm 
Métropole franco genevoise) and two of them have been invited to build this dimension into their metropolitan proposal now being prepared (the Sillon lorrain with Luxembourg, the Côte d'Azur with Italy and Monaco). DATAR and the regional prefects will work with the selected metropolitan areas in preparing their projects, mobilising financial support and enlisting the central government ministries. The 15 metropolitan areas selected will receive an overall budget of EUR 3.5 billion covering 2005 and 2006 . That time will be primarily devoted to preparing the metropolitan projects. The deconcentrated State ministry offices placed under the authority of the regional prefects will also contribute. DATAR expects to introduce a national support mechanism in partnership with the ministries, associations of elected officials, and the national technical agencies concerned in order to help the chosen metropolitan areas exchange good practices during the project preparation phase.

Up to the mid-1990s, metropolitan areas were absent from the Swiss Confederation's major policies. The concept of 'urban policy' was virtually unknown. Areas benefiting from regional aid were primarily rural. The only exception was with areas in economic difficulty which included a few urban areas but mainly old industrial regions based on provisions of the deprived regions law. Sectoral policies only took metropolitan areas marginally into account by providing small federal subsidies to promote regional public transport in urban areas.

It was the general economic crisis in the first half of the 1990s which caused the financial difficulties of cities, instigating political action at the federal level. The amendment to the Constitution in 2001 opened the door to urban policies. The new Article 50, by stating that the Confederation 'shall take into consideration the particular situation of cities, urban agglomerations' extended the Confederation's scope of action to agglomerations. On conclusion of the preliminary work on metropolitan areas, the Government defined four priorities for an urban strategy: 1) taking into account the challenges of agglomerations in developing federal sectoral policies; 2) greater vertical co-operation between the three levels of government with shared responsibility for the provision of public services; 3 ) greater horizontal co-operation for the supply of services in all metropolitan areas; and 4) integration of Swiss cities in the network of European cities.

In 2001, a 'Tripartite Conference for the Agglomerations' gathering together the three levels of government (federal, cantonal and municipal) was set up to encourage vertical co-operation in areas affecting metropolitan areas. An agglomerations policy network composed of representatives of the federal offices concerned was given responsibility for the technical co-ordination of the various sectoral actions, under the aegis of the Federal Office of Territorial Development (ARE) and the Secretariat of the Economy (SECO). In order to encourage intermunicipal co-operation initiatives, model projects were put in place with the Confederation providing technical and financial support. In the medium term, it is planned to add a legal framework for a pluri-annual programme.

Source: DATAR (2004), OECD territorial review of Switzerland (2006) and Swiss Federal Council (2001).

\section{Sustainable urban finance}

\subsection{Traditional and new funding mechanisms for cities}

There is a large variation in decentralisation across countries and there are huge differences in city's responsibilities for expenditures and in revenue sources needed to finance these. In addition to basic local services, such as traffic lights, waste management and fire services, several cities are responsible for other goods and services, including transport, planning, education and social services. This means that cities have different financing needs and different funding sources that are most suitable. This makes it difficult to generalise about urban finance.

The composition of revenues varies hugely across OECD cities. Although grants, local taxes and fees provide the most substantial part of funding for the majority of cities, the proportion of these three revenue sources differs considerably: in a selection of 18 OECD cities revenues from grants from national or regional governments range from $5 \%$ to almost $70 \%$ and a similar range of variety applies to tax revenues. Istanbul relies for $68 \%$ of its income on grants, Stockholm only for $4 \%$. Amsterdam gets less than $5 \%$ of its revenues from local taxes, Stockholm $74 \%$. In addition, cities have to a varied extent access to capital markets. Since every revenue source has its drawbacks, it is important that the revenue sources of a metropolitan area are diversified. Cities should have possibilities to tax at the 
margin in order to be able to adapt to new circumstances. Beyond this room for manoeuvre, large shares of tax income are not necessarily more desirable than large shares of grant-income.

An important share of the revenues of a metropolitan area can come from local taxes. The most commonly found local taxes are those on property, incomes, sales and businesses. Local governments with property-related responsibilities such as sewerage and waste management are usually funded by a property tax, whereas local governments with more responsibilities within the field of social welfare tend to be financed more often by local income taxes.

Good local tax bases are generally more immobile than national tax bases, in order to avoid tax evasion and wasteful tax competition between local jurisdictions. This immobility of the tax base means that there are minimal risks of tax flight or other forms of manipulation to evade taxation. Furthermore, a property tax is highly visible and therefore fosters accountability. For this reason, property taxes are considered to be very suitable local taxes; they are also the most common taxes in cities. High reliance on the property tax, however, appears to impose restrictions on revenue flexibility. No country seems able to raise more than $10 \%$ of total tax revenues from property taxes. This can be debilitating for large urban administrations that find themselves pushed to provide more than a minimal set of services and infrastructures. The property tax should be designed in such a way that it does not distort the local property market. It was found that the Korean property tax, in which the main focus is on taxing property transactions, limits the liquidity of the property market in Busan (OECD, 2004a). Shifting the tax base more towards the value of assets could solve this problem. A further reform recommended by the OECD is to split the property tax rate in a rate for the land and a lower rate for buildings. In this way, urban development and redevelopment could be stimulated. The "split-rate"-approach has been used with particular success in many Pennsylvanian cities.

Most other taxes in cities are shared with other government tiers (national or regional), e.g. surcharges on income taxes in many countries. Income taxes are levied at the local level in 13 of 27 OECD countries. In a few cases - such as Sweden - the income tax is the only local tax. The income tax is highly responsive to changes in the economy and so offers good buoyancy in periods of growth. Some analysts argue that in large metropolitan areas the income tax may be more appropriate than the property tax. This is because the incomes of residents in big cities appear sometimes to correlate better with the consumption of locally supplied goods and services than property values do.

In most OECD countries central governments impose limits on tax rates and reliefs that can be set by sub-central governments, but most possess some tax autonomy. Tax limits are affected by institutional factors. They would appear to be less necessary the more transparent is the impact of the tax on the local population where the tax base is less mobile and the greater the degree of tax competition where the base is mobile. More generally, local democracy makes tax rules less necessary, but in that instance, rules may be required to contain any compensatory upward pressures on subnational borrowing or spillovers. Revenue assignments that expose sub-central government budgets to cyclical variation may require fiscal rules to damp pro-cyclical fiscal policy responses and thus ward off potential ratchet effects.

User fees cover all individual payments to public service providers, including collective, private co-payments through insurance schemes, in return for services provided. User fees can be beneficial both for containing excessive demand for and for fostering supply of public services. Since many city services are well suited for individual pricing, user fees have become an important city revenue source. User fees cover a significant part of cost in sub-central services like public transport and waste collection but less so in services like tertiary education, nursing homes and childcare. User fees are generally levied not in primary and secondary education. Fees and charges are ideal for funding local services where specific beneficiaries can be identified and non-payers excluded. An example of such a 
fee with specific beneficiaries is the additional levy in Business Improvement Districts, charged with the agreement of the major businesses in the area. ${ }^{69}$

User fees make up a considerable part of public sector revenue in OECD countries, accounting for $2.3 \%$ of GDP or $6.3 \%$ of total government expenditure. User fees are a typical sub-central revenue source: in federal countries around $75 \%$ of fees accrue to local and state governments combined, while in a majority of unitary countries local government accounts for more than $50 \%$ of total user fee receipts. In a few countries fee revenue even exceeds revenue from local taxes (Greece, Ireland, and the Netherlands). Tax and fee revenue are positively correlated, i.e. sub-central governments with a higher tax share tend to have higher user fees. Fees and charges play a large role in city budgets: in a selection of OECD cities, revenues from fees represent between $2 \%$ and $17 \%$ of revenue on the current budget (Figure 40).

Figure 40. Fee income as share of total city revenue (2005)

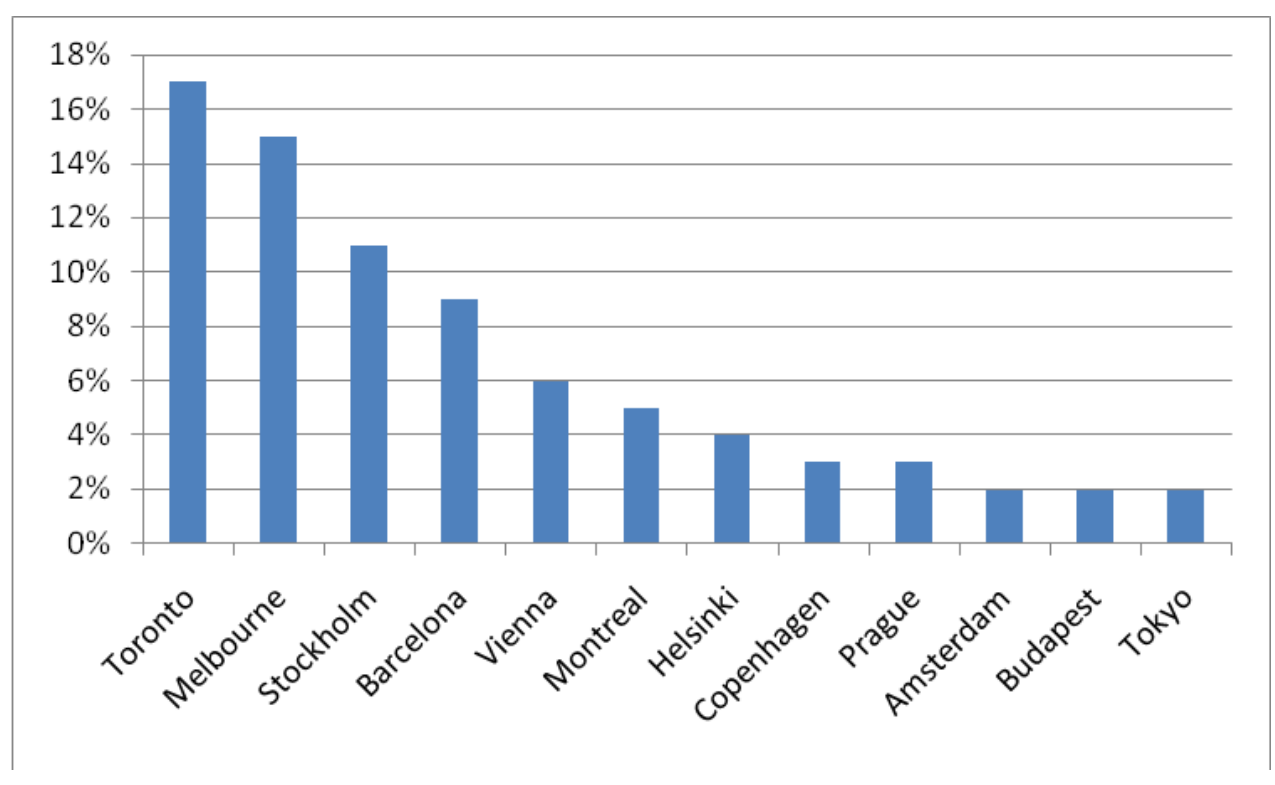

Source: Based on OECD (2006f), OECD Territorial Reviews of Competitive Cities in the Global Economy, OECD Publishing, Paris

Intergovernmental grants are often applied when fiscal discipline and spillovers are major concerns. Cities rely on grants from other levels of government, in the form of general and specific

69. Business Improvement Districts (BIDs), originally invented in Ontario, Canada, is widely used in the US but also in Europe since 1960s. This is a mechanism for financing and managing improvements to commercial and industrial environments through the agreement by a majority of businesses (either land owners or tenants) who accept an additional levy. Once a district is established, it then has the revenue at its disposal and can capitalise through longterm debt for capital investment. The BID resources often begin by supporting additional safety and sanitation services, but they can also develop into much more sophisticated investments and initiatives such as joint promotional initiatives. District governing board, usually consisting of city government representatives and private business representatives, avail itself of a host of financing methods for district improvement. The boundaries of such districts are usually a contiguous commercial or industrial area within a central city location, though they can also be effectively used in suburban and ex-urban industrial locations. In cases of multiplicity of fragmented jurisdictions at the local level, coupled with multiple tax rates and fiscal system, BIDs have become an attractive new addition to local fiscal and management instruments. Of note is that BIDs are not workable without a critical mass of businesses that are willing to pay for particular services. Equally, BIDs are good tools for reasonably healthy commercial and industrial centres that are densely populated by the owners/users, having tight boundary. They are less effective for more spread out situations or for areas with a high degree of mixed land use where the payer is harder to capture the benefits of targeted improvements in services (OECD, 2004). 
grants. General grants are generally suitable instruments for city finance as they provide cities with relatively much autonomy to spend. Specific grants could however be particularly suitable in case of spillovers across local boundaries. The relatively limited amount of local freedom connected to a grant, as compared to a local tax, makes it an attractive local revenue source from the perspective of a national government that is attached to fiscal discipline of sub-national governments. It can also be used as means to implement specific central government policies for instance to promote horizontal collaboration between local jurisdictions within metropolitan areas. Cities can in some cases negotiate on the level of the grant (as is the case in Italy), but as soon as it is set they cannot influence how much revenue come from it. In addition, cities can have tax revenues that do in fact have the characteristics of grants like tax sharing arrangements. In this case sub-national governments get a certain, usually pre-determined, share of the national tax revenues. Sometimes this is linked to the tax revenues that were collected in this sub-national unit. Since metropolitan areas do usually have a larger tax base than other regions, it is sometimes argued that grants could be reserved for smaller urban and rural areas, leaving room for financing by metropolitan tax resources. This approach is less evident for services that have spillovers to the rest of the country.

Several cities depend for a large part of their revenues on land-related income. This income could take various forms, including land auctions (Hyderabad, Hong Kong), land leases, land development rights. This land-related income can make up a large part of city revenue. This is for example the case with the metropolitan cities in Guangdong province in China. The contribution of land sales to local revenue in Guangzhou has been estimated to be 55\% in Guangzhou in 2006 and around $80 \%$ in the city of Shenzhen throughout the 1990s (Tian and Ma, 2009; Peterson, 2006). Although these could be valuable instruments to capture land value increases and to finance infrastructure, in practice local governments in China have been so motivated to generate revenues from land sale and leasing that they have generated an oversupply of land for construction. This has stimulated sprawled development and loss of cultivated land in China. Similar dynamics, although less extreme, are at work around other metropolitan regions in the OECD. Municipalities in the peri-urban fringe of many German agglomerations compete with each other in the attraction of inhabitants and companies via the development of new land, bringing in gains that are used to finance public services. This dynamic is made possible by municipal autonomy in land use planning and large demand for building land; the result is an undermining of sustainable planning principles.

\subsection{Financing urban infrastructure}

The fiscal challenges for fast growing cities is to find appropriate funding sources for infrastructure that make use of the growing attractiveness of the city. One of such funding sources is the value capture tax. The basic principle of a value capture tax is to capture a portion of the increased value that accrues to various property owners when a large infrastructure improvement is constructed in close proximity to their property. Studies in several OECD countries have concluded that proximity of property to public transit services leads to an increase in property values. Meta-analysis of these different studies indicates a price gap between zones within a quarter mile of the railway station and other areas of $4.2 \%$ for the average residence and about $16.4 \%$ for the average commercial property (Debrezion et al. 2007). The increased value results from increased desirability of the location, better access and the potential for higher rents, increased resale value or higher-density development. This suggests some room for capturing some of the value increase of the property due to infrastructure investment. The funds captured by the tax could then be used to fund the infrastructure that is provided. Value capture taxes should be distinguished from development fees or impact fees, which are levied on the buyers of a newly constructed house in order to have them finance part of the infrastructure connected to the house. A value capture tax is levied on already existing properties. Value capture taxes can be imposed or take the form of a negotiated agreement; they can be levied as an ongoing annual charge or as a one-time tax. Value capture taxes are less useful in a situation in 
which the value assessment of property for the property tax takes place on a yearly basis, as this captures increases in the property value that might result from public infrastructure investment.

Another tool used to finance infrastructure is to advance future tax revenues, through tax increment financing (TIF). This allows municipalities to finance development by dedicating property tax revenue from increases in assessment values within a designated TIF district. TIFs are not always viable as a financing method, though, because they may not generate enough additional revenue. Despite their mixed record of success to date, TIFs and allow cities to implement public improvements without an increase in tax rates and they have been used frequently in the United States (Dye and Merriman, 1999; Brueckner and Kim, 2003).

In some OECD cities, metropolitan transit authorities have access to tax income and other revenue sources. For those metropolitan transit agencies with tax revenues, the share of these in their budget ranges from 36\% (Lyon) to 68\% (Atlanta). Most of these tax revenues are levied on indirect beneficiaries, i.e. entities that are understood to benefit from the existence of urban public transport services, independently of the actual use of these activities by their affiliates. This can include economic activities benefitting from greater ease of access to their premises by their employees and customers; land owners benefiting from higher property values because of increased accessibility; and private car drivers from less congested roads. Examples of revenue charges on economic activities benefitting from greater ease of access are the transport charge ("versement transport") in France, surcharges on sales taxes in several metropolitan areas in the United States (New York, Atlanta, Los Angeles), a mortgage recording tax in New York, and a share of the fuel tax and licence fee in Montreal. These tax revenues in many cases bear more resemblance to tax shares, rather than own tax revenues, as the metropolitan transit agency does not have the right to set tax rates or define the tax base. Another example is revenues from congestion charges; a substantial share of the revenues from the London Congestion Charge is allocated to urban public transport. In Stockholm, the design is slightly different: grants compensate the transit agency for additional costs due to the introduction of the congestion charge. An interesting alternative scheme along the lines of land-value capture consists of internalising transport investment costs and land valuation benefits in the same entity, i.e. the same agency or company receives the land development rights and builds the infrastructure within those areas; this practice is common in Japan. Other revenue sources for metropolitan transit authorities include revenues from advertisement, rents, taxi licenses and parking.

User fees can also raise revenue to relieve infrastructure bottlenecks or improve service quality. In most countries, user fees cover $50 \%$ or less of urban public transport cost, depriving transport investment funds from sufficient revenue. As the price elasticity of urban transport is very low, higher ticket prices is a way of generating resources for new transport infrastructure. As fees should be used for the services for which they are levied, their revenue should remain with providers -- transport companies, etc. -- or be earmarked for investments in those services if they enter general government accounts. Metropolitan transit authorities in OECD metropolitan areas are largely financed by transit fares. The coverage of urban public transport operating costs by fare box revenues varies greatly in OECD countries (Figure 41). The definition of cost categories is not uniform across countries, which makes comparisons risky, but in the majority of operations, cost-coverage levels vary between onethird and two-thirds. Some metropolitan transport bodies, such as in London and Oslo, manage to get $75 \%$ of their revenues from transit fares, while the cost-coverage share can be as low as $20 \%$ (Atlanta) and 11\% (Los Angeles). 
Figure 41. Revenue sources of transit agencies in selected OECD metropolitan areas (2008)

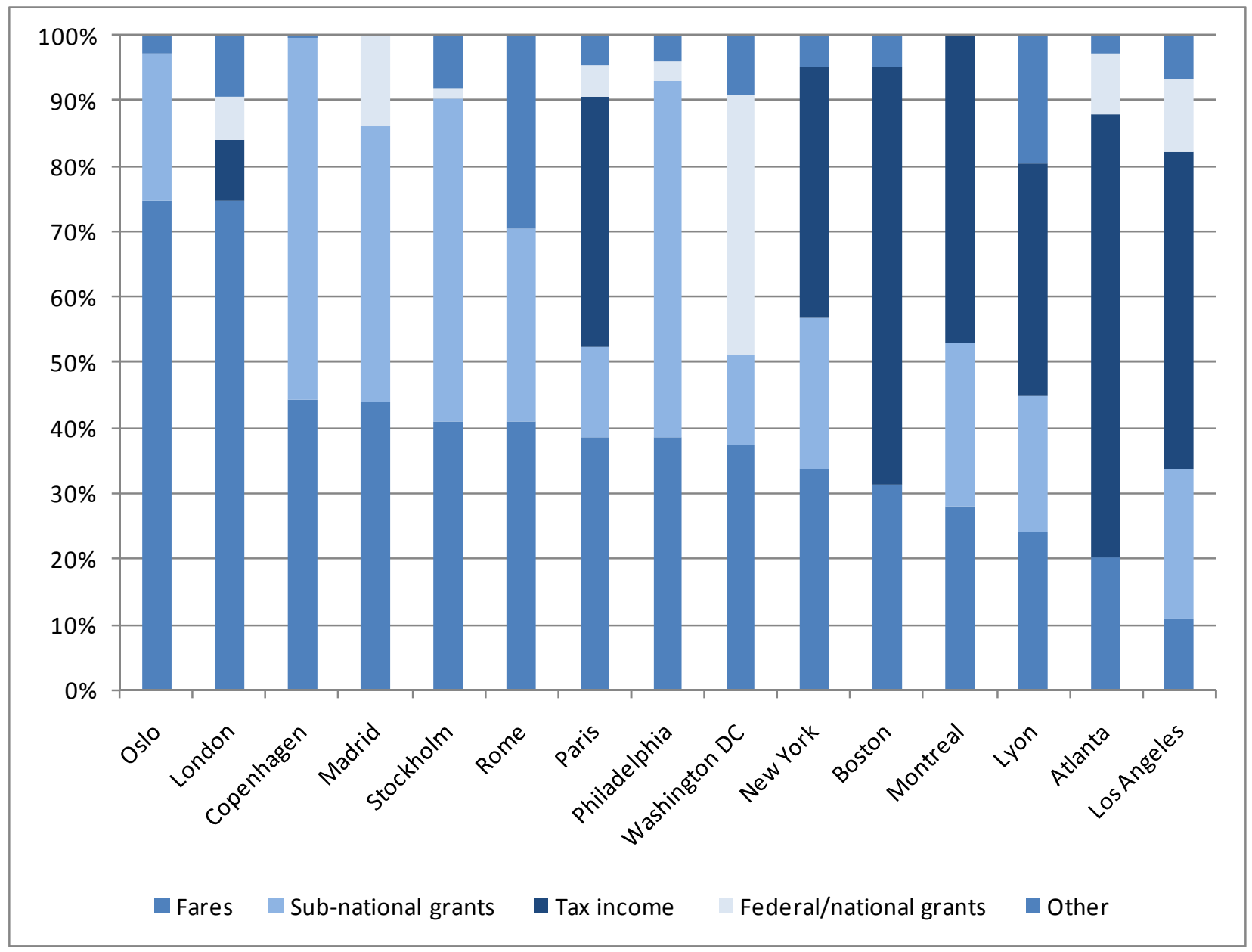

Source: 2007/2008 Annual reports of New York Metropolitan Transportation Authority, ATAC (Rome), Southeastern Pennsylvania Transportation Authority, Agence Métropolitaine de Transport (Montréal), Storstockholms Lokaltrafik, Movia (Copenhagen), Oslo Sporveier, Metropolitan Atlanta Rapid Transit Authority (MARTA), Washington Metropolitan Area Transit Authority, STIF (Paris), Los Angeles County Metropolitan Transportation Authority, Transportation for London, Massachusetts Bay Transportation Area, SYTRAL (Lyon).

Proper pricing of environmentally sensitive services such as waste collection, water treatment, or transportation can help contain environmental degradation. Several countries charge waste collection fees based on the amount of waste produced, and similar schemes based on volumes are applied for water and energy. In addition to these, several fees and charges could both serve a revenue-raising purpose and as an instrument to reduce sprawl and environmental degradation. Three of such instruments are: congestion charges, parking fees and development charges:

- A congestion charge is an effective instrument for regulating traffic congestion, decreasing air pollution and a revenue source to fund urban infrastructure. The congestion charge, increasingly applied in various metropolitan areas, has been shown to reduce congestion considerably, ranging from a $14 \%$ reduction in Milan (over 2008), 15\% in London (20022003) and Singapore (1998) and 22\% in Stockholm (January-July 2006) (Beevers and Carslaw, 2005; Olszewski, 2007; Milan municipality, 2009; Johansson et al. 2008). In addition, it has been observed to reduce $\mathrm{CO}_{2}$ emissions up to $19.5 \%$ (in London), along with 
emissions of other air pollutants (Beevers and Carslaw, 2005). Some of these initiatives (Singapore, Milan) are designed to tax higher-polluting vehicles more heavily, and different technologies support congestion charging systems.

- Parking fees can have similar effects as congestion charges, but might be easier to implement. Parking fees and taxes are price-elastic, and there is ample evidence that they are effective in reducing car trips and decreasing the car share in the modal split, in addition to generating revenue. Parking charges have led to a $12 \%$ decrease of vehicle miles of commuters in US cities, a 13\% point reduction of car shares in modal splits in British cities, a 20\% reduction in single car trips in Ottawa and a 38\% increase of car pooling in Portland (Shoup, 1997; Bianco, 2000; Dasgupta el al., 1994, Wilson and Shoup, 1990).

- Development charges could be used to cover the costs of urban infrastructure development, but much depends on their design. Development charges are levied on developers to provide funding for the infrastructure needed to provide services the developed area. They are in principle good instruments for compensating for the costs of sprawl, as long as they take into account real costs and as long as charges for single detached homes are considerably larger than those for apartments. More efficient use of the development charges would imply charging a fee to developers that resembles closely the real and full costs for building and providing the infrastructure to a particular area. The effects of development charges on social equity appear ambiguous. On the one hand, low income families might try to find affordable housing far from the city centre; internalising costs of sprawl could raise the price of this housing so that they become unaffordable to these groups. On the other hand, development charges can include a partial subsidy to finance social housing inside the development area.

\subsection{Cost recovery policies for urban services}

Fees are particularly effective when they recover full costs and when fees are paid according to individual or household use, as these give users incentives for more efficient use of resources. Full cost recovery is common in waste, water and energy, but less frequent in other services such as transport and social services. Cities all over the world have shown different practices; in a variety of them costs are more than recovered by these utility fees; they provide additional income for cities than it uses to fund other expenditures. Such is for example the case in Cape Town, as it was the case in many German cities, where the integrated supply of water, electricity and sometimes other utilities together with public transport allowed consolidated accounts to show a positive balance, with surpluses from the first group making up for deficits in public transportation. This practice has been significantly reduced because of the lack of transparency and because markets, mainly in the energy sectors, have been opened up to competition. Total cost recovery of fees for local services is not always the case. Fees for these services are highly visible, so not easy to increase politically. This is one the reasons why it is a good local revenue sources: it makes the costs of service provision transparent to citizens. Although it appears to be revenue sources that can have disproportionate adverse effects for poor population, many local governments solve this by waiving fees for local income groups.

\subsection{Experiences of OECD countries with local debt and borrowing}

Cities in OECD countries have, to a varied extent, access to capital markets. Larger cities especially have increasing access to international capital markets, although this aspect of their funding is still a modest proportion of the total funding. It occurs mostly by intermediation of a specialised body and in all cases, the issuing community must have been subject to a credit rating carried out by a rating agency, such as Moody's or Standard and Poor. There is a striking difference that separates 
Europe and North America: in Europe, investments are made largely by specialised financial institutions, such as Dexia in France and Belgium, while in the United States, a large part is provided by the bond market. This can be explained both by the absence of a financial institution specialised in financing local authorities and also the reluctance of banks to finance them. Overall, the use of the bond market is very important in the United States, it is estimated to finance between $70 \%$ and $80 \%$ of local authorities' investments. Tax-exempt bonds are used extensively throughout the United States to finance infrastructure. Under such a bond, the interest earnings to the bondholder are exempted from federal and state income tax, which allows the government issuing a bond to sell it at an interest rate below the prevailing market rate.

Governments have often adopted or strengthened fiscal rules at the sub-national level to correct or pre-empt unsustainable increases in debt or public spending, often at times of budgetary crisis or when expenditure or tax assignments across levels of governments have been changed. In strategic terms, the implementation or reform of fiscal rules usually aims at safeguarding macroeconomic objectives -- most notably the containment of the public sector, and hence the tax burden, long-term debt sustainability and short-term stability - while exploiting the potential allocative efficiency gains of decentralisation. The most common fiscal rule is the budget balance requirement, which predominantly targets the outturn of an annual budget. Most sub-central governments also face a restriction on borrowing. There has been a move in a number of countries away from micromanagement through a prior approval system on a case-by-case basis towards aggregate and numerical targets. Borrowing is rarely explicitly guaranteed by a higher level of government, but implicit guarantees may be more widespread. Enforcement mechanisms are necessary to ensure objectivesetting budget rules are implemented but information on and monitoring/auditing of sub-central fiscal performance are often poor and sanctions are not always credible or effective. Increased transparency surrounding budgetary policy may help ensure that objective-setting rules are observed and reduce the temptation to meet them through fiscal gimmickry. Greater transparency can also assist the population to hold sub central governments accountable.

\subsection{Experiences with public-private partnerships in OECD countries}

Cities are important users of Public-Private Partnerships (PPPs). These are applied in infrastructure projects whose design, funding, construction and, sometimes, operation is conferred to a private provider. In turn, the private provider receives an annual subsidy for a fixed time. PPPs have become popular since they not only tend to increase allocative efficiency but allow sub-central governments to spread spending more evenly over an investment's life span. Most PPPs are contracted at the sub-central level: in Germany, around $80 \%$ of PPP-investment is spent at the Länder and municipal level, while in France more than $50 \%$ of PPPs are arranged at the sub-central level. The United Kingdom has the most advanced PPPs covering around 200 projects totalling $£ 26$ billion in 2007 and representing 10 to $15 \%$ of total public service investment, mostly administered by local governments. Cities and metropolitan areas are the most frequent sub-national users of PPPs, due to the concentration of infrastructure in urban agglomerations, Areas that are well covered by PPPs are road infrastructure (such as the 407 Highway in Toronto and the Sydney harbour tunnel), urban development (development of the Orestad in Copenhagen), extending into urban and transport planning (Antwerp Masterplan).

Use of PPP's is not without risks for cities and national governments. Cities often find it difficult to specify contracts, to assess the risks associated with long-term projects and to distribute them fairly between the private and the public sector. Contractual agreements can unduly play in favour of the private sector as cities negotiate with experienced private contractors, often operating internationally. While some central governments have set up specialised agencies to deal with private sector involvement in out-contracting projects (Australia, Ireland, the United Kingdom), cities might have 
less access to specialised knowledge. Stronger inter-municipal co-operation and information exchange could reduce asymmetries and build up the capacities to deal with privately financed projects. Moreover, some funding arrangements -- PPPs in particular -- shift financial obligations to the future and may serve to bypass self-established or central-government-imposed fiscal rules. Out-contracting and PPPs may also reduce sub-central budget accountability; particularly they are financed through off-budget operations.

\subsection{Monitoring performance of local services}

Well-designed performance indicator systems are information tools that can enhance the quality of decision making by reducing information asymmetries, and can promote the accountability of public services to national, sub-national, and citizens' priorities. As a "powerful" tool it has its strengths and weaknesses. On the one hand, in the absence of central-sub-central communication and collaboration, the use of indicator systems can introduce tension in intergovernmental relations if used by the central government as an ex-post substitute for ex-ante control of public services. On the other hand, its strength is that it contributes to a persistent need: information. Indicators contribute to enhancing the efficiency and effectiveness of sub-central service delivery by revealing information and reducing information asymmetries which exist among levels of government, and encouraging performance improvements by altering the incentives which sub-central governments face.

There are several examples within the OECD of successful indicator systems to benchmark subcentral performance. Australia's Review of Government Service Provision is a comprehensive assessment that provides performance information on 14 areas of public services. Denmark's system for monitoring municipal performance has published, since 1984 comparative data for benchmarking municipalities and regions, including social conditions, economic background, local financial data, and outputs. Norway's KOSTRA system produces key municipal indicators on financial figures, productivity, and priorities, covering about $40 \mathrm{key}$ indicators and an additional 1000 indicators in 16 service areas. Some of these indicator systems are bottom up systems. E.g. in France, each subcentral authority may develop its own system to meet its information needs. Due to the constitutional principle of self-regulation of local authorities, the national and the sub-national governments have not agreed to adopt a general system of indicators. In some cases, benchmarks of sub-national services and performance are made by the association of local governments.

Implementing a standardised system of indicators is likely to be easier where the central government has leverage over sub-central entities and the power to mandate performance measurement. The extent of central government authority and ability to monitor sub-central performance is determined by an interplay of factors: institutional arrangements and autonomy of subcentral governments, allocation of responsibilities for service provision, and the design and share of intergovernmental transfers. For example, attaching rewards and sanctions to performance indicators in Italy was possible despite the decentralised institutional setting in force because sub-central governments remain considerably financially dependent on grants coming from the central government. Because indicator systems can be used to promote learning and diffusion of good practice, failure to implement any type of information system can represent lost opportunities for learning and improvement. Thus, despite institutional hurdles, there are examples of voluntary participation in a common system (U.S). Cases in the U.S. are most successful where central government adds value to the sub-central data, depoliticises its use, and enters into an information partnership with sub-central authorities that emphasise learning as a primary benefit.

The selection and development of indicators raises a fundamental issue of the measurability of public sector performance. Numerous factors contribute to difficulties in this regard: the complexity of public service delivery, the nature of outputs produced and outcomes achieved, and the lag between 
activities and results. The challenge of choosing measures and compiling indicators is further constrained by basic issues such as the validity, reliability, and comparability of data. Not only is the selection of indicators constrained by data quality and availability, but the production of knowledge about efficiency and effectiveness is subsequently constrained. Indicator systems are not static. There are likely to be persistent challenges regarding data quality and measurement, ongoing opportunities to enhance the use of information, new technologies to reduce administrative burden, or opportunities to enhance information partnerships between central and sub-central authorities. As a result, indicator systems should be seen in a dynamic and collaborative context.

\section{Summing up}

\section{Urbanisation: a step-by-step evolutionary process}

Experience in OECD countries shows that the process of urbanisation is essentially a function of a country's economic development and diversification, driven in large part by such positive externalities as technological advances - notably the Industrial Revolution - and the democratisation of access to education. Strong urbanisation has been fuelled by rural-to-urban migration (and in North America by significant in-migration from abroad over the last two centuries), which in turn drove solid economic performance as the industrial revolution took hold by the middle of the $19^{\text {th }}$ century. A century later, migration began to ease as congestion and other centrifugal forces grew. Urbanisation slowed, and was accompanied by a process of suburbanisation after World War II.

Since the mid-1990s, the rate of urbanisation has again been increasing in the majority of OECD countries. This process of re-urbanisation in the context of globalisation has been accompanied by the growth in the services sector in OECD countries and the concomitant out-migration of significant primary and heavy manufacturing activity of OECD-based trans-national corporations to non-OECD countries. This process of tertiarisation of the economy in the OECD is also a predominantly urban phenomenon: it has been driven by a concentration of human capital (especially highly qualified persons) and a large increase in the participation rates of women in the economy, almost exclusively in urban areas. At the same time, this process has led to a more fragmented pattern of urbanisation with some urban cores regaining population and others showing decline.

These stages of urbanisation, de-urbanisation and re-urbanisation have not been uniformly felt across the OECD. Some countries urbanised faster than others: for example, France, Spain and Italy remained largely rural until as late as the 1950s, while the United States and the United Kingdom had begun their rapid urbanisation by the end of World War I. Moreover, rates of urbanisation can vary significantly within countries. The patterns of economic growth and diversification neatly map against these differing rates as well.

\section{Large cities: importance of, and limits to, their role}

Indeed, urbanisation is generally associated with higher income and productivity levels. Higher urban population shares are generally associated with higher per capita GDP than their national average, partly attributable to metropolitan areas. In many OECD countries, one single metropolitan area produces between one-third and one-half of the national GDP.

However, the benefits associated with economies of agglomeration are not unlimited. Cities can reach a point where external diseconomies outweigh centripetal forces and become less competitive. At least one-third of OECD metro-regions ranks systematically lower than their national average for almost all indicators, such as income, economic growth, productivity, skills, employment and unemployment. This is in large part due to negative externalities caused by historically 
unregulated/unmanaged urban growth and diminishing marginal returns: after a certain point, congestion and smog, land scarcity and sprawl, marginalised human capital and infrastructure deterioration due to lack of financial resources begin to contribute to an urban area's dysfunction and decline. Once-attractive urban areas become regions to avoid - and highly qualified talent, along with endogenous and foreign capital, can flee or decide to focus their business decision-making elsewhere. These negative externalities can therefore lead to diseconomies of scale, which can serve to illustrate the limits of urban agglomerations' influence on economic development across the OECD.

\section{Medium-sized cities have potential.}

Among OECD urban areas, it is medium-sized ones that outgrow the rest since the mid-1990s. Medium-sized cities are half the economic size (GDP) of large ones and less than one-third of those with more than 1.5 million people. Yet, they grow by half a percentage point more every year. Focusing on medium-sized cities would bring about not only greater economic growth but also greater efficiency in metro-regions and larger urban areas, as they are often pressed by congestion costs, greater land-rent prices and other diseconomies of scale.

\section{Defining an optimum city size serves no purpose}

City size drives positive urban growth and economic performance only up to the point at which negative externalities begin to cause diseconomies of scale in the urban area. There is therefore no single optimum city size, but rather an efficient city size which depends on local circumstances (indeed, one country's medium-sized city is another's megalopolis).

Not only that, but the nature and scope of the agglomeration effect on a city's economic growth will vary strongly by economic sector. Growth in some sectors - the media and entertainment industries, for example - is sustained by highly skilled human capital, while others are dependent on technological innovation (ITC), while still others are dependent on both (biopharmaceuticals; banking and finance). The size and configuration of urban centres that specialise in particular economic sectors tend to reflect their sectors' component make-up.

Trend analysis in OECD countries shows that those cities that attract firms and workers will continue to do so as long as the benefits associated with higher wages, productivity and employment continue to be positive. Moreover, preferences for different sized cities will vary by household. Some highly qualified people chose to live and work in large metropolises because they like the vibrancy, dynamism and choice of professional and leisure amenities such big cities tend to offer; other people, with the identical qualifications, will prefer smaller centres precisely because they eschew what they regard as congested, dirty, noisy, expensive big cities. So the driver is not size, but the efficiency with which a city or urban area operates - any sized cities will continue to attract and retain workers and firms so long as the benefits from living and working there continue to outweigh the costs associated with agglomeration, costs which will vary depending on the economic sector and area of specialisation.

Therefore, for emerging economies, experiencing urbanisation, it might make sense for spatial urban development strategies to focus not on defining an optimum size for city growth and urban inmigration, but rather on efficiency issues in the provision of public services, on strategic infrastructure, human capital formation and integration and on economic growth/diversification and agglomeration strategies. 
Urban competitiveness is mainly driven by endogenous factors.

Whilst a sound macro-economic environment, efficient products and markets as well as performing regulatory and taxing environment are crucial elements to ensure productivity and growth, competitiveness (and decline) of the business sector increasingly depends on factors related to the regional business environment. Performance in the productivity level of urban regions (the main explanation of regional differences) is strongly associated with economic specialisation, as well as human and physical endowments.

OECD works on urban regions highlights the level of skills as a main determinant that influences their productivity level. This finding is corroborated by the OECD regional growth model which shows that human capital - mainly tertiary educational attainment - is the most explanatory factor whilst infrastructure has an impact on other factors in place (e.g. human capital, innovation, agglomeration). More generally, as countries integrate with the globalising economy, their competitiveness will increasingly be driven by the capacities of their urban regions to improve the productivity of enterprises in ever-widening supply chains. These urban capacities not only include the bricks and mortar of infrastructure, but also the knowledge and skills of workers, and the social capital needed to trigger and sustain innovation that is shared among firms.

\section{The urban paradox: dynamic growth and social exclusion co-exist in urban regions}

Although most urban areas in OECD countries appear to be characterised by high concentrations of wealth and employment, associated with leading sectors and the focal points of their national economies, they also tend to concentrate a high number of unemployed residents. In other words, wealth is not adequately translated into job creation. While employment and employment growth are typically higher in cities, urban areas also contain disproportionate numbers of people who are either unemployed or inactive (or who work in the informal economy). Among the main explanations for this paradox are the lack of affordable child care facilities, larger proportions of immigrants who generally have lower skills and who may be discriminated against, and in some cases, the presence of a sizeable informal economy, typically bigger in large cities. Consequently, cities in OECD tend to concentrate pockets of exclusion and poverty, so that these challenges have become urban phenomena.

Certain characteristics of dynamic post-industrial cities result in increasing socio-economic inequalities, which increase segregation and its consequent social stresses. Exclusion does not, of course, take the same form or intensity in every city but most urban regions, including the wealthiest ones, have pockets of populations that have low standards of living and experience social problems. This creates a need to apply integration strategies to urban services, job opportunities, housing, and the like. Social exclusion in urban areas is generally associated with strong residential segregation between the prosperous and disadvantaged populations that concentrate in deprived neighbourhoods. Poverty, exclusion and spatial polarisation alter the pattern of employment and investment, therefore reducing the city's capacity to pursue area-wide goals, such as competitiveness and sustainability. The repercussions are difficult to quantify, but a certain number of direct and indirect costs can be easily identified. They include the loss of human capital and diminished social capital, as well as a burden on public spending due to higher criminality and related destruction of public goods in distressed areas. This points to a need for policymakers to address social segregation and the needs of disadvantaged urban populations in order to keep the engines of local economic growth and competitiveness running smoothly. 
Environment quality becomes key for urban competitiveness - urban policy can contribute to a global climate change agenda

Environmental quality has become a key factor in determining cities' competitiveness. Climate change threatens cities' growth, as more severe storms and coastal flooding, urban heat island effects, pollution and resource shortages threaten to damage infrastructure, reduce efficiency and exacerbate urban poverty. The challenge for emerging economies is to pursue urban development while addressing environmental degradation and dealing with climate change. OECD modelling of metropolitan regions finds that low pollution levels will increasingly be a factor driving the attractiveness of urban areas, and therefore of competitiveness. Further, policies to reduce urban sprawl and congestion can be implemented without having a detrimental effect on long-term economic growth, particularly when coupled with incentives for innovation. The trade-off between economic growth and climate/environmental policy can actually be lower at the local level than at the national level, in part because more complementarities and synergies can be observed at this scale among the different policy objectives. As cities concentrate a large part of global GHG emissions, national governments in OECD countries now understand that an urban lens should be applied to climate change policies. OECD work has demonstrated that an urban climate policy agenda (densification/congestion tax) can halve the abatement costs of a global climate change policy (e.g. carbon tax).

\section{Policy Approaches}

Strategic and Methodological Considerations

\section{Target an "Urban Development", not an "Urbanisation" Strategy}

An "Urban Development" approach might be more appropriate than an "Urbanisation" approach. City size matters but need not be a driver for developing the strategy's framework. While urbanisation brings further growth and productivity, governments should not target an optimum city-size but rather aim at maximising the benefits of agglomeration economies and removing obstacles to their establishment, based on local comparative advantages and weaknesses. Although it should focus on long term outcomes, an Urban Development Strategy also needs to remain flexible and encompass a vision that is tailored to the specific stages of urbanisation that might vary across the country as well as to regional differences and city specificities.

\section{An integrated, multi-sectoral, forward-looking approach is necessary}

Urban competitiveness depends on several input factors; it is therefore important for national policymakers to adopt an integrated approach to urban development issues.

What has become increasingly clear to OECD central governments as they become conscious of the key role cities play in sustaining their country's national growth and international competitive position, is that a siloed, sectoral approach to solving place-based challenges does not work. Issues that play out in urban areas - indeed issues that all regions face - are far too complex and interrelated for a single order of government or a single government ministry to address effectively. On the contrary, across the OECD, evidence suggests that it is the multi-sectoral approach, for example linking land-use issues to housing, infrastructure, the fiscal framework and human capital integration, which produces the best results.

Recognising this principle, many OECD countries have complemented their traditional remedial policies (concern with remedying the decline of industrial cities and managing issues of decay, crime 
and social problems were often the automatic associations of the term 'urban policy' in the 1980s and even the 1990s) and infrastructure-based approach with forward-looking programmes for attracting firms in the most innovative and dynamic sectors, their associated highly skilled work forces (through human capital improvement, attraction and retention measures), as well as efforts to foster innovation. More recently, the environmental dimension is beginning to be included both as a function of the recognition of the impact of climate change on cities and of the potential for urban areas to contribute effectively to climate change mitigation objectives as well as their complementary impact on equity and efficiency objectives.

\section{Policy planning needs to be grounded in the reality of the market}

Whilst strategic planning for urban development can help manage demand for future public investment, it is important to ensure that it is sustained as a function of market forces. A main objective of strategic planning is to emphasise trajectories that maximise growth opportunities without overstretching public investment requirements. It is important to recall however that trends in OECD countries show that urbanisation has been driven by market forces, not by governments. However, the same evidence also demonstrates that active regional public policies as well as some sectoral policies (housing, fiscal, etc.) have had important effects on the development of urban areas. There is also evidence of urban regions having failed to realise their potential because of a lack of appropriate public policy and the fact that containment policies to limit urban growth have not produced expected outcome.

\section{Urban development is a key component of the national spatial policy framework}

Addressing long term strategic planning for urban areas within national spatial/regional planning frameworks is essential to avoid duplication and conflicts within and between regions and foster synergies. There are several reasons to ensure consistency between an urban development strategy (addressed to urban regions or cities only) and a national spatial/regional planning framework. First, it is a way to meet certain nationally agreed-upon objectives such as controlling regional disparities and working towards sustainable development. It is important however to recall that the new paradigm for regional development policies that is being developed in OECD countries addresses the equity issues among regions differently than in the past. Current approaches are based on the principles that opportunities for growth exist in the entire territory and across all types of regions and therefore departs from the old view of regional development as a zero-sum game aimed at responding to efficiency-equity trade-offs. Second, ensuring consistency with national spatial/regional planning can foster rural-urban linkages, which have strong economic interactions based on natural, human-capital, economic and financial interdependencies.

\section{A-spatial sectoral policies also matter}

Assessing the impact of national public policies in urban areas requires recognising the impact of implicit "urban" policies. The concept of urban policy transcends the confines of narrow definitions given that nearly all public policies directly or indirectly affect urban development. Central governments have a large impact on urban living conditions through a variety of policies, programmes and projects that are being implemented by a wide number of national ministerial departments and agencies. It is important for the success of urban policy that these 'implicitly urban' policies are recognised as such. 


\section{Policy trade-offs need not include pitting one city-region against another}

An Urban Development Strategy needs to build up competitive cities whilst ensuring that others do not fall into neglect. Whether or not the identification of 'national champion cities' can produce positive spillovers for the rest of a country or prevent those other parts developing their own dynamism is of overwhelming importance to an evaluation of the strategy. The choice is not between using national policy to favour growth poles as opposed to regeneration and social repair of declining areas, but of putting the national eggs into a smaller or larger number of baskets. A national government that focuses strongly on its most promising cities runs the risk of producing very uneven development within its territory, with whole regions missing out on chances to enter the new economy; conversely, a government that tries to spread its urban infrastructure evenly may end up with no cities able to enter the competitive arena of global cities. The importance of a national policy framework that focuses not only on producing global champions is shown by the evidence that subsidiary/regional growth poles, while unable to act on the global stage, may generate important autonomous dynamism for regions remote from a country's main growth pole(s) and thus contribute effectively to overall national growth.

Governments in many OECD countries have therefore tried to ensure that supporting champion cities does not compromise earlier policy goals of even-handed treatment of different regions. Experience suggests three potential ways out of achieving such a balance and creatively resolving this question:

- Even where a country has one clearly dominant metro-region, government and other policy actors can plan for a number of subsidiary strong regions, which, while they might not rival and may even be dependent upon the leading one, can have positive effects in parts of the country remote from the leading city.

- This approach will benefit even larger areas if potential wider positive regional impacts of key growth centres can be realised and encouraged.

- The policy of developing subsidiary growth poles can be extended to former deprived regions if the policy switch can be made from thinking in terms of regeneration and dealing with social casualty to a proactive and positive approach to urban economies.

\section{A statistical tool-kit is essential}

An adapted urban development approach requires developing appropriate statistical tool to assess trends and challenges of urban policies, both within a national context and to allow for international comparison. Defining what is urban has been a difficult task and there is no commonly agreed definition which makes international comparisons difficult; however, the OECD has developed powerful tools for the analysis of urban and metropolitan areas. Statistical tools, from outcome indicators to output measurements, are crucial to monitor progress toward achieving the strategic policy outcomes defined in urban development strategies. Based on reliable, comparable measurement tools, decision-makers can adjust plans over the medium term if the indicators demonstrate that the chosen policy and programming tools are not optimising the achievement of the urban development strategy's outcomes. These tools are equally key to ensuring that each actor involved in the development and delivery of multi-sectoral, multi-government strategies can measure the impact of their contribution to the achievement of these outcomes. They are key to enhancing transparency and citizens' participation, as all community members can readily gain access to benchmark indicators that show progress (or lack thereof) in achieving the "vision" that they will have established for themselves and their community in the urban development strategies. 
Identifying the Policy Focus

\section{Unique assets tend to generate common challenges in most OECD urban areas}

Unique urban attributes notwithstanding, most urban centres across the OECD tend to face a similar set of negative externalities. It is therefore not surprising that urban development strategies across the OECD tend to focus on addressing a similar set of policy challenges: land use and the related issues of urban sprawl and urban attractiveness and liveability, as urban land tends to be scarce and expensive no matter where the urban centre in the OECD, the economic behaviour of firms and industrial groupings in driving urban economic diversification and competitiveness, most notably cluster-building and innovation capacity, human capital development, attraction, retention and integration, particularly as a function of innovation and competitiveness, housing and strategic urban infrastructure, and more recently the relationship between urban development and climate change.

As well, since OECD governments have been addressing urban development challenges systematically since the end of the Second World War, trial and error has led to the adoption of methodological approaches that resemble each other across the OECD. One methodological feature common to the most successful urban development strategies in the OECD is their focus on policy outcomes. The most effective urban development strategies tend to be outcomes-driven, focussing on achieving clearly-defined long-term results. They also tend to identify concrete, practical plans to move forward, along with the fiscal, regulatory and programming tool-kit required to achieve results.

Hence, the similarity of policy challenges in most urban centres across the OECD explains why, notwithstanding the uniqueness of a city's specific strengths and attributes, public policy frameworks focusing on urban development tend to converge around a common policy-cluster focus and a common methodology.

\section{Manage spatial development through land-use assessment, tax reform and growth plans}

Many OECD countries have developed land-use policies to improve the cost effectiveness of public investment and address market failures linked with rapid urbanisation and unplanned growth. OECD governments employ a wide arsenal of tools to control the speed and the location of urban development. These can be divided into three categories: land assessments, property taxation, and growth management tools.

Ongoing land assessments: Policymakers require information to measure and accommodate the demand for urban development. With these assessments, infrastructure allocation can be programmed to reduce long-term patterns of congestion and sprawl. Future land-use analysis and scenario modelling are useful in determining which lands are potentially developable to accommodate urban growth. They can also illuminate the spatial impact of public policies, e.g. possible effects of changes in permitted density, zoning ordinances, and the construction of roads and public transportation facilities.

Property taxation: The introduction of a property tax can reduce distortions on land markets and stimulate more efficient land use. As the most important tool for most OECD countries to recoup the increased land value due to development, the property tax is effectively used by many OECD countries to control excessive land conversion. Excessive reliance of local government revenue sources on revenues from land leasing may generate irrational investment spending given the fiscal incentive to acquire and convert agricultural land into developable areas. 
Growth management: The need to align urban growth and infrastructure allocation justifies urban growth management in OECD countries. These policies anticipate and incorporate the impacts of growth on local infrastructure and environment systems, and can also protect open space and farmlands in peri-urban areas. OECD member countries have developed policy tools to control the speed of urban growth and complement it with infrastructure development as well as tools to control where urban growth occurs.

\section{Address urban sprawl, which has long term economic and environmental costs}

The environmental and economic costs of sprawl can be avoided by developing a more extensive transportation system, by applying land-use policies aimed at increasing density and by linking economic success of metro-regions to the development of medium-sized cities. Urban sprawl not only increases carbon emissions due to transportation and longer commuting journeys, but it also imposes economic costs on workers and firms. The development of public transportation systems in metropolitan regions as well as in medium-sized cities are key to fostering mass transit commuting to employment centres and to encouraging housing development near public transit. In addition, land-use policies that favour denser urban areas through zoning and the provision of high-quality urban services can also help reduce the need to build housing in suburban areas. The development of medium-sized cities is also key to offering industrial location alternatives to firms, which would support an economic strategy for those cities and release the pressure for urban sprawl in metropolitan regions. The development of rail and bus services both within and between cities becomes an essential part of any new urban strategy designed to tackle increase public transit and reduce sprawl. This normally requires a strong role for central government, as local governments lack the power and resources to construct major transport systems by themselves.

\section{Target attractiveness and liveability as a main objective of dynamic cities}

Rapid change and increasing size are essential attributes of urban dynamism, but they are both associated with a number of negative phenomena, which together have led to invention of the term 'liveability' when contemporary cities are assessed; 'liveability' being in large part a question of public goods, this issue is a highly important one on the urban public policy agenda. One consequence of this is that a Urban Development Agenda finds itself including many of the issues of the more familiar agenda of coping with decline and symptoms of social stress. Economically successful cities declining in liveability constitute examples of how diseconomies of scale may set in, and as such demonstrate why it is very difficult for governments to stand back and let the market take its course. Much policymaking here devolves to local authorities, as they witness the emerging problems 'on the ground', but some of the issues concerned are beyond the reach of local governments, and central governments have a role in ensuring that city authorities are equipped with the legal powers and finances they need in order to improve urban infrastructures. The highly mobile groups and firms that constitute the dynamic sectors have a capacity to choose where they live, and they will avoid cities with poor environments; good physical and social infrastructure are aspects of the creation of dynamic cities, not just compensation for their consequences.

\section{Innovation and cluster development: Build on local assets}

Market forces alone may not always support a city's pursuit of a particular economic activity. Markets sometimes fail - for instance, key factors in the innovation or production and commercialisation process may be absent in the urban region; educational and training institutions may be inadequate or lack the knowledge of the skills requirements in their urban region's key economic sectors, or the urban labour force's skills may not match the jobs available in the region's key industrial sectors. There is therefore an important role for national governments in helping city 
and urban regional authorities identify potential new economic activities and in matching input factors to output requirements at times of rapid change.

In the past, regional policy initiatives aimed at stimulating a region's economy have often focused on attracting foreign direct investment through direct subsidies, for example to encourage foreign investors to locate their firms in the region, under the assumption that FDI will automatically stimulate local input factors (such as the endogenous labour force) to produce dynamic economic activity in a way that endogenous investments could not. If a region's business environment is not dynamic, if a region's labour force is not well trained or if a region's infrastructure is inadequate to meet the business community's needs, no amount of FDI will change this state of affairs.

Having learned this sometimes expensive lesson through trial and error, governments around the OECD began to focus in the 1990s on how best to encourage endogenous firms to become more competitive, which led to the policy interest in cluster development and in how to foster inter-firm linkages. This in turn led to the now current focus on stimulating a region's endogenous innovation capacity, along with recognition that there is significant policy interdependence between innovation capacity, human capital development, infrastructure and land-use.

Although initiatives have tended to focus on innovation in research hubs, which have met with the most success, governments have shown an increasing interest in encouraging innovation capacity beyond leading-edge sectors by focusing on more traditional industries to encourage firms in these sectors to "move up the value-added food chain". But encouraging innovation capacity as a component of cluster-building remains a popular policy response across the OECD. Despite a certain level of "cluster fatigue" in policy and academic circles, national innovation strategies using the cluster model continue to be popular and in some cases are featured prominently on the policy agendas of national governments.

Indeed, there are numerous examples within OECD countries of partnerships between central and local authorities that focus on identifying and building nascent clusters - starting with practical feasibility studies to define realistic possibilities that are market-driven rather than unrealistic. The identification of cluster potential is usually made at the city level, but central governments play a crucial role in providing macro as well as targeted help for nascent clusters, from creating a positive fiscal environment (including fiscal and regulatory incentives to encourage cluster development) to providing strategic infrastructure development support (for instance for transit and transportation, ITC networks, water/wastewater and solid waste systems and the like) or to giving local authorities guidance and training to pursue realistic approaches to development. Central to these partnerships is the identification by the central and local government partners of policy areas where they can see scope for targeted action in support of firms' existing, market-based strategies. Another prominent way in which governments can provide general but targeted support for activities that are emergent rather than centrally planned is by building up universities as strategic hubs and by encouraging partnerships between the universities/colleges/vocational institutions and the private sector in the urban region to ensure that the training institutions are fully aware of the nature and scope of the skillsets required by the urban region's clusters.

\section{Regionalise labour market policies}

Experiences from OECD cities show that sudden increases in labour inflows do not need to have large negative effects on employment, earnings and security if local labour markets are flexible and resilient. Integrated strategies need thus to be developed in collaboration among levels of government to strengthen local labour markets, through regulatory reforms, workforce development, support to SMEs and business incubators. City governments have important responsibilities in the design and 
implementation of these strategies but strong co-ordination with higher levels of government is required. In recent years, the widening activism of local government authorities and local public employment services in OECD cities have lead to smarter prioritisation of employment programs and sharper targeting of those more in need. Job-creation programs should be pursued simultaneously with safety-net programs for those transiting into unemployment and integration programs for the migrants.

\section{Develop place-based "neighbourhood regeneration" strategies for distressed areas.}

Stressed neighbourhoods in large urban centres present a challenge to central governments because they reduce a city's attractiveness and liveability. This in turn affects an urban centre's ability to attract and retain highly qualified talent, capital and technology. The more stressed the urban centre, the less competitive it is because key input factors for economic growth, starting with people, will chose not to live or invest there. The more stressed urban centres tend to constitute a drag on national productivity and competitiveness, which explains why central authorities in the OECD have begun to focus on these issues.

Neighbourhood regeneration in large urban centres across the OECD is primarily a social policy challenge due to the nature and scope of the factors underlying the neighbourhood's decline: poor quality housing, low educational attainment, and social related issues. The concentration of poverty in stressed neighbourhoods is usually exacerbated by a lack of community infrastructure and the lack of businesses location. More recently, the public policy challenges in this area have been exacerbated across the OECD by the disturbing trend toward ethno-cultural concentration in stressed neighbourhoods. Recent immigrants to large cities in North America and western Europe, for a series of complex and interrelated reasons, have begun to concentrate in distressed areas in the urban core and in near and distant suburbs.

The policy response by central governments across the OECD has been as varied as the local circumstances which demanded it. That said certain common approaches are beginning to emerge. First and foremost, the recognition that addressing the needs of distressed neighbourhoods must be a part of any holistic urban development strategy is key. Indeed, given that the overarching policy objective is to foster the conditions for cities to drive national economic growth, recognising that the people who live in distressed neighbourhoods possess talent and skills that can be harnessed to generate sustainable growth becomes an operating policy imperative for governments across the OECD. Data shows that immigrants are often more entrepreneurial than their locally-born neighbours; immigrants can therefore become a vital source of job creation. The ability to speak more than one language and the networks of contacts that immigrants bring from their homelands to their adopted city are increasingly being seen by central governments as highly prized attributes upon which to build sustainable urban growth.

Second, policy and programming responses must be tailored to meet the specific circumstances of the local affected communities. Various urban Territorial Reviews have shown that it is the programming that has been specifically tailored to address local circumstances that work best, whether it is establishing mechanisms to provide "bridging", mentoring, apprenticeship and other credentialrecognition initiatives for newcomers by local small and large firms in urban centres where the skills and training of the immigrant labour pool is being under-utilised or ignored, or by stimulating the provision of affordable housing in those neighbourhoods were housing is a key issue.

Third, governments are becoming increasingly aware that addressing stressed neighbourhoods effectively is as much a governance challenge as it is a policy one. Indeed, central governments have recognised that "going it alone" in a top-down, a-spatial fashion will not produce desired policy outcomes. Across the OECD, the development and implementation of place-based social policy 
initiatives by central authorities to address distressed neighbourhoods have become increasingly more decentralised. This means that the partnership role of local urban authorities, as well as neighbourhood and community leaders within the urban centre, is crucial if centrally-driven neighbourhood regeneration initiatives are to be successful

Finally, OECD governments are recognising that the policy response must be multi-sectoral and integrated: at its most basic level, it is of no use to build housing in neighbourhoods were there are no jobs or schools or day-care centres. It is no use building affordable housing that is not near public transit - if the working poor cannot walk to and from work and their children cannot walk to and from school, efficient and affordable public transportation is often the only alternative, as the private automobile is often out of their financial reach. This integrated approach also implies governance mechanisms that are inclusive of the communities at which the policy response is aimed. Vertical and horizontal governance tools linking ministries within a single government to each other, linking governments to governments operating in the urban centre and establishing ongoing dialogue with the private sector, academia and community leaders have proven to be the most effective in achieving positive neighbourhood regeneration results across the OECD.

\section{Ensure adequate, affordable housing for all in a rapidly growing urban environment}

Across the OECD, national, regional and city authorities have developed a range of policy tools to address the supply of adequate affordable housing. This involvement dates to the end of World War II, when a massive influx of returning war veterans into OECD cities first prompted governments to act systematically to ensure that a steady housing supply could support rapid population growth and economic development. Some policy tools worked better than others, but key common best practices include a reliance on the private and not-for-profit sectors to build supply along with ensuring deep coordination between housing policies and those related to land-use, infrastructure development and fiscal frameworks. Here are some examples:

- Monitor housing affordability regularly to identify the neediest households and to prepare for necessary action. To support this monitoring, the development and maintenance of a reliable database on housing supply (e.g. new construction starts, number of stock, age, vacancy, etc.), housing quality (e.g. size, etc.) and other related problems (e.g. social segregation, crimes, illegal occupation, slums, etc.) is an important task for national and local governments.

- Address housing supply inelasticity in order to cope with a growing housing demand and to avoid a sharp rise in housing prices. Empirical studies in OECD countries show that low housing supply elasticity may cause a housing affordability "crisis", because new construction will not meet an increased demand if housing supply is inelastic, leading to a sharp rise in housing prices. Measures to improve housing supply elasticity include: increasing the flexibility of zoning regulations; improving co-ordination of infrastructure and housing development policies; and increasing the predictability, consistency, simplicity and transparency of the planning permit processes.

- Promote the affordable housing supply through the not-for-profit sector and create efficient private rental housing markets. In many OECD countries, the government has retreated from the role of directly supplying housing and the private sector now provides most dwellings. However, for-profit housing providers tend to build for the top end of the market because there is more profit in high-end homes than in economy homes, which leaves many communities with an inadequate supply of moderately priced homes. Thus, the public or notfor-profit sectors are often called upon to fill the affordable housing gap. Measures to 
promote the affordable housing supply include: establishing mandatory quotas or voluntary targets for affordable housing provision by the private sector; enhancing the housing supply through facilitating affordable housing development by not-for-profit organisations; ensuring land availability for affordable housing development; fiscal incentives to promote the supply of rental housing; and encouraging the supply of housing for households with special needs, such as the elderly.

\section{Urban centres hold the keys to successful national climate change strategies}

Cities across the OECD have begun to take action to mitigate their contribution to greenhouse gas emissions and adapt to expected climate change impacts through urban sectoral policies and through co-ordination with national and regional governments. Experience in OECD metropolitan regions demonstrates that:

- Cities have key competencies to act on climate change by optimising and are well-placed to seek policy complementarities and innovative policy solutions. Cities and metropolitan regions' influence on public transportation systems, the built environment, renewable energy and energy efficiency measures, and the sustainability of services delivery put them in a position to develop policy and programmatic solutions that best meet specific geographic, climatic, economic, and cultural conditions. They are equally well placed to develop innovative policy solutions that can be scaled up into regional or national programmes, or to provide a laboratory for national pilot programmes on the urban level. Important opportunities exist where cities are service providers, although cities generally are still reluctant to make full use of their regulatory authority to achieve climate goals. Effective climate policy packages should seek policy complementarities among and within urban sectors to implement policies that enhance each other's effectiveness.

- Strategic planning of land-use and transportation patterns is key to low-carbon, climateadaptive development. Policies to increase the concentration of urban areas in the long term and manage outward expansion have gained popularity across the OECD. Successful compact cities policies rely on well-designed strategic plans. While the higher residential densities targeted by these policies have the most direct effect on GHG emissions, transportation linkages - particularly between employment centres and residential zones and a mix of land uses within neighbourhoods are crucial to ensuring that increases in density translate into reductions in personal vehicle use. High quality urban services and amenities, including open space, are also crucial to the long-term attractiveness and effectiveness of compact cities policies.

- National governments can play an important role in supporting and removing barriers to urban climate change policies. Key national roles include: providing funding and technical assistance to cities and regions; establishing climate mandates in national urban and regional policies to advance local climate action; and setting strong national adaptation and emissions-reductions targets to ensure successful local implementation through the country, prevent regional competition based on environmental regulations and even promote a "race to the top" through incentives. The need exists for a review of national urban policies in light of climate change priorities to identify potential national policy barriers to urban climate initiatives 


\section{Governance and Finance}

Just as the key components of the urban development policy focus tend to be replicated across the OECD, so too do the governance and fiscal tools that OECD central governments use - and adapt to their own circumstances. At the end of the day, repeated urban development policy failures since the end of World War II have taught OECD governments - and the citizens that elect them - some valuable lessons on how best to address fundamental challenges in urban centres. While success has been varied, of course, and in many cases hard-won, and while success has by no means been uniform across the OECD, what follows is a presentation of some of the elemental best practices in urban governance and finance that have met with success in most OECD countries.

Horizontal and vertical governance tools insure coherence in strategy development, planning and delivering for results

A key challenge in many countries has been to define the most effective and efficient allocation of functional responsibilities among various levels of government and between the key relevant public and private actors in a metropolitan area. Defining who does what provides the framework through which the structures and processes of metropolitan governance can be refined, realigned, or even entirely re-designed.

For national governments this issue has traditionally presented itself mainly as a question of whether to introduce measures of local and regional government reform. Extensions to city administrative boundaries must be considered, so that these correspond more closely to the shape of the city as an economic unit. While reforms of this kind will provide strategic capacity, attention also has to be given to the structure of municipal government below the level of the identified city or metro-region. Governments have to balance the administrative simplicity and lack of inter-authority conflict that can be achieved with single-tier local government against the alienation and remoteness that may be experience by citizens if they have no more local level available to them.

An alternative approach to overall local government reform is the establishment of separate authorities for certain specialised strategic tasks - such as regional public transport authorities. These can avoid some, though by no means all, the conflicts that major boundary changes can involve, and can produce sets of authorities whose geographical boundaries correspond fairly closely to the functional needs of the task in hand. However, these goals may be achieved at the expense of 'joined up government', as it becomes difficult to co-ordinate the policy areas so organised with those remaining with various tiers of local government. This problem can be partly addressed if the specialised authorities are formed by the local authorities in the area concerned, but they can then become subject to rivalries between these.

At its most elemental, however, the issue of governance for effective urban strategies speaks to the need to harness the expertise, knowledge and policy "tool kits" of all key actors, both public and private, from all governments that implement policy and deliver programs and services in a given urban area, to the institutions that train human capital, the private sector that hires it and the citizenry itself, implicated in the development and implementation of a vision and its policy outcomes for the urban area. This need not imply huge institutionalised bureaucracies - in many cases in the OECD, a "light touch" has worked best, where actors come together in loose coalitions or under voluntary agreements to pursue commonly defined objectives for urban development.

Indeed, what has proven to be arguably more important than institutionalising vertical and horizontal governance mechanisms is the codification of the vision, outcomes and planning needed to implement the urban strategy over the long term. From France's contrats de ville to Canada's Urban 
Development Agreements, codified agreements that spell out clearly what the strategy is trying to achieve, who does what to achieve it, how progress will be measured and how progress will be reported to the players themselves and to the general citizenry, seem to achieve the best results most efficiently.

\section{No two alike: city administrations differ, and some cope better than others}

It is essential to build strong capacity at the local level to design, implement, monitor and evaluate local public policies. Moving towards more proactive bottom-up urban policy requires more than designing a new territorial administrative structure. Equally important is capacity building at the regional level, so that public actors and a broad variety of stakeholders - private actors, SMEs, universities, NGOs, citizens - are able to co-operate to design regional and local development strategies that draw on untapped regional resources. Local governments need qualified public employees, as well as sufficient number of staff to be able to manage an increasing set of competencies. National governments have a role to play in enhancing local capacities, through a focus on staff mobility, training and performance management - although a balance has to be found between national governments' involvement and local governments' flexibility in its management of local public employees.

Moreover, it is important to keep in mind that local capacity will vary greatly between city administrations. While size is a determinant of course, so too are other local factors, such as the economic base of a particular city and the resulting labour pool available to the local authorities. For instance, a mining town may not have ready access to a pool of office managers required to run a city administration effectively, but a town of identical size whose economic mainstay is a university or a pharmaceutical company might.

\section{Multilevel governance - institutional co-ordination}

Horizontal co-ordination is indispensable for effective policy implementation. Horizontal coordination includes co-ordination across sectors, for example, transportation and land use, and coordination among neighbouring communities. For example, because urban sprawl often transcends a municipality's boundary, regional-level (or metropolitan-level) co-ordination has often been identified as being the most effective means to achieve the desired policy results.

The need for effective horizontal coherence is not only vitally important between municipalities within a single urban region, but within all orders of government operating in a given urban territory. Indeed several of the Territorial Reviews on urban areas identified a lack of co-ordination between ministries in the central government as being as problematic as poor inter-municipal co-ordination in the achievement of positive policy outcomes in the particular urban region under review. Implementing climate-change adaptation and mitigation strategies is a case in point - central ministries, from those responsible for environmental policy to industrial policy, infrastructure, housing and municipal affairs and the fiscal framework, are key players in any climate change strategy; their activities must be co-ordinated closely if a coherent strategy is to emerge from the central authorities with which local authorities can engage. Other examples include human capital development or housing and land use: various central ministries play on these issues, and their mandates must be coordinated if policy coherence - and efficiency in central programming and service delivery - is to be optimised.

Vertical collaboration between central and local governments is equally essential as appropriate speed and place of urbanisation depends on local circumstances which can vary extensively across a given territory. At the central government level, sustainable urban policy which is economically, 
socially and environmentally balanced should be further promoted, but the appropriate and concrete balance of those three considerations (economy, society and environment) would be better discussed at regional and local level to reflect its unique opportunities and challenges.

\section{Citizen relations: foster metropolitan governance whilst ensuring citizen participation.}

A key issue is the extent to which large cities and regions have a capacity to formulate their own policies within a national framework. Across the OECD the trend has been to de-centralise and to devolve responsibility to regions. Large cities, especially those having the characteristics of metroregions require a strategic capacity at the level of the whole urban area if they are both to realise the potential of their region's attributes and to cope with such problems as transport congestion. But the erection of large authorities with populations of more than a million persons creates problems of remoteness from citizens and risks a decline in civil society among them. These problems become particularly intense if social segregation of the kind is taking place.

The strategic national and metropolitan level and the local, even 'street' level, offer different perspectives, which must both be grasped in a successful approach to urban policy. Focus on the metro-region changes the perspective that might be taken on areas of decline. From a metro-regional view these might be seen as parts of the complex spatial readjustments that take place within a context of dynamism, rather than as the isolated problem cases that they may appear to be from a more local perspective. On the other hand, an approach of constant adjustment and alertness to new things implies a democratic responsiveness to large number of participants and citizens. Policy makers need to concern themselves with the trade-off that might exist between greater economies of scale and the importance of local identities.

Facilitate relations between government and business interests and between these and educational and training institutions

The phenomenon of 'insider corporations' has become an important feature of the current period of major structural change and globalisation; it presents governments with both opportunities and dangers, and the new urban policy is one of the arenas in which these are played out. There are advantages of directness of contact and a chance for public officials to become better informed, but there are two dangers. First, when some firms gain privileged access to ministers and senior civil servants, becoming 'corporate insiders' to government, they erect entry barriers to those firms who remain outsiders. Competition becomes distorted and displaced from the quality of products to the quality of political influence. Second, only large firms can usually participate in this kind of relationship with government, leading to public policy overlooking the role of small and medium sized enterprises

In the OECD, it has become a truism to state that it is SMEs that by far create the most jobs and generate the greatest amount of innovation. Even if this were only half true, the fact remains that innovation and creativity - whether generated in SMEs or in large firms in a given urban area - is based first and foremost on people. The quality of a city's human capital - its local labour force - is crucial to sustaining growth and building agglomeration economies. Therefore, governments have to play the role of catalyst and convenor: they can create the venues for firms - large and small - to exchange among each other and with academic and training institutions so that all actors know what skills are required to drive cluster development in their urban community and so that they can become aware of the innovative ideas that are being incubated locally along with which of these could lead to commercial successes in local, national and international markets. 


\section{Municipal finance: Design a fiscal toolkit specifically tailored for cities}

Experience across the OECD points to cities' need for a fiscal toolkit that reflects their specific functions, characteristics and challenges. The most important principles for the design of an optimal mix of fiscal policy are:

- $\quad$ Provide cities with a mix of revenue sources that is appropriate for the functions they have to deliver: Grants, local taxes and fees provide the most substantial part of funding for the majority of cities in OECD countries, but the proportion of these three revenue sources differs considerably depending on city functions. Fees and charges are ideal for funding local services where specific beneficiaries can be identified and non-payers excluded. Intergovernmental grants are often applied when fiscal discipline and spillovers are major concerns. General grants are generally suitable instruments for functions that benefit from large city autonomy. Specific grants could however be particularly suitable in case of spillovers across local boundaries. Cities should have possibilities to tax at the margin in order to be able to adapt to new circumstances. Local governments with property-related responsibilities such as sewerage and waste management are usually funded by a property tax, whereas local governments with more responsibilities within the field of social welfare tend to be financed more often by local income taxes. Since every revenue source has its drawbacks, it is important that the revenue sources of a metropolitan area are diversified.

- Re-design local taxes and fees to improve environmental sustainability: Several metropolitan regions use land-related income, such as land sales, land auctions and land development rights, but high dependence on this could generate an oversupply of land for construction, sprawled development and loss of cultivated land. Instead, appropriate funding sources for infrastructure could make use of the growing attractiveness of the city now and in the future; this forms the basis of instruments such as the value capture tax and tax increment financing. Proper pricing via fees and charges of environmentally sensitive services such as waste collection, water treatment, or transportation can help contain environmental degradation, especially if costs are fully recovered, which is common in waste, water and energy.

- Avoid local tax policies that lead to wasteful tax competition and market distortions: Good local tax bases are generally more immobile than national tax bases, in order to avoid tax evasion and wasteful tax competition between local jurisdictions. An example of a tax with such an immobile tax base is the property tax. The property tax should be designed in such a way that it does not distort the local property market. This could mean shifting the tax base more towards the value of assets instead of property transactions and splitting the property tax rate in a rate for the land and a lower rate for buildings, in order to stimulate urban redevelopment. 


\section{BIBLIOGRAPHY}

Agrell, Per J. and Peter Bogetoft (2005), "Economic and Environmental Efficiency of District Heating Plants", Energy Policy, Vol. 33, No.10, Elsevier, pp. 1351-1362

Amcoff, J. (2006) Rural Population Growth in Sweden in the 1990s: Unexpected Reality or SpatialStatistical Chimera?' Population, Space and Place, 12, 171-185.

Archer, R.W. (1983), "The Use of the Land Pooling/Readjustment Technique to Improve Land Development in Bangkok", HSD Working Paper No. 10, Urban Land Program, Human Settlements Division, Asian Institute of Technology, Bangkok.

Arnott, R. (1987), "Economic Theory and Housing”, in E. S. Mills, ed., Handbook of Regional and Urban Economics, Ch.24, North-Holland, 959-988

Barker, K. (2003), "Review of Housing Supply: Securing Our Future Housing Needs”, Interim Report Analysis, HM Treasury, London, December 2003

Barker, K. (2006) Barker Review of Land Use Planning; Interim Report - Analysis, London: HMSO.

Barro, R. J. and X. Sala-i-Martin, (1991), Convergence, Journal of Political Economy 100 (1991) (2), pp. 223-251.

Beevers, S. and Carslaw, D. (2005), - The impact of congestion charging on vehicle emissions in London, Atmospheric Environment, Vol. 39, pp. 1-5

Bengston, D.N., J.O. Fletcher and K.C. Nelson (2004), Public Policies for Managing Urban Growth and Protecting Open Space: Policy Instruments and Lessons Learned in the United States", Landscape and Urban Planning 69 (2004), pp.271-286.

Berke, P. D.R. Godschalk, E.J. Kaiser, D. Rodriguez (2006) Urban Land Use Planning, $5^{\text {th }}$ edition, University of Illinois Press, Urbana, IL.

Berry, B.J.L. (1976) 'The Counterurbanisation Process: Urban America since 1970', Urban Affairs Annual Reviews, 11, 17-30.

Berry, M. and J. Hall (2001), "Policy Options for Stimulating Private Sector Investment in Affordable Housing across Australia - Stage 1 report: Outlining the Need for Action", Australian Housing and Urban Research Institute, September 2001

Bertaud, A. (2004) "The Spatial Organization of Cities: Deliberate Outcome or Unforeseen Consequence?" (http://alain-bertaud.com/).

Bianco, M. (2000), -Effective Transportation Demand Management: Combining Parking Pricing, Transit Incentives, and Transportation Management in a Commercial District of Portland, Oregon, Journal of the Transportation Research Board, Vol. 1711, pp. 46-54

Bird R. and E. Slack (2004), Fiscal Aspects of Metropolitan Governance, www.mgmt.utoronto.ca/iib/ITP0401.pdf. 
Boelhouwer, P. J. and P. de Vries (2002), "Housing Production in the Netherlands: A Growing Misbalance Between State and Market", Paper presented at the ENHR 2002 conference "Housing Cultures - Convergence and Diversity" in Vienna, 1-5 July 2002

Brueckner, J. and H. Kim (2003) "Urban sprawl and the property tax", International Tax and Public Finance, Vol. 10, pp. 5-23

Buehler, R., J. Pucher and U. Kunert (2009), "Making Transportation Sustainable: Insights from Germany", The Brookings Institution Metropolitan Policy Programme, Washington, DC.

Building Center of Japan (2008), “A Quick Look at Housing in Japan”, 6 ${ }^{\text {th }}$ edition, August 2008

Bundesministerium für Verkehr, Bau und Stadtentwicklung (2006), Perspektiven der Raumentwicklung in Deutschland (Berlin: BVBS).

Burchell, R. W., G. Lowenstein, W. R. Dolphin, C. C. Galley, A. Downs, S. Seskin, K. G.Still, and T. Moore (2002). TCRP Report 74: Costs of Sprawl-2000. Transportation Research Board, National Research Council, Washington, D.C

Burchfield, M., H.G. Overman, D. Puga and M.Turner (2006) The Determinants of Urban Sprawl: A Portrait from Space, Quarterly Journal of Economics, 121(2), 587-633

C40 Cities (2009), "Energy Saving Partnership Berlin (ESP), - An effective and innovative model to reduce $\mathrm{CO} 2$ and energy costs without expenses for building owners", www.c40cities.org/bestpractices/buildings/berlin_efficiency.jsp, accessed 28 August 2009.

Cambridge Systematics, Inc. (2009), Moving Cooler: An Analysis of Transportation Strategies for Reducing Greenhouse Gas Emissions. Urban Land Institute, Washington, DC.

Carpello, R. and R. Camagni (2000) Beyond Optimal City Size: An Evaluation of Alternative Urban Growth Patterns, Urban Studies, 37: 1479-1496

Cheshire, P. C. (2007) 'Introduction of Price Signals into Land Use Planning: Are they applicable in China', in Song, Y, and C. Ding (eds) Urbanization in China: Critical Issues in an Era of Rapid Growth, Cambridge MA: Lincoln Institute.

Cheshire, P. C. and G. Gornostaeva (2001) 'More useful Londons: The comparative development of alternative concepts of London', Geographica Helvetica, 56, 3, 179-192.

Cheshire, P.C. (1995) 'A New Phase of Urban Development in Western Europe? The evidence for the 1980s', Urban Studies, 32, 7, 1045-63

Cheshire, P.C. and Hay, D.G. (1989) Urban Problems in Western Europe: An Economic Analysis. London: HarperCollins Academic / Routledge.

Churchman, Arza (1999), "Disentangling the Concept of Density", Journal of Planning Literature, Vol. 13, No. 4, Sage, London, pp. 389-411.

Churchman, Arza (2003), "Is There a Place for Children in the City", Journal of Urban Design, Vol. 8 No. 2, pp. 99-111. 
City of Boston Redevelopment Authority (2009), Green Building Task Force website, City of Boston, United States, www.bostonredevelopmentauthority.org/gbtf/GBTFhome.asp, accessed 25 August 2009.

City of Chicago (2005), "City Launches Green Roof Grants Program" City of Chicago website, http://egov.cityofchicago.org/city/webportal/portalContentItemAction.do?BV_SessionID=@@ @@0628823192.1260183006@@@@BV_EngineID=ccccadejdekkhihcefecelldffhdfhk.0\&co ntentOID $=536932287 \&$ contenTypeName $=\overline{C O C}$ EDITORIAL\& topChannelName $=$ Dept\&block Name $=$ Environment $\% 2$ FGreen + Roof $+\% 26+$ Cool + Roof + Grants + Programs $\% 2 F I+$ Want + To \& context $=$ dept \& channelId $=0 \&$ programId $=0 \&$ entityName $=$ Environment\&deptMainCategoryOI $D=-536887205$.

City of Los Angeles (2008), Climate LA, Municipal Program Implementing the GreenLA Climate Action Plan, Executive Summary, Los Angeles, United States, www.environmentLA.org.

City of New York (2007), PlaNYC - a Greener, Greater New York, City of New York, United States.

City of Paris (2009), “Jusqu'à 400 EUR de subvention pour l'achat d'un scooter électrique”, 9 June 2009, City of Paris, France, www.paris.fr/portail/deplacements/Portal.lut?page_id=2\&document_type_id=2\&document_id $=65582 \&$ portlet_id $=21994$.

City of Toronto (2008), "Mayor's Tower Renewal Executive Report", City of Toronto, 19 August 2008, City of Toronto, Canada, www.towerrenewal.ca/MTR_execReport.pdf.

Coombes, P-P., G. Duranton, H. Overman (2005) Agglomeration and the Adjustment of the Spatial Economy, Papers in Regional Science, 84: 311-349

Costa, D.L., Kahn, M.E. (2000), Power couples: changes in the locational choice of the college educated, 1940-1990, Quarterly Journal of Economics, 115: 1287-1315.

Dasgupta, M. el al., (1994), Impact of Transport Policies in Five Cities, Project Report 107, Transport Research Laboratory. Crowthome, Berkshire.

DATAR, (1999), Pour une métropolisation raisonnée: diagnostic socio-économique de l'Ile-de-France et du bassin parisien, La Documentation Française, Paris.

De Macedo, Jorge Braga and Joaquim Oliveira Martins (2006), "Growth, reform indicators and policy complementarities" Economics of Transition, Vol. 16, No. 2, Blackwell Publishing, Oxford, UK, pp.141-164.

Debrezion, G., Pels, E. and Rietveld, P. (2007), The Impact of Railway Stations on Residential and Commercial Property Value: A Meta-analysis, Journal of Real Estate and Financial Economics, Vol. 35, pp. 161-180

Dievert, E (2007), "The Paris OECD-IMF Workshop on Real Estate Price Indexes: Conclusions and Future Directions", Discussion Paper 07-01, University of British Colombia.

Doebele, W. (1982), Land Readjustment: A Different Approach to Financing Urbanization, Health and Company, Lexington Books, Massachusetts, D.C. 
Donovan, M.G. (2007), “At the Doors of Legality: Planners, Favelados, and the Titling of Urban Brazil", Ph.D. dissertation, Department of City and Regional Planning. University of California, Berkeley

Duranton, Gilles and Diego Puga (2000), "Diversity and Specialisation in Cities: Why, Where and When does it Matter?", Journal of Urban Studies, Vol. 37, No. 3, pp. 533-555.

Dye, R. and Merriman, D. (1999), Popular financing tool hurts, Engineering News Record, Vol. 243, p. 123

Eggers, W. D. (1990), “Land Use Reform Through Performance Zoning”, Policy Insight, No.120, Reason Foundation, Los Angeles

European Economic and Social Council (EESC), (2004), Opinion on the subject of European metropolitan areas and their socio-economic impact, EESC, July 2004

European Mortgage Federation (2006), Study on the Cost of Housing in Europe, European Mortgage Federation Publication, Brussels

Evans, A. W. and O. M. Hartwich (2005), "Bigger Better Faster Move: Why Some Countries Plan Better Than Others", Policy Exchange, London

Evans, Anne with Nick Manning. (2004). "Administrative Decentralization: A Review of Staffing Practices in Eight Countries - Draft Paper Prepared for the World Bank". Washington DC

Farvacque, C. and P. McAuslan (1992), Reforming Urban Land Policies and Institutions in Developing Countries, World Bank Urban Management Program Policy Paper, No. 8.

Gennaio, M-P, A.M. Hersperger, and M. Bürgi (2009), "Containing Urban Sprawl-Evaluating Effectiveness of Urban Growth Boundaries Set by the Swiss Land Use Plan", Land Use Policy 26 (2009), pp.224.232

Giordano, B. and E. Roller (2003), “A Comparison of City Region Dynamics in the UK, Spain and Italy: More Similarities than Differences?”, Regional Studies, 37, pp. 911-927.

Glaeser, E. L. and J. Gyourko (2002), “Zoning’s Steep Price”, Regulation, Fall 2002, pp.24-30

Glaeser, E. L. and J. Gyourko (2003), "The Impact of Building Restrictions on Housing Affordability”, FRBNY Economic Policy Review 9, pp.21-39, June 2003

Graham, D. J. (2007) Variable returns to agglomeration and the effect of road traffic congestion, Journal of Urban Economics, 2007, 62: 103 - 120

Graham, D. J. and H.Y. Kim (2008) An Empirical Analytical Framework for Agglomeration Economies, Annals of Regional Science, 42, 267-89.

Heinelt H. and Kübler, D. (2005), Metropolitan Governance, Capacity, Democracy and the Dynamics of Place, Routledge, London and New York.

Henderson, V, A. Kuncoro and M. Turner (1995), "Industrial Development in Cities", Journal of Political Economy, Vol. 103, No. 5, pp. 1067-1090. 
Hirt, S. (2007), "The Devil Is in the Definitions: Contrasting American and German Approaches to Zoning", Journal of the American Planning Association, Vol. 73, No. 4, Routledge, London, pp. 436- 450.

IEA (2008a), Energy Efficiency Requirements in Building Codes, Energy Efficiency Policies for New Buildings, IEA information Paper March 2008, OECD/IEA, Paris.

IEA (2008b), Promoting Energy Efficiency, Best Practice in Cities, September 2008, OECD/IEA, Paris.

IEA (2009), Cities and Towns and Renewable Energy -YIMFY: Yes In My Front Yard, 4 August, 2009, $\mathrm{OECD} / \mathrm{IEA}$, Paris.

IEA (International Energy Agency) (2005), Evaluating Energy Efficiency Policy Measures \& DSM Programmes, Volume I Evaluation Guidebook. OECD/IEA, Paris.

Ioannides, Y. and Overman, H. (2000) "Cross Sectional Evolution of the US City Size Distribution", Centre for Economic Performance

IPCC (Intergovernmental Panel on Climate Change), (2007), Climate Change 2007: Mitigation, Contribution of Working Group III to the Fourth Assessment Report of the Intergovernmental Panel on Climate Change, B. Metz, O.R. Davidson, P.R. Bosch, R. Dave and L.A. Meyer (eds), Cambridge University Press, Cambridge and New York.

Isaksen, A. and E. Hauge (2002), Regional Clusters in Europe, European Commission, Observatory of European SMEs, 2002/3, Office of Official Publications of the European Communities, Luxembourg.

Johansson, C. Burman, L. and Forsberg, B. (2008), The effects of congestions tax on air quality and health, Atmosperic Environment, Vol. 42, pp. 1-12

Jutaku Shimpo (2006), Monthly Jutaku Shimpo (in Japanese), Augst 2006, Tokyo, Japan.

Kaiser, E., D. Godschalk, and F.S. Chapin. 1995. Urban Land Use Planning, $4^{\text {th }}$ ed., University of Illinois Press. Urbana, IL.

Kamal-Chaoui, L., E. Leman and Z. Fufei (2009), "Urban Trends and Policy in China", OECD Regional Development Working Papers, 2009/1, OECD Publishing

Katz, L. and K. Rosen (1987), "The Interjurisdictional Effects of Growth Controls on Housing Prices", Journal of Law \& Economics, Vol.30, No.1, 1987, pp.149-160

Keeble, D., P. L. Owens and C. Thompson (1983) The urban-rural manufacturing shift in the European Community, Urban Studies, 20, 405-18.

Knaap, G. and T. Moore (2000) Land Supply and Infrastructure Capacity Monitoring for Smart Urban Growth, Lincoln Institute of Land Policy Working Paper

Kühn, M. (2003), "Green belt and Green Heart: Separating and Integrating Landscapes in European City Regions", Landscape and Urban Planning 64 (2003), pp19-27. 
Laurila, T. (2005), "Innovation Strategy Process in the Helsinki Region”, Baltic Sea Region Micro/Nano Technologies Seminar, available at www.fmnt.fi/berlin/Lectures/Laurila.pdf.

Lefevre, Christian (2006), Comparative Analysis of Metropolitan Governance in City-Regions, paper presented at the "Metropolitan Areas for City-Regions and Medium-sized Cities", International Workshop, OECD-Region of Galicia, 30-31 March, Santiago de Compostella.

Leven, C.L. (1979) The Mature Metropolis, Boston: Lexington Books. Alvin Toffler

Local Government Denmark (2009), "Municipality Plan with climate adaptation", 25 June 2009, www.kl.dk/Dokumenter/Artikler/BEM/2009/06/Municipality-Plan-with-climate-adaptation.

Lukkarinen, Margita (2004), "Local Development Agreements as a Tool to Stop Segregation in Vulnerable Metropolitan Areas: the Main Elements of the Policy", Peer Review in the Field of Social Inclusion Policies, European Commission, DG Employment and Social Affairs.

Luo, Q., P. Catney and D. Lerner (2009), "Risk-based Management of Contaminated Land in the UK: Lessons for China?", Journal of Environmental Management 90 (2009), pp.1123-1134.

Maclennan, D. and Williams, R. (1990), “Affordable Housing in Britain and America”, York, Joseph Rowntree Foundation

Mayer, C. J. and C. T. Somerville (2000), "Land Use Regulation and New Construction”, Regional Science and Urban Economics 30, 2000, pp.639-662

Milan municipality, 2009; Monitoraggio Ecopass, Gennaio - Dicembre 2008, Agenzia Milanee Mobilità Ambiente

Morris, Jeffrey (2005), "Comparative LCAs for Curbside Recycling Versus Either Landfilling or Incineration with Energy Recovery" International Journal of Life Cycle Assessment, vol. 10, no. 4, ecomed publishers, Landsberg, Germany, pp. 273-284.

Neuman, Michael (2005), “The Compact City Fallacy”, Journal of Planning Education and Research Vol. 25, No. 1, Sage Publications, pp. 11-26.

Nordregio (2005), ESPON 1.1.1 Potentials for polycentric development in Europe, Nordregio, Stockholm.

ODPM, United Kingdom (2004), "Making it happen: The Northern Way", UK Office of the Deputy Prime Minister, London

OECD (1998), Integrating Urban Distressed Areas, OECD Publishing, Paris

OECD (2001a), OECD Territorial Reviews: Hungary, OECD, Paris.

OECD (2001b), OECD Territorial Reviews: Italy, OECD, Paris.

OECD (2001c), OECD Territorial Reviews: Korea, OECD Publishing, Paris

OECD (2002a), Impact of Transport Infrastructure Investment on Regional Development, OECD, Paris. 
OECD (2002b), OECD Territorial Reviews: Canada, OECD, Paris, France

OECD (2002c), OECD Territorial Reviews: Champagne-Ardenne, France, OECD, Paris, France

OECD (2002d), Redefining functional regions, OECD DT/TDPC/TI(2002)3

OECD (2003a), Aging, Housing and Urban Development, OECD Publishing, Paris

OECD (2003b), Environmentally Sustainable Buildings: Challenges and Policies, OECD, Paris.

OECD (2003c), OECD Territorial Reviews: Oresund, Denmark/Sweden, OECD Publishing, Paris

OECD (2003d), OECD Territorial Reviews: Vienna-Bratislava, Austria/Slovak Republic, OECD Publishing, Paris

OECD (2004a), OECD Territorial Reviews: Busan, Korea, OECD, Paris.

OECD (2004b), OECD Territorial Reviews: Czech Republic, OECD, Paris.

OECD (2004c), OECD Territorial Reviews: Mexico City, OECD Publishing, Paris

OECD (2004d), OECD Territorial Reviews: Montreal, Canada, OECD Publishing, Paris

OECD (2005a), "Towards the Sustainable Use of Building Stock: Final Synthesis Report”, OLIS document, OECD, Paris

OECD (2005b), Building Competitive Regions, OECD Publishing, Paris

OECD (2005c), OECD Territorial Reviews: Finland, OECD, Paris.

OECD (2005d), OECD Territorial Reviews: Japan, OECD, Paris.

OECD (2005e), OECD Territorial Reviews: Seoul, Korea, OECD Publishing, Paris.

OECD (2005f), Regions at glance, OECD Publishing, Paris

OECD (2006a), "Interim Report on Socially Sustainable Housing", presented to Working Party on Territorial Policy in Urban Areas, June 2006.

OECD (2006b), OECD Territorial Review of France, OECD Publishing, Paris

OECD (2006c), OECD Territorial Review of Newcastle, UK, OECD Publishing, Paris

OECD (2006d), OECD Territorial Review of Stockholm, Sweden, OECD Publishing, Paris

OECD (2006e), OECD Territorial Review of Switzerland OECD Publishing, Paris

OECD (2006f), OECD Territorial Reviews of Competitive Cities in the Global Economy, OECD Publishing, Paris

OECD (2006g), OECD Territorial Reviews: Copenhagen, Denmark, OECD 
OECD (2006h), OECD Territorial Reviews: Milan, Italy, OECD, Paris. OECD

OECD (2007a), "What Policies for Globalising Cities? Rethinking the Urban Policy Agenda., OECD Conference Proceedings", Madrid, Spain, 29-30 March 2007.

OECD (2007b), Competitive Cities: A New Entrepreneurial Paradigm in Spatial Development, OECD Publishing, Paris.

OECD (2007c), OECD Rural Policy Reviews: Mexico, OECD Publishing, Paris

OECD (2007d), OECD Territorial Policy Monitoring Review, Mexico. GOV/TDPC (2007)5

OECD (2007e), OECD Territorial Reviews of Luxembourg, OECD Publishing. Paris

OECD (2007f), OECD Territorial Reviews of Norway, OECD Publishing. Paris.

OECD (2007g), OECD Territorial Reviews: Madrid, Spain, OECD Publishing, Paris.

OECD (2007h), OECD Territorial Reviews: Randstad Holland, Netherlands, OECD Publishing, Paris.

OECD (2008a) Environmental Outlook 2030, OECD Publishing, Paris

OECD (2008b), "Working Party No.2 on Competition and Regulation: Competitive Effects of Regulations of Real Property-United States-“, presented at 18 February 2008, DAF/COMPM/WP2/WD (2008)11.

OECD (2008c), Competitive Cities and Climate Change: OECD Conference Proceedings, Milan, Italy, 9-10 October 2008, OECD, Paris.

OECD (2008d), OECD Rural Policy Reviews, Netherlands, OECD Publishing, Paris.

OECD (2008e), OECD Territorial Reviews, Cape Town, South Africa, OECD Publishing, Paris.

OECD (2008f), OECD Territorial Reviews, Istanbul, Turkey, OECD Publishing, Paris.

OECD (2008g), OECD Territorial Reviews, Poland, OECD Publishing, Paris.

OECD (2008h), OECD Territorial Reviews, Portugal, OECD Publishing, Paris.

OECD (2009a), "Cities, Climate Change and Multilevel Governance", Environment Working Papers, OECD, Paris

OECD (2009b), Designing Local Skills Strategies, OECD, Publishing Paris

OECD (2009c), Green Cities: New Approaches to Confronting Climate Change, OECD Workshop Proceedings, 11 June 2009, Las Palmas de Gran Canaria, Spain.

OECD (2009d), How Regions Grow: Trends and Analysis, OECD Publishing Paris.

OECD (2009e), OECD Rural Policy Reviews, China, OECD Publishing. Paris.

OECD (2009f), OECD Rural Reviews, Italy, OECD Publishing, Paris 
OECD (2009g), OECD Territorial Review of Chile, OECD Publishing, Paris

OECD (2009h), OECD Territorial Review of Copenhagen, Denmark, OECD Publishing, Paris

OECD (2009i), Regions Matter: Economic Recovery, Innovation and Sustainable Growth, OECD Publishing Paris.

OECD (2010a), OECD Territorial Review of Guangdong, China, OECD Publishing, Paris

OECD (2010b), OECD Territorial Review of Toronto, Canada, OECD Publishing, Paris

OECD (2010c), OECD Territorial Review of Venice, Italy, OECD Publishing, Paris

OECD (2011), OECD National Urban Policy review of Poland, OECD Publishing, Paris

Olszewski, P. (2007), Singapore motorisation restraint and its implications on travel behaviour and urban sustainability, Transportation, Vol. 34, pp. 319-335

Orfield, M. (1997), "METROPOLITICS: A Regional Agenda for Community and Stability", Brookings Institution Press, Washington, D.C.

Orlebeke, C. J. (2000), “The Evolution of the Low-Income Housing Policy: 1949 to 1999”, Housing Policy Debate, Volume11, Issue 2, 2000, Fannie Mae Foundation

Pinson, G., (2006), "Strategic Planning: Vector or Substitute for Metropolitan Integration: Lessons from Italy", paper for the conference "Governance and Spatial Discontinuities:

Reterritorialization or a New Polarization of Metropolitan

Policy Research Institute for Land, Infrastructure and Transport, Ministry of Land, Infrastructure and Transport, Japanese Government (2006), Suburban land use control in Germany, France and the Netherlands. (in Japanese). Tokyo.

Povey, M. and T. Lloyd-Jones (2000) - Mixed value urban development: Mechanisms for sustaining the livelihoods and social capital of the urban poor in core urban areas - May $2000 \mathrm{ESF} / \mathrm{N}$ AERUS workshop.

Prudhomme (2008), "Patterns and prospects in China's urbanization strategy", Paper presented at the SDPC-MOC-World Bank sponsored seminar on urbanization, Beijing, May 8-10, 2000, and revised in light of the discussions held during and after the seminar.

Quigley, J.M. (2009) 'Agglomeration, Urbanization, and the Growth of Metropolitan Regions', unpublished paper

Rasmussen, J. (2003), European Seminar on Cluster Policy - Workshop 2: National Policies, 10 June, available at www.ebst.dk/file/4233/cluster_rasmussen.pdf.

Rice, P., A. J. Venables and E. Patacchini (2006) Spatial Distribution of Production: analysis for the regions of Great Britain, Regional Science and Urban Economics, 36, 727-52. 
Rodriguez Alvarez, (2004), "Strategies of Spanish cities in a global, competitive world: Between leadership, technocracy and participative strategic planning" International Conference, City Futures Conference, July 8 - 10, 2004.

Roelandt, T.J.A. and P.D. Hertog (eds.) (1999), Boosting Innovation, the Cluster Approach, OECD Proceedings, OECD, Paris.

Romer, Paul M, 1986. "Increasing Returns and Long-run Growth," Journal of Political Economy, University of Chicago Press, vol. 94(5), pages 1002-37, October

Saizen, I., Mizuno, K. and S. Kobayashi (2006), "Effects of land-use Master Plans in the Metropolitan Fringe of Japan", Landscape and Urban Planning 78(2006), pp.411-421.

Sassen, S. (2003), Keynote Speech at international conference on Technology Clusters, 7-8 November, Montreal, (conference highlights prepared by Manon Bourgeois and Mireille Brochu).

Sejong (Korea) (2009), Green City Sejong, Multifunctional Administration City Construction Agency, Yeongi-gun, Korea.

Seoul City Government (2009), “2030 Low-carbon Green Development Masterplan”, proposed July 2, 2009, Seoul City Government, Korea.

Short, J., S. Fleming and S. Witt (1986), "House building, Planning and Community Action: The Production and Negotiation of the Built Environment", Routledge \& Kegan Paul, London

Shoup, D., (1997), - The High Cost of Free Parking\|, Journal of Planning Research, Vol. 17, pp. 3-20

State of Minnesota (2001), "Affordable Housing”, Office of the Legislative Auditor, State of Minnesota, January 30, 2001

Stein-Holmes, Rachel (2007), "Human Resource Management across Levels of Government Concept Note", Project conducted under the auspices of the PEMWP, April 3, 2007, not published

Stimson, R.J., R.R. Stough and B. Roberts (2002), Regional Economic Development: Analysis and Planning Strategy, Springer, New York.

Swiss Federal Council (2001), "Politique des agglomérations de la Confédération", Report of the Federal Council of 19 December 2001.

Tan,R.et al (2009), "Governing Farmland Conversion: Comparing China with Netherlands and Germany", Land Use Policy 26 (2009), pp.961-974.

Tang, B-S, Wong, S-W, and A. K-W Lee (2007), "Green Belt in a Compact City: A Zone for Conservation or Transition?”, Landscape and Urban planning 79 (2007), pp.358-373.

Tian,L. and W. Ma (2009), "Government Intervention in City Development of China: A Tool of Land Supply”, Land Use Policy 26 (2009), pp.599-609.

Titus, James G. and Vijay Narayanan (1996), “The Risk of Sea Level Rise: A Delphic Monte Carlo Analysis in which Twenty Researchers Specify Subjective Probability Distributions for Model 
Coefficients within their Respective Areas of Expertise", Climatic Change, Vol. 33, No. 2, Springer Netherlands, pp. 151-212.

UNEP (United Nations Environment Programme), (2007), Assessment of Policy Instruments for Reducing Greenhouse Gas Emissions from Buildings, UNEP Sustainable Buildings \& Construction Initiative and Central European University, Paris.

United Nations (1974) Manuals on Methods of Estimating Population, Methods for Projection of Urban and Rural Population, UN: New York.

United Nations (2007) Principles and Recommendations for Population and Housing Census, UN Department of Economic and Social Affairs, Statistical Papers Series M. No. 67/Rev2

United Nations (2007) State of World Population 2007: Unleashing the Potential of Urban Growth, New York: United Nations Publishing.

United States Environmental Protection Agency (US EPA) (2009) "Brownfields and Land Revitalization", www.epa.gov/brownfields

United States Global Change Research Programme, (2009), Global Climate Change Impacts in the United States, Cambridge University Press, Cambridge, UK

Wallace, J. E. (1995), "Financing Affordable Housing in the United States", Housing Policy Debate, Volume 6, Issue 4, 1995, Fannie Mae Foundation

Walter-Rogg, Melanie (2006), "Metropolitan Governance Reform in Germany", paper for the conference "Governance and Spatial Discontinuities: Reterritorialization or a New Polarization of Metropolitan Spaces?” INRS-Urbanisation, 24-25 April 2006, Montreal,www.vrm.ca/documents/Montreal2006_Working_Paper_Walter_Rogg_Sojer.pdf

Wheeler, S. M. (2008), "State and Municipal Climate Change Plans: The First Generation", Journal of the American Planning Association, Vol. 74, No. 4, Routledge, London, pp. 481-496.

Yokohari, M. et al. (2000), "Beyond Green belts and Zoning: A New Planning Concept for the Environment of Asian Mega-cities", Landscape and Urban Planning 47 (2000), pp.159-171. 